\title{
CONSTRUÇÃO DE UM SISTEMA BASEADO EM CONHECIMENTO PARA APOIAR A MODELAGEM DE DADOS NO CONTEXTO DE UMA METODOLOGIA DE INTEGRAÇÃO DA MANUFATURA
}

\author{
Autor: Geraldo Nunes Corrêa
}

Orientadora: Profa. Dra. Solange Rezende Rodrigues

\begin{abstract}
Dissertação apresentada ao Instituto de Ciências Matemáticas de São Carlos como parte dos requisitos para a obtenção do título de Mestre em Ciências: Área - Ciências de Computação e Matemática Computacional.
\end{abstract}

São Carlos, setembro de 1994. 
Aos meus pais, Geraldo e Vergínia, pelas oportunidades fornecidas e por sempre me apoiarem.

Aos meus irmãos, Luis, Rita e Paulo, por sempre torcerem por mim. 


\section{AGRADECIMENTOS}

Antes de tudo agradeço a Deus por iluminar meu caminho e por me dar todas as condições para a realização deste trabalho.

À minha orientadora, Profa. Dra. Solange Rezende Rodrigues, pelo companherismo e esforço realizado nesta dissertação.

À Profa. Dra. Maria Carolina por viabilizar, desde o início, a realização deste trabalho.

Ao CNPq, pela bolsa concedida.

À todos integrantes do grupo que realizou a implementação da ferramenta para modelagem de dados, em especial Renato e Chandler por participarem de todo o processo, Cristina Endo, Maradona e Valtemir.

À FIM por todos os recursos indispensáveis para a realização deste trabalho e por todos os seus integrantes pela confortável convivência diária.

Ao Maurício, pelas conversas nos momentos dificeis da realização de nossos trabalhos.

Ao Preá, pelos estudos iniciais em base de dados.

Ao Hugo, pela ajuda na formulação do índice desta dissertação

À Ana Claúdia, pela leitura cuidadosa tanto da monografia de qualificação como da dissertação final.

Finalmente, agradeço à Luciana por compartilhar todos os momentos "estressantes" e por sempre me incentivar. 


\section{Sumário}

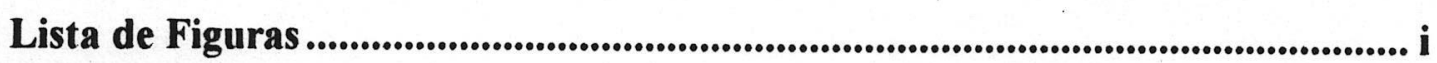

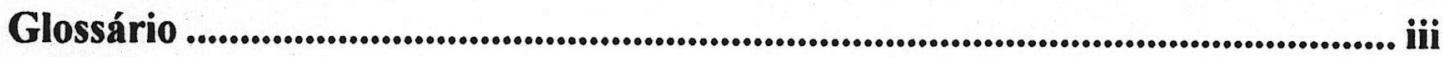

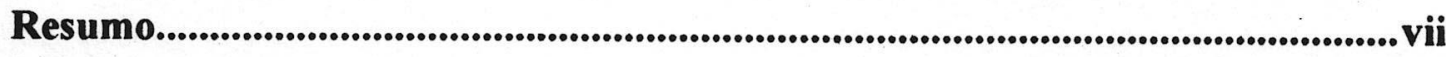

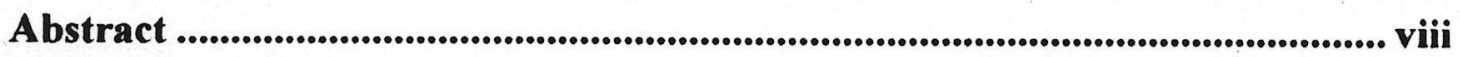

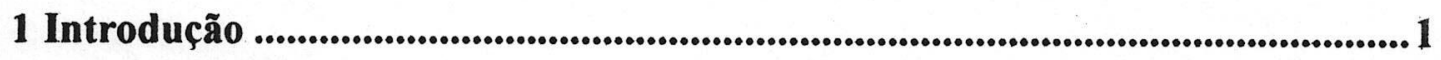

1.1 Considerações Iniciais .........................................................................................1

1.2 Objetivos do Trabalho ............................................................................................2

1.3 Organização do Trabalho ................................................................................2

2 Cenário Atual de Integração das Empresas de Manufatura....................................4

2.1 Considerações Iniciais ...............................................................................................4

2.2 Sistemas de Manufatura ............................................................................6

2.2.1 Requisitos Atuais para os Sistemas de Manufatura ................................ 7

2.2.2 A Manufatura Integrada por Computador ........................................... 9

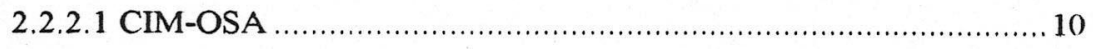

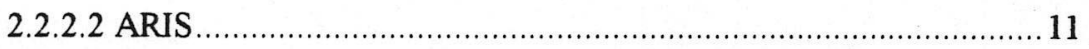

2.2.3 Sistemas de Informação para Manufatura ................................................ 11

2.3 Estratégias de Atuação

2.4 Tecnologia de Informação..................................................................................... 14

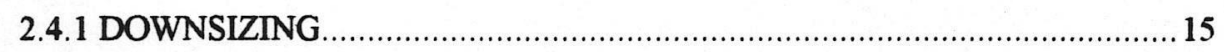

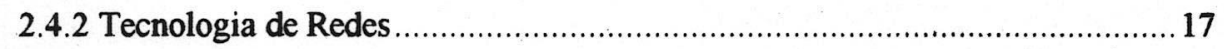

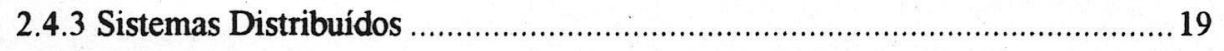

2.4.4 Sistemas Gerenciadores de Banco de Dados.............................................. 20

2.4.4.1 Linguagem SQL..................................................... 21 
2.4.4.3 Arquitetura Cliente/Servidor para os SGBD's ............................22

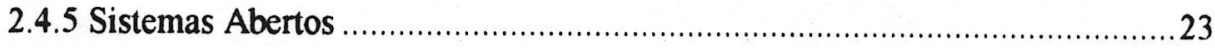

2.4.6 Ferramentas para Desenvolvimento de Sistemas ...........................................2 24

2.5 Paradigmas de Integração.................................................................. 25

2.5.1 Conectividade de Banco de Dados Empresariais ........................................26

2.5.2 Arquitetura para Conectividade Aberta....................................................22

2.6 Metodologia de Integração da Manufatura ............................................31

2.7 O Modelo de Empresa..................................................................................33

2.7.1 O Modelo de Empresa para a Metodologia de Integração da Manufatura .......35

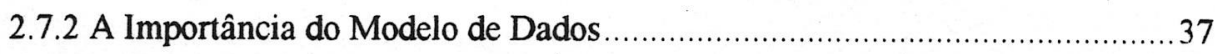

2.8 Considerações Finais ...........................................................................38

3 Conceitos Básicos para a Modelagem de Dados............................................... 40

3.1 Considerações Iniciais .....................................................................40

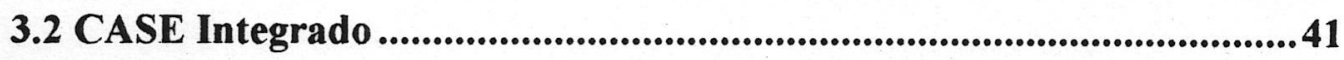

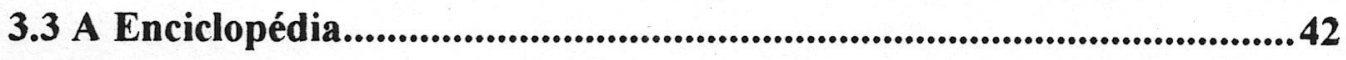

3.4 Análise Lógica dos Dados...............................................................43

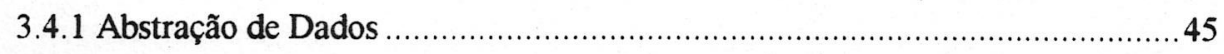

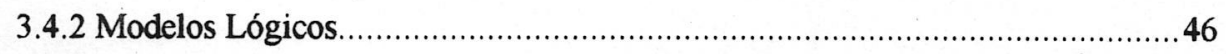

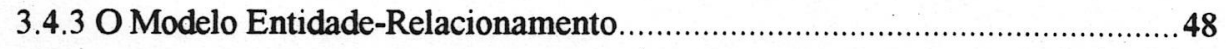

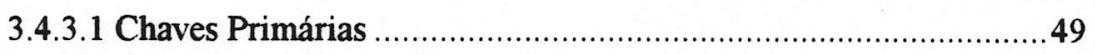

3.4.3.2 Extensões do Modelo Entidade-Relacionamento ...........................49

\subsection{Conceitos Envolvidos na Geração do Modelo Físico da Base de}

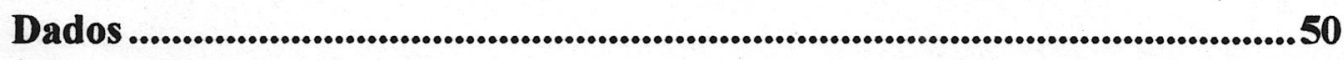

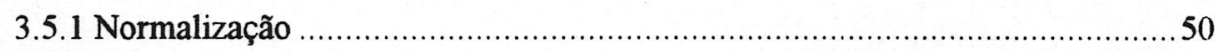

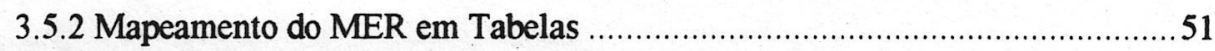


3.6 Metodologia de Desenvolvimento para Bases de Dados

3.7 Importância do Conhecimento Envolvido no Projeto de Base de

Dados 53

3.8 Sistemas Baseados em Conhecimento..........................................................53

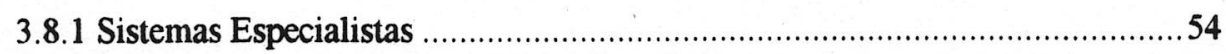

3.8.2 Estrutura Básica de um Sistema Baseado em Conhecimento ..........................57

3.9 Engenharia de Conhecimento $\ldots . . \ldots \ldots \ldots \ldots \ldots \ldots \ldots \ldots \ldots \ldots \ldots \ldots \ldots \ldots \ldots \ldots \ldots \ldots \ldots \ldots \ldots \ldots \ldots \ldots \ldots \ldots \ldots \ldots \ldots \ldots . . . .58$

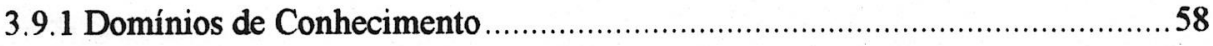

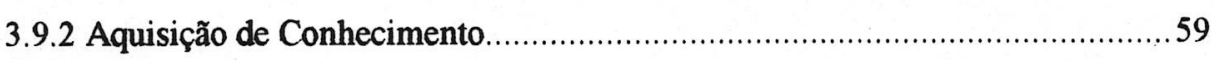

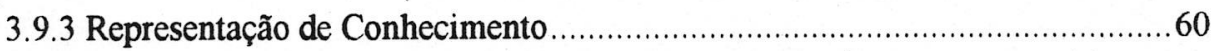

3.9.3.1 Regras de Produção .......................................................61

3.9.3.2 Redes Semânticas................................................... 62

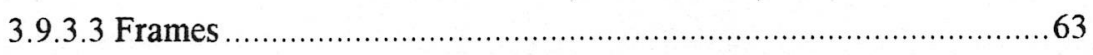

3.9.3.4 Orientação a Objetos ...............................................6 64

3.10 Fases do Desenvolvimento de um SBC ............................................65

3.11 Considerações Finais ..........................................................................67

4 Requisitos para o Desenvolvimento de uma Ferramenta para Modelagem de

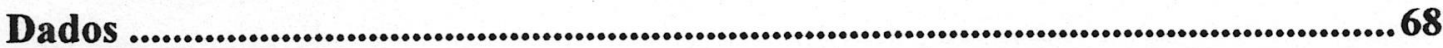

4.1 Considerações Iniciais ..................................................................................68

4.2 Metodologia de Desenvolvimento de Base de Dados.........................69

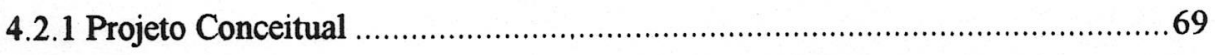

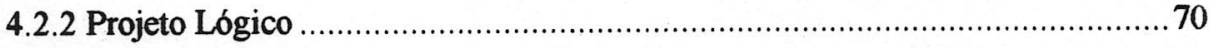

4.3 Requisitos de uma Enciclopédia ............................................................ 70

4.3.1 Interface da Ferramenta ............................................................ 71

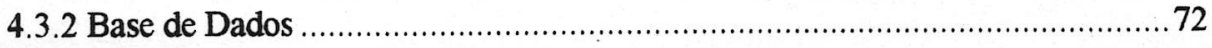

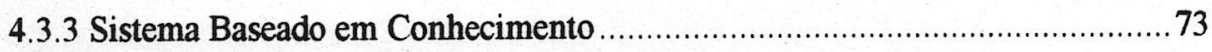


4.4 Recursos Computacionais ..................................................................................... 75

4.10 Considerações Finais ................................................................................................. 76

\section{Concepção e Implementação de uma Ferramenta para Modelagem de}

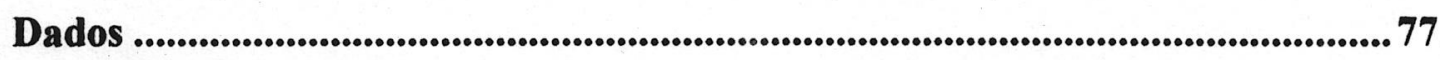

5.1 Considerações Iniciais .................................................................................................77

5.2 Concepção de uma Ferramenta para Modelagem de Dados .................. 77

5.3 Visão Geral do Desenvolvimento da Ferramenta.......................................80

5.4 Desenvolvimento da Ferramenta ...........................................................................8 81

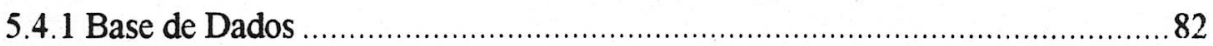

5.4.1.1 Metodologia Utilizada para a Representação do Meta Modelo ......82

5.4.1.2 O Meta Modelo de Dados Desenvolvido ..................................83

5.4.1.3 Implementação da Base de Dados.........................................85

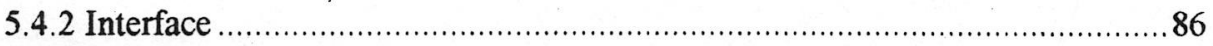

5.4.2.1 Metodologia Utilizada para o Desenvolvimento da Interface........87

5.4.2.2 Implementação da Interface ............................................... 88

5.4.2.3 Descrição do Menu Principal da Ferramenta para Modelagem de

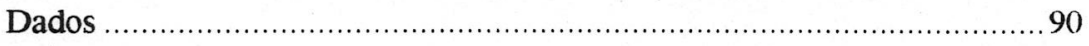

5.4.2.4 Interface Diagramática ................................................. 91

5.4.3 Sistema Baseado em Conhecimento .............................................. 93

5.4.3.1 Identificação das Características .........................................99

5.4.3.2 Metodologia Utilizada para a Construção do SBC ..................... 94

5.4.3.3 Estruturação do SBC ....................................................95

5.3.4.4 Descrição do Shell Utilizado .............................................96

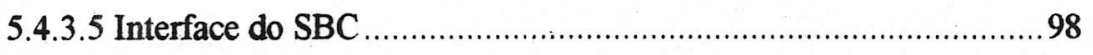

5.4.3.6 Engenharia do Conhecimento........................................98

5.3.4 Recursos Utilizados para a Integração dos Componentes.............................. 102 
5.4.4.2 Descrição dos Produtos Utilizados na Integração dos Componentes 104

5.5 Arquitetura de Implementação da Ferramenta 105

5.6 Considerações Finais ...................................................................... 106

6 Exemplo de Aplicação da Ferramenta 107

6.1 Considerações Iniciais ................................................................................. 107

6.2 A Fábrica Integrada Modelo ..............................................................107

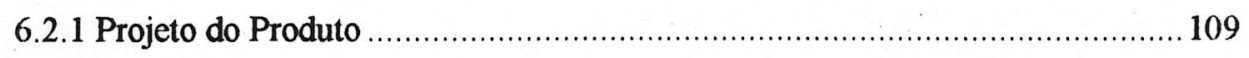

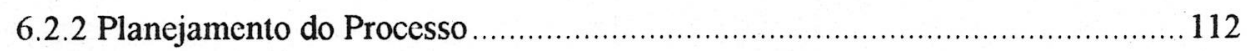

6.2.3 Visualização Simultânea dos Modelos de Dados ........................................... 114

6.3 Verificação de Consistências nos Modelos de Dados ............................115

6.4 Exemplos de Utilização das Extensões do MER....................................117

6.5 Considerações Finais ..............................................................................119

7 Conclusões e Sugestões para Trabalhos Futuros......................................... 120

Referência Bibliográfica ........................................................................................ 123

Anexo 1 - Criação da Base de Dados ............................................................... 126

Anexo 2 - Engenharia do Conhecimento ................................................................ 133 


\section{Lista de Figuras}

Figura 2.1: Conceitos Relacionados à Integração das Empresas ...........................5

Figura 2.2 Modelo Conceitual de Sistema de Manufatura .................................... 6

Figura 2.3: Uma Característica da Evolução do Sistema de Manufatura .................8

Figura 2.4: Esquema de Desenvolvimento de SI's Integrados ........................... 12

Figura 2.5: Estratégias de Atuação para as Empresas de Manufatura .................... 13

Figura 2.6: O Novo Papel do Mainframe nos anos 90 ..................................... 16

Figura 2.7: A Abordagem de Sistemas Abertos ................................................ 23

Figura 2.8: Variações da Abordagem por Interface Comum .............................. 28

Figura 2.9: Abordagem por Portão Comum …............................................. 29

Figura 2.10: A Abordagem por Protocolo Comum ............................................. 31

Figura 2.11: Objetivos e Utilizações do Modelo de Empresa .............................. 34

Figura 2.12: Componentes e Relacionamentos do Modelo de Empresa.................. 36

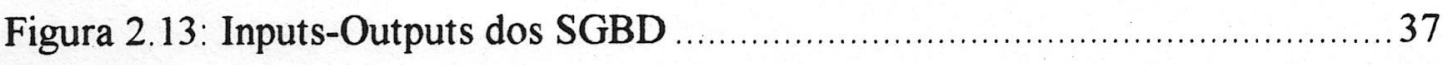

Figura 2.14: Localização do Desenvolvimento da Ferramenta ............................. 39

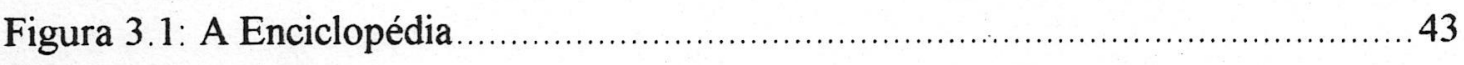

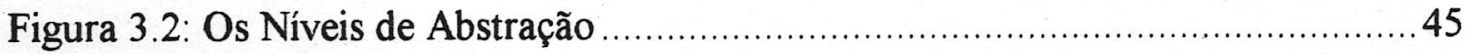

Figura 3.3: Uma Amostra de Banco de Dados Relacional ............................... 47

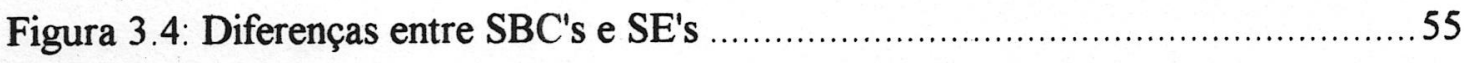

Figura 3.5: Justificativas para o Desenvolvimento de SE's ................................56

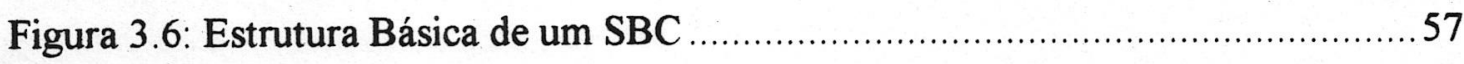

Figura 3.7: Fases da Elicitação de Conhecimento .......................................... 60

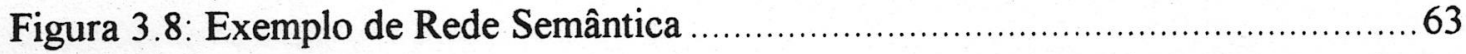

Figura 3.9: Uma Representação do Frame Retificadoras................................... 64 
Figura 3.10: Exemplo de um Diagrama de Análise Orientada a Objetos 65

Figura 3.11: Estágios do Desenvolvimento de um SBC 66

Figura 4.1: Blocos de Requisitos para o Desenvolvimento da Ferramenta. 68

Figura 4.2: Arquitetura de uma Ferramenta para Modelagem de Dados. .71

Figura 4.3: Requisitos da Interface .72

Figura 4.4: Requisitos para a Base de Dados da Ferramenta 73

Figura 4.5: Requisitos do SBC 74

Figura 4.6: Integração dos Componentes da Arquitetura da Ferramenta 75

Figura 5.1: Descrição do Menu Principal de uma Ferramenta para Modelagem de

Dados .78

Figura 5.2: Processo Geral do Desenvolvimento da Ferramenta 81

Figura 5.3: Meta Modelo de Dados. 84

Figura 5.4: Projeto Funcional da Ferramenta 88

Figura 5.5: Menu Principal da Ferramenta 91

Figura 5.6: Caixa de Ferramenta Representando os Elementos de um Modelo de

Dados .93

Figura 5.7: Ciclo de Vida de um SBC .95

Figura 5.8: Estrutura do SBC Implementado. .96

Figura 5.9: Relação Regras-Objetos no SmartElements 97

Figura 5.10: Atividades Realizadas no Processo de Elicitação 99

Figura 5.11: As Fases de Representação e Validação 101

Figura 5.12: Exemplo de um Mapeamento Realizado pela Ferramenta 103

Figura 5.13: API's Utilizadas pela Ferramenta 105

Figura 6.1: O Cenário 2 da FIM 108

Figura 6.2: Modelo de Dados da Fase de Projeto do Produto 110 
Figura 6.3: Modelo de Dados da Fase de Projeto do Produto na Ferramenta

Figura 6.4: Modelo de Dados da Fase de Planejamento do Processo

Figura 6.5: Modelo de Dados da Fase de Planejamento do Processo na Ferramenta .. 114

Figura 6.6: Visualização Instantânea dos Modelos de Dados 115

Figura 6.7: Modelo da Área de Projeto Alterado. 116

Figura 6.8: Modelo da Área de Projeto Consolidado. 117

Figura 6.9: Exemplo de Generalização 118

Figura 6.10: Exemplo de Composição 118

Figura 6.11: Exemplo de Agregação 119 


\section{Glossário}

ANSI: American National Standart Institute. Instituto Nacional Americano de Padrões.

API: Application Programing Interface. Interface de Programação de Aplicação.

BC: Base de Conhecimento.

CASE: Computer Aided Software Engineering. Engenaria de Software Auxiliada por Computador

CCE: Comunidade Comum Européia.

CIM: Computer Integrated Manufacturing. Manufatura Integrada por Computador.

CIM-Manager: Sistema utilizado na Fábrica Integrada Modelo para o gerenciamento das informações.

CIM-OSA: Computer Integrated Manufacturing - Open Systems Architecture. Manufatura Integrada por Computador - Arquitetura de Sistemas Abertos.

CLIPPER: Linguagem de Programação Estruturada.

CN: Comando Numérico.

C++: Linguagem de Programação Orientada a Objetos.

DBA: Database Administrator. Administrador da Base de Dados.

DB2: Sistema Gerenciador de Banco de Dados Relacional da IBM.

DDCS/2: Distribuited Database Connection Services. Produto de abordagem por portão comum, fornecido pela IBM.

DLL: Dynamic Link Library. Biblioteca de Ligação Dinâmica.

DRDA: Distribuited Relational Database Architecture. Produto de abordagem por protocolo comum, fornecido pela IBM.

EAN: Enterprise Area Network. Rede que abrange uma empresa.

EDA: Enterprise Data Access. Produto de abordagem por interface comum.

EDC: Enterprise Database Connectivity. Conectividade de Bancos de Dados Empresariais.

EIS: Executive Information Systems. Sistemas de Informação Executivos. 
ESPRIT: European Strategic Programme for Research in Information Technology. Programa Estratégico Europeu para Pesquisa em Tecnologia de Informação.

FIM: Fábrica Integrada Modelo.

IA: Inteligência Artificial.

IBM: É uma marca registrada da International Business Machines Corporation.

ICMSC: Instituto de Ciências Matemáticas de São Carlos.

ISO: International Standart Organisation. Organização Internacional de Normas Técnicas.

I-CASE: Integrated CASE. CASE Integrado.

LAMAFE: Laboratório de Máquinas e Ferramentas.

LAN: Local Area Network. Rede local

MD: Modelo de Dados.

MDI: Multiple Database Interface. Interface de Múltiplas Bases de Dados.

MER: Modelo Entidade Relacionamento.

MN: Modelo de Negócios.

MO: Modelo de Operação

MOr: Modelo Organizacional.

MI: Modelo de Integração.

MIM: Metodologia de Integração da Manufatura.

MT: Memória de Trabalho.

ODBC: Open Database Connectivity. Conectividade Aberta para Base de Dados, padrão de acesso a banco de dados do sistema operacional Windows.

ODS: Open Data Services. Produto baseado na abordagem por portão comum.

PC: Personal Computer. Computador Pessoal.

PCP: Planejamento e Controle da Produção, componente CIM. 
PL/1: Linguagem de Programação.

RDA: Remote Database Access. Produto baseado na abordagem por protocolo comum.

SADT: Structured Analisys and Design Technique. Técnica de Análise e Projeto Estruturado.

SBC: Sistema Baseado em Conhecimento.

SGBDR: Sistema Gerenciador de Banco de Dados Relacionais.

SI: Sistema de Informação.

SIS: Strategic Information Systems. Sistemas de Informação Estratégicos.

SQL: Structured Query Language. Linguagem de consulta estruturada, padrão de acesso a banco de dados.

TDS: Sybase Tabular Data Stream. Produto baseado na abordagem por protocolo comum.

TI: Tecnologia da Informação.

USP: Universidade de São Paulo.

WAN: Wide Area Network. Rede de longa distância. 


\section{Resumo}

Integração é uma forma de auxiliar às empresas de manufatura a sobreviverem frente à competição internacional, utilizando de forma coordenada modernas filosofias e ferramentas disponíveis. $O$ gerenciamento da informação em ambientes integrados de manufatura vem se tornando cada vez mais complexo devido à necessidade de tratamento de um grande volume de dados. A utilização crescente de ferramentas CASE e conceitos de modelagem CIM está se tornando indispensável no contexto de integração da manufatura e, consequentemente, para o sucesso das empresas. Neste ambiente identifica-se a crescente necessidade de automação do conhecimento humano. Este trabalho apresenta a concepção e implementação de uma ferramenta para modelagem de dados utilizando a tecnologia de Sistemas Baseado em Conhecimento para a representação e manipulação do conhecimento humano. Este ambiente foi desenvolvido para um propósito geral, mas foi testado num ambiente de manufatura. 


\begin{abstract}
Integration is a way of helping manufacturing companies to survive in a competitive international environment, using modern philosophies and available tools in a coordenated way. Information management in integrated manufacturing environments is becoming more and more complex mostly due to treatment of a large volume of data. The use of CASE tools and CIM modeling concepts is becoming indispensable to the solution in the manufacturing integration context and, consequently, to the success of the companies. In this new environment, there has been identified a growing need for automation of human knowledge. This work presents the conception and implementation of a tool for data modeling using the technology of Knowledge-Based Systems for the representation and manipulation of human knowledge. This environment was developed for a general purpose, but was tested in a manufacturing environment.
\end{abstract}




\section{INTRODUÇÃO}

\subsection{Considerações Iniciais}

Atualmente, a palavra Integração tornou-se requisito indispensável para auxiliar as empresas de manufatura a sobreviverem frente à competição internacional, utilizando, de forma coordenada, modernas filosofias e ferramentas. A concorrência, as exigências do mercado consumidor e a evolução tecnológica estão forçando a empresa de manufatura a se reestruturar para responder a estes estímulos externos da maneira mais rápida possível.

A utilização dos recursos atuais da tecnologia da informação é fundamental para as empresas no atendimento aos requisitos atuais do sistema de manufatura. Dentre esses recursos, pode-se destacar a tecnologia referente aos sistemas gerenciadores de banco de dados, onde as informações operacionais da empresa são armazenadas. Um requisito para utilização desses sistemas é uma análise estratégica das necessidades gerais de informações da empresa, combinanda com alguma metodologia de análise lógica dos dados. Vários conceitos/filosofias estão relacionados com a análise lógica dos dados da empresa, entre os quais destacam-se as estratégias de atuação para a obtenção da Integração da Manufatura e modelagem de empresas. A modelagem de dados constitui-se em uma atividade de modelagem de empresas que por sua vez suporta as metodologias de integração.

A fase de modelagem de dados deve ser realizada por especialistas em análise lógica dos dados como um recurso da empresa. Esta atividade deve suportar principalmente o desenvolvimento dos sistemas de informação que compõem o sistema de manufatura. Dessa forma, verifica-se um nível de dependência da empresa com relação a esses especialistas. Esta afirmação justifica a necessidade da empresa em armazenar e manipular o conhecimento de seus especialistas.

Neste sentido, as empresas estão utilizando tecnologias fornecidas pela área de Inteligência Artificial, onde um de seus objetivos básicos é a automação do processamento do conhecimento humano [KUSIAK-90]. Uma das formas de viabilizar este processo de automação é através da construção de Sistemas Baseado em Conhecimento. Tais sistemas possuem a capacidade de armazenar e processar o conhecimento humano, possibilitando assim a sua automação.

Dessa forma, a representação do conhecimento humano na área de modelagem de 1. A. . . Jininnn um mainr nivel de ceguranca na utilizacão dos sistemas de informação 
da empresa. O objetivo da utilização combinada dos conceitos envolvendo modelagem de dados e sistemas que manipulam o conhecimento humano é fornecer subsídios para as empresas de manufatura no controle sobre seus sistemas de informações e, com isso, responder em tempo hábil aos estímulos externos.

\subsection{Objetivos do Trabalho}

O desenvolvimento integrado dos sistemas de informação de uma empresa de manufatura envolve vários conceitos/metodologias. Para suportar esta integração, estão sendo utilizadas ferramentas que representam as metodologias de desenvolvimento de sistemas. Neste sentido, um dos objetivos desta dissertação consiste na revisão descritiva dos conceitos envolvidos na integração dos sistemas de informação.

Outro objetivo deste trabalho é a construção de uma ferramenta para auxiliar a modelagem de dados de uma empresa de manufatura, onde uma de suas principais funcionalidades é a verificação automática de seus modelos. Neste sentido é utilizada a tecnologia de Sistemas Baseado em Conhecimento para a manipulação do conhecimento envolvido. Com isto, espera-se uma aquisição de maturidade na aplicação dos conceitos/metodologias relevantes ao desenvolvimento integrado dos sistemas de informação que compõem o sistema de manufatura de uma empresa.

Vale ressaltar que neste trabalho é aplicada uma tecnologia consolidada da área de Inteligência Artificial, os Sistemas Baseado em Conhecimento, no desenvolvimento da ferramenta para modelagem de dados.

\subsection{Organização do Trabalho}

Este trabalho está organizado da seguinte forma:

O Capítulo 2 apresenta o cenário atual no qual as empresas de manufatura estão inseridas, onde são abordados o Sistema de Manufatura e seus requisitos atuais, a Metodologia de Integração de Manufatura (em desenvolvimento no Projeto CIM do Departamento de Engenharia Mecânica da USP São Carlos), o papel capacitor da Tecnologia da Informação e os conceitos envolvidos em Modelagem de Empresas.

O Capítulo 3 apresenta os conceitos envolvidos no desenvolvimento de uma ferramenta para modelagem de dados, onde são abordados os elementos de uma Análise Lógica dos Dados e a tecnologia dos Sistemas Baseado em Conhecimento. 
No Capítulo 4 são abordados os requisitos para a construção de uma ferramenta para modelagem de dados. Uma arquitetura para a ferramenta é proposta utilizando alguns dos recursos da Tecnologia da Informação.

O Capítulo 5 apresenta a concepção e implementação do protótipo da ferramenta para modelagem de dados desenvolvida neste trabalho. Para cada componente da arquitetura são mostradas as metodologias e os softwares utilizados para a implementação. Vale ressaltar que em todo o processo de concepção e implementação foram utilizados recursos do Projeto CIM da USP São Carlos.

O Capítulo 6 descreve uma aplicação do protótipo da ferramenta para modelagem de dados que envolve as fases de Projeto do Produto e Planejamento do Processo de uma empresa de manufatura.

O Capítulo 7 apresenta as conclusões sobre o desenvolvimento deste trabalho e aborda algumas sugestões para trabalhos futuros. 


\section{CENÁRIO ATUAL DE INTEGRAÇÃO DAS EMPRESAS DE MANUFATURA}

\subsection{Considerações Iniciais}

Atualmente existe uma crise econômica mundial que está afetando a maioria dos países industrializados. Isso está ocorrendo tanto a nível de países desenvolvidos e industrializados quanto a nível de países sem um parque industrial muito desenvolvido e moderno, como é o caso do Brasil [AGOSTINHO-89]. Com relação à empresa de manufatura, além de todo esse panorama mundial, existe outro estímulo muito forte que a afeta: a rápida evolução tecnológica. Neste sentido, os computadores possuem grande influência sobre a empresa, sendo sua utilização considerada como um fator decisivo que permite ganhos em flexibilidade e produtividade.

O mercado consumidor, por sua vez, estimula as empresas a aumentar a variedade de seus produtos, cada vez mais adaptados ao uso [BREMER-92]. Este estímulo externo somado a outros, como a integração econômica mundial e a evolução tecnológica, agem de forma sinérgica sobre a estrutura das empresas que desejam sobreviver mediante a competividade. Dessa forma, o grande desafio das empresas de manufatura nesta década é a adaptação às novas características do meio. Entre essas novas características destacam-se:

- aumento da exigência de produtos de qualidade;

- frequentes mudanças no mercado;

- produtos com um curto ciclo de vida;

- produtos variados;

- grande concorrência de preços.

Estas características implicam em uma grande preocupação com a obtenção de produtos de boa qualidade a baixos custos, desenvolvidos em prazos restritos. Além dos produtos, a qualidade também é uma preocupação no atendimento ao consumidor.

Como reflexo dessas novas condições, surge a necessidade de uma nova filosofia para a empresa de manufatura. Esta nova filosofia baseia-se na racionalização, simplificação e integração das atividades desenvolvidas pela empresa para aumentar sua adaptabilidade 
[AGOSTINHO-89]. Desse modo tenta-se não só garantir a sobrevivência como também o crescimento do sistema de manufatura, e consequentemente de todo um país. Essa nova filosofia implica em uma organização das informações operacionais adequada para que a empresa possa responder aos estímulos externos [ROZENFELD-92a]. A empresa que armazenar, de uma forma eficiente, as informações relevantes e o conhecimento necessário para a manipulação das mesmas será considerada uma empresa do futuro [MARTIN-91].

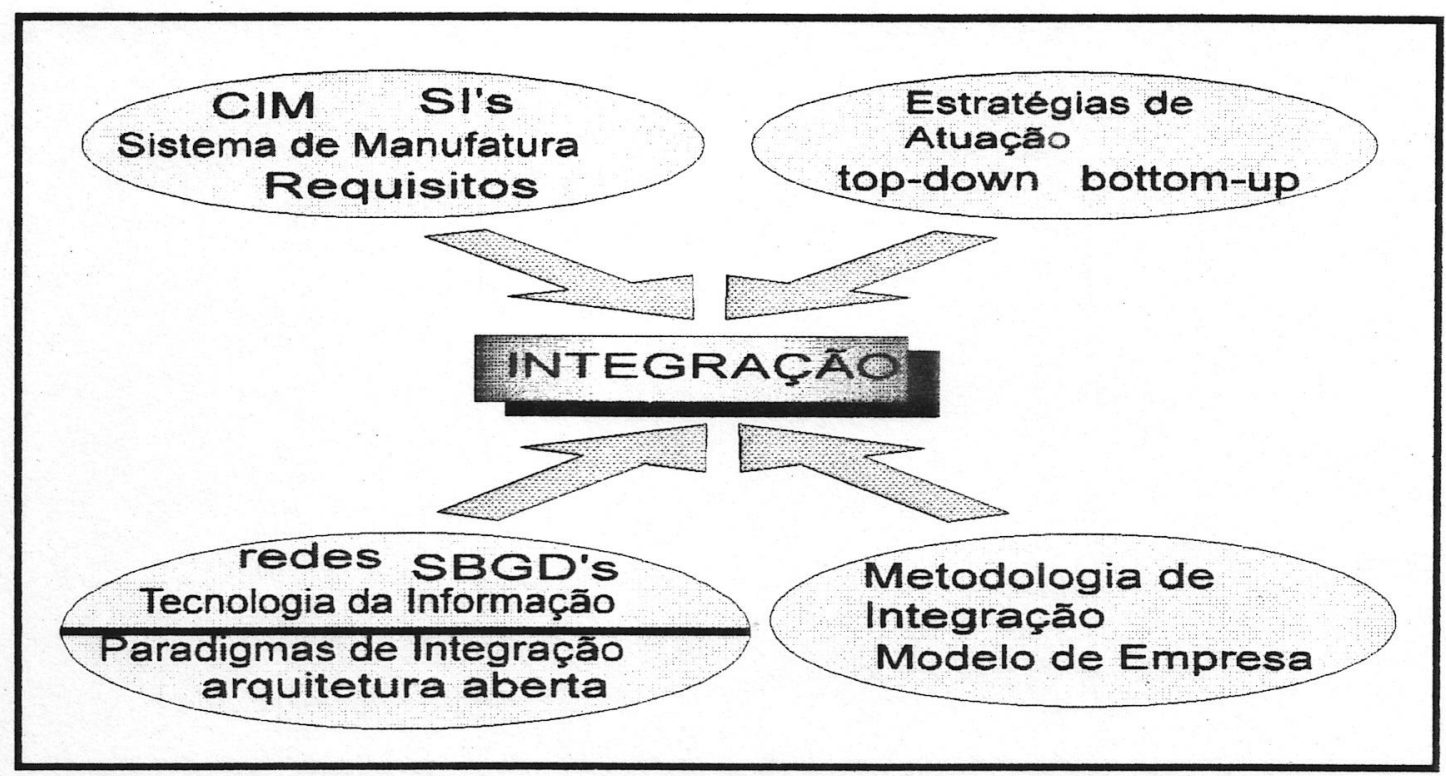

Figura 2.1: Conceitos Relacionados à Integração das Empresas

Este capítulo apresenta alguns conceitos que podem ser ressaltados neste ambiente de integração das informações operacionais (Figura 2.1). Dentro deste contexto, na seção 2.2 são apresentados os conceitos de sistema de manufatura, seus requisitos atuais e duas arquiteturas de referência para o desenvolvimento da manufatura integrada por computador. Na seção 2.3 são abordadas as estratégias de atuação para integração da empresa de manufatura. Os fatores que influenciam o desenvolvimento das estratégias de atuação são apresentados nas seções 2.4 e 2.5. Na seção 2.6 é apresentada uma Metodologia de Integração da Manufatura, em desenvolvimento no Projeto CIM da USP-São Carlos. Dentro do desenvolvimento desta metodologia existe o processo de modelagem de empresas que é abordado na seção 2.7 . 


\subsection{Sistemas de Manufatura}

Um sistema de manufatura pode ser definido como um sistema que integra diferentes estágios da fabricação de um produto, necessitando para isso de uma análise das influências externas a fim de responder às mesmas em um tempo viável [AGOSTINHO91]. O sistema de manufatura pode ser dividido em 4 elementos básicos, Figura 2.2, que são:

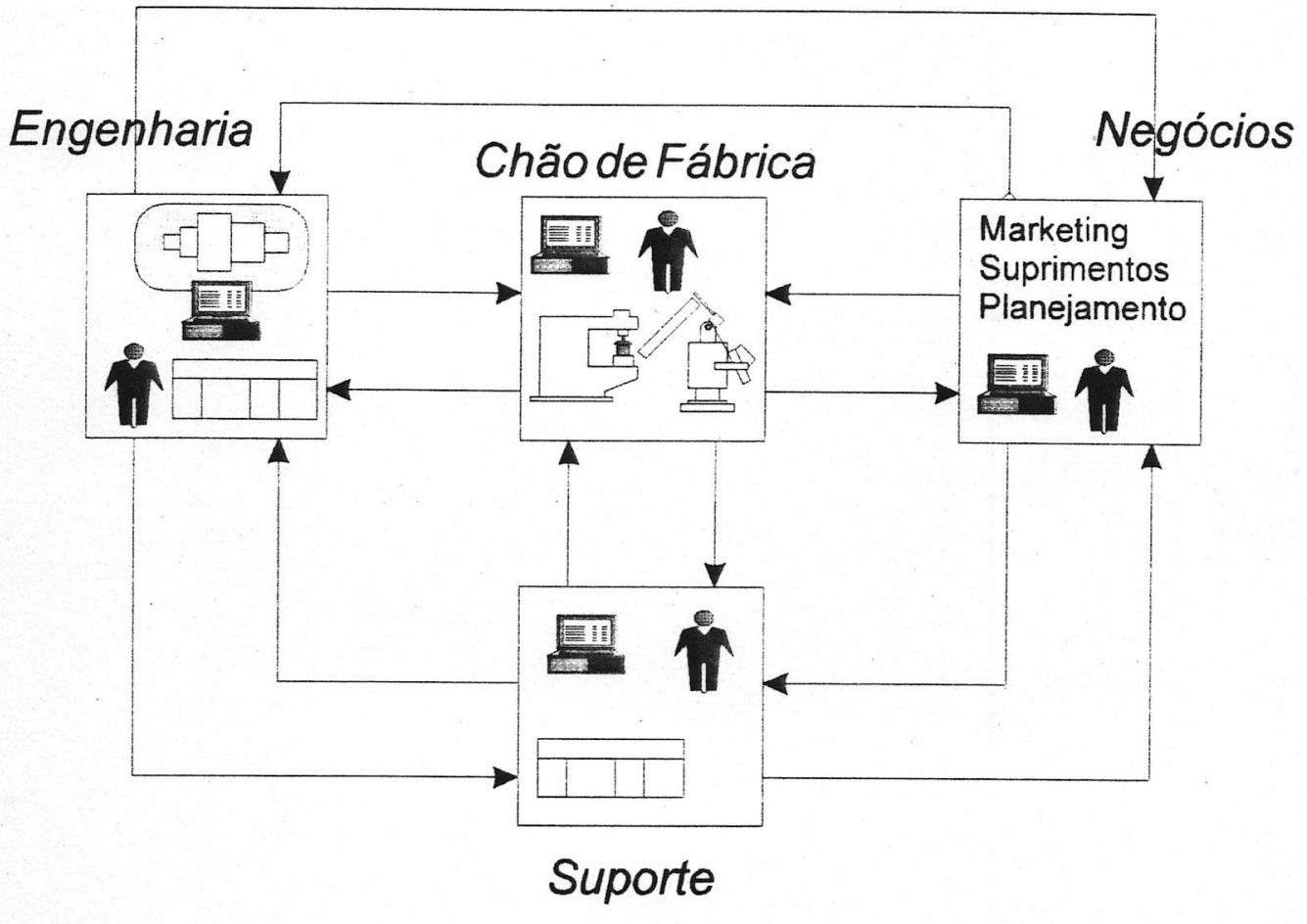

Figura 2.2 Modelo Conceitual de Sistema de Manufatura [AGOSTINHO-89]

- o elemento Criação pode também ser chamado de engenharia. Trata-se do elemento responsável pela criação e desenvolvimento de novos produtos, bem como pelo desenvolvimento dos meios de produção (processo, ferramental, dispositivos, etc). Este elemento engloba o que hoje é conhecido nas empresas como engenharia do produto e fabricação; 
- o elemento Chão de Fábrica corresponde à real fabricação dos produtos. Seus recursos são equipamentos e mão de obra direta e indireta;

- o elemento Negócios é responsável pelo contato com o meio externo. O sensoriamento do contato com o mercado consumidor é função atualmente conhecida como marketing. Para realizá-la, é necessário sensibilidade na detecção das mudanças no meio, de forma que estas sejam introduzidas o mais rápido possível no sistema. $\mathrm{O}$ contato com o mercado fornecedor também é feito pelo elemento Negócios, com a divisão de Suprimentos. Por fim, a última função é o planejamento e controle da produção que está em contato direto com a demanda de produtos do mercado consumidor. Com esta função, o elemento Negócios procura coordenar a produção, de forma que o sistema produza saídas compatíveis às entradas;

- o elemento Suporte corresponde aos setores responsáveis por garantir a operação do sistema de manufatura, visando manter suas características de qualidade e de desempenho operacional. Nas empresas de manufatura atuais, este elemento corresponde aos setores de qualidade e manutenção. O setor de qualidade deve prover meios de manter controlada e estável a qualidade dos produtos, e até fazê-la evoluir caso haja estímulos externos nessa direção. O elemento Suporte deve prover meios para que equipamentos e a própria instalação estejam em condições adequadas para o funcionamento da produção.

Assim, é possivel observar que o elemento Negócios tem que ser eficiente, pois é o responsável por introduzir no sistema de manufatura alterações decorrentes de mudanças no ambiente externo à empresa.

\subsubsection{Requisitos Atuais para os Sistemas de Manufatura}

Em seus estudos, Agostinho mostra que o sistema manufatureiro de bens produtivos sofreu grandes transformações nos últimos quinze a vinte anos [AGOSTINHO-91]. Nas décadas de 60/70, a competitividade não influenciava a estruturação das empresas. As necessidades do mercado não tinham importância relevante, pois o consumidor era pouco exigente e consequentemente os produtos eram dirigidos pelas organizações para o mercado consumidor. A produção caracterizava-se pela baixa diversificação, o tamanho dos lotes de peças era médio ou grande $e$ as instalações típicas eram de automação rígida de acordo com o produto fabricado. 
A situação das fábricas das décadas de 80/90 apresenta grandes mudanças no seu perfil. Elas possuem uma grande variedade de produtos e a estratégia é de negócios orientados para o cliente ("customer oriented business"), isto é, a administração agora é voltada para o mercado consumidor (Figura 2.3). As variações no comportamento e as necessidades do mercado consumidor levam as empresas a adotarem uma postura de grande diversidade de peças em fabricação e montagem, o que resulta em lotes de tamanhos menores. Assim as empresas devem reagir rapidamente às necessidades dos clientes, com os menores custos de produção, para poderem competir num mercado cada vez mais exigente

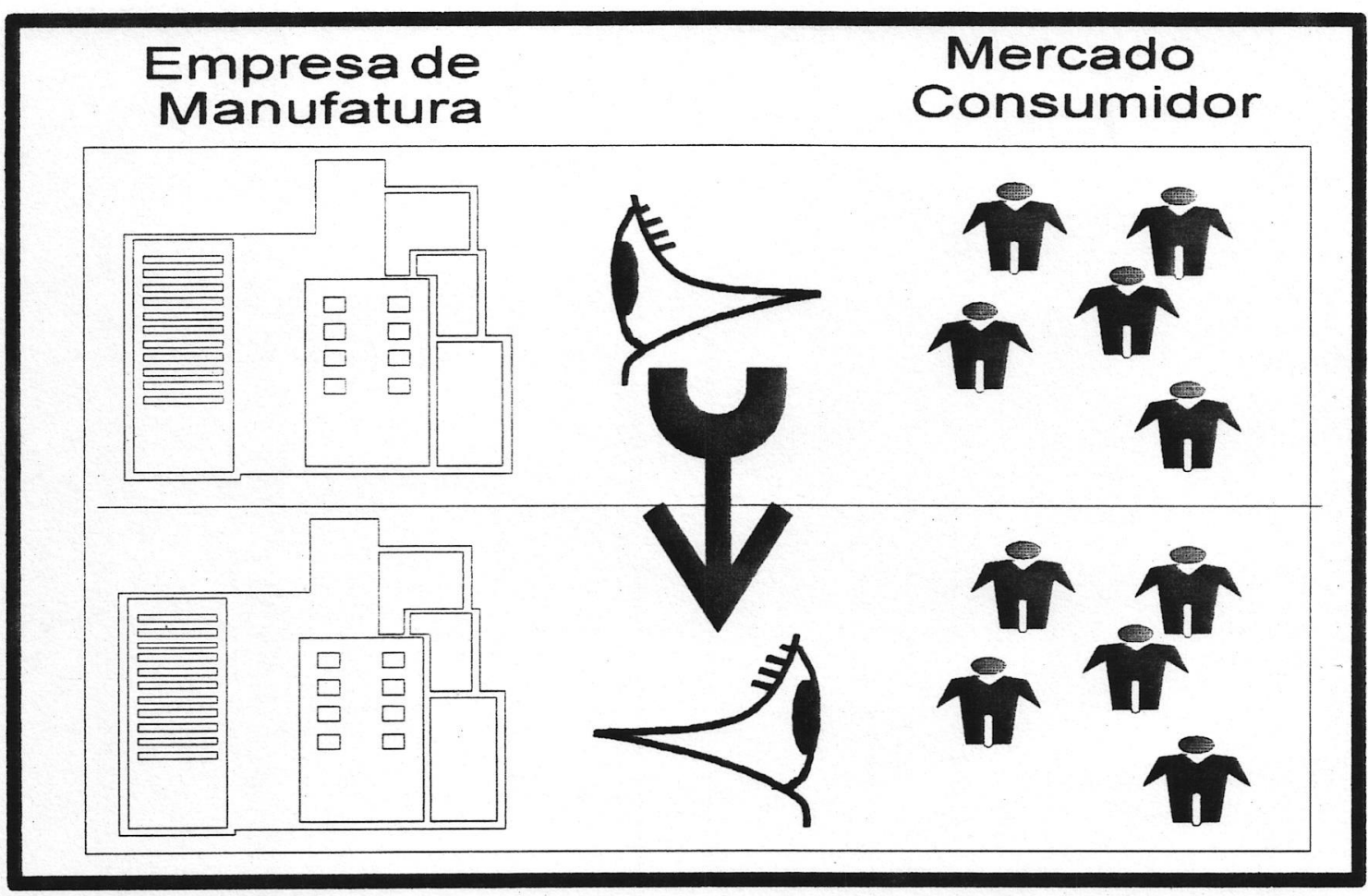

Figura 2.3: Uma Característica da Evolução do Sistema de Manufatura

Para uma empresa atender aos estímulos atuais, Agostinho aponta os seguintes requisitos [AGOSTINHO-92]:

- integração entre as atividades da empresa;

- sinergia do sistema de informação; 
- coerência entre os estímulos externos e a arquitetura do sistema de manufatura.

As mudanças que ocorrem deverão ser sensoreadas através de pesquisas, com o objetivo de conhecer antecipadamente as tendências do mercado consumidor. Com esses dados e através da análise e interação da empresa com os fatores de influência externos, pode-se tomar medidas adequadas para a adaptação.

Como suporte no atendimento às necessidades criadas pelas novas tendências, citadas anteriormente, as empresas deverão possuir recursos para:

- fabricação simultânea dos componentes do produto;

- transferência de um alto volume de informações entre as várias atividades da empresa.

A capacidade de adaptação das empresas pode ser caracterizada por sua flexibilidade. Esta flexibilidade é observada nas atividades do chão de fábrica, onde são implementadas alterações de quantidades, tamanhos de lotes e diferentes ítens de produtos em tempos adequados.

Para se obter índices de adaptabilidade crescentes é necessário reduzir o tempo consumido em cada atividade do processo de fabricação e reduzir o número de atividades necessárias para o desenvolvimento de um novo produto.

Como foi citado, integração e sinergia dos sistemas de informação são requisitos vitais para empresa de manufatura, uma vez que a transferência eletrônica das informações entre os sistemas constitui-se em uma forte tendência

\subsubsection{A Manufatura Integrada por Computador}

Uma definição para a Manufatura Integrada por Computador (Computer Integrated Manufactured --- CIM) consiste no processamento integrado das informações necessárias às tarefas técnicas e operacionais de uma empresa de manufatura [SHEER-91].

A expectativa da indústria em torno de CIM é que ele aumente a competitividade através de um aumento da adaptabilidade e flexibilidade da empresa. Através de CIM, espera-se que a organização e operação da empresa melhore o aproveitamento de seus bens e recursos da mesma (pessoal, capital de investimento, informações, entre outros) [KOSANKE-90]. 
Em geral, CIM busca, através da integração e racionalização de toda a cadeia produtiva (processos e troca/fluxo de informações), uma maior adaptabilidade da empresa, resultando em um ganho de competitividade perante o mercado consumidor.

Algumas filosofias existentes na literatura servem como padrões de referência para CIM. Entre elas destacam-se o CIM-OSA (Computer Integrated Manufactured - Open Systems Architecture) e a ARIS (Architecture for Integrated Information System).

\subsubsection{CIM-OSA}

O CIM-OSA é uma arquitetura de referência na qual os sistemas de informação de empresas de manufatura são desenvolvidos de maneira integrada. O projeto do CIMOSA está vinculado ao programa ESPRIT suportado pela CCE (Comunidade Comum Européia) [ESPRIT-89]. A meta estratégica do programa ESPRIT foi a de fornecer à indústria de informática européia a base tecnológica necessária para manter-se competitiva em relação aos EUA e Japão nos anos 90.

Inicialmente foram definidos neste projeto três níveis de integração que guiam o desenvolvimento do CIM-OSA:

- Integração de Sistemas Físicos (comunicação): consiste na interconexão fisica entre os sistemas com utilização de redes locais, assim como regras e convenções para troca de dados e gerenciamento de configuração de redes de comunicação;

- Integração de Aplicaçôes: consiste na promoção do compartilhamento de dados pelos aplicativos e na integração de funções pela execução de um mesmo aplicativo;

- Integração de Negócios (comercial): é uma evolução da integração fisica e de aplicativos, onde são integradas funções complementares da empresa tais como finanças, maketing, planejamento estratégico.

A principal meta do CIM-OSA é prover uma Arquitetura de Sistemas Abertos que suporte todas as necessidades de informações internas e externas à empresa. Os sistemas que forem desenvolvidos e construídos de acordo com o CIM-OSA suportarão todos os níveis de administração e seus planejamentos estratégicos, táticos e operacionais, assim como as funções operacionais [KOSANKE-90]. 
O padrão de referência CIM-OSA deve suportar todas as fases para a integração dos sistemas de informação. Esta integração engloba tanto o ciclo de desenvolvimento dos sistemas como a aquisição de sistemas comerciais.

\subsubsection{ARIS}

A arquitetura ARIS constitui um "framework" (arquitetura de referência) no qual sistemas integrados podem ser desenvolvidos e otimizados. Em paralelo, ARIS demonstra como a administração dos negócios da empresa pode analisar os sistemas de informação para implementar suas metas.

A arquitetura apresenta três níveis de abstração:

- a camada conceitual analisa os fatores que são relevantes para a empresa sem considerar os requisitos de implementação. Todavia, a estrutura do modelo é formalizada o suficiente para permitir a transformação subsequente com suporte computacional;

- a camada técnica representa as áreas de negócios que foram definidas na camada conceitual e que usarão as tecnologias de processamento eletrônico de dados;

- na camada de implementação, os requisitos são implementados para estruturas de dados físicos e o código do programa é descrito.

Na monografia apresentada, como parte dos requisitos para o exame de qualificação desta dissertação, foi proposta a construção de um Sistema Baseado em Conhecimento para auxiliar o processo de modelagem de dados baseado na arquitetura ARIS. No entanto, foi verificado que esta arquitetura não fornecia uma descrição clara de seu funcionamento o que impediu o prosseguimento dessa proposta.

\subsubsection{Sistemas de Informação para Manufatura}

O objetivo fundamental dos Sistemas de Informação --- SI --- para CIM é a integração de processos de negócios de empresas e de manufatura. Nesse sentido, esses sistemas devem suportar a troca de informações entre os vários níveis de organização (estratégico, gerencial e operacional) bem como funções de negócios da empresa (marketing, compra, produção e distribuição, etc.). 
Segundo Sheer, o desenvolvimento e aquisição de SI's para a integração do sistema de manufatura é influenciado por dois fatores (Figura 2.4) [SHEER-93]:

- a tecnologia de informação;

- o modelo de negócios da empresa.

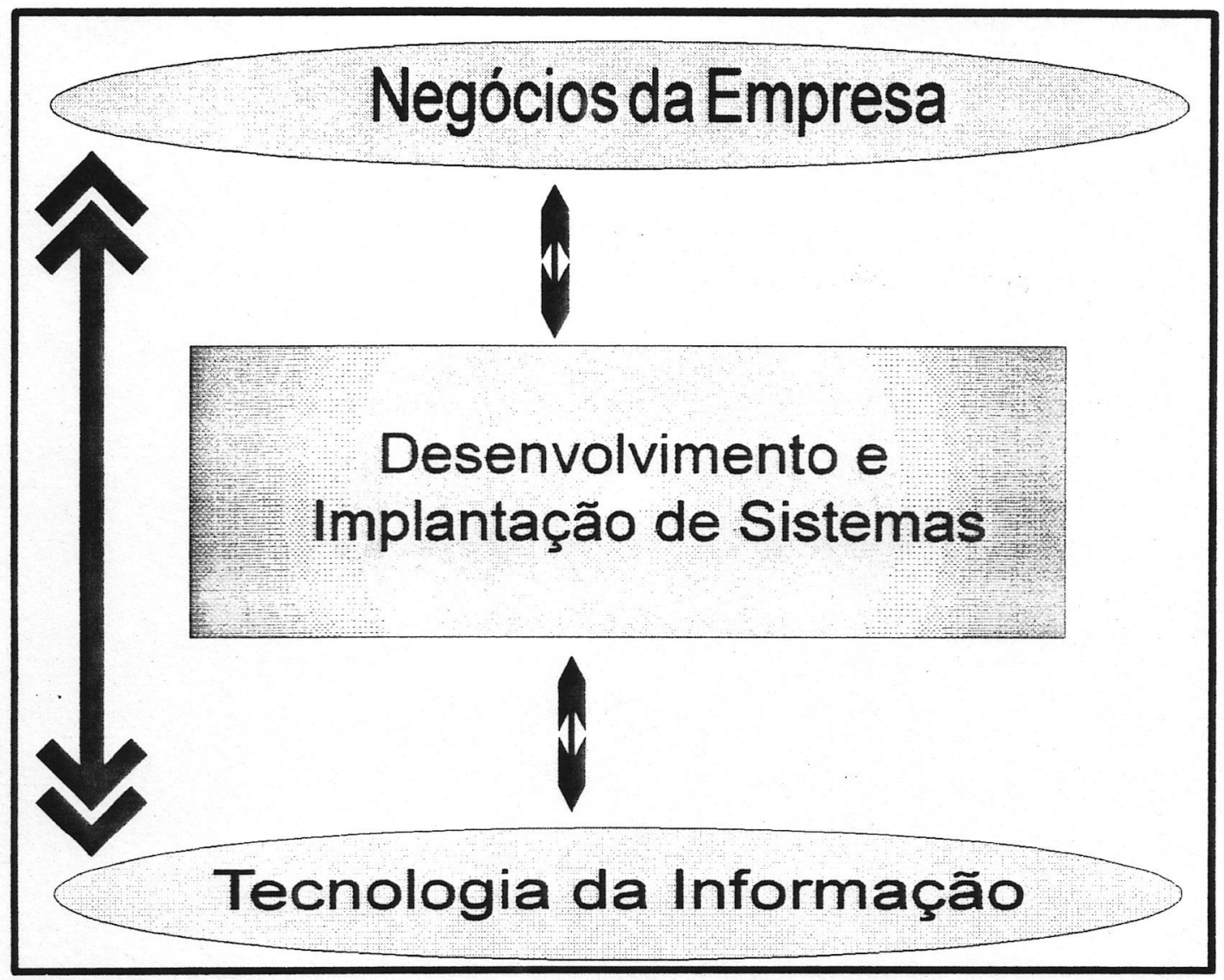

Figura 2.4: Esquema de Desenvolvimento de SI's Integrados [SHEER-93]

Os SI's estão diretamente relacionados com estratégias de manufatura e de negócios da empresa. Estratégia de negócios pode ser definida como requisitos impostos pelo mercado, os quais deverão ser atendidos no presente ou em um futuro previsível, e estratégia de manufatura é definida como o conjunto de medidas adotadas ou previstas pela empresa para satisfazer os requisitos de mercado no âmbito da manufatura [MOODY-90]. 
Para que haja uma correspondência entre os elementos das estratégias citadas acima e a tecnologia da informação há a necessidade de uma metodologia que suporte uma estratégia de atuação por parte das empresas para corresponder aos estímulos externos.

\subsection{Estratégias de Atuação}

Geralmente, existem nas empresas dois tipos de estratégia de manufatura. Na primeira, conhecida como "top down", a alta gerência da empresa apenas filosofa sobre mudanças mas normalmente não consegue chegar a resultados palpáveis. $\mathrm{Na}$ segunda, conhecida como "bottom up", implementam-se soluções de forma descoordenada em busca da modernização na base da estrutura da empresa. Esta estratégia resulta nas ilhas de integração, que na grande maioria dos casos não alcançam o potencial dessas tecnologias (Figura 2.5) [ROZENFELD-92b][ROZENFELD-94].

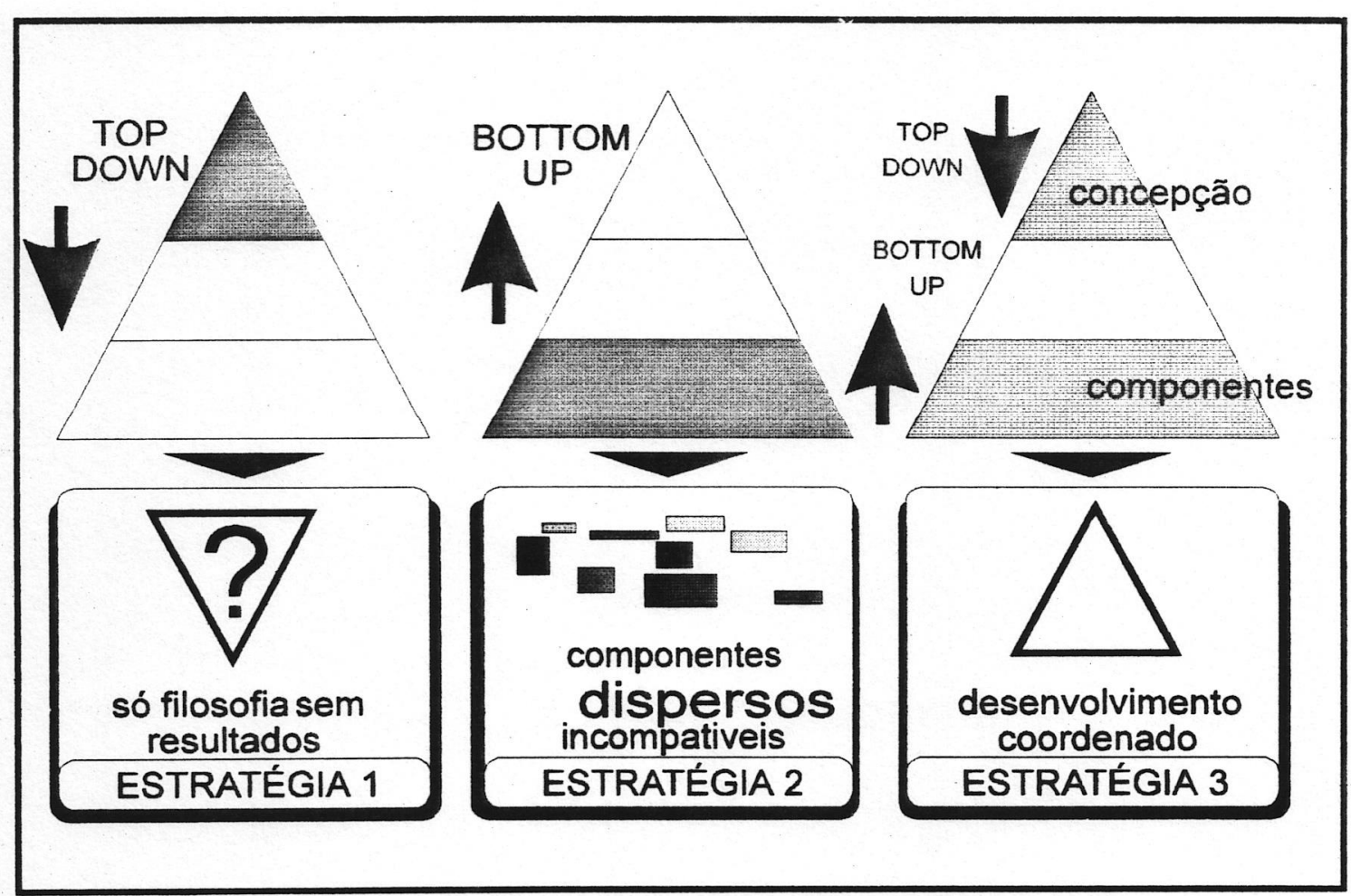

Figura 2.5: Estratégias para as Empresas de Manufatura [ROZENFELD-94]

No Projeto CIM da USP São Carlos encontra-se em desenvolvimento uma Metodologia de Integração da Manufatura -- MIM -- onde as duas estratégias anteriores são 
combinadas, em busca de um desenvolvimento coordenado entre a concepção das filosofias de alto nível da empresa (modelo de negócios) e a incorporação de soluções de modernização na sua base (Tecnologia de Informação) [ROZENFELD-94].

Para salientar o que pode ser realizado para se alcançar a integração (base da pirâmide), as seções 2.4 e 2.5 apresentam alguns dos principais recursos fornecidos pela tecnologia da informação que estão alterando a estrutura das empresas. A seção 2.6 apresenta, de uma forma sucinta, a metodologia citada acima ressaltando apenas como o desenvolvimento deste trabalho se encaixa na mesma.

\subsection{Tecnologia de Informação}

Segundo Zuboff [ZUBOFF-88],

Tecnologia de Informação -- TI --- é uma denominação que reflete a convergência de diversas correntes de desenvolvimento tecnológico, incluindo microeletrônica, ciência de computação, telecomunicações, engenharia de software e análise de sistemas.

Atualmente, a TI propicia aplicações no nível estratégico das organizações, com sistemas voltados ao apoio dos executivos (Executive Information System --- EIS), e principalmente com sistemas de informações estratégicas (Strategic Information Systems --- SIS), voltados para a administração de negócios das organizações e para a orientação ao ganho ou manutenção de vantagens competitivas.

Aplicações planejadas de TI podem modificar a forma tradicional de exercício do poder dentro das organizações, normalmente de padrão hierárquico, assim como a natureza do trabalho dos colaboradores, que de alguma forma lidam com informações no seu local de trabalho [YONG-92].

Dentro deste contexto, as seções seguintes apresentam os principais recursos fornecidos pela TI que estão alterando a estrutura da empresa. A seção 2.4.1 aborda o downsizing e apresenta brevemente uma evolução do hardware relacionado com a centralização e/ou descentralização da função de processamento de dados. As seções 2.4.2 e 2.4 .3 abordam, respectivamente, a tecnologia de redes e os sistemas distribuídos que estão relacionados com a troca e transparência de localização das informações entre os sistemas da empresa. Com relação ao armazenamento das informações é apresentada na seção 2.4 .4 a tecnologia dos sistemas gerenciadores de banco de dados e alguns conceitos que 
surgiram a partir desta teconologia. A filosofia de sistemas abertos é abordada na seção 2.4 .5 bem como a sua importância na integração de aplicativos. Para o desenvolvimento integrado e eficiente de sistemas de informação, algumas caraterísticas das ferramentas utilizadas neste processo são apresentadas na seção 2.4.6.

Devido a importância da conexão entre diferentes sistemas gerenciadores de banco de dados, a seção 2.5 enfatiza os paradigmas de integração. Dentro desta seção é discutida a conectividade de banco de dados empresariais e uma arquitetura para conectividade aberta.

\subsubsection{DOWNSIZING}

O termo dowsizing é muito utilizado quando se fala em evolução de hardware e pode ser definido como um processo que as empresas devem implementar para poder sair da atual geração de tecnologia de informação (TI) para entrar na próxima [HAMMER-93]

O principal aspecto relacionado ao downsizing é a decisão sobre a centralização ou a descentralização do processamento de dados (Figura 2.6). A tendência é que as duas maneiras de processamento de dados coexistam segundo as necessidades da empresa [GUENGERICH-94]

A forma centralizada baseia-se na segurança de grandes centros de dados e possui uma considerável quantidade de recursos quanto ao provimento de adequados sistemas de proteção contra uma ampla gama de perigos. Esta característica leva aos beneficios fornecidos pelos mainframes, onde a segurança neste tipo de hardware já atingiu certa maturidade, ou seja, a centralização dos dados.

Por outro lado, o grande custo atrelado aos mainframes proporcionou o desenvolvimento de outras tecnologias para o processamento de dados. Com isso, surgiram os minicomputadores e os microcomputadores. Os minicomputadores surgiram para operar aplicações que necessitavam de dúzias e, às vezes, centenas de terminais on-line, onde são julgadas mais adequadas ou mais produtivas que os mainframes. No entanto, esta tecnologia tende a ser substituída por uma rede de microcomputadores, pois a quantidade de conectividade e compartilhamento de programas e dados com outros computadores no sistema de manufatura como um todo é limitada. Na sequência da evolução do hardware, surgiram os micromputadores (também conhecidos como computadores pessoais -- PC). 
Esta evolução do hardware, que diminiu o custo de manutenção dos sistemas, levou à descentralização dos processamento dos dados.

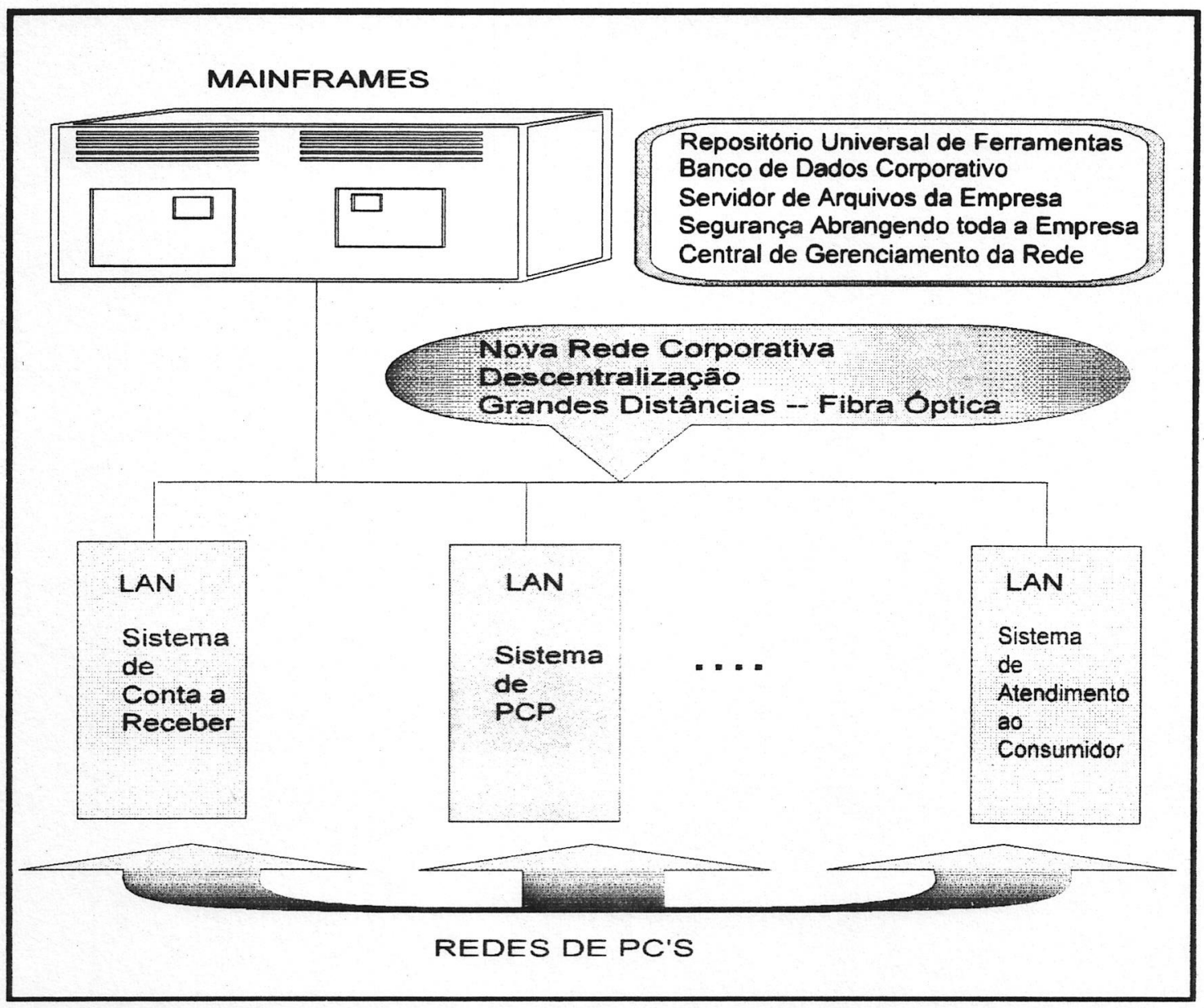

Figura 2.6: O Novo Papel do Mainframe nos anos 90

Como mostra a Figura 2.6, os mainframes estão se adaptando ao seu novo ambiente. Interligações a longa distância via fibra ótica, gateways entre outras tecnologias estão tornando os mainframes mais poderosos e mais fáceis de ser conectados com outros produtos. Estão sendo desenvolvidos recursos para integração de mainframes com PC's, os quais permitem que as empresas possam utilizar os mainframes para grandes aplicativos de processamento de transações, bem como para gerenciamento de rede e de dados, ao mesmo tempo que ainda podem utilizar redes de PC's para construir aplicativos mais flexíveis e de fácil operação. A seguir, é abordada a tecnologia de redes que 
constitui-se um recurso fornecido pela TI que evidentemente alterou a estrutura das empresas, como foi mostrado na Figura 2.6.

\subsubsection{Tecnologia de Redes}

A tecnologia de LAN (Local Area Network) e WAN (Wide Area Network) tornaram-se as plataformas preferidas para aplicativos do downsizing. As LAN's podem encolher, crescer e serem remanejadas com a mesma velocidade com que se realocam pessoas [TANEMBAUM-89]. As WAN's viabilizaram a comunicação a grandes distâncias e atualmente têm tido grandes avanços em termos de velocidade. Uma tecnologia intermediária tem surgido para as necessidades de grandes empresas que são as EAN (Enterprise Area Network). Basicamente existem dois modelos para a construção de redes:

- " "Peer-to-peer" (homogênea)

- Cliente/Servidor

O modelo de rede "peer-to-peer" capacita qualquer nó da rede a atuar como cliente, servidor, ou ambos, para uma determinada aplicação. Conceitualmente, a rede "peer-topeer" é atraente pelo fato de possibilitar total flexibilidade de rede e independência de equipamento. Na prática, contudo, esse tipo de rede torna-se dificil e menos desejável de ser implementado quando as dimensões da rede e a complexidade ultrapassem aquilo que pode ser definido como pequeno e simples. A razão para tal dificuldade é que os PC's, que operam como clientes e também como servidores (isto é, como "peers" dos demais computadores da rede) podem tornar-se muito lentos quando são utilizados como servidores. Além disso, pode ser dificil a administração de aplicativos na rede local "peerto-peer" devido ao fato de que os dados e aplicativos poderem ser armazenados em qualquer local. O principal problema relacionado com a utilização deste modelo é o fator segurança, pois a utilização de um computador como cliente e servidor simultâneamente exige uma alta performance. A maior parte das redes locais "peer-to-peer" não conta ainda com recursos suficientemente sofisticados para gerenciamento de rede [GUENGERICH-94].

O outro modelo de rede, cliente/servidor, possibilita que certos nós da rede sejam operados como clientes, e que outros sejam operados como servidores para um determinado aplicativo. Os clientes tipicamente fornecem o processamento das 
informações e interface com o usuário em cada aplicativo. Os servidores tipicamente fornecem serviços de gerenciamento de funções de arquivos e de rede. $\mathrm{O}$ modelo cliente/servidor é mais prático do que o "peer-to-peer" por ser capaz de proporcionar maior nível de especialização do hardware utilizado na rede.

Para o gerenciamento de uma rede do tipo cliente/servidor é necessária a utilização de um sistema operacional eficiente. Ele consiste do software que administra a rede LAN, fornecendo os serviços de arquivos, de impressão, de segurança no acesso aos arquivos, bem como outras funções de gerenciamento. A escolha do sistema operacional de rede é crucial para o sucesso de uma rede LAN [GUENGERICH-94]. Algumas diretrizes na escolha do pacote de software do sistema operacional de rede são: compatibilidade com aplicativos, gerenciabilidade, confiabilidade, segurança, performance, expansibilidade, entre outros.

A tecnologia de LAN vem sofrendo avanços em termos de hardware e software devido às necessidades das empresas. No entanto, uma discussão detalhada dos componentes desse recurso da TI foge do escopo deste trabalho.

A tecnologia de redes fornece um suporte fundamental para o desenvolvimento dos sistemas distribuídos e dos sistemas gerenciadores de banco de dados, que por sua vez suportam a integração da empresa

\subsubsection{Sistemas Distribuídos}

Os sistemas distribuídos estão se tornando cada vez mais importantes nesta nova fase de desenvolvimento de sistemas, devido a questões de amplitude, localização e redes de comunicação de dados cada vez mais sofisticadas e rápidas. Estes sistemas permitem uma transparência de localização, ou seja, permitem ao usuário acessar dados de qualquer banco de dados residente em um ou múltiplos computadores, sem a necessidade de especificar em que máquina essas informações se encontram armazenadas [BAN-90]. Cabe ao sistema localizar e recuperar o dado solicitado. Em outras palavras, o sistema distribuído deve se apresentar ao usuário como um sistema não-distribuído. Grande parte dos problemas dos sistemas distribuídos são relativos a implementação interna dos softwares que apresentam este recurso e não ao desenvolvimento do usuário. 
O interesse atual nos sistemas distribuídos deve-se à importância das razões envolvidas, quer pelo alto custo de manutenção dos sistemas centralizados, como pelas falhas ao explorar novas oportunidades.

Os sistemas distribuídos compreendem a atualização das informações cooperativas em aplicações nos computadores micro, mini e mainframe, dentro de um processamento misto. A conectividade entre os computadores é fundamental para utilização de sistemas distribuídos. A diminuição dos custos de transmissão de informações digitais através da utilização de redes compartilhadas de comunicação de pacotes constitui em um grande incentivo para o desenvolvimento de sistemas distribuídos.

O conceito de sistema distribuído também implica em delegação de autoridade aos usuários locais sobre as atividades de processamento de dados locais. Os sistemas distribuídos se aplicam a situações nas quais algumas das características relacionadas são as seguintes [BAN-90]:

- acesso instantâneo a dadọ locais, e referências infrequentres aos dados remotos;

- grande quantidade de dados gerados centralizadamente, porém com acesso rápido necessário em sítios remotos;

- processadores múltiplos (possivelmente com banco de dados múltiplos);

É possível obervar que os sistemas distribuídos trouxeram grandes vantagens para as empresas, principalmente no aspecto do processamento de dados descentralizados. Entre essas vantagens destacam-se: economia de escala e integração disponível através de ligação de redes, redução nos custos de comunicação, melhoria no tempo de resposta interativo.

\subsubsection{Sistemas Gerenciadores de Banco de Dados}

O aumento da capacidade, acompanhado de redução do custo dos modernos equipamentos computacionais, tornou possível o uso dos mesmos como uma ferramenta auxiliar eficaz na execução de inúmeras tarefas. Este auxílio é conseguido através do uso iterativo dos computadores e do armazenamento e recuperação de dados via sistemas gerenciadores de banco de dados (SGBD), em especial os relacionais (SGBDR) [KORTH-89]. 
As empresas que adotam computadores como ferramenta auxiliar de administração, enfrentam hoje problemas comuns, como: redução de custos, aumento da produtividade e melhoria da eficiência e eficácia. $\mathrm{O}$ acesso à informação, em tempo hábil, para a tomada de decisões gerenciais, se torna cada vez mais premente para alcançar esses objetivos.

Ao contrário das primeiras aplicações de banco de dados, que eram simples, pequenas e exigiam para a sua construção apenas alguns poucos dados estatísticos, tais como volume de dados ou frequência de uso, as atuais aplicações de banco de dados são muito mais extensas e operam, diversas delas, sobre uma mesma base de dados. Decorre daí que um projeto de banco de dados, para dar apoio a todas as aplicações, torna-se extremamente complexo, exigindo uma completa e rigorosa formulação e análise de necessidades de informação na dianteira do processo de projeto de um banco de dados relacional, que constitui o tema principal deste trabalho [CERÍCOLA-91]

Dá-se especial ênfase ao modelo de dados relacional por ser o mais prático e difundido hoje em dia. Um SGBDR de alto desempenho é a base de um ambiente gerenciador de informação relacional e a base da produtividade que dele se deve derivar. Com a utilização de um SGBDR, a empresa determina o quão rápido pode responder a novas oportunidades de negócio e a facilidade com que novas aplicações poderão ser desenvolvidas, respondendo às necessidades crescentes de usuários.

A partir do desenvolvimento da tecnologia de SGBD's surgiram conceitos que permitiram às empresas implementarem soluções que atendessem às necessidades de armazenamento e recuperação das informações. Para a recuperação dos dados, normalmente a linguagem utilizada é SQL, abordada na seção 2.4.4.1. Dois recursos, apresentados anteriormente, são utilizados pelos SGBD's formando novas tecnologias como os bancos de dados distribuídos e a aquitetura cliente/servidor, abordados respectivamente nas seções 2.4.4.2 e 2.4.4.3.

\subsubsection{Linguagem $S Q L$}

Atualmente, os fabricantes de computadores e os desenvolvedores de lógica computacional estão sempre lutando para estabelecer padrões. A necessidade é grande: os bancos de dados são os principais repositórios de informação e o acesso padrão é importante para integrá-los dentro de uma empresa ou entre diferentes empresas. É ainda mais importante no mundo da microinformática, onde o desenvolvimento de bases de 
dados tem sido aleatório e banco de dados de diferentes fabricantes podem ser utilizados numa mesma empresa.

Um padrão está praticamente consolidado para os SGBDR's: a linguagem de pesquisa estruturada (Structured Query Language), também conhecida como SQL, que foi desenvolvida para o modelo relacional na década de 70. Essa linguagem suporta transações de processamento de pesquisas, segurança de administração de dados, integridade e recuperação em caso de perda. Devido ao fato de ter sido adotada como a linguagem padrão para banco de dados, a SQL ocupa um lugar de destaque no processamento distribuído e interligação entre computadores [HACKATHORN-93].

No momento ainda não existe uma SQL completamente padronizada. Em seu lugar existem vários dialetos que estão competindo pela preferência do mercado. $O$ padrão oficial da SQL, como definido pelo ANSI (American National Standards Institute), é considerado com utilidade limitada [CERÍCOLA-91].

\subsubsection{Banco de Dados Distribuídos}

Um sistema de banco de dados distribuído é composto de uma rede de bancos de dados locais, armazenados em diversas máquinas, devendo ser transparentes ao usuário, de modo a parecer um único banco de dados lógico, instalado em uma única máquina. Cada banco de dados local é controlado pelo seu próprio gerenciador de banco de dados local.

A tecnologia de banco de dados distribuído está em constante mudança, pois ainda não foi implementada uma solução totalmente eficiente [CERÍCOLA-91]. Com o advento de sistemas distribuídos, os usuários passaram a considerar a possibilidade de distribuir os seus dados.

Os bancos de dados distribuído oferecem vantagens potenciais, porém surgem muitas questões relacionadas com o gerenciamento de dados [GUENGERICH-94]. Diferentes tipos de aplicações requerem diferentes filosofias de distribuição de dados. Um banco de dados distribuído opera coordenando ações de diversos bancos de dados conectados entre si. 


\subsubsection{Arquitetura Cliente/Servidor para os SGBD's}

Com a emergência do modelo de redes cliente/servidor, a aplicação cliente e o servidor de banco de dados estão em plataformas separadas. A interação entre o cliente e o servidor não é visível tanto para a aplicação cliente quanto para o banco de dados servidor. A arquitetura cliente-servidor fornece uma interação estrutural entre o cliente e o servidor. Os benefícios são suportados para um determinado grau de processamento paralelo.

As interações a partir do cliente para o servidor são chamadas requisições; as interações para o cliente são chamados resultados. No caso de servidores de banco de dados SQL, a requisição consiste do texto das declarações SQL ou referências a parâmetros SQL previamente estabelecidos.

A arquitetura cliente-servidor é composta por [HACKATHORN-93]:

- interface de cliente: é a interface de programação que consiste das convenções de chamada, definições de procedimento/função e da sintaxe/semântica da linguagem (normalmente SQL) passada pela interface;

- protocolo: é simplesmente um fluxo de bits fluindo em algum transporte de comunicação entre duas interfaces. Um protocolo simples, por exemplo, deve consistir de um comando a partir do cliente para executar imediatamente o texto da declaração SQL seguinte. O servidor deve responder com os resultados do processamento da declaração $\mathrm{SQL}$, como em códigos de dados, número de colunas, nome e tipo de cada coluna, dados para a primeira linha e a segunda, etc. Protocolo e interface de usuário implicam diretamente nas características de portabilidade e interoperabilidade dos sistemas;

- interface do servidor: é uma interface que é uma imagem espelho da interface do cliente. $\mathrm{O}$ propósito da interface de servidor é aceitar requisições a partir do cliente, via seu transporte e passagem para o motor de banco de dados.

A principal caraterística da arquitetura cliente/servidor é que ela transferiu parte do processamento para o cliente. Antes, o servidor se encarregava do processamento de todos os clientes, o que acarretava uma queda de performance. Com esta arquitetura, o servidor tem o papel de fornecer os dados para o processamento através das requisições do cliente. 


\subsubsection{Sistemas Abertos}

Um problema chave para as empresas é a conectividade entre os componentes individuais da TI. Na indústria de hoje, os níveis de medo, incerteza e dúvida são frequentemente muito altos para tomadas de decisões racionais. A escolha de um produto geralmente envolve mais de um fornecedor, o que dificulta esta atividade (Figura 2.7). $\mathrm{O}$ requisito principal para esta escolha, sem dúvida nenhuma, é a abordagem por sistemas abertos [GUENGERICH-94]. Como os componentes da TI são muito difundidos pelas empresas, as decisões referentes à estas tecnologias estão espalhadas por toda a empresa. Os produtos fornecidos pela TI são muito tentadores para a compra, mas podem implicar em implementações que constituem-se em ilhas de integração dentro da empresa, como já foi mencionado anteriormente.

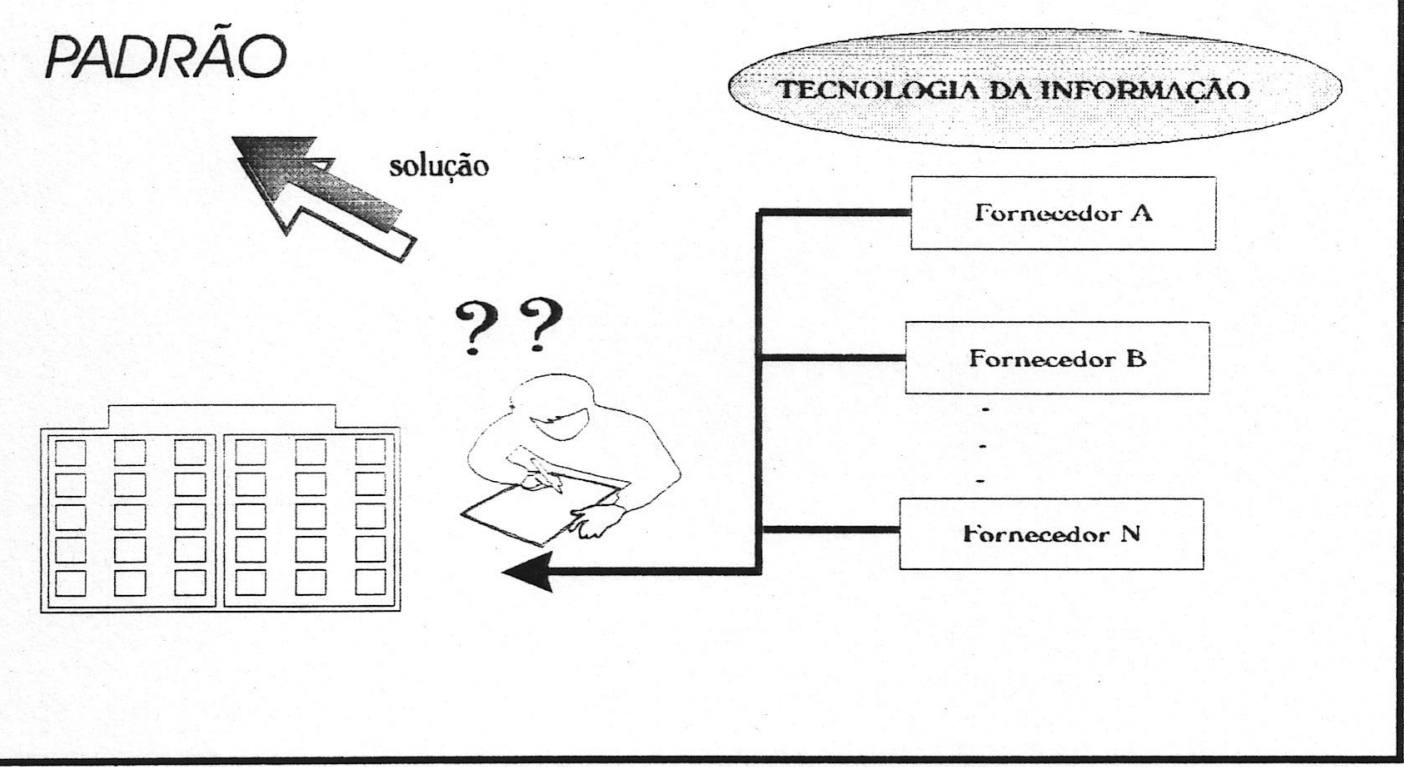

Figura 2.7: A Abordagem de Sistemas Abertos

A melhor abordagem parece ser optar pela arquitetura de TI apropriada para a empresa, baseando-se em um conjunto de padrões abertos adequados, ou seja, adquirir a filosofia de sistemas abertos. Um sistema aberto é um sistema implementando componentes que aderem a padrões específicos [HACKATHORN-93]. A implicação é que estes componentes podem ser comprados de vários fornecedores independentes, reduzindo a 
dependência da empresa com um vendedor particular. Da mesma forma, assume-se que os clientes suportam estes padrões requerendo-se como parte de suas compras de tecnologia da informação. Portanto, a dinâmica de mercado deve moldar a indústria em uma direção que persiga bons padrões.

\subsubsection{Ferramentas para Desenvolvimento de Sistemas}

A abordagem por sistemas abertos é fundamental para a escolha de ferramentas de desenvolvimento, as quais são utilizadas principalmente para definir e gerenciar interfaces de usuários com programas e aplicativos. Muitos sistemas de gerenciamento de banco de dados têm alguns elementos desse conjunto de ferramentas, porém as mais poderosas e mais completas estão disponíveis separadamente [GUENGRICH-93]. As melhores ferramentas são aquelas que podem ser utilizadas em diversos ambientes e ter mecanismos de acesso aos diversos sistemas de gerenciamento de banco de dados.

Neste contexto, para suportar as necessidades de integração dos sistemas de informação, algumas características foram introduzidas nas ferramentas de desenvolvimento, tais como:

- verificação de integridade de modelos;

- verificação de consistências entre modelos;

- construção de interfaces na forma de diagramas;

- geração de código

Com a utilização destas ferramentas, diversas aplicações de computador podem ser projetadas e construídas em lugares diferentes, por equipes diferentes e em épocas diferentes. De acordo com as características citadas acima, estas ferramentas encaixarão estas diversas aplicações em uma estrutura computadorizada global.

Para garantir uma boa posição no mercado, as empresas dependerão cada vez mais de ferramentas poderosas aplicáveis à engenharia de sistemas de informação. As metodologias de processamento de dados de organizações eficientes terão que englobar vários aspectos novos da tecnologia de desenvolvimento [MARTIN-91]:

- ferramentas de I-CASE (CASE Integrado);

- linguagens de quarta geração; 
- centros de informações;

- administração de dados e modelagem de dados;

- prototipagem;

- planejamento do ramo de negócios;

- automação do processo de projeto de sistemas;

- envolvimento de usuários finais no projeto;

- sistemas baseado em conhecimento;

- envolvimento da alta administração na determinação das prioridades e na definição das necessidades de informações.

Alguns destes aspectos são abordados nas seções 2.6 e 2.7 que apresentam a metodologia de integração da manufatura. Outros são abordados no capítulo 3 que apresenta os conceitos utilizados para o desenvolvimento deste trabalho.

Atualmente, uma condição essencial para as ferramentas de desenvolvimento é o fornecimento de um efetivo suporte de múltiplos fornecedores para a construção de um novo aplicativo. Em outras palavras, com a incorporação da filosofia de sistemas abertos, estas ferramentas devem fornecer meios para a implementação de aplicativos utilizando softwares de diferentes fornecedores. Com relação a localização e acesso às informações, surgiram alguns paradigmas que viabilizam a integração entre diferentes fornecedores de SGBD's, os quais serão abordados na próxima seção.

\subsection{Paradigmas de Integração}

O surgimento das tecnologias citadas anteriormente alteraram, sem dúvida nenhuma, as filosofias adotadas pelas empresas de manufatura para responder aos estímulos externos. Um aspecto importante que deve ser ressaltado baseia-se no fato que se por um lado existem várias alternativas para o desenvolvimento dos sistemas de informação por outro lado essas alternativas comumente não se integram perfeitamente. Como foi mostrado, a abordagem por sistemas abertos é a filosofia que deve ficar emergente na implantação e desenvolvimento de sistemas dentro das empresas.

O ponto central de um sistema de manufatura é o gerenciamento das informações, onde, para esta função, são utilizados os SGBDR's. No entanto, alguns desenvolvedores de 
aplicativos para CIM implementaram soluções acessando SGBDR's diferentes. Esta situação estimulou o desenvolvimento de alguns paradigmas para a integração ou conectividade entre diferentes bancos de dados empresariais [HACKATHORN-93].

Esta seção apresenta os recursos desenvolvidos para solucionar o problema de conectividade entre diferentes bancos de dados e uma arquitetura geral para a conectividade aberta.

\subsubsection{Conectividade de Banco de Dados Empresariais}

A abordagem de sistemas abertos e o compartilhamento de dados entre diferentes plataformas fornecem o tópico de Conectividade dos Bancos de Dados Empresariais (EDC - Enterprise Database Connectivity). EDC é definida como sendo o conjunto de conceitos e práticas referentes a interconexão dos bancos de dados. A EDC se concentra na definição e gerenciamento de arquiteturas uniformes que se espalham pela empresa, para sustentar sua conectividade.

Para lidar com suas complexidades, algumas camadas crescentes de funcionalidade podem ser destacadas na EDC: gerenciamento de acesso e gerenciamento de cópia. As camadas constituem a faixa de funções necessárias para suportar a conectividade dos banco de dados na empresa, tanto para suporte de decisão como para propósitos de produção. Além disso, essas camadas são capacitadas pelos meios de gerenciamento de dados (como SQL) e gerenciamento de processos

Gerenciamento de acesso é o gerenciamento da arquitetura para prover o acesso de qualquer cliente a qualquer fonte de dados. Em particular, esse gerenciamento se concentra na habilidade de uma aplicação cliente acessar diretamente bancos de dados locais ou remotos. $\mathrm{O}$ acesso de dados inicial concentrou-se em prover aplicativos de acesso para os bancos de dados locais. Recentemente, o acesso aos dados mudou para prover ferramentas de suporte à decisão (como as planilhas) para o acesso a vários bancos de dados remotos. No futuro, o acesso aos dados será uma mistura de ambos objetivos, em um espectro contínuo desde a produção até o suporte de decisão. Com a tecnologia atual, o gerenciamento de acesso lida com problemas de transparências de SQL e canalização de redes.

O gerenciamento de cópia é o gerenciamento da arquitetura para fornecer a coordenação entre quaisquer duas fontes de dados via cópia de dados e processos. Em particular, se 
concentra na execução, agendamento e monitoração de cópias de um banco de dados para outro com o propósito de manter ou garantir a consistência dos dados.

O objetivo da EDC está relacionado com a transparência da conectividade dos bancos de dados, ou seja, a aplicação cliente não deve se preocupar com as variações nos tipos de servidores, modelos de dados, linguagens SQL, etc. Com a introdução de novos recursos, deve haver um impacto mínimo na aplicação e no seu uso. As abordagens da EDC que podem ser destacadas são: interface comum, porta de entrada comum e protocolo comum. Estas abordagens não são exclusivas, ou seja, podem ser combinadas para formarem uma arquitetura aberta.

\subsubsection{Arquitetura para Conectividade Aberta}

Há cerca de 20 anos, o campo das comunicações de dados estava em grande desordem. Existiam muitos padrões compentindo pelos aparelhos de conexão de comunicação. Os clientes normalmente compravam todo o sistema de um vendedor, sendo-lhe fornecida uma arquitetura de comunicação unificada (e proprietária). Quando os sistemas se tornaram mais complexos (e globais), a solução fornecida por um único vendedor não era mais adequada. Os padrões precisavam ser estabelecidos de forma que, muitos vendedores pudessem fornecer uma maior variedade de produtos. Dessa forma a abordagem dos sistemas abertos começou a ser desenvolvida.

Uma situação que as grandes empresas atualmente enfrentam é a conexão entre bancos de dados de diferentes fornecedores. Neste sentido, a indústria é forçada a adotar uma abordagem de sistemas mais aberta. No contexto da arquitetura cliente-servidor, esta abordagem implica na combinação das interfaces de cliente e servidor em uma arquitetura aberta.

Para a solução de conectividade de banco de dados de diferentes fornecedores, existem três abordagens arquiteturais que suportam as camadas funcionais da EDC.

Uma abordagem de interface comum usa a interface (tanto cliente como servidor) como um elemento comum, fornecendo conectividade aberta. $\mathrm{O}$ princípio baseia-se no fato que a aplicação do cliente se programa para uma especificação de interface, desconsiderando o tipo do servidor. Esta assume a responsabilidade de transparência do cliente para o servidor, podendo o cliente ser reendereçado para outro tipo de servidor. $O$ código da 
aplicação do cliente não muda. A Figura 2.8 mostra algumas alternativas na utilização desta abordagem.

Nos últimos três anos, apareceram muitos produtos adotando a abordagem de interface comum. Exemplos destes são o Apple Data Access Language, IBI Enterprise Data Access/SQL (EDA/SQL) e o Microsoft Open Database Connectivity (ODBC).

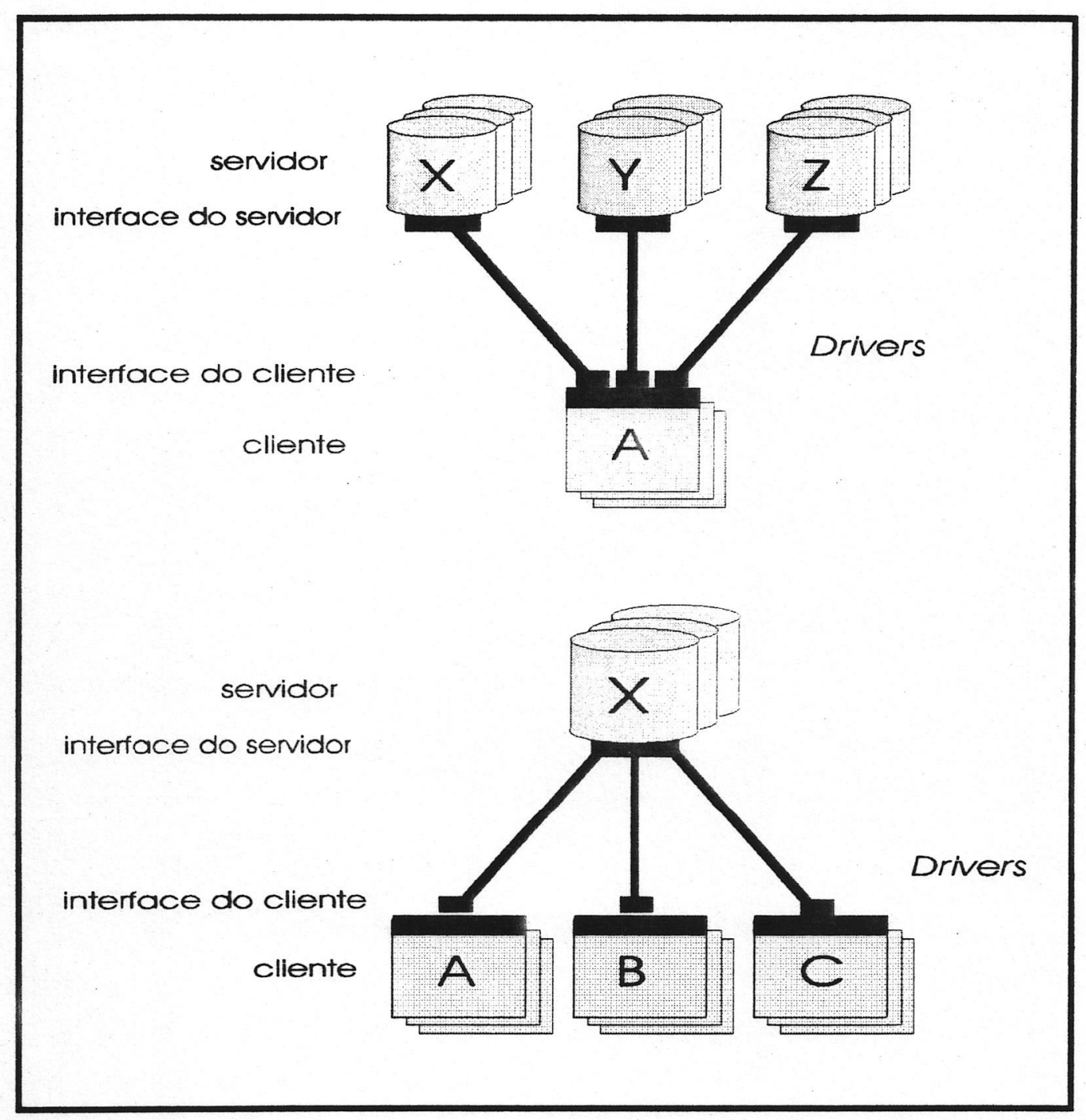

Figura 2.8: Variações da Abordagem por Interface Comum

Uma abordagem de portão comum utiliza um portão de banco de dados ou simplesmente um portão como o elemento comum para aliviar as diferenças entre os tipos de servidor alvo. A distinção com a abordagem de interface comum é que a interface do servidor de 
um tipo é compatibilizada com a interface de cliente de outro tipo, via portão. Na Figura 2.9 , o cliente A está escrevendo na interface do cliente do servidor $\mathbf{X}$. Conectando o portão de banco de dados como se fosse um servidor do tipo $\mathrm{X}$, cliente $\mathrm{A}$ possui agora um acesso aos bancos de dados $\mathrm{Y}$ e $\mathrm{Z}$. A interface do portão recebe a requisição dos clientes, como se fossem do tipo do servidor $\mathrm{X}$. $\mathrm{O}$ portão mapeia estas requisições para $\mathrm{o}$ formato adequado de outro tipo de servidor, e usa a interface do cliente para o servidor poder resubmeter as requisições. O mapeamento oposto ocorre para retornar os resultados para o cliente.

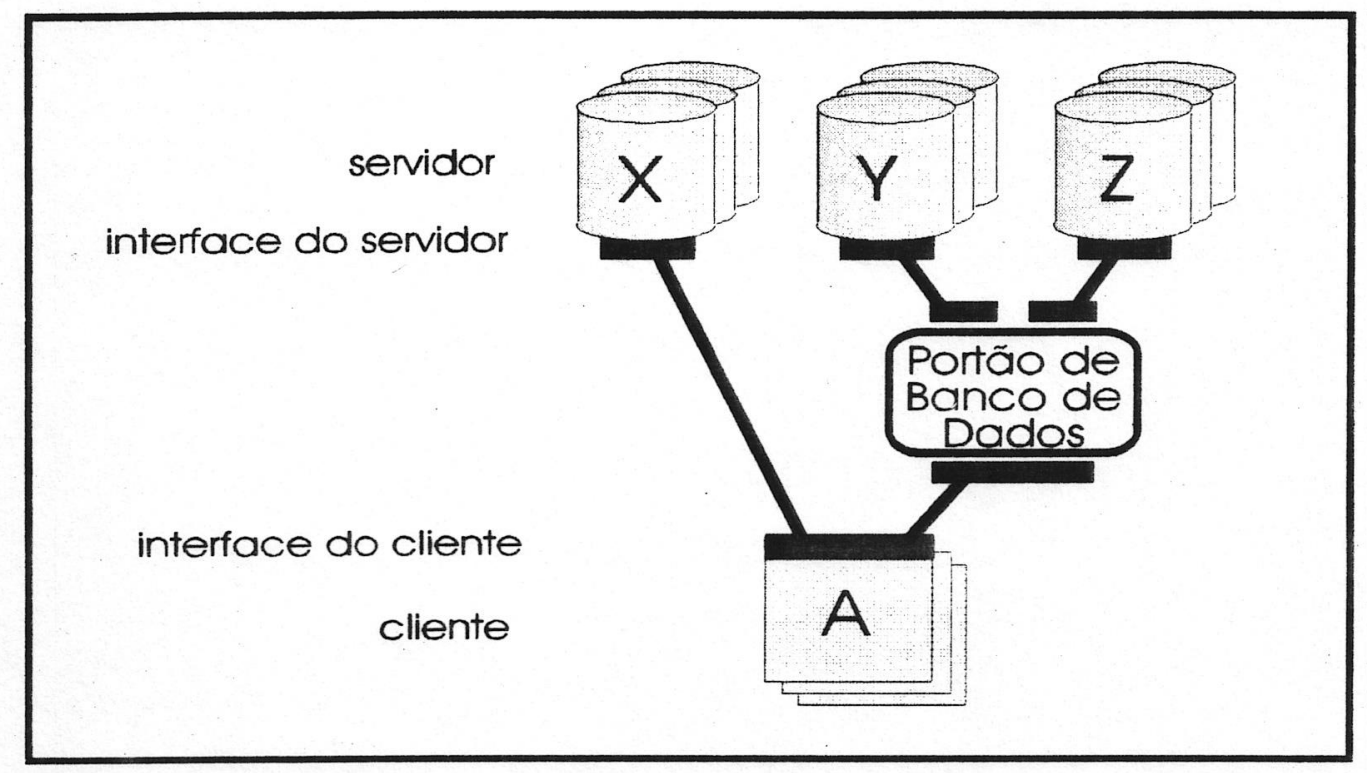

Figura 2.9: Abordagem por Portão Comum

A efetividade da abordagem do portão comum é dependente do valor adicionado pelo componente do portão. Quando transformar requisições ao servidor $\mathrm{X}$ em requisições ao servidor $\mathrm{Y}$, as áreas onde se podem agregar valor pelo portão são [HACKATHORN93]:

- sintaxe de transformação $S Q L$ do tipo $X$ para o tipo $Y$;

- detecção de diferenças semânticas entre X e Y;

- conversão de tipos de dados;

- catálogo de acesso a sistemas genéricos;

- manutenção das fronteiras de transação; 
- mapeamento de identificação de usuário e verificação de segurança;

- balanceamento e limites de carga para o servidor;

- fornecimento de pontos de controle gerenciáveis para grandes redes de dados;

- mapeamento de transportes LAN para transportes WAN.

A expectativa adequada para a abordagem de portão comum é a de que complemente e estenda todas as outras abordagens. Quando usado com alguma combinação de interface comum e protocolo comum, o bloco de construção do portão comum normalmente adiciona flexibilidade à arquitetura do sistema.

Entre os produtos que adotaram a abordagem de portão comum estão IBM Distribuited Database Connection Services (DDCS/2), Microsoft Open Data Services (ODS), Sybase Open Server e MDI Database Gateway para DB2.

Uma abordagem de protocolo comum utiliza um protocolo aberto bem definido para conectar aplicações de clientes para vários tipos de servidores. A Figura 2.10 mostra que cada interface de cliente aceita requisições das aplicações de clientes e traduz estas requisições nos protocolos comuns adequados. Da mesma forma, cada interface de servidor traduz o protocolo comum para requisições, as processa e traduz novamente os resultados para os protocolos comuns adequados para os clientes. Um protocolo consiste dos seguintes componentes: transporte, comandos requisitados e respostas de resultados, codificação de dados e códigos de status e dialeto SQL.

O principal beneficio da abordagem em protocolo comum é que sempre que as interfaces de clientes e servidores acessam o mesmo protocolo, novos tipos de clientes ou servidores poderão ser adicionados no futuro sem o conhecimento de outros já existentes. Exemplos de produtos que utilizam a abordagem de protocolo comum são o Sybase Tabular Data Stream (TDS), IBM Distribuited Relational Database Architecture (DRDA) e ISO Remote Database Access (RDA). 


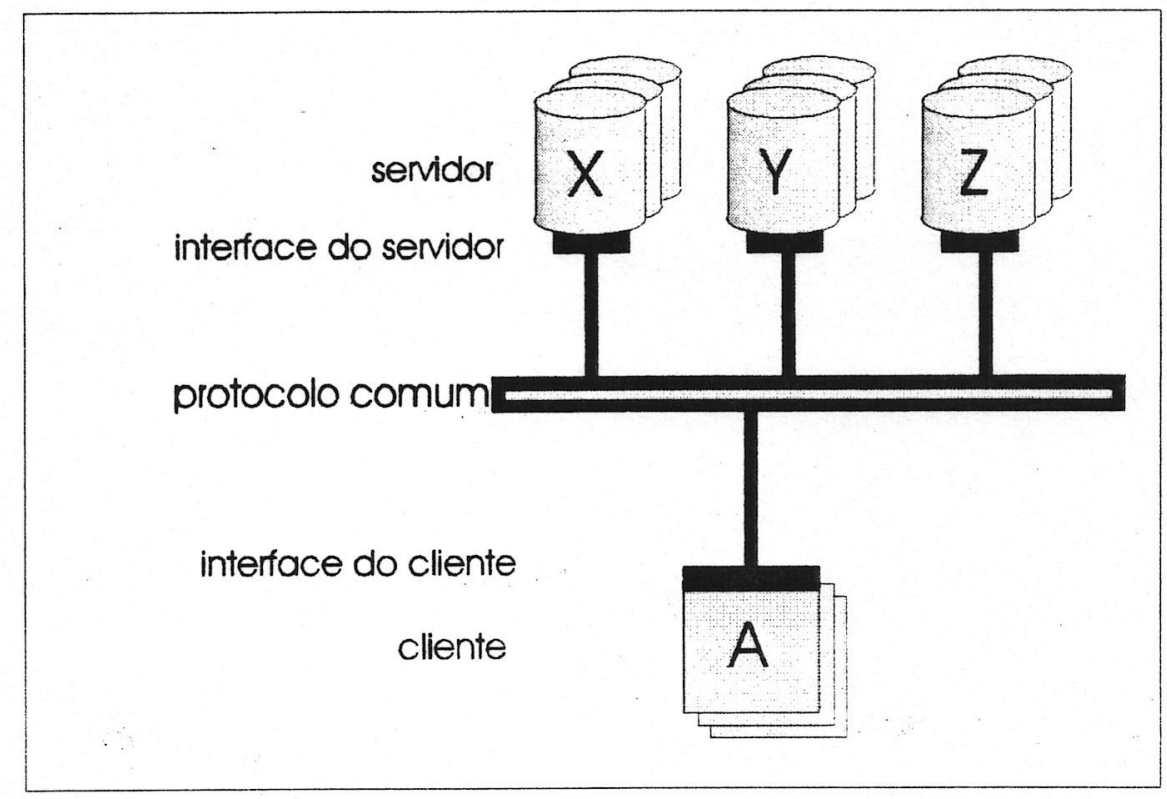

Figura 2.10: A Abordagem por Protocolo Comum

Como pôde ser visto, há uma grande variedade de recursos fornecidos pela TI. Esses recursos vieram para auxiliar a empresa de manufatura a responder aos estímulos externos impostos pelo mercado consumidor. Por outro lado, a má utilização desses recursos resulta em situações insatisfatórias, o que implica em problemas na integração dos sistemas. A busca da solução para estes problemas proporcionou o desenvolvimento do tópico de EDC que viabiliza a conectividade de recursos de diferentes fornecedores. Este tópico fornece subsídios para as estratégias de atuação, citadas na seção 2.3, que incorporam metodologias de integração. Em outras palavras, a construção de ferramentas para auxiliar a aplicação de uma metodologia para integração é influenciada pelos recursos fornecidos pela TI. A próxima seção descreve, de uma maneira geral, a metodologia de integração da manufatura em desenvolvimento no Projeto CIM da USP São Carlos.

\subsection{Metodologia de Integração da Manufatura}

Como já foi dito, esta metodologia busca um desenvolvimento coordenado entre o modelo de negócios e a TI. No processo de desenvolvimento da MIM, parte-se de um modelo de empresa (detalhado na seção 2.7) como referência de um Plano de Integração. Este plano pode suportar diversos graus de detalhamento, dependendo dos objetivos da 
integração. Durante a definição das soluções a serem implantadas na base da pirâmide, pode-se voltar ao nível superior detalhando-se o Plano de Integração. Esse processo iterativo permite que se detalhe o planejamento de acordo com o conhecimento e disponibilidade da tecnologia.

Este plano consolida as principais informações a respeito dos esforços que estão sendo realizados e planejados pela empresa na busca de um processo de integração. Ele centraliza todas as informações e documentos relacionados à integração da manufatura englobando [ROZENFELD-92a]:

- as estratégias de manufatura da empresa;

- o resumo de índices representativos (identificando os fatores críticos de sucesso);

- os padrões de automação e os procedimentos adotados;

- a lista dos projetos de automação existentes com seus respectivos relatórios de acompanhamento;

- cronograma geral desses projetos com a ordem de grandeza dos recursos envolvidos

A essência desta metodologia parte do significado básico da palavra "Integração" e sua estratégia baseia-se na premissa de "pensar grande, começar pequeno" [ROZENFELD94]. Como já foi dito, a estratégia de atuação utilizada nesta metodologia busca um desenvolvimento coordenado entre a concepção das filosofias de alto nível da empresa e a incorporação de soluções de modernização na sua base. A MTM está dividida em três grandes estapas:

- ETAPA 1 - Levantamento de Requisitos e Situação Atual: Nesta etapa consegue-se obter uma visão da estratégia da empresa, seus índices e métricas, e diagnóstico da situação atual;

- ETAPA 2 - Especificação de Projetos: Envolve a obtenção do Plano de Integração da Manufatura;

- ETAPA 3 - Implementação e Monitoração: Nesta etapa os projetos são detalhados, desenvolvidos, implantados e os processos de manutenção são inicializados.

$\mathrm{Na}$ primeira etapa, o passo inicial é o estabelecimento da forma organizacional e administrativa da empresa para a aplicação da metodologia. A próxima fase está relacionada com a identificação das estratégias de negócios, onde são definidas as 
diretrizes de longo prazo da relação mercado-produto. Das estratégias de negócios são estabelecidas estratégias de manufatura. Paralelamente são definidos critérios de avaliação para medir posição relativa de uma empresa no seu mercado de atuação. $O$ resultado da primeira etapa é um diagnóstico da situação atual, onde é levantado a atual forma de operação da empresa.

$\mathrm{Na}$ segunda etapa são realizadas algumas fases importantes para a reestruturação da forma organizacional e administrativa da empresa, onde algumas delas são as seguintes:

- formalização de procedimentos de qualidade que objetiva a documentação dos procedimentos existentes na empresa;

- realização da reengenharia que busca novas formas de implementação dos processos que envolvem a empresa;

- sistematização para gestão total de custos que procura aplicar os conceitos de $\mathrm{ABC}$ ("Actived Based Costing"), onde um dos pontos determinantes é a definição das atividades e seus direcionadores de custo;

- definição de projetos para garantir que as fases anteriores sejam implantadas de forma integrada.

A partir desta última, são realizadas duas fases que estão diretamente relacionadas com os objetivos deste trabalho: seleção de sistemas e desenvolvimento. O capítulo 3 mostra a importância da utilização dos modelos de dados nestas fases.

$\mathrm{Na}$ última etapa da metodologia são realizadas algumas atividades para garantir a integração e monitoração dos sistemas adquiridos/desenvolvidos. Uma delas é a identificação de oportunidades de melhoria, a qual é realizada inspecionando e atualizando índices, levantando problemas e propondo soluções.

Todo o desenvolvimento da MIM é suportado por um padrão de referência que é o modelo de empresa. Este é levantado da fase de diagnóstico da situação atual da empresa e é utilizado por todas as fases seguintes. A próxima seção apresenta as visões contidas no modelo de empresa e suas utilizações.

\subsection{O Modelo de Empresa}

O modelo de empresa consiste em um padrão de referência contendo todas as informações sobre o funcionamento da empresa de forma estruturada, top-down, 
hierárquica e modular, estabelecendo-se assim uma lógica explícita da empresa [TAKAHASHI-91]. Este modelo contém informações como: funções, dados, recursos, sequências de funções, dados organizacionais e de negócios e índices representativos, espelhando assim a dinâmica da empresa.

O modelo de empresa é uma ferramenta que viabiliza e suporta diversas atividades de implantação de novas tecnologias, filosofias e métodos na manufatura. $\mathbf{O}$ modelo pode ser dividido em três partes, como mostra a Figura 2.11, e é utilizado para as seguintes finalidades:

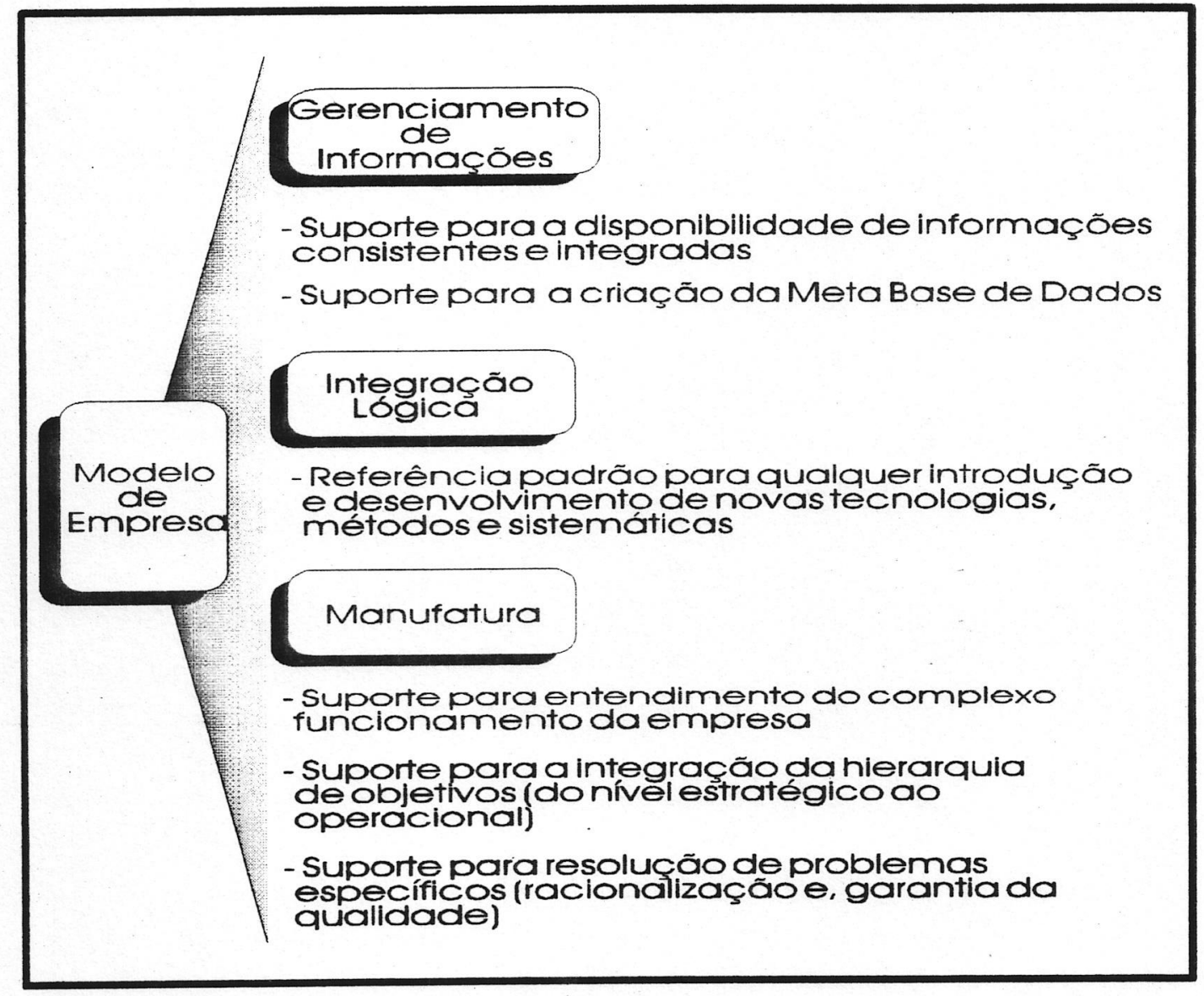

Figura 2.11: Objetivos e Utilizações do Modelo de Empresa

- padrão formalizado, onde toda e qualquer inovação tecnológica ou metodológica deve seguir os meandros deste modelo, ou seja, qualquer novo sistema a ser desenvolvido ou modificado deve obedecer o padrão; 
- suporte para o entendimento do complexo funcionamento de uma empresa (desde vendas até a entrega do produto) e suas funções, dados, recursos, estruturas e suas inter-relações;

- suporte para a integração de objetivos para o estabelecimento das estratégias de manufatura e de um plano diretor de integração dos processos da manufatura;

- padrão de comunicação na empresa;

- suporte para o desenvolvimento e funcionamento de um gerenciamento de informações consistente e integrado.

Dessa forma, o modelo de empresa constitui-se em um componente fundamental para o desenvolvimento dos sistemas de informação integrados. O ponto inicial para este desenvolvimento é o planejamento estratégico da empresa.

\subsubsection{O Modelo de Empresa para a Metodologia de Integração da Manufatura}

O modelo de empresa utilizado pela MIM compreende cinco sub-modelos. Estes modelos são visões diferenciadas da empresa, porém com pontos de intersecção bem definidos entre eles [ROZENFELD-93]. São eles:

Modelo de Negócios (MN): constitui-se na representação de um conjunto de dados de nível institucional, obtido junto às pessoas de nível estatégico da empresa. O MN compreende a formalização dos objetivos, estratégias de manufatura e políticas da empresa.

Modelo Organizacional (MOr): Constitui-se na representação da estrutura organizacional, da distribuição física dos elementos, dos perfis existentes e da adequação destes perfis aos requisitos de operação.

Modelo de Operação (MO): constitui-se na representação de como a empresa funciona em termos operacionais. Ele abrange o fluxo de informações entre os processos realizados pela empresa.

Modelo de Dados (MD): constitui-se na representação da empresa em termos de necessidades de manipulação de dados. Este trabalho está diretamente relacionado com este componente do modelo de empresa, no qual consiste do desenvolvimento de uma ferramenta que auxilia a elaboração dos modelo de dados da empresa. 
Modelo de Integração (MI): constitui-se na representação dos padrões de integração definidos para empresa, dos sistemas existentes, dos equipamentos computacionais existentes, das características dos sistemas aplicativos em uso e dos sistemas em processo de benchmarking.

A Figura 2.12 mostra os principais elementos componentes das representações apresentadas e os respectivos relacionamentos entre estes modelos.

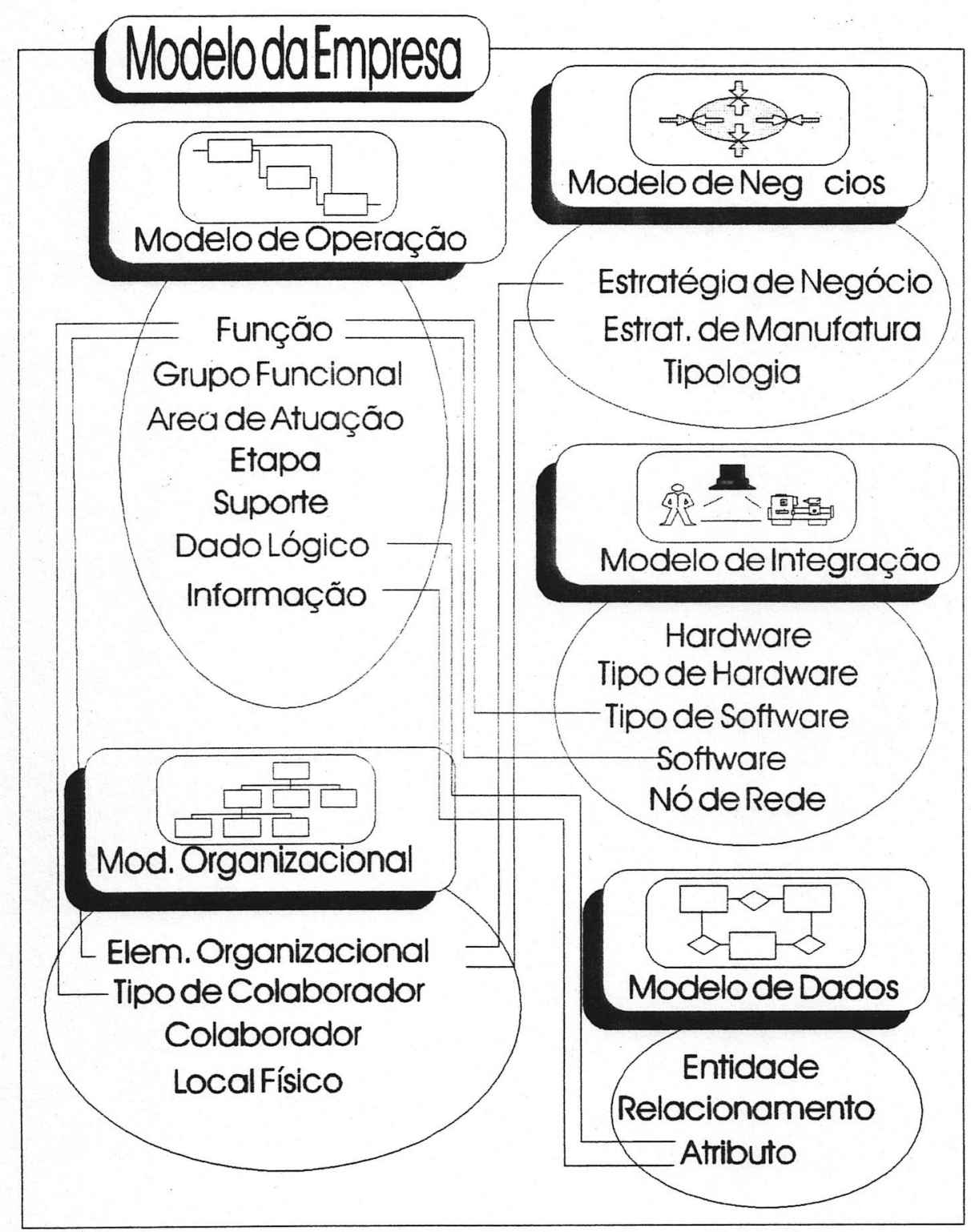

Figura 2.12: Componentes e Relacionamentos do Modelo de Empresa 
Como já foi dito, a área de atuação para este trabalho é o modelo de dados, onde objetivo é a elaboração de um suporte para a construção de modelo de dados. A seguir é abordada a importância desta visão para a empresa.

\subsubsection{A Importância do Modelo de Dados}

O processamento de dados é composto por ações que criam e modificam dados. Isto é feito utilizando-se controles de precisão adequados e processos que usam, analisam e manipulam dados, ou imprimem documentos com os mesmos (Figura 2.13).
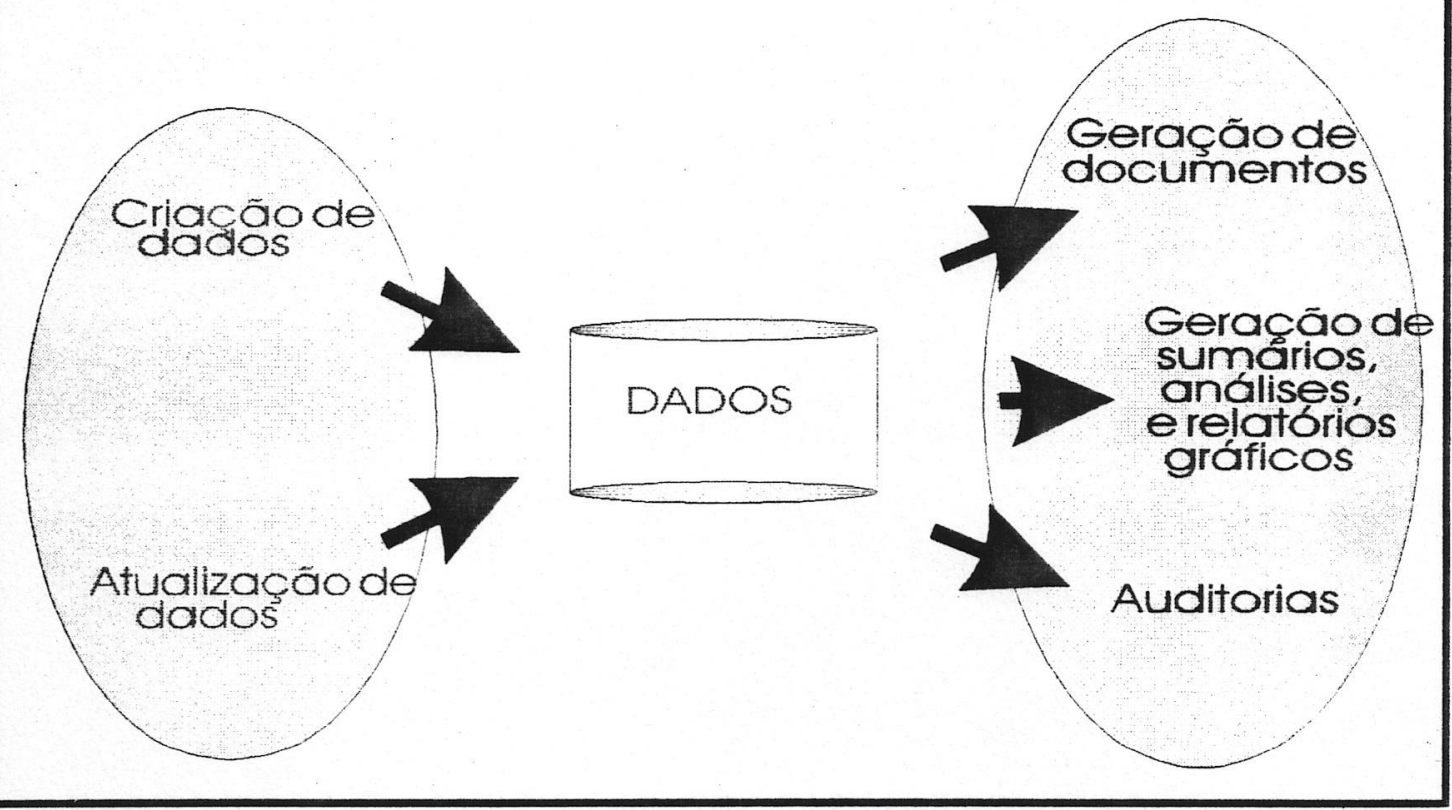

Figura 2.13: Inputs-Outputs dos SGBD

A premissa básica para os SI's que compõem o sistema de manufatura é que os dados são o centro de todo o processamento. Eles são armazenados e mantidos com a ajuda de SGBD's que devem ser periodicamente atualizados. Executivos ou profissionais às vezes precisam de informações; eles criam sumários ou análises dos dados e produzem gráficos e relatórios. Fazem perguntas do tipo "E se?" e usam os dados para ajudá-los a tomar decisões [MARTIN-91].

Uma segunda premissa básica é que os tipos de dados usados em uma organização não sofrem grandes mudanças. Os tipos de atributos armazenados sobre estas entidades também raramente são alterados. 
Para que estes dados sejam acessados de maneira rápida e precisa, é necessário representá-los de maneira correta. $\mathrm{O}$ administrador de dados deve usar técnicas formais para criar modelos estáveis de dados. Ele cria um modelo de entidades e relacionamentos com dados corretamente normalizados. $\mathrm{O}$ modelo fundamental dos dados só é confiável se os mesmos forem identificados e estruturados corretamente, para que possam ser usados com a flexibilidade necessária.

\subsection{Considerações Finais}

Neste capítulo foi ressaltada a importância da integração para as empresas de manufatura, baseada nas influências externas tais como concorrência, mercado consumidor e evolução tecnológica. O sistema de manufatura, seus requisitos atuais e alguns conceitos relacionados foram apresentados para permitir um melhor entendimento sobre o ambiente no qual este trabalho está inserido.

Após a apresentação do sistema de manufatura, foram abordados as estratégias de atuação que estão sendo utilizadas pelas empresas para responder aos estímulos externos. Foi ressaltada uma metodogia que está sendo desenvolvida na USP de São Carlos (MIM) que visa o desenvolvimento coordenado das estratégias de negócios e a utilização dos recursos da tecnologia da informação, os quais foram amplamente discutidos.

Finalmente foi abordada a funcionalidade de um modelo de empresa e sua relação com a MIM. Com relação ao modelo de empresa, foi ressaltada a importância do modelo de dados para suportar as necessidades de informações dos sistemas de informação da empresa. Com isto, o domínio de conhecimento para este trabalho pode ser situado conforme mostra a Figura 2.14. 


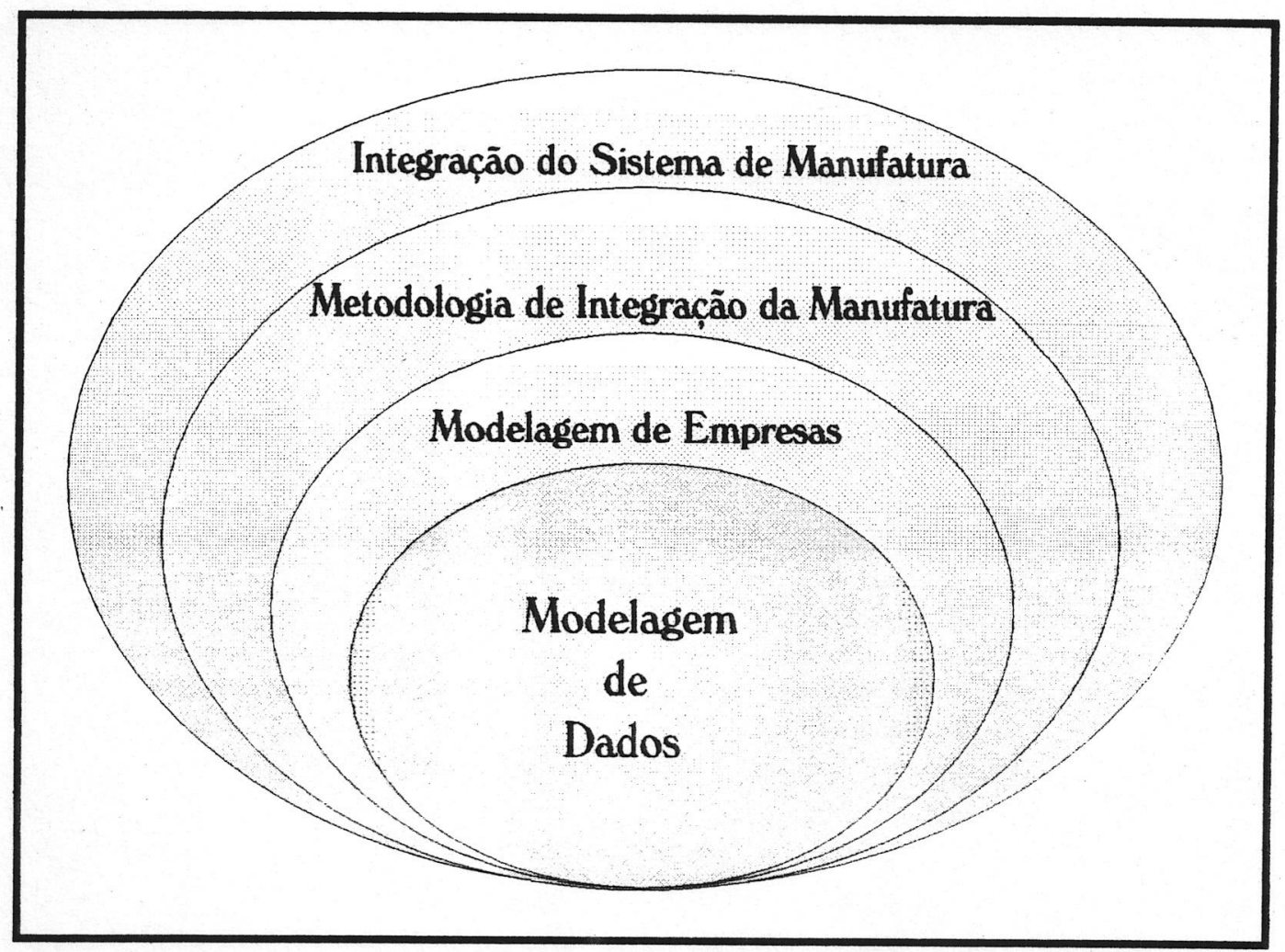

Figura 2.14: Localização do Desenvolvimento da Ferramenta

O capítulo 3 apresenta os principais conceitos envolvidos no desenvolvimento de uma ferramenta para modelagem de dados que são a análise lógica dos dados de uma empresa e a tecnologia de Sistemas Baseado em Conhecimento. 


\section{CONCEITOS BÁSICOS PARA A MODELAGEM DE DADOS}

\subsection{Considerações Iniciais}

Como mencionado no capítulo anterior, as empresas necessitam de uma reestruturação para se manterem competitivas diante das novas exigências do mercado consumidor. Paralelamente às mudanças do ambiente externo à empresa, houve uma grande evolução tecnológica que provocou o surgimento de novos requisitos para o desenvolvimento dos sistemas de informação que compõem o sistema de manufatura. A tecnologia da informação atual fornece um considerável suporte para a organização destes sistemas com a finalidade de responder aos estímulos externos. No entanto, os benefícios da tecnologia da informação devem ser analisados estrategicamente para que possam ser aplicados de maneira eficiente.

Neste contexto, surgiram ferramentas com o objetivo principal de auxiliar o processo de integração do sistema de manufatura. Estas ferramentas suportam o desenvolvimento dos sistemas de informação que compõem o sistema de manufatura, desde a fase de planejamento estratégico até a implementação. O processo de desenvolvimento deste tipo de ferramenta envolve vários conceitos e metodologias. Em outras palavras, para a construção de uma ferramenta neste ambiente é necessário representar computacionalmente os passos realizados pela metodologia que deseja-se implementar.

No capítulo anterior, foi apresentada a Metodologia para Integração da Manufatura, que se baseia em um modelo de empresa para o seu desenvolvimento. $O$ modelo de empresa, por sua vez, possui cinco outros modelos de menor nível, sendo que este trabalho está relacionado com a modelagem de dados.

Neste capítulo serão apresentados a metodologia e os conceitos relacionados com a construção de uma ferramenta para modelagem de dados. Nas seções 3.2 e 3.3 são abordados os conceitos de CASE Integrado e Enciclopédia que fornecem as características que uma ferramenta deste tipo deve representar. Na seção 3.4 são mostradas as utilizações de uma Análise Lógica dos Dados e os conceitos envolvidos nesta atividade. A seção 3.5 apresenta os conceitos envolvidos na geração de modelos físicos e a seção 3.6 aborda brevemente uma metodologia para desenvolvimento de base 
de dados. Na seção 3.7 é enfatizada a importância de representação do conhecimento envolvido em projeto de bases de dados. Neste sentido, as seções $3.8,3.9$ e 3.10 abordam a tecnologia de Sistemas Baseado em Conhecimento, onde são mostradas suas aplicações, a engenharia do conhecimento, a estrutura e o desenvolvimento destes sistemas.

\subsection{CASE Integrado}

Em meados da década de 80, o termo CASE (Computer Aided Software Engineering) tornou-se popular para descrever ferramentas que auxiliavam os analistas de sistemas. $O$ fato dessas ferramentas terem seu escopo reduzido motivou o surgimento do termo Integrated CASE (I-CASE, ou CASE Integrado). Com isso, o termo I-CASE é usado para descrever um conjunto de ferramentas nas quais todos os aspectos de desenvolvimento de software estão integrados.

Os analistas de sistemas interagem com uma ferramenta de I-CASE através de diagramas, nos quais representam:

- as informações nas quais o planejamento é baseado;

- uma visão geral do sistema;

- modelos e fluxos de dados;

- projetos detalhados e estruturas de programas.

Uma ferramenta de I-CASE é capaz de converter as informações contidas nos diagramas em um formato processável pelo computador, mantendo seu significado. A ferramenta auxilia a elaboração de um projeto, de um modelo de dados, ou de outro segmento do processo de desenvolvimento, de tal forma que o mesmo possa ser validado e então usado em uma etapa de desenvolvimento posterior.

Alguns exemplos de diagramas utilizados para o desenvolvimento dos sistemas de informação são:

- Diagrama de Decomposição de Processos;

- Diagrama de Fluxos de Dados;

- Diagrama de Entidades e Relacionamentos. 
Uma das características fundamentais de uma ferramenta de I-CASE é que ela pode gerar programas executáveis. O gerador de programas é orientado pelo projeto. A forte integração das ferramentas de análise e projeto com um gerador de programas oferece uma produtividade muito maior do que quando estas ferramentas são usadas separadamente.

Outra caraterística fundamental é a verificação da integridade de modelos e planos e a verificação de consistências entre diferentes tipos de modelos. A implementação desta característica está relacionada com o conceito de enciclopédia.

\subsection{A Enciclopédia}

Uma enciclopédia contém a representação completa e codificada de planos, modelos e projetos, com módulos capazes de fazer a verificação cruzada e validação desta representação. A enciclopédia armazena informações representadas em diagrama e garante a consistência desta representação. A Figura 3.1 ilustra os componentes de uma enciclopédia.

Durante o desenvolvimento dos sistemas de informação, os modelos de dados e de processos, bem como as informações de planejamento, são armazenados na enciclopédia, assim como os atos, normas, regras e políticas vigentes na empresa e em seus sistemas. A enciclopédia é construída gradativamente à medida em que a empresa coloca em prática o desenvolvimento dos sistemas.

A enciclopédia contém regras para verificação de consistências relativas ao conhecimento (planos, modelos e projetos) nela armazenado. $\mathrm{O}$ processamento dessas regras pode garantir um alto grau de precisão, integridade e completeza nos planos, modelos e projetos. Dessa forma, a enciclopédia deve armazenar informações para suportar o desenvolvimento dos sistemas de informação de uma maneira integrada, bem como conter um sistema baseado em conhecimento para auxiliar o controle sobre a exatidão e validade da integração desses sistemas. 


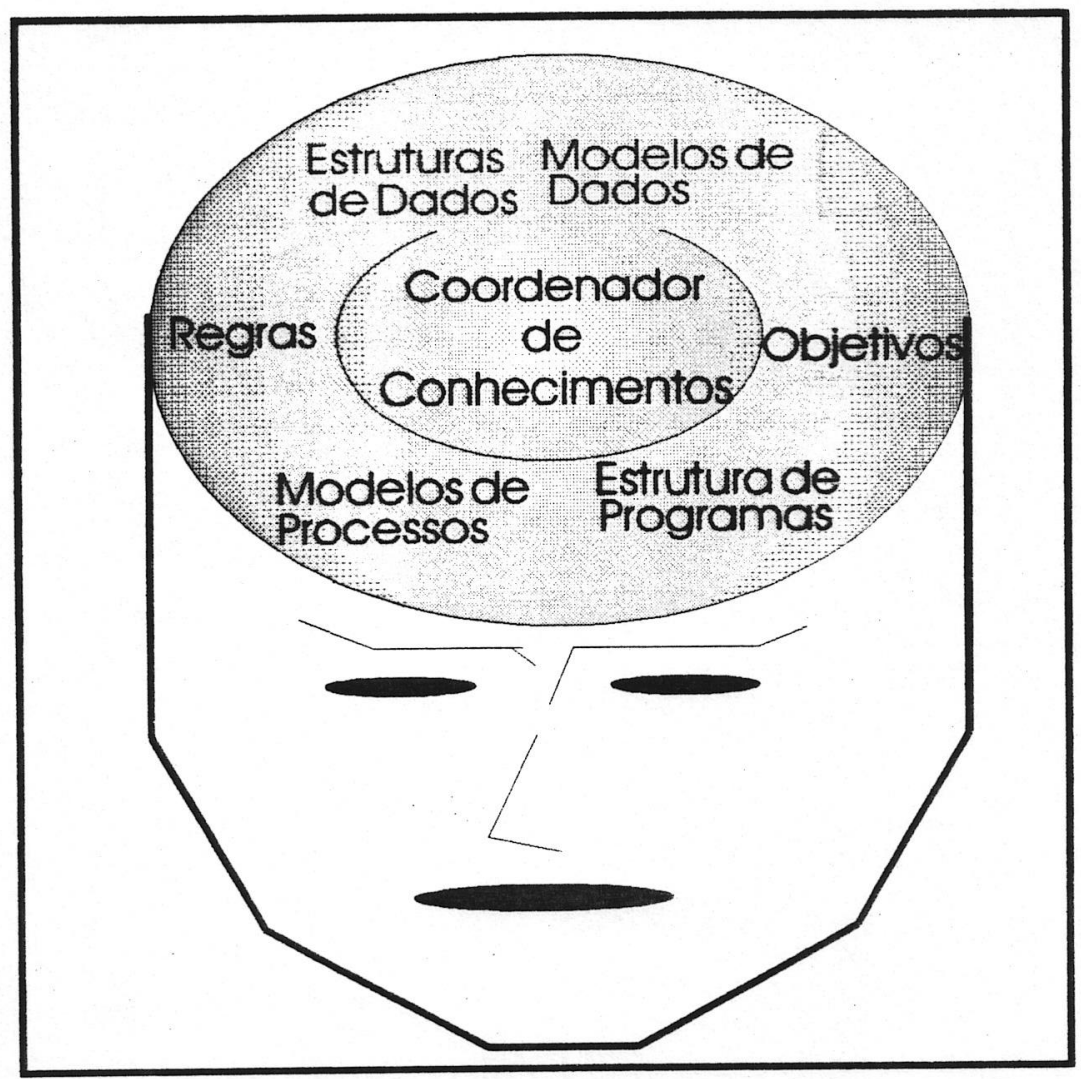

Figura 3.1: A Enciclopédia [MARTIN-91]

Dentro deste contexto, para o desenvolvimento deste trabalho foram utilizadas as caraterísticas contidas na elaboração de uma enciclopédia referentes à modelagem de dados. Baseado nestas características, foram levantados os conceitos relativos à análise lógica de dados de uma empresa. A seção 3.4 aborda esses conceitos e a seção 3.5 apresenta as ligações importantes no processo de geração de modelos físicos. A seção 3.6 mostra, de maneira sucinta, os passos de uma metodologia geral para o desenvolvimento de base de dados. Com relação ao armazenamento e processamento das regras envolvidas no processo de modelagem de dados, as seções $3.8,3.9$ e 3.10 abordam a tecnologia de sistemas baseado em conhecimento.

\subsection{Análise Lógica dos Dados}

A análise lógica dos dados está relacionada com a identificação desse recurso em uma empresa, a qual faz parte integrante de uma análise estruturada de sistema, onde um dos 
elementos mais utilizados é o diagrama de fluxo de dados. Embora a metodologia para a análise de dados tenha surgido como decorrência de projetos de sistemas num ambiente de banco de dados, sua aplicabilidade é muito mais ampla [CERÍCOLA-91].

A capacidade de separar os dados das funções que os utilizam é uma característica dos bancos de dados que transfere a importância da administração do computador para adminstração do dado como recurso. A ênfase para cada uma das tarefas que devem ser realizadas, bem como o tempo a ser-lhes dedicado, dependerá, naturalmente, de cada projeto.

Nesta fase são analisadas todas as visões de dados do sistema a desenvolver, como: documentos, telas, relatórios, eventualmente gabaritos de arquivos já existentes. Usando uma técnica determinística nessa análise, obtém-se como resultado um modelo lógico de dados, que representa a estrutura de informação a ser utilizada mediante entidades, atributos e relacionamentos. É interessante ressaltar que a análise dos dados, independentemente dos processos que os utilizam, traz como consequência imediata estruturas de informação livres de "impurezas" resultantes da clássica associação dadosprocessos.

Algumas utilizações da análise lógica dos dados são [CERÍCOLA-91]:

- análise da estrutura essencial dos dados que devem ser compartilhados por mais de um sistema;

- auxílio na conversão de sistemas, proporcionando uma grande compreensão dos dados envolvidos;

- documentação das redundâncias do sistema, dando maior segurança no controle dos dados;

- facilidade de integração das diversas divisões de uma empresa pela indicação dos dados que lhes são comuns, evitando inconsistências geradas por tratamentos diferentes para os mesmos dados.

Alguns dos conceitos envolvidos na análise lógica dos dados refletem diretamente o nivel de experiência que um projetista de banco de dados deve possuir para contruir modelos confiáveis. 
Da seção 3.4.1 até 3.4.3 são apresentados alguns conceitos relacionados à análise lógica dos dados. Estes conceitos são essenciais para suportar o desenvolvimento de algumas tarefas cujas utilizações foram citadas acima.

\subsubsection{Abstração de Dados}

Um ponto central de um sistema de banco de dados é proporcionar aos usuários uma visão abstrata dos dados. Isto é, o sistema esconde certos detalhes de como os dados são armazenados ou mantidos. Porém, para que o sistema seja utilizável, os dados precisam ser recuperados eficientemente.

A preocupação com eficiência leva à concepção de estruturas complexas para a representação dos dados no banco de dados. Porém, uma vez que sistemas de banco de dados são frequentemente usados por pessoal sem treinamento na área de computação, esta complexidade precisa ser escondida dos usuários do sistema de banco de dados. Isto é conseguido definindo-se diversos níveis de abstração pelos quais o banco de dados pode ser visto (Figura 3.2) [KORTH-89]:

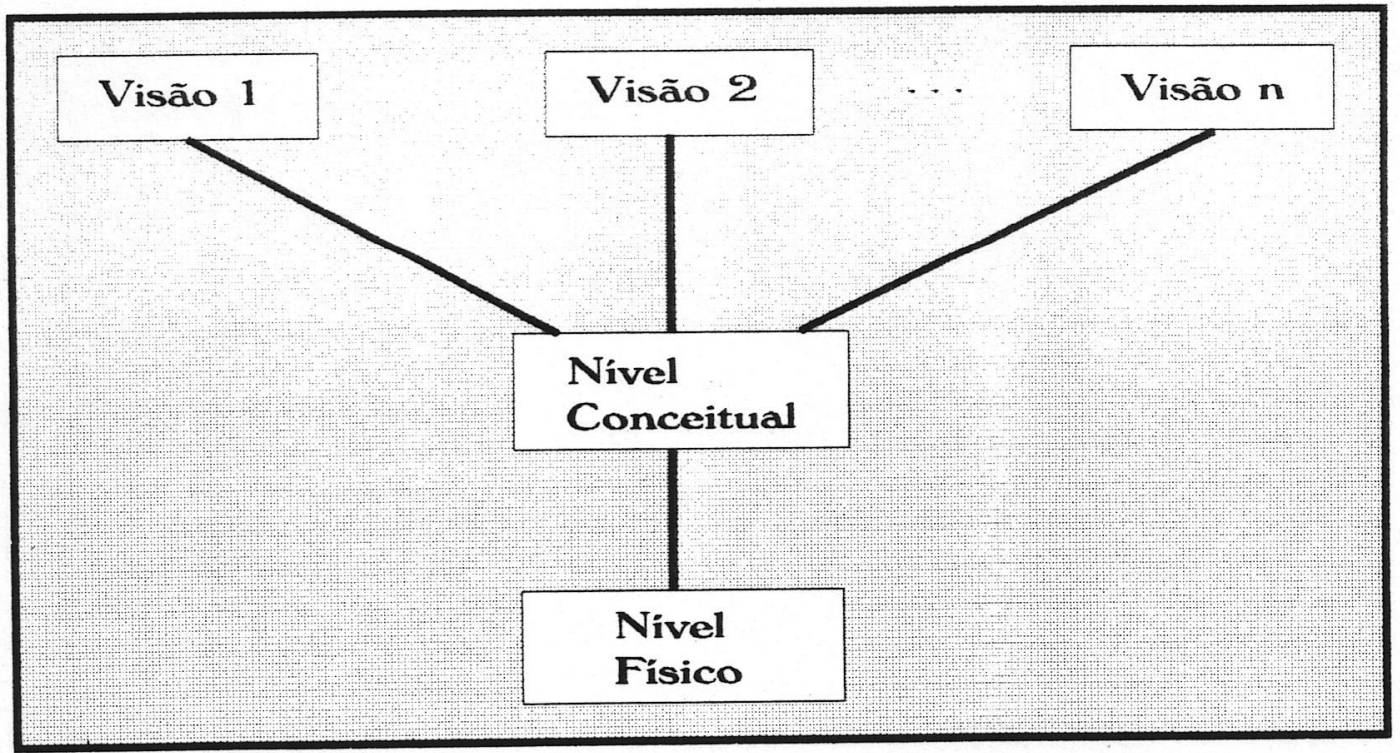

Figura 3.2: Os Níveis de Abstração 
- Nível Físico. Este é o nível mais baixo de abstração, no qual se descreve como os dados são armazenados. Neste nível, estruturas complexas, de baixo nível, são descritas em detalhe;

- Nível Conceitual. Este é o próximo nível de abstração no qual se descreve quais dados são realmente armazenados no banco de dados e quais os relacionamentos existentes entre eles. Este nível descreve, inteiramente, o banco de dados como um pequeno número de estruturas relativamente simples. Muito embora a implementação de estruturas simples no nível conceitual possa envolver estruturas complexas do nível físico, as mesmas devem ser transparentes ao usuário do nível conceitual. $\mathrm{O}$ nível conceitual de abstração é usado pelos administradores do banco de dados;

- Nível Visão. Este é o nível mais alto de abstração, no qual se expõe apenas parte das informação do banco de dados. Apesar do nível conceitual utilizar estruturas mais simples, há ainda um tipo de complexidade resultante do grande tamanho do banco de dados. Muitos dos usuários do sistema não estarão preocupados com toda esta informação. Pelo contrário, tais usuários necessitam acessar apenas parte das informações nele contidas. Para simplificar a interação de tais usuários com o sistema, o nível visão de abstração é definido. Podem haver diferentes visões providas pelo sistema para um mesmo banco de dados.

\subsubsection{Modelos Lógicos}

Para descrever a estrutura de um banco de dados é necessário definir o conceito de modelo de dados. Este é uma coleção de ferramentas conceituais para descrição dos dados, os relacionamentos entre eles, sua semântica e suas restrições. Diversos modelos de dados foram propostos, e estão divididos em três diferentes grupos: modelos lógicos baseados em objetos, modelos lógicos baseados em registros e modelos de dados físicos [KORTH-89]. O objetivo deste trabalho é atuar principalmente nas fases lógicas do desenvolvimento de uma base de dados, e por isso os modelos de dados físicos não serão abordados.

Modelos lógicos baseados em objetos são usados na descrição de dados nos níveis conceitual e visão. Caracterizam-se por proporcionar ampla e flexível capacidade de estruturação e por permitir a especificação de restrições de dados de forma explícita. Alguns dos modelos mais conhecidos são: 
- modelo entidade-relacionamento;

- modelo binário;

- modelo de semântica de dados;

- modelo infológico.

Para o desenvolvimento deste trabalho foi escolhido o modelo entidade-relacionamento, devido a sua aceitação e grande utilização como modelo de dados apropriado para a concepção de banco de dados e sua grande utilização. Este modelo será detalhado na próxima seção.

Modelos lógicos baseados em registros são usados na descrição de dados nos níveis conceitual e visão. Esses modelos são usados para especificar tanto a memória lógica global do banco de dados como uma descrição em alto nível da implementação. Eles não proporcionam, no entanto, facilidades para especificar explicitamente restrições de dados. Os modelos de dados mais conhecidos são:

- Modelo Relacional. Os dados e os relacionamentos entre eles são representados por uma coleção de tabelas, cada qual com um número de colunas e nomes únicos. A Figura 3.3 ilustra uma amostra de um banco de dados relacional. Este é o tipo de modelo mais utilizado devido a maturidade por ele atingida. $O$ presente trabalho utiliza este tipo de modelo.

\begin{tabular}{|l|l|l|l|}
\hline número & sobrenome & \multicolumn{1}{|c|}{ nome } & \multicolumn{1}{c|}{ cargo } \\
\hline \hline 1231 & Silva & Carlos Alberto & projetista \\
1332 & Seixas & Raul & torneiro \\
1431 & Santos & Marco Antônio & processista \\
1453 & Vega & Hugo Araújo & gerente \\
1541 & Tiberti & Alexandre José & analista \\
\hline
\end{tabular}

Figura 3.3: Uma Amostra de Banco de Dados Relacional 
- Modelo de Rede. Os dados do modelo de rede são representados por coleções de registros (no conceito Pascal ou PL/1) e os relacionamentos entre os dados são representados por ligą̧ões que podem ser vistas como ponteiros. Os registros no banco de dados são organizados como coleções arbitrárias de grafos.

- Modelo Hierárquico. $\mathrm{O}$ modelo hierárquico é similar ao modelo em rede no aspecto de que dados e relacionamentos são representados por registros e ligações, respectivamente. $\mathrm{O}$ modelo hierárquico difere do modelo em rede porque os registros são organizados como coleções arbitrárias de árvores em vez de grafos.

\subsubsection{O Modelo Entidade-Relacionamento}

O Modelo Entidade-Relacionamento (MER) baseia-se na percepção de um universo constituído por um grupo básico de objetos chamados entidades, as quais relacionam-se entre si. Uma entidade é um objeto que existe e é distinguível de outros objetos. A distinção é conseguida associando-se a cada entidade um conjunto de atributos que a descrevem. Um relacionamento é uma associação entre diversas entidades. $O$ conjunto de todas as entidades e todos os relacionamentos do mesmo tipo são chamados de conjunto de entidades e conjunto de relacionamentos, respectivamente [DATE-84]. Existem diferentes tipos de diagramas que representam o MER de acordo com as notações de diferentes autores.

Em um MER podem ser definidas certas restrições às quais o conteúdo do banco de dados precisa obedecer. Uma restrição importante está relacionada com a cardinalidade de relacionamento, que expressa o número de entidades ao qual outra entidade pode estar associada via um relacionamento.

Cardinalidades de mapeamentos são especialmente úteis na descrição de um conjunto de relacionamentos binários, apesar de contribuirem ocasionalmente na descrição dos conjuntos de relacionamentos que envolvem mais de dois conjuntos de entidades. Para um conjunto de relacionamentos binário entre dois conjuntos de entidades, a cardinalidade de mapeamentos pode ser um-para-um, um-para-muitos ou muitos-paramuitos. A cardinalidade de mapeamento apropriada para um dado conjunto de relacionamentos é obviamente dependente do mundo real que está sendo modelado pelo conjunto de relacionamentos. Além da cardinalidade dos relacionamentos outras características importantes, ao levantar um modelo entidade relacionamento, são a 
definição de chaves primárias e a utilização de extensões para uma melhor representação do mundo real.

\subsubsection{Chaves Primárias}

Uma tarefa importante na modelagem do banco de dados é a especificação da distinção entre entidades e relacionamentos. Conceitualmente, entidades individuais $e$ relacionamentos são distintos, mas na perspectiva do banco de dados a diferença entre eles deve ser expressa em termos de seus atributos. Para se fazer tais distinções, uma chave primária é assinalada para cada conjunto de entidades. Esta chave primária é um conjunto de um ou mais atributos, que tomados em conjunto, permite identificar unicamente uma entidade no conjunto de entidades. $\mathrm{O}$ conjunto de todas as chaves que podem se tornar a primária é chamado de conjunto de chaves candidatas.

As entidades que não possuem chave primária são denominadas de entidades fracas. A chave primária de um conjunto de entidades fracas é formada pela chave primária da entidade forte da qual ela é existencialmente dependente.

\subsubsection{Extensões do Modelo Entidade-Relacionamento}

A análise lógica de dados tem sido muito difundida por Peter Chen que tornou-se o precursor da técnica do MER [CHEN-76]. A partir dele foram desenvolvidas extensões para abstrair vários conceitos, dentre os quais alguns de orientação a objetos [SHEER91]. Entre os conceitos mais utilizados atualmente estão os de generalização/especialização, composição e agregação.

Generalização é o resultado da união de dois ou mais conjuntos de nivel mais baixo produzindo um conjunto de entidades de nível mais alto. Especialização é o resultado da separação de um subconjunto de entidades de nível mais alto, formando um conjunto de entidades de nível mais baixo. $O$ conceito de generalização é utilizado para enfatizar as semelhanças entre entidades de nível mais baixo e ocultar suas diferenças; a de especialização é o inverso.

No conceito de generalização/especialização, os atributos são usados como meios de distinção entre conjuntos de entidades através do mecanismo de herança. Os atributos dos conjuntos de entidades de nível mais baixo são herdados dos conjuntos de entidades de nivel mais alto. 
Composição é a integração de dois ou mais conjuntos de entidades (partes) onde existe no conjunto de entidade composto uma maior representação além da soma das partes. Uma entidade parte depende da existência da entidade composta. Na composição não há herança.

Agregação é uma abstração na qual relacionamentos são tratados como entidades de nível mais baixo. Dessa forma é possível expressar relacionamentos entre relacionamentos o que facilita modelar certas situações do mundo real.

Atualmente as ferramentas que auxiliam a fase modelagem de dados representam alguns conceitos conforme a área de atuação na qual está dedicada. No entanto, entre as ferramentas de propósito geral não há uma ferramenta, pelo menos de baixo custo, que suporte todos conceitos citados acima.

\subsection{Conceitos Envolvidos na Geração do Modelo Físico da Base de Dados}

Apesar de não constar entre os objetivos deste trabalho, uma vez que este se concentra nas fases lógicas de uma metodologia para o desenvolvimento de base de dados, a normalização e o mapeamento do modelo entidade relacionamento para o modelo relacional são conceitos importantes que devem ser apresentados. O processo de normalização relaciona-se com a definição das chaves primárias e as tabelas do modelo relacional definem o conjunto de entidades e relacionamentos do modelo entidade relacionamento.

\subsubsection{Normalização}

A normalização consiste no processo de cristalizar os conjuntos de entidades e seus relacionamentos no formato de tabelas utilizando os conceitos relacionais. A busca de uma representação apropriada para algo que existe no mundo real depara-se com problemas relacionados com as propriedades dos objetos a ele pertencentes, suas características e inter-relacionamentos. Tais dificuldades devem-se ao fato de que o valor de um atributo numa relação pode determinar de modo completo o valor de outro atributo [CERÍCOLA-91]. 
Quando a relação é normalizada, os problemas de consistência e anomalias de inclusão e exclusão nas transações com a base de dados desaparecem. A normalização assegura que cada tipo de atributo tenha somente valores simples para cada ocorrência do tipo de entidade à qual se refere (primeira forma normal). A segunda e a terceira formas normais estão relacionadas com o conceito de dependência funcional, onde são verificadas as dependências dos atributos com a chave primária escolhida para a entidade.

O projeto normalizado da base de dados aumenta a integridade dos dados minimizando as redundâncias e inconsistências, mas para certos desempenhos haverá um custo para algumas aplicações de recuperação. Isto implica que pode haver uma desnormalização para um ganho em desempenho desde que haja um controle sobre a mesma.

Vale ressaltar novamente que a descrição detalhada das formas normais foge ao escopo deste trabalho, atendo-se apenas na descrição da importância de um projeto normalizado.

\subsubsection{Mapeamento do MER em Tabelas}

Um banco de dados com forma correspondente a um modelo entidade-relacionamento pode ser representado por uma coleção de tabelas. Para cada conjunto de entidades no banco de dados, há uma tabela única que pode ter o mesmo nome. Cada tabela possui um número de colunas que, novamente, possuem nomes únicos e representam os atributos do conjunto de entidades mapeado. Para o conjunto de relacionamentos é necessário observar a cardinalidade.

- Cardinalidade um-para-um: os conjuntos de relacionamentos não são representados através de tabelas. Seus atributos são incluídos em qualquer uma das entidades relacionadas. Escolhe-se uma das entidades para conter a chave primária da outra entidade na representação do relacionamento;

- Cardinalidade um-para-muitos: novamente os conjuntos de relacionamentos não são representados através de tabelas. Os atributos do relacionamento devem ser colocados junto à entidade que participa com cardinalidade muitos. Além disso, essa entidade deve ser acrescida da chave primária da outra entidade, que corresponde à definição da chave estrangeira;

- Cardinalidade muitos-para-muitos: esses relacionamentos são mapeados como uma nova tabela que tem todos os atributos do conjunto de relacionamentos. A chave para 
esta nova relação é formada pelas chaves primárias dos conjuntos de entidades envolvidos.

Basicamente estas são as regras para o mapeamento do MER em tabelas do modelo relacional, valendo também para os conceitos extendidos do MER, citados anteriormente, com algumas regras adicionais.

\subsection{Metodologia de Desenvolvimento para Bases de Dados}

$\mathrm{O}$ desenvolvimento de uma base de dados também obedece a um ciclo de vida. As fases para esse desenvolvimento são [CERÍCOLA-91]:

- Análise das necessidades. Esta fase analisa os planos empresariais levantando as necessidades gerais de informação. É feito ainda um estudo das necessidades de processamento, da viabilidade do sistema e da utilização do dicionário de dados;

- Projeto conceitual. Esta fase visa a construção de modelos de acordo com a estruturação das necessidades globais de informações. Entre os modelos estão diagrama de contexto (Tom de Marco), diagrama de fluxo de dados (DFD), e o modelo entidade-relacionamento (MER);

- Projeto lógico. Esta fase propõe a análise das opções de montagem de um banco de dados e normalização das entidades, atributos e seus relacionamentos;

- Projeto físico. Esta fase tem por função transformar o projeto lógico no formato mais adequado a um SGBD específico através das especificações das caracteríticas do banco de dados, e de um mapeamento dos acessos a serem feitos ao banco de dados;

- Implementação. A atividade desta fase é a geração e processamento das definições do banco de dados na linguagem de definição de dados do SGBD específico;

- Monitoração. Esta é a etapa que acompanha o projeto já nos primórdios de sua existência com a finalidade de medir e analisar a evolução de seu desempenho;

- Sintonização. Esta fase tem por objetivo apresentar uma avaliação sólida de desempenho do banco de dados frente à utilização massiva de sua informação. Esta avaliação baseia-se nos pontos críticos de desempenho, especificação de novas estruturas e otimização do banco de dados. 
A apresentação desta metodologia constituiu-se no último conceito relacionado a modelagem de dados. Como já foi mencionado, o objetivo deste trabalho é atuar nas fases de projeto conceitual e projeto lógico da metodologia apresentada. Com isso, o domínio do conhecimento no qual foram levantadas as regras que verificam a consistência de modelos de dados restringe-se a essas duas fases. A próxima seção enfatiza a necessidade de representação e manipulação do conhecimento envolvido nestas duas fases.

\subsection{Importância do Conhecimento Envolvido no Projeto de Base de Dados}

Uma das motivações para o desenvolvimento deste trabalho baseia-se no fato que as empresas necessitam de profissionais com grande experiência em metodologia de desenvolvimento do banco de dados nas áreas onde serão desenvolvidos os sistemas. Com isso, é gerada uma relação de dependência com os respectivos profissionais. Por exemplo, se por motivos quaisquer um desses profissionais mudar de empresa sem avisar antecipadamente, as consequências podem ser desastrosas. Além de levar consigo todo o conhecimento relacionado com as funções que desempenhava, pode não haver outro profissional com o mesmo nível de conhecimento para a empresa.

Neste sentido, uma ferramenta que seja capaz de manipular o conhecimento humano torna-se essencial para as empresas, pois além de armazenar o conhecimento de especialistas a ferramenta pode ser utilizada em treinamento de novas pessoas. Outro fato que pode ser considerado é que este tipo de ferramenta libera as pessoas responsáveis pela modelagem de dados de tarefas que são meramente técnicas, onde normalmente ocorrem falhas [CORREAA-94b].

Para a construção de uma ferramenta que auxilia a fase de modelagem de dados. Uma das alternativas para a automação deste conhecimento é a utilização da tecnologia de sistemas baseado em conhecimento.

\subsection{Sistemas Baseados em Conhecimento}

Os Sistemas Baseados em Conhecimento -- SBC -- são programas de computador que resolvem, ou ajudam a resolver problemas que geralmente requerem o uso de inteligência humana. Uma característica que torna os SBC's mais poderosos que as tecnologias usuais 
de armazenamento e transmissão do conhecimento (p.ex. livros, manuais), é o fato que estes sistemas possuem a capacidade de representar e manipular este conhecimento [RODRIGUES-93].

Os avanços em hardware, tecnologia de software e ciência cognitiva estão se unindo para produzir a próxima geração de ferramentas e técnicas baseadas em conhecimento. Os SBC's constituem-se na vanguarda desta geração.

Atualmente, há uma grande gama de aplicações para SBC's. O número dessas aplicações está crescendo de acordo com a tecnologia e as necessidades de mercado. Uma das características da evolução acelerada de uma sociedade agrícola para uma sociedade industrial e tecnológica é a necessidade de representação e manipulação do conhecimento.

O elo de ligação entre o conhecimento humano e os métodos de resolução de problemas por computador é o profissional conhecido como Engenheiro do Conhecimento. O produto desenvolvido por um Engenheiro de Conhecimento é a simulação do conhecimento humano, de tal forma que este seja acessível pelo computador.

Os SBC's dividem-se em tipos básicos, tais como [TUTHILL-90]:

- CASE inteligentes --- sistemas que apoiam o desenvolvimento de sistemas;

- Sistemas Especialistas;

- Hipertextos-Hipermídia na área de sistemas de conhecimentos;

- Sistemas Tutoriais Inteligentes --- sistemas educacionais e de treinamento controlado por computador.

A tecnologia de CASE Integrado, abordado na seção 3.2, corresponde ao termo de CASE inteligente descrito por Tuthill, ou seja, possui as mesmas características que já foram descritas. Além da utilização desta tecnologia, este trabalho utiliza algumas das caracteristicas de Sistemas Especialistas

\subsubsection{Sistemas Especialistas}

Sistema Especialista é um nome genérico associado à uma classe de programas de software que tem a habilidade de interagir com o usuário para a definição de um problema e, então, inferir uma solução a nível de um especialista na área. Estes sistemas 
usam técnicas de raciocínio e conhecimento para resolver problemas que normalmente requerem habilidades de especialistas humanos [PAYNE-90].

Há uma diferença entre SE e SBC que deve ser ressaltada: os SBC's são sistemas que resolvem problemas usando o conhecimento sobre o domínio do problema, enquanto que os SE's são SBC's que resolvem problemas da vida real, mas que requerem uma considerável habilidade quando resolvidos pelo homem (Figura 3.4). Neste trabalho os termos Sistemas Baseados em Conhecimento e Sistemas Especialistas serão usados indistintamente.

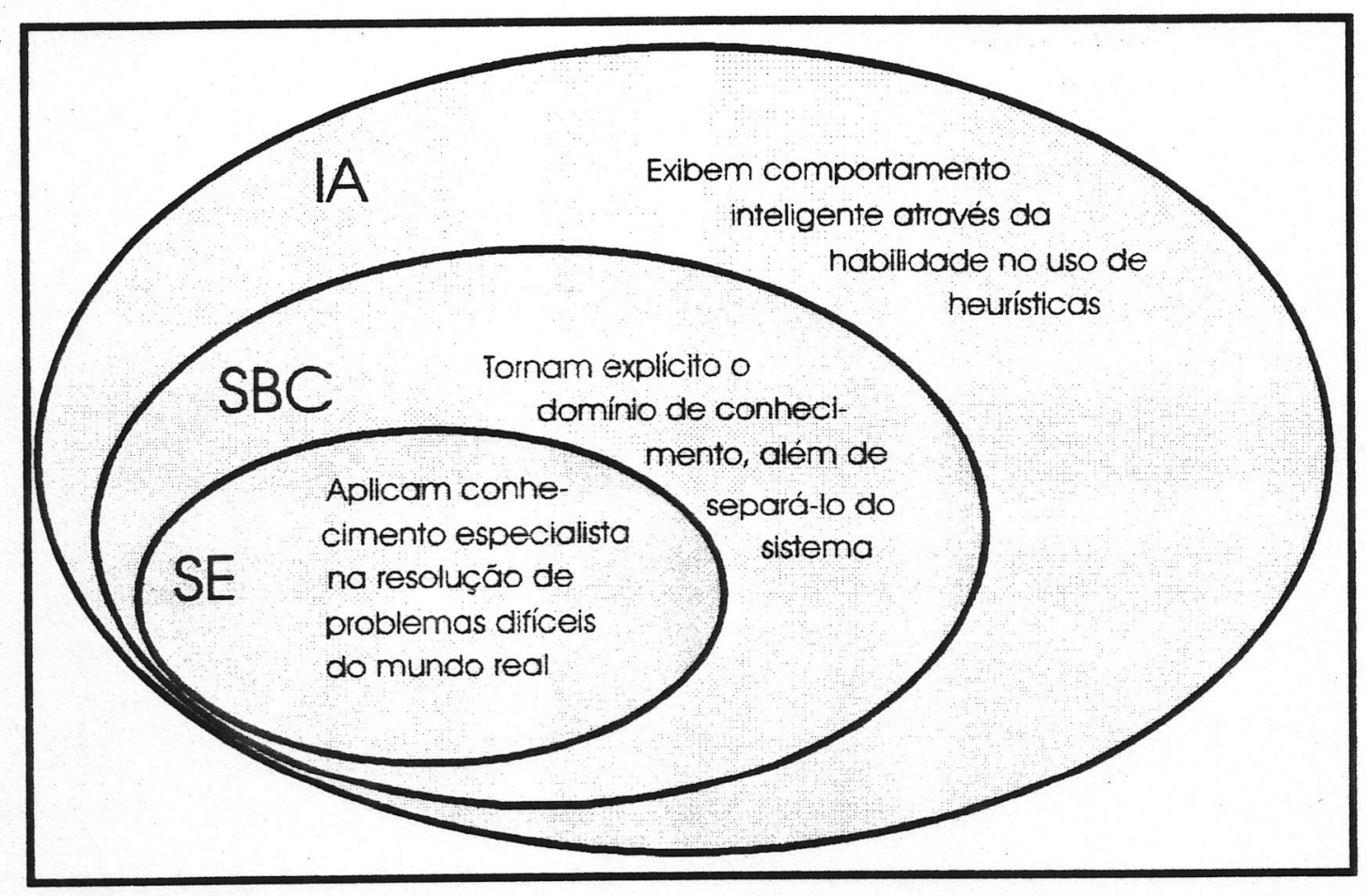

Figura 3.4: Diferencas entre SBC's e SE's [RODRIGUES-93]

Para a construção de SE's, há necessidade de um estudo de viabilidade da aplicação desta tecnologia no domínio do problema em questão. Alguns dos fatores a serem considerados são: custos, habilidades do especialista e delimitações do domínio do conhecimento [LUGER-89].

A Figura 3.5 mostra a combinação de algumas justificativas para o desenvolvimento de SE's. 
Como mencionado, os SE's ajudam as pessoas a resolverem problemas da vida real. Em outras palavras, os SE's são programas computacionais que usam raciocínio simbólico especializado para ajudar as pessoas a resolverem problemas.

Isto é realizado através de uma interação homem-máquina, onde:

- o sistema pode fornecer algumas etapas do raciocínio e parte do conhecimento;

- o homem pode fornecer uma direção geral para a resolução do problema, bem como o conhecimento específico não incorporado ao sistema.

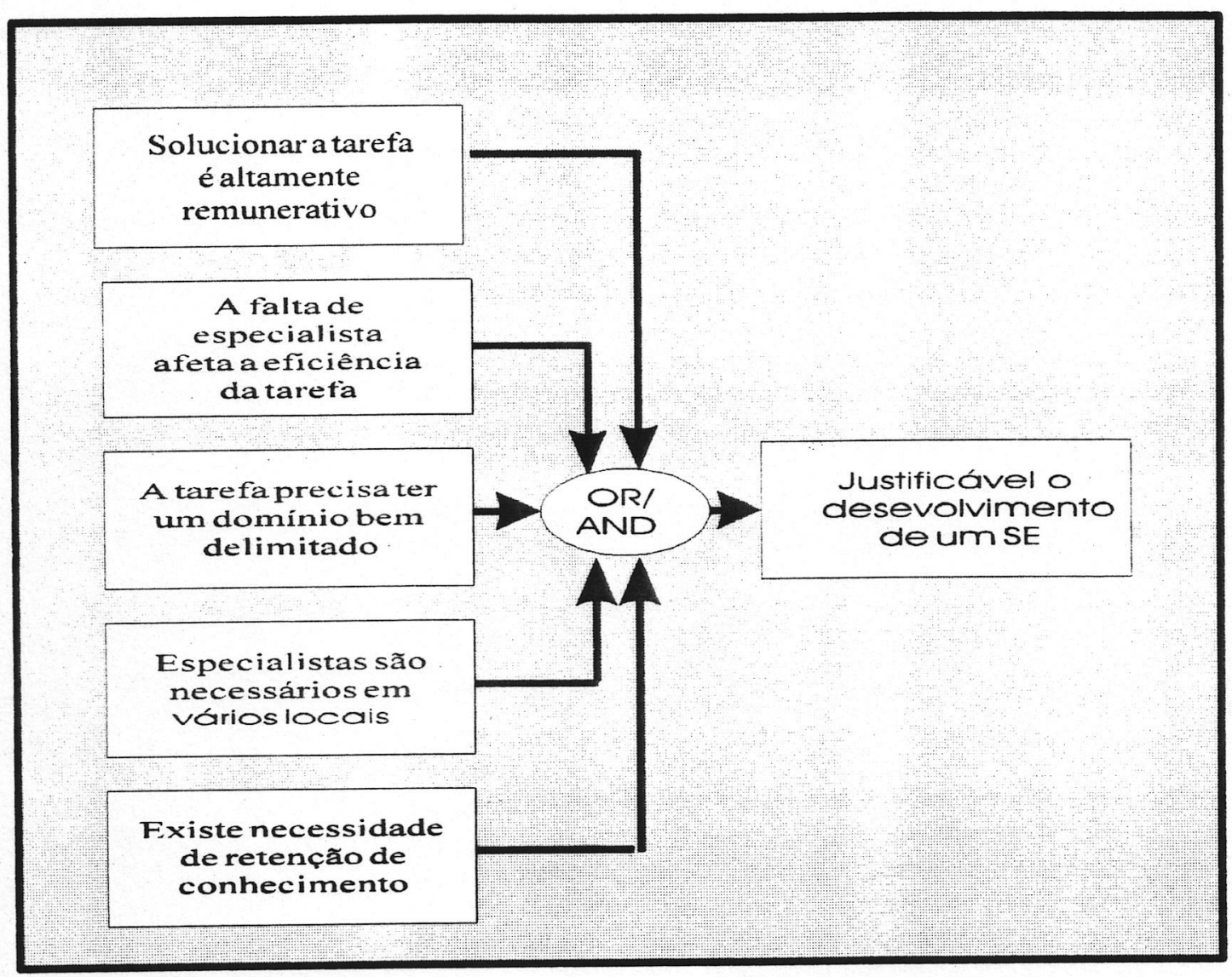

Figura 3.5: Justificativas para o Desenvolvimento de SE's

Um SE deve ser acessível, para tornar a resolução dos problemas mais próxima do entendimento dos usuários, o que é feito através de recursos explanatórios, e maleável para que os Engenheiros do Conhecimento modifiquem com facilidade o conhecimento, os procedimentos, objetivos ou estratégias, em qualquer ponto do processo de resolução do problema. 
A importância da construção de SE's para empresas encontra-se na capacidade desses sistemas em aproveitar e fazer uso de um recurso cada vez mais procurado: o talento e a experiência de membros da empresa no processo de tomada de decisões.

\subsubsection{Estrutura Básica de um Sistema Baseado em Conhecimento}

Para entender como os SBC's diferem dos aplicativos tradicionais, é importante compreender seus componentes principais, como mostra a Figura 3.6 [RODRIGUES93]:

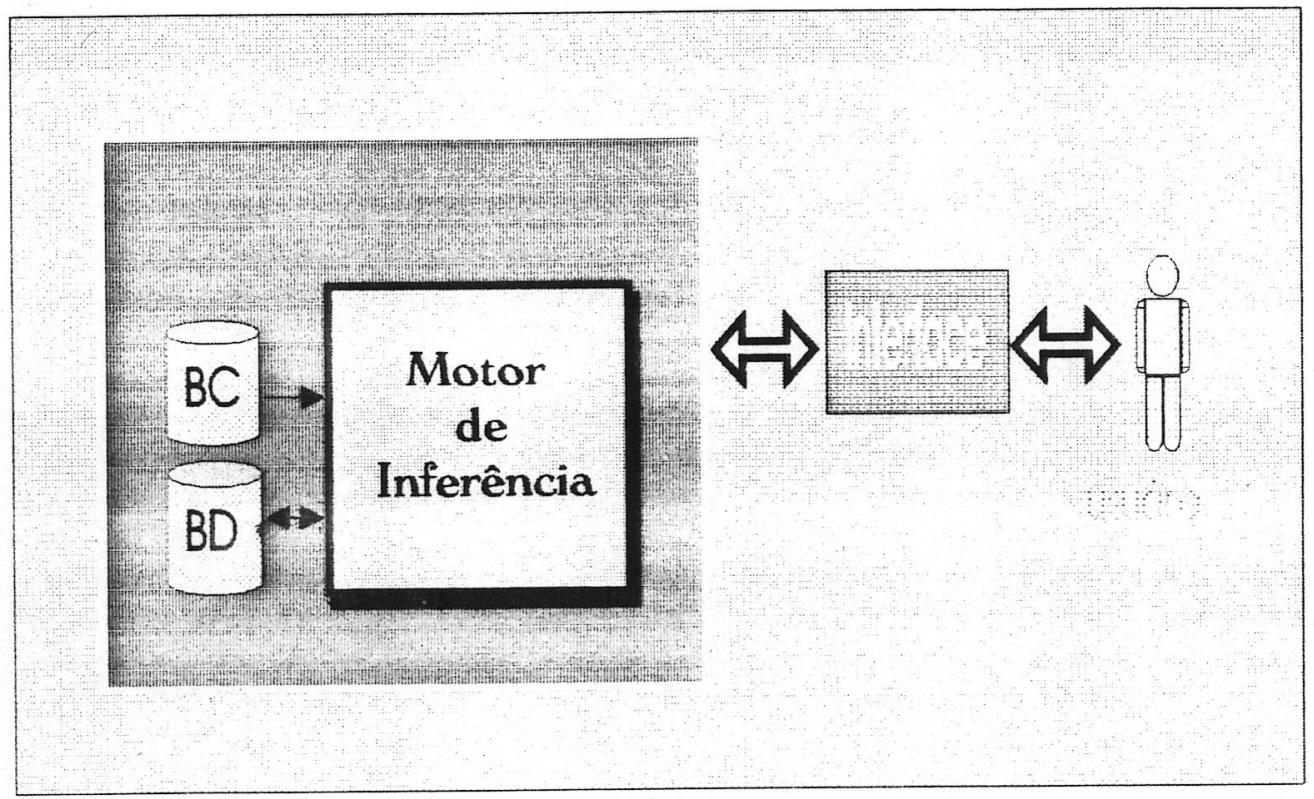

Figura 3.6: Estrutura Básica de um SBC

- a interface deve ser amigável, fornecendo explicações às perguntas feitas pelo usuário tais como: Como chegou à essa conclusão? ou Porque esses dados são requisitados?;

- a Base de Conhecimento --- BC --- é composta de fatos e regras relacionados ao domínio do problema. Novos conhecimentos podem ser acrescentados à $\mathrm{BC}$ de modo que todos os fatos e métodos de raciocínio existentes continuem sendo válidos;

- A Bace de Dados --- BD --- é responsável por armazenar todas as informações necessárias ao processo de inferência; 
- o Motor de Inferência --- MI --- possui um conjunto de métodos de raciocínio que interage com as informações da $\mathrm{BC}$ a fim de resolver o problema. O MI é responsável pelo processamento do conhecimento da $\mathrm{BC}$ usando alguma linha de raciocínio.

Os métodos de raciocínio empregados quando o conhecimento é representado usando regras são [PAYNE-90]:

- encadeamento para frente (Forward Chaining). Neste método,o MI pesquisa uma lista de hipóteses e procura reunir evidências para viabilizar a conclusão da validade de alguma(s) dela(s);

- encadeamento para trás (Backward Chaining). Neste método, o MI parte dos dados ou asserções existentes e deduz novas asserções até chegar à solução do problema.

Para evidenciar a melhor organização e projeto para um determinado SBC, deve-se considerar o tipo e a complexidade do problema, bem como a adequação e forma de conhecimento heurístico disponivel para resolvê-lo

\subsection{Engenharia de Conhecimento}

Os computadores têm muitas vantagens sobre os seres humanos, principalmente no que diz respeito à velocidade e consistência. Para fazer um rápido e consistente processador de símbolos ter um desempenho tão bom quanto o de um especialista humano, alguém deve muní-lo de "know-how" especializado, comparável ao de um especialista humano. Ou seja, os projetistas de SBC's precisam incorporar uma grande quantidade de conhecimento que pode ser incompleto, inexato, de senso comum e, em alguns casos, de conhecimento heurístico. Isto é tratado pela área denominada Engenharia de Conhecimento, que estuda o processo de transferência do conhecimento do especialista humano para o computador [HAYES-ROTH-87a].

\subsubsection{Domínios de Conhecimento}

O domínio de conhecimento é uma coleção de informações, metas e procedimentos de um problema específico. Estes são unidos pelos conceitos, atributos e relações incluídos dentro da definição.

As metodologias para resolução de problemas usadas pelos SBC's são geralmente determinadas pelas peculiaridades da classe de problemas nas quais o sistema vai ser 
utilizado. Entre as classes mais significativas de problemas onde é viável a utilização da tecnologia de SBC's encontram-se: diagnose, interpretação, monitoramento, planejamento, projeto, instrução, simulação e aconselhamento. A classe de problemas no qual este trabalho está inserido pode ser classificado como diagnose e/ou aconselhamento, que consiste no processo de diagnosticar situações apresentadas e sugerir algumas ações para o usuário. Um exemplo é quando um projetista elabora um modelo de dados e, com a utilização de um SBC, aciona as regras para a verficação do modelo. Após a inferência, o resultado pode detectar alguma inconsistência, e nesta situação o SBC fornece sugestões para a correção do modelo.

Para que o conhecimento de um domínio seja incorporado ao computador, há necessidade de extrair o conhecimento de alguma fonte (especialista, livros, exemplos, etc...) e representá-lo em um sistema.

\subsubsection{Aquisição de Conhecimento}

A aquisição de conhecimento consiste na extração do conhecimento do especialista no domínio de aplicação. Esta aquisição pode ser realizada de várias formas, onde a modalidade mais utilizada é por intermédio do Engenheiro do Conhecimento [HAYESROTH-83]. Nesta modalidade, a origem do conhecimento a ser adquirido pode ser tanto um especialista como livros, teses, manuais, exemplos, etc.

Quando a extração do conhecimento é realizada pelo Engenheiro do Conhecimento, o processo é chamado Elicitação do Conhecimento (Figura 3.7). A elicitação é realizada por uma equipe de aquisição que pode ser composta por mais de uma pessoa, dependendo do domínio a ser elicitado. Nesse caso, as fases do processo com as respectivas pessoas envolvidas são:

$\begin{array}{ll}\text { aquisição } & \text { (equipe de aquisição + especialistas); } \\ \text { estruturação } & \text { (equipe de aquisição); } \\ \text { validação } & \text { (equipe de aquisição + especialistas); } \\ \text { pré-representação } & \text { (equipe de aquisição). }\end{array}$




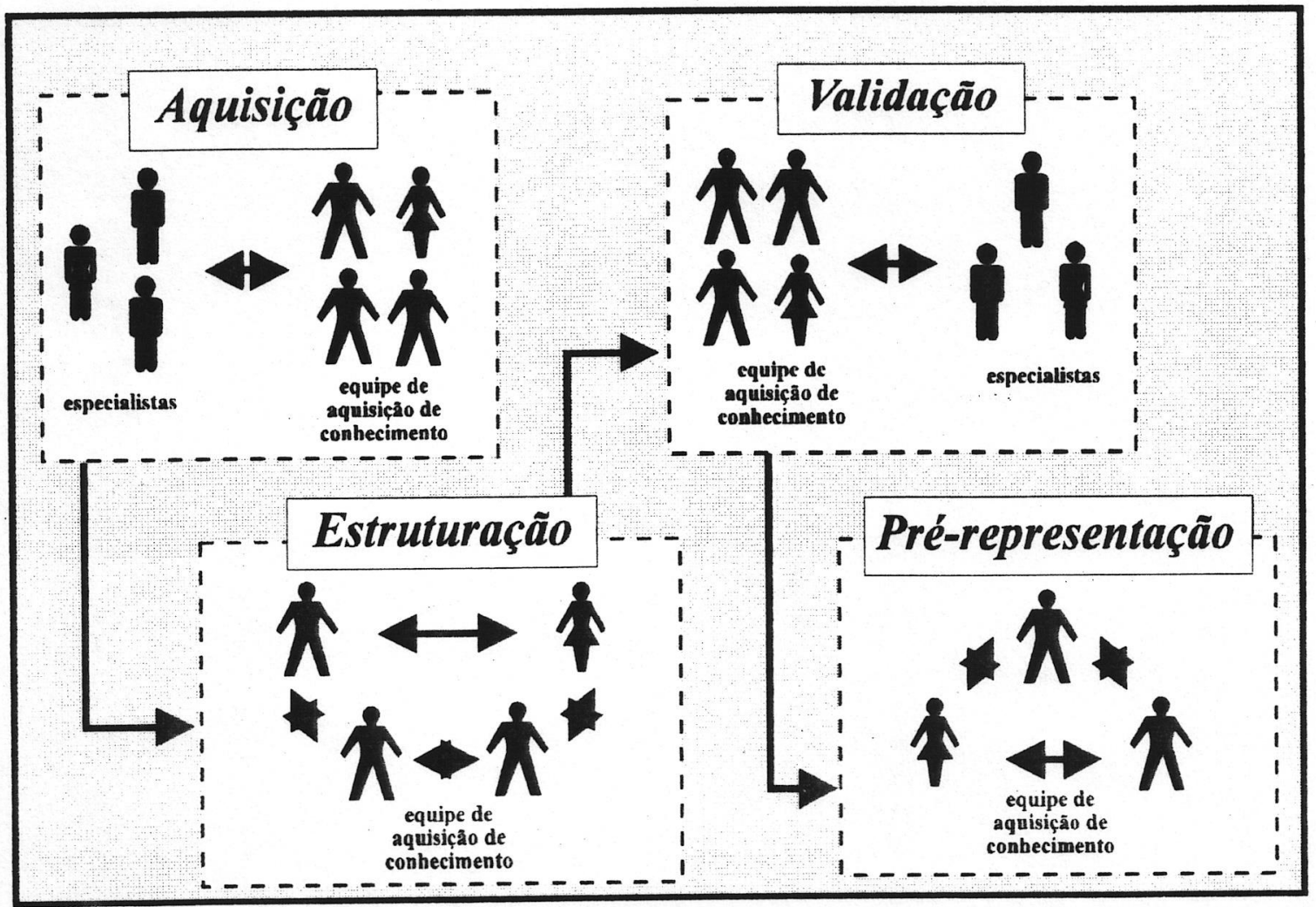

Figura 3.7: Fases da Elicitação de Conhecimento [RODRIGUES-93]

Esta modelagem pode ser complicada devido ao fato de que eventualmente os dados podem estar incompletos. A integração das várias fontes de dados (quando mais de um especialista é consultado) também pode causar inconsistências no processo de aquisição de conhecimento [BELLI-92]

A fase seguinte à pré-representação corresponde a representação do conhecimento.

\subsubsection{Representação de Conhecimento}

A representação de conhecimento é uma forma sistemática de estruturar e codificar o conhecimento de um especialista sobre um domínio [SAWAKI-91]. Esta representação deve exprimir o conhecimento em uma forma acessível e fácil de ser manipulada. A representação efetiva do conhecimento é uma das preocupações fundamentais da área de IA.

Existem vários modelos de representação de conhecimento tais como: regras de produção, redes semânticas, frames e orientação à objetos. Para avaliar esses modelos, 
existem alguns critérios, onde os principais são adequação lógica e conveniência notacional, sendo que:

- adequação lógica observa se o formalismo usado é capaz de expressar o conhecimento que se deseja representar;

- conveniência notacional verifica as convenções da linguagem de representação; se estas forem muito complicadas, a tarefa de codificação se torna extremamente complexa.

A seguir serão apresentados brevemente alguns dos esquemas de representação de conhecimento comumente usados para organizar e representar conhecimentos.

\subsubsection{Regras de Produção}

Os Sistemas Baseados em Regras simulam o processo de tomada de decisão. As regras podem expressar relacionamentos lógicos e equivalências de definições para simular o raciocínio humano [ARARIBOIA-89]. Assim como outros esquemas de representação, as regras podem ser usadas para justificar a conduta do sistema na busca da solução. As regras de produção são estruturas do tipo:

$$
\mathbf{S E}<\text { condições }>\text { ENTÃ } \mathbf{O} \text { conclusões }>\text { FAÇA }<\text { ações }>
$$

onde a parte SE é uma lista de condições a serem satisfeitas, a parte ENTÃo é uma lista de conclusões e FAÇA são as ações a serem executadas. Cada uma das condições da lista é verificada, e se todas forem satisfeitas, as conclusões são provadas verdadeiras e as ações são executadas.

Por exemplo, na geração de uma linguagem de definição de dados (DDL) a partir de um modelo relacional, uma das regras poderia ser a seguinte: 


\section{SE}

entidade A se relaciona com entidade B $\mathbf{e}$ tipo de relacionamento for $1: 1$

\section{ENTÃO}

conjunto de atributos de B é alterado

\section{FAÇA}

incluir a chave primária de A no conjunto de atributos de B

Entre as várias alternativas de representação de conhecimento, as regras constituem uma forma natural de representar o conhecimento de um especialista humano [HAYESROTH-87b]

\subsubsection{Redes Semânticas}

Uma Rede Semântica é um grafo direcionado formado por um conjunto de nós representando os objetos (indivíduos, objetos, conceitos, situações em um domínio) e por um conjunto de arcos representando as relações entre os objetos [RICH-93]. Um arco é rotulado com o nome da relação que ele representa. Vários arcos podem ter o mesmo rótulo, entretanto cada objeto é representado por apenas um nó.

Objetos complexos muitas vezes podem ser decompostos em objetos mais simples. Essas decomposições produzem dois tipos de relações:

- classe_de: as relações entre os objetos estão em uma taxonomia hierárquica;

- faz_parte: as relações entre os objetos obedecem a um tipo de composição, ou seja, um objeto é componente de outro, não havendo nenhum tipo de herança.

Uma das propriedades mais importantes destas relações é a transitividade, pois permite uma declaração concisa de propriedades nos objetos mais gerais. Mecanismos de inferência podem, então, ser utilizados para derivar essas propriedades para os objetos mais específicos. Este procedimento é denominado Herança de Propriedades. 
Um exemplo de rede semântica é ilustrado na Figura 3.8. No exemplo, colaborador é um termo genérico que indica alguma espécie de funcionário de uma empresa. Na Figura também podem ser observados os tipos de decomposições citados anteriormente.

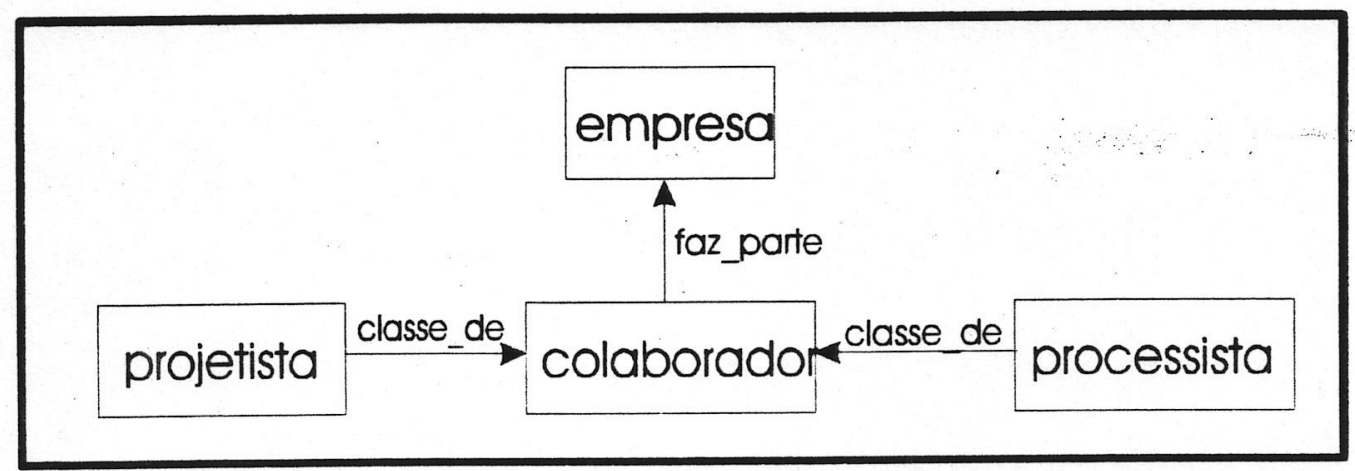

Figura 3.8: Exemplo de Rede Semântica

\subsubsection{Frames}

Frame é uma coleção de conhecimentos relevantes a um objeto, situação ou conceito. O frame possui um nome que identifica o conceito por ele definido e consiste de um conjunto de "slots" [AVILA-91]

Cada slot possui, por sua vez, um nome e consiste de um conjunto de atributos, denominados facetas. As facetas contêm informações que descrevem os slots. Estas informações podem definir explicitamente os valores que o slot pode assumir, ou podem indicar de que forma calcular ou deduzir o seu valor (procedimentos). Exemplos de facetas são: tipo, domínio, valor default, etc.

Uma das principais características deste modelo de representação é a herança de propriedades, onde uma classe mais especializada pode herdar todas as propriedades da classe mais geral.

Um exemplo é apresentado na Figura 3.9, onde o frame retificadoras contém os atributos identificação e localização e seu frame superior é máquinas.

Os frames fornecem uma representação estrutural concisa de relações estáticas, mas não fornecem facilidades diretas para descrever declarativamente como o conhecimento 
armazenado deve ser utilizado. As principais deficiências de frames são tratadas com sucesso por regras de produção. Por isso, está cada vez mais difundido o uso de combinação de regras de produção e frames, de maneira a explorar as vantagens que as duas representações oferecem

\begin{tabular}{|c|}
\hline retificadoras \\
incluído em \\
valor:máquinas \\
identificação \\
valor:0021 \\
localização \\
valor: setor 6
\end{tabular}

Figura 3.9: Uma Representação do Frame Retificadoras

\subsubsection{Orientação a Objetos}

Este esquema reúne características de redes semânticas e frames. A estratégia principal está no fato que o conhecimento é visto como conjuntos completos de objetos com comportamentos. É hierarquicamente estruturado de modo que níveis inferiores na estrutura acessam atributos e relacionamentos de níveis superiores na estrutura [TUTHILL-90],[PAYNE-90].

Objetos são similares a frames porque usam conjuntos de descrição para caracterização. Objetos usam atributos; frames usam slots. Todavia, ambos tem uma estrutura hierárquica. Objetos usam métodos e frames usam procedimentos. A comunicação entre objetos é feita através de mensagens, enquanto frames podem usar regras.

Objetos são similares às redes semânticas devido à estrutura hierárquica de redes. Dessa forma, os conjuntos de objetos em níveis inferiores herdam atributos dos conjuntos localizados em níveis superiores na estrutura. 
Um conceito importante comum a frames e objetos é o encapsulamento, que pode ser entendido como o ato de agrupar dados e métodos relacionados a um objeto. 0 conhecimento encapsulado dentro do objeto pode ser escondido de outros objetos, o que é denominado de "information hidding" (ocultamento da informação).

Um exemplo é ilustrado na Figura 3.10 onde colaborador é uma classe genérica que possui duas subclasses: processista e projetista. A classe colaborador mantém ainda um relacionamento com a classe projeto.

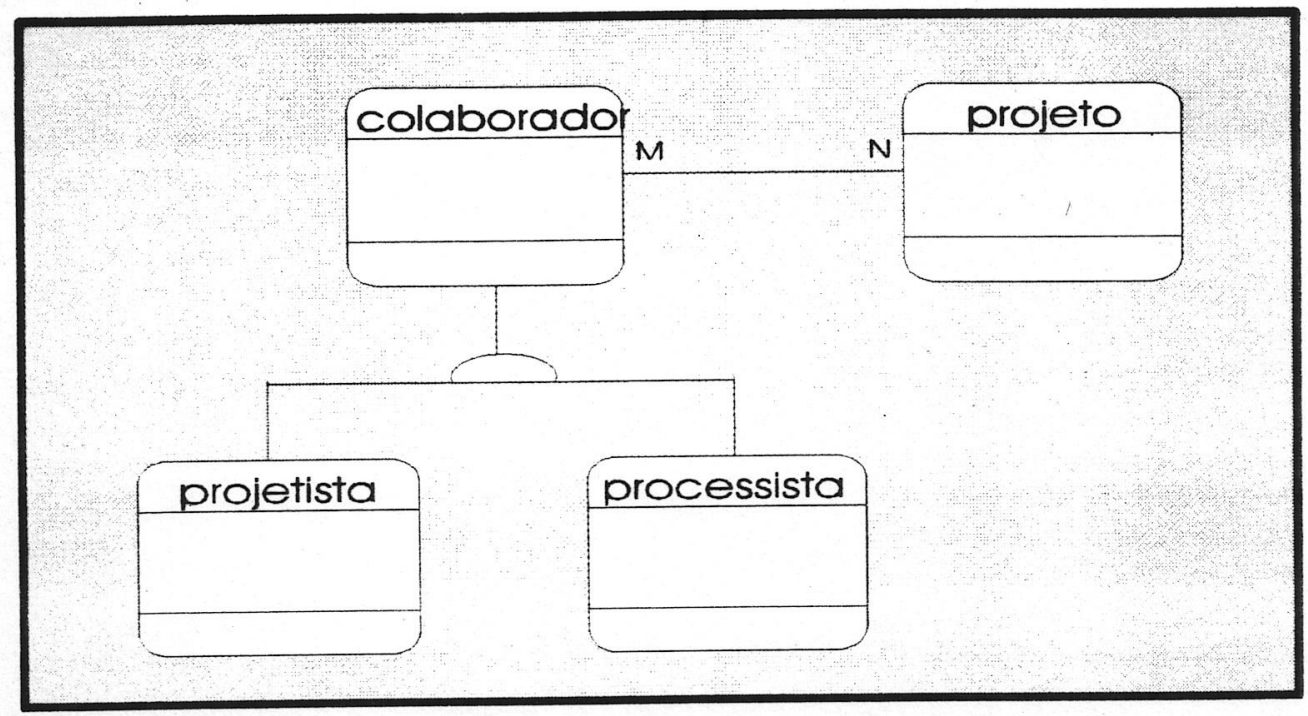

Figura 3.10: Exemplo de um Diagrama de Análise Orientada a Objetos É possível observar um relacionamento do tipo generalização/especialização onde projetista e processista herdam os atributos e métodos definidos em colaborador. Outro tipo de relacionamento é do tipo todo/parte que define composição entre objetos.

A flexibilidade na descrição é o ponto mais forte de sistemas orientados a objetos. Um conjunto básico de objetos pode ser estabelecido e então ser utilizado na implementação de vários sistemas através de modificações, de acordo com cada situação.

\subsection{Fases do Desenvolvimento de um SBC}

A Figura 3.11 ilustra o processo iterativo do desenvolvimento de SBC's. No entanto, o processo não é tão claro e bem definido como a Figura sugere. Estes estágios são 
simplesmente uma caraterização grosseira da complexa atividade de desenvolvimento de um SBC [RODRIGUES-93].

A primeira fase corresponde à aquisição do conhecimento, onde identifica-se as características do problema e são encontrados os conceitos para a representação do conhecimento. $\mathrm{O}$ processo de aquisição de conhecimento continua até que seja extraído conhecimento suficiente para capacitar o SBC a atingir um desempenho adequado. Como já foi visto, este processo é denominado elicitação do conhecimento (figura 3.7) quando é realizado por uma equipe de engenheiros do conhecimento.

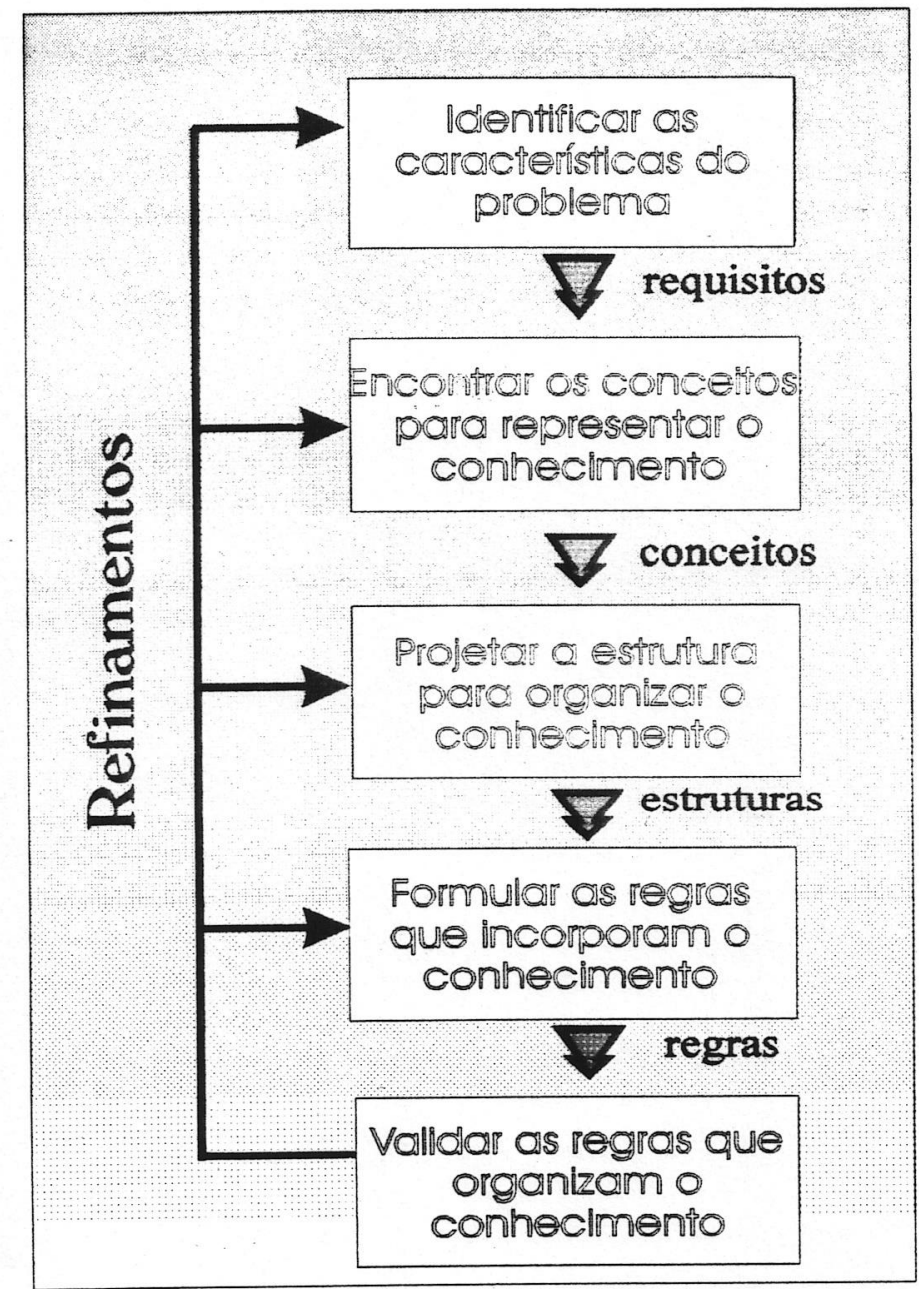

Figura 3.11: Estágios do Desenvolvimento de um SBC

As fases seguintes (formalização, implementação e teste) correspondem à representação do conhecimento. O projeto do SBC produz uma estrutura ou arquitetura para o SBC, e 
- Engenheiro do Conhecimento seleciona um modelo apropriado para representar o conhecimento [RINGLAND-88]. Na próxima atividade, o Engenheiro de Conhecimento transfere o conhecimento humano para a Base de Conhecimento que alimenta o Motor de Inferência. É de fundamental importância que a BC seja bem estruturada [PEDERSEN89]. A última atividade está relacionada com a realização de testes para a validação da BC. Esta atividade inicia um mecanismo de feed-back de acordo com a representação que está sendo testada.

O processo de refinamento do conhecimento continua até o que SBC atinja um nível adequado de desempenho. Ás vezes, os conceitos abstratos não são interpretados corretamente, pois as regras são expressas de maneira grosseira e negligenciam muitos detalhes necessários para assegurar a validade do conhecimento. Entretanto, esses erros não refletem a incapacidade dos profissionais, uma vez que não existem abordagens livres de erros

\subsection{Considerações Finais}

Neste capítulo podem ser observados três blocos de informações gerais que forneceram conceitos para o desenvolvimento da ferramenta de modelagem de dados. $O$ primeiro bloco apresentado está relacionado com a tecnologia atual de ferramentas que auxiliam a construção dos sistemas de informação de uma empresa, onde foram abordados os conceitos de CASE Integrado e enciclopédia. O segundo está relacionado com as fases lógicas de uma metodologia para desenvolvimento de base de dados, onde foram abordadas as tarefas necessárias para uma análise lógica dos dados. O último está relacionado com a tecnologia de sistemas baseado em conhecimento, onde a sua utilização está localizada na implementação das características de verificação de consistências de uma ferramenta para modelagem de dados.

Neste trabalho é proposto a construção de uma ferramenta para modelagem de dados que envolve os conceitos apresentados neste capítulo. O próximo capítulo apresenta tanto os requisitos relacionados com as fases lógicas da metodologia para desenvolvimento da base de dados como os requisitos necessários para a implementação dessa ferramenta. 


\section{REQUISITOS PARA O DESENVOLVIMENTO DE UMA FERRAMENTA PARA MODELAGEM DE DADOS}

\subsection{Considerações Iniciais}

Neste capítulo são apresentados os requisitos necessários para a implementação de uma ferramenta para modelagem de dados. Estes requisitos são provenientes de dois blocos fundamentais [CORRÊA-94a]: metodologia de desenvolvimento de banco de dados e a tecnologia da informação.

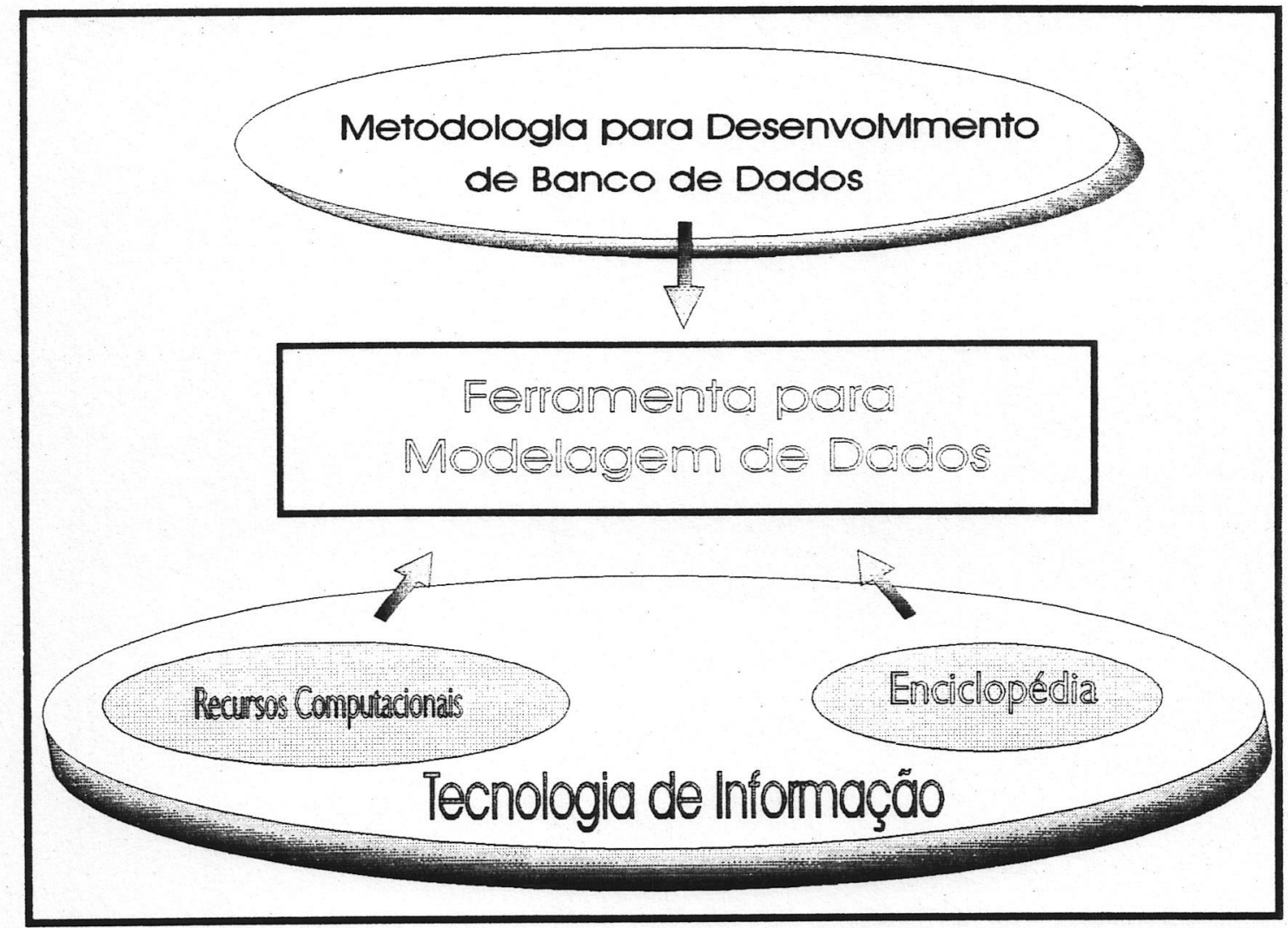

Figura 4.1: Blocos de Requisitos para o Desenvolvimento da Ferramenta

Como pode ser observado na Figura 4.1, os requisitos são provenientes de três fontes: as fases lógicas da metodologia para desenvolvimento de base de dados, a enciclopédia e os recursos computacionais. 


\subsection{Metodologia de Desenvolvimento de Base de Dados}

Como mencionado, as fases da metodologia de desenvolvimento de banco de dados envolvidas neste trabalho são projeto conceitual e projeto lógico. Estas fases são escolhidas por estarem dentro de um contexto lógico no qual pode ser aplicado a uma maior variedade de empresas, uma vez que as fases físicas da metodologia são específicas para cada SGBD. Esta característica se enquadra na filosofia da metodologia de integração da manufatura, abordada no capítulo 2 , onde a implementação das soluções depende dos recursos da tecnologia de informação disponíveis.

É importante ressaltar que a fase de análise das necessidades gerais de informação da metodologia é realizada por ferramentas de propósito estratégico, as quais levantam o fluxo de informações entre os processos de uma empresa.

\subsubsection{Projeto Conceitual}

Para a fase de projeto conceitual é necessária a utilização de um modelo lógico que auxilia e documenta o desenvolvimento da mesma, onde o mais utilizado é o modelo entidade-relacionamento (MER) com algumas extensões. O MER fornece uma documentação diagramática das entidades e relacionamentos que suportam as necessidades gerais de informação.

Além do conhecimento sobre os conceitos envolvidos em um MER, o projetista de banco de dados deve possuir um nível de experiência adequado para desenvolver sistemas livres de "impurezas", ou seja, de inconsistências e redundâncias. Por exemplo, o projetista da área de Planejamento e Controle da Produção -- PCP -- (componente do conceito CIM) deve possuir elevado conhecimento sobre o assunto a fim de levantar as entidades e relacionamentos existentes para a construção do MER da respectiva área. Caso esta tarefa não seja realizada por um projetista experiente, o MER elaborado pode não ter uma representação satisfatória na área em questão. Isto implica na geração de uma base de dados contendo inconsistências e, portanto, não confiável.

Dessa maneira, os requisitos que podem ser ressaltados aqui estão relacionados com o conhecimento envolvendo o MER e a área onde ele é aplicado. Uma ferramenta para modelagem de dados pode ter módulos de aconselhamento a nível de como se elaborar um MER para uma determinada área. Para isso, é necessário que a ferramenta armazene modelos de dados já consistentes da área onde está sendo realizado o projeto, o que 
viabiliza o aconselhamento. No entanto, neste trabalho a ferramenta visa apenas auxiliar a verificação de consistências de modelos de dados.

\subsubsection{Projeto Lógico}

Para a fase de projeto lógico o conceito de normalização torna-se fundamental. A normalização, como já foi dito, é um processo que cristaliza os conjuntos de entidades e seus relacionamentos no formato de tabelas utilizando os conceitos relacionais. Esta cristalização se dá através da definição de chaves candidatas e primárias. A partir desta definição, é possível levantar as dependências funcionais entre os atributos de uma entidade e com isso realizar a normalização.

Para a realização da normalização, novamente o requisito necessário é a experiência do projetista do banco de dados na área onde está sendo realizado o projeto. Vale ressaltar novamente que um projeto normalizado garante a integridade dos dados minimizando as redundâncias e inconsistências, e com isso aumentando a confiabilidade da base de dados.

Dessa forma, o requisito principal que uma ferramenta de modelagem de dados deve representar nesta fase é a garantia de que o modelo de dados seja normalizado.

\subsection{Requisitos de uma Enciclopédia}

Como já foi mencionado, uma enciclopédia contém a representação completa e codificada de planos, modelos e projetos, com módulos capazes de fazer a verificação cruzada e validação desta representação. A enciclopédia deve armazenar as informações representadas em diagrama e garantir a consistência desta representação.

De acordo com esta definição de enciclopédia é possível definir a arquitetura de uma ferramenta para a modelagem de dados, ilustrado na Figura 4.2. Com isso, o levantamento de requisitos é direcionando por cada componente desta arquitetura.

Como pode ser observado na Figura 4.2, os componentes da arquitetura para uma ferramenta de modelagem de dados são um Sistema Baseado em Conhecimento, uma interface com o usuário e uma base de dados que armazena as informações sobre os modelos de dados. 


\section{Interface Diagramática}

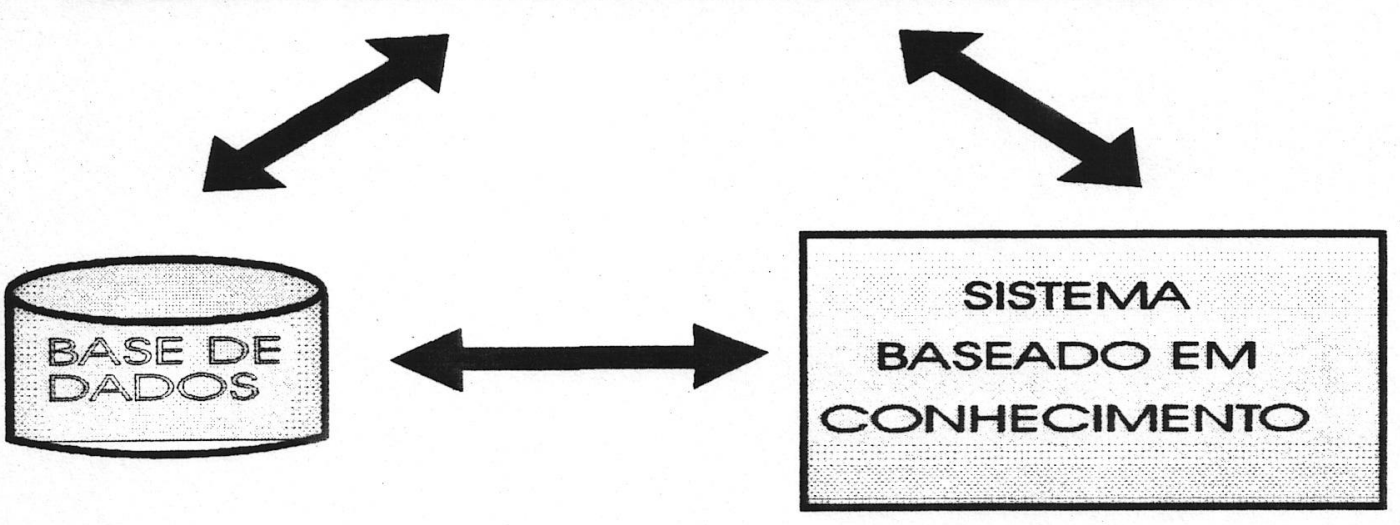

Figura 4.2: Arquitetura de uma Ferramenta para Modelagem de Dados.

\subsubsection{Interface da Ferramenta}

Uma enciclopédia deve possuir interfaces diagramáticas para facilitar a compreensão e desenvolvimento dos planos, modelos e projetos. Como o objetivo deste trabalho é o desenvolvimento de uma ferramenta para modelagem de dados, a forma diagramática para a interface corresponde à de um MER. Para isto, é necessário criar objetos de tela que correspondam aos elementos do MER e suas extensões.

O requisito principal para a implementação desta interface é que tanto o sistema operacional a ser utilizado quanto a linguagem de desenvolvimento devem fornecer meios de desenvolver a diagramação (Figura 4.3). Neste sentido, a utilização de uma ferramenta de desenvolvimento em ambiente Windows é indicada devido aos recursos fornecidos que torna a interface mais amigável para o usuário.

A linguagem de desenvolvimento por sua vez deve conter interfaces padrões para programas de aplicação (Application Programing Interface - API) de acesso a SGBD's e interface com o usuário. A API de acesso a banco de dados está dentro do contexto de 
arquitetura de conectividade aberta que utiliza a abordagem por interface comum discutida no capítulo 2.

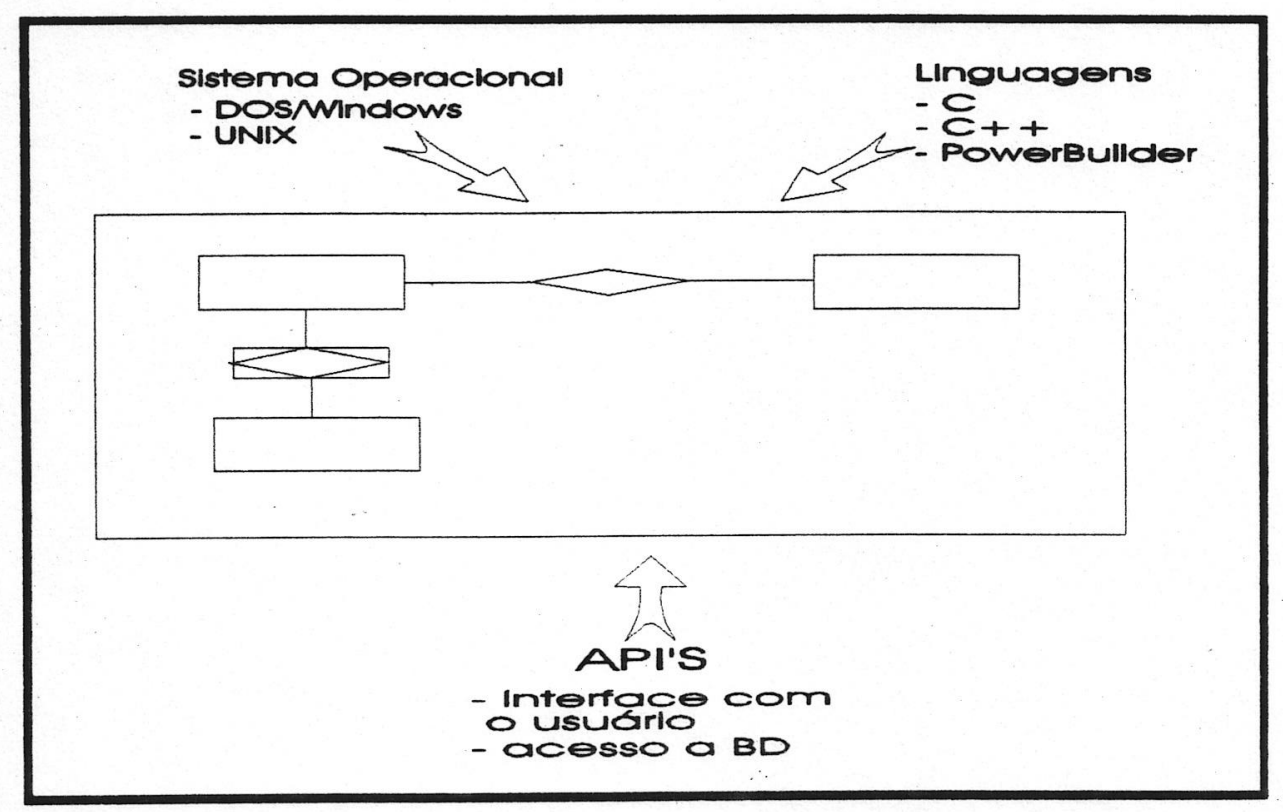

Figura 4.3: Requisitos da Interface

\subsubsection{Base de Dados}

Para a implementação da base de dados é necessário entender em que nível de abstração se encontra a análise para o desenvolvimento da ferramenta. Por se tratar de uma ferramenta que auxilia a construção de modelos, a análise é realizada em um nível "meta", ou seja, é necessário desenvolver um modelo de dados que represente os elementos de um modelo de dados. Em outras palavras, um MER é elaborado para representar os elementos de um MER (Figura 4.4). Neste trabalho, o MER da ferramenta é denominado meta modelo de dados.

Além desta colocação sobre o nível de análise, outro requisito para a base de dados da ferramenta é que a mesma esteja localizada de maneira centralizada. Isto implica que as informações contidas na base de dados da ferramenta possa ser acessada por toda a empresa. Com isso, a utilização de um SGBD para gerenciar a base de dados da ferramenta é de fundamental importância. Por outro lado a utilização de um SGBD em um servidor de rede fornece alguns requisitos que serão abordados na seção 4.4 . 


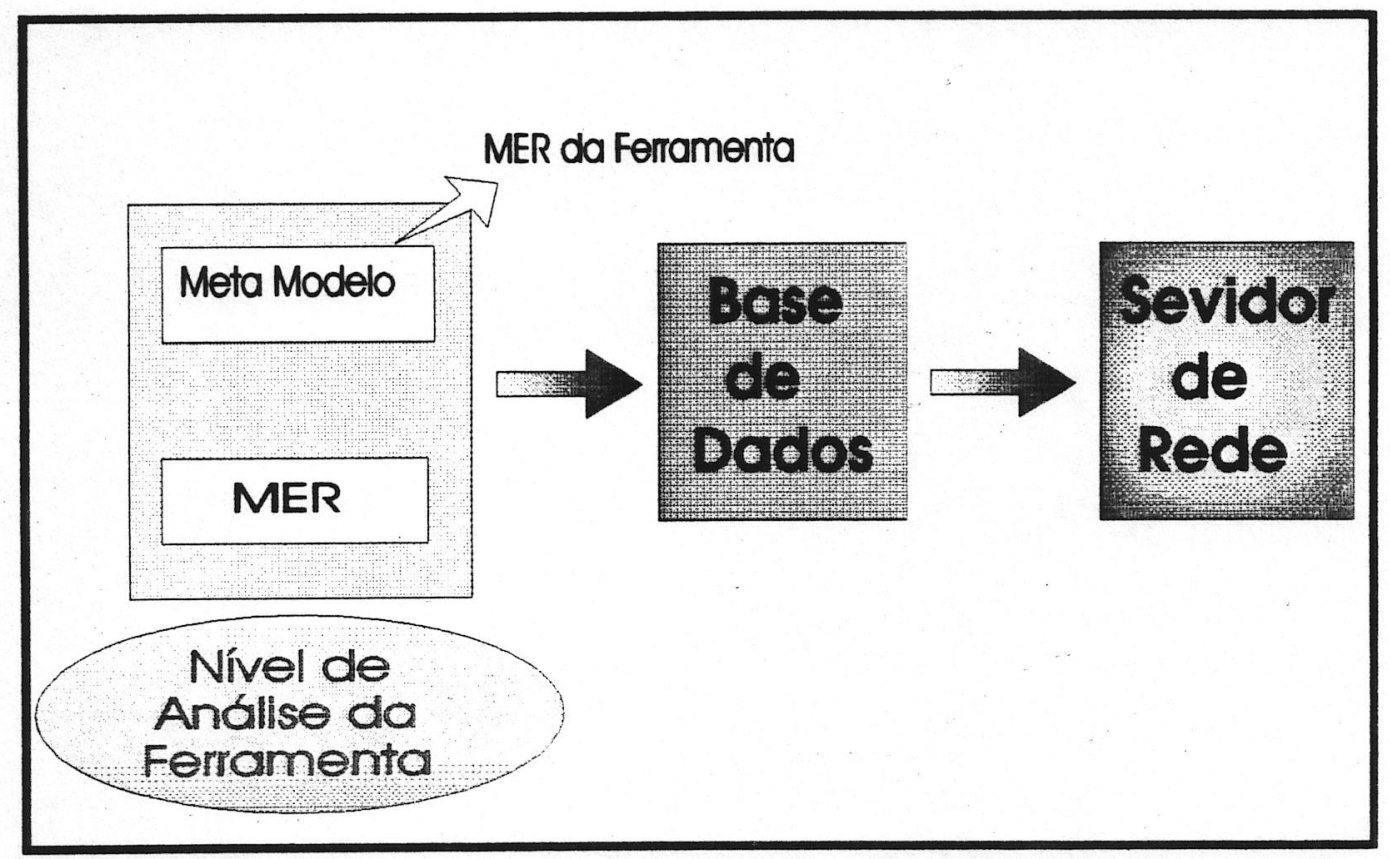

Figura 4.4: Requisitos para a Base de Dados da Ferramenta

\subsubsection{Sistema Baseado em Conhecimento}

Os requisitos para a construção do SBC estão diretamente relacionados com seus componentes (Figura 4.5)

O SBC deve ser um componente independente da ferramenta, ou seja, pode ser acessado diretamente pelo usuário sem interagir com a interface. Desse modo, para que o usuário acesse o SBC é necessário a construção de dois tipos de interface: uma que o SBC interage apenas com a interface da ferramenta e a outra onde o SBC interage diretamente com o usuário.

Como já foi mencionado, o motor de inferência contém os métodos de raciocínio. Quanto maior as variações dos métodos básicos (foward e backward chaining) que podem ser utilizados maior será o número de opções que o engenheiro do conhecimento pode usar para estruturar o Sistema Baseado em Conhecimento. Devido à grande dificuldade de se implementar um motor de inferência, é aconselhável a utilização de um Shell para o desenvolvimento de SBC's. O Shell, além de conter o motor de inferência, fornece modelos para a representação do conhecimento. Dessa forma, um requisito fundamental 
para a construção do SBC é a utilização de um Shell, sendo assim eliminada a necessidade de se construir um motor de inferência.

No entanto, para a aquisição de um Shell é necessário levantar os modelos nos quais o SBC fará a representação do conhecimento. Como o Shell já contém alguns modelos de representação do conhecimento, os mecanismos levantados para a construção do SBC direcionam a escolha do Shell apropriado.

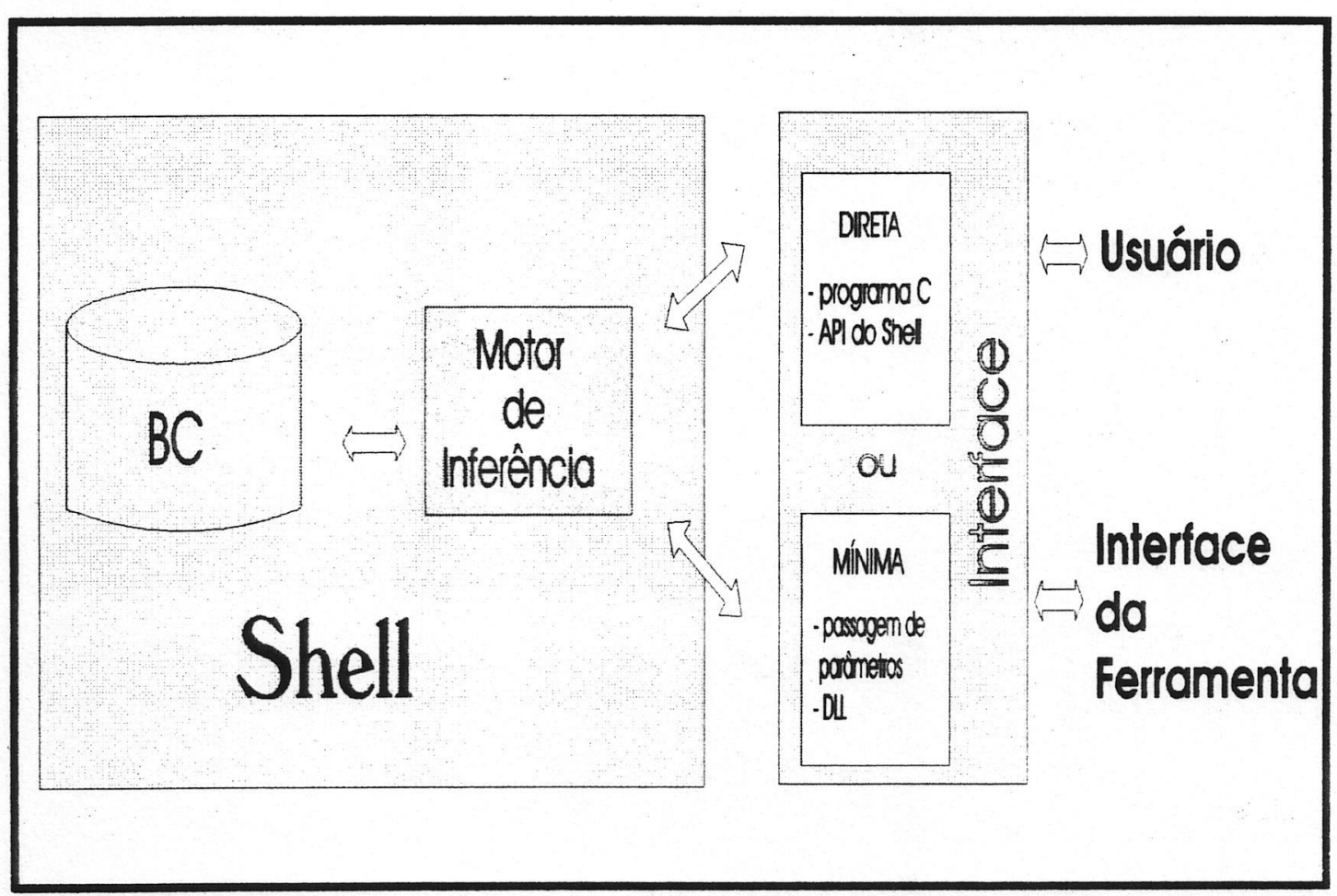

Figura 4.5: Requisitos do SBC

Para a realização das fases envolvidas na Engenharia do Conhecimento (aquisição, representação e validação) é necessária a utilização de uma metodologia que especifique as atividades a serem realizadas em cada uma dessas fases. Com o levantamento da metodologia, pode ser formada uma equipe onde cada elemento pertencente possui determinadas funções dentro das atividades da metodologia.

Os requisitos para a realização destas fases baseiam-se principalmente na interação com um especialista na área de projeto de base de dados. Além de fornecer diretamente o conhecimento do domínio estabelecido, o especilista pode indicar algum material onde são realizadas pesquisas complementares para a aquisição de novos conhecimentos. Deste 
material podem ser levantados alguns modelos de dados já consolidados para a realização da fase de validação.

\subsection{Recursos Computacionais}

Para cada componente da arquitetura da ferramenta foram abordados os recursos computacionais necessários para a sua implementação. Um ponto a ser considerado na escolha destes recursos é que estes suportam a filosofia de sistemas abertos que suporta a integração dos componentes. Os requisitos para a integração entre estes componente pode ser ilustrada na Figura 4.6.

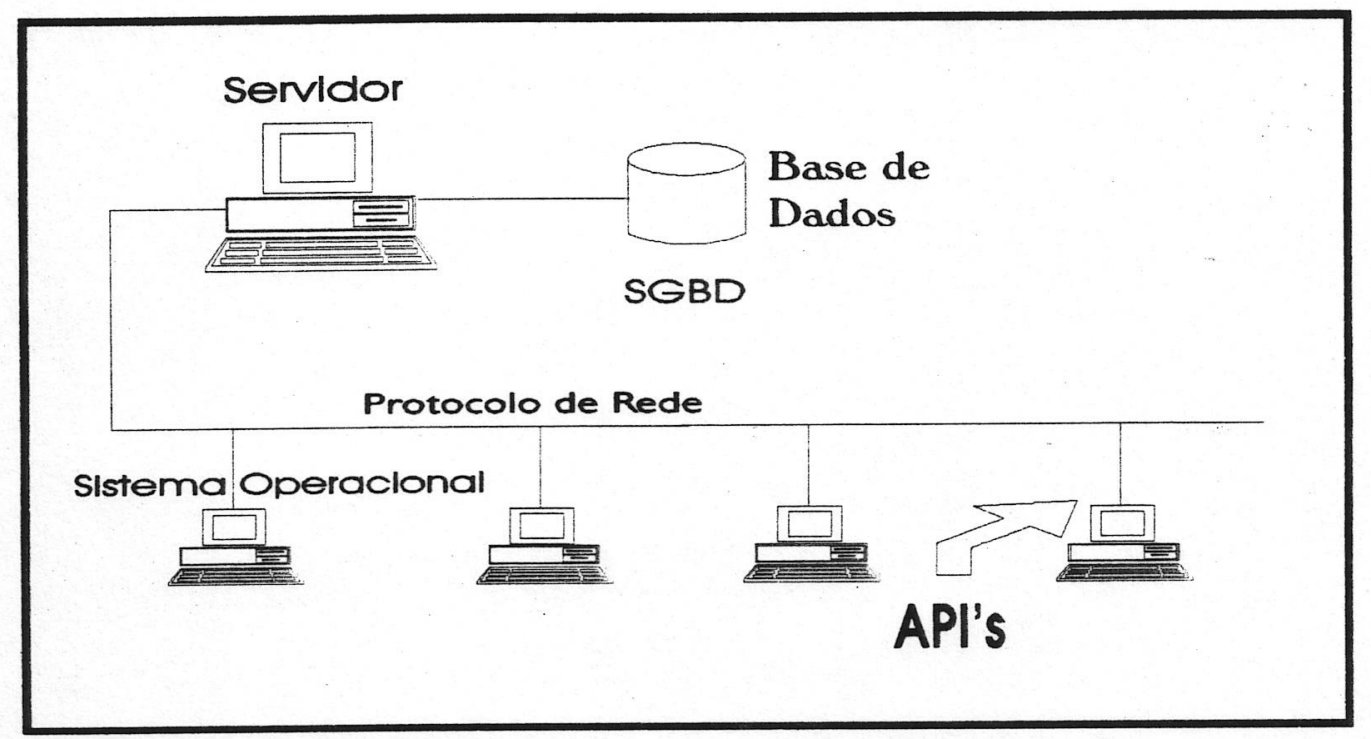

Figura 4.6: Integração dos Componentes da Arquitetura da Ferramenta

O fato do SGBD estar localizado em um servidor de rede fornece alguns requisitos adicionais para a implementação da ferramenta. O mais importante deles é a escolha do sistema operacional que armazenará o SGBD, pois para cada sistema operacional existe um conjunto específico de produtos que podem ser utilizados. $O$ primeiro produto a ser selecionado a partir desta escolha é o protocolo de rede. Conforme a escolha da plataforma, basicamente dois protocolos de redes podem ser utilizados: TCP/IP ou SPX/IPX.

A escolha da plataforma e do protocolo direciona a seleção de outros produtos como as API's de acesso ao banco de dados. Para a integração da interface e do SBC com o 
SGBD, localizado no servidor de rede, é necessário algumas API's dentre as quais podese destacar:

- um produto de interface comum que viabiliza tanto a interface da ferramenta como o SBC acessar o SGBD escolhido;

- um software que possibita a comunicação entre cliente e servidor. Este produto geralmente é fornecido pelo representante do SGBD e possui a função de encapsular as transações com a base de dados no formato do protocolo de rede utilizado.

\subsection{Considerações Finais}

Os requisitos para a construção de uma ferramenta para modelagem de dados envolvem conceitos de: uma metodologia para desenvolvimento da base de dados, uma enciclopédia e recursos computacionais fornecidos pela tecnologia da informação. Para a construção da ferramenta para modelagem de dados, foram abordados os requisitos relacionados com cada componente da arquitetura.

A implementação da ferramenta proposta neste trabalho visa atender os requisitos apresentados neste capítulo baseada em uma concepção geral abordada no próximo capítulo. Além da concepção, o próximo capítulo mostra as metodologias utilizadas e os passos realizados para a implementação da ferramenta. 


\section{CONCEPÇÃO E IMPLEMENTAÇÃO DE UMA FERRAMENTA PARA MODELAGEM DE DADOS}

\subsection{Considerações Iniciais}

De uma maneira geral, a concepção de uma ferramenta para modelagem de dados é baseada nos requisitos levantados no capítulo anterior. Para a realização deste trabalho foi elaborada uma metodologia para o desenvolvimento geral da ferramenta.

O passo inicial foi levantar a funcionalidade de uma ferramenta deva ter para realizar a fase de modelagem de dados, ou seja, foi desenvolvida a concepção. A partir desta concepção iniciou-se o desenvolvimento de cada componente da arquitetura da ferramenta. Para cada componente é mostrado a metodologia e o recurso computacional utilizados em seu desenvolvimento e uma descrição de sua implementação. Além disso, este capitulo apresenta os recursos utilizados para a integração dos componentes e uma visão geral da arquitetura final implementada.

\subsection{Concepção de uma Ferramenta para Modelagem de Dados}

Normalmente, os usuários de uma ferramenta para modelagem de dados são pessoas ligadas à área de desenvolvimento e implantação de aplicativos dentro da empresa. Neste sentido, a elaboração de modelos de dados suporta principalmente a atividade de desenvolvimento dos sistemas de informação.

A implementação de uma ferramenta para modelagem de dados pode apresentar várias funções dependendo dos requisitos levantados. Duas grandes dificuldades de implementação são os recursos para a diagramação e a verificação de consistências.

Caso não seja solicitada uma interface diagramática, não há necessidade de se implementar rotinas que manipulem os objetos de tela ou de se utilizar uma linguagem de desenvolvimento em ambiente windows. Consequentemente, a complexidade para a implementação de um componente da ferramenta diminui em uma grande escala. 
Caso a implementação da verificação automática de consistência dos modelos de dados não seja requisitada, um componente da ferramenta pode ser eliminado (SBC), e com isso esta função de verificação fica sob total responsabilidade do projetista.

No entanto, a concepção geral de uma ferramenta para modelagem de dados, além de apresentar os dois conceitos acima, apresenta uma série de outras funções. Uma ferramenta em ambiente Windows pode apresentar as seguintes opções de trabalho, como mostra o menu principal ilustrado como área de trabalho (Figura 5.1).

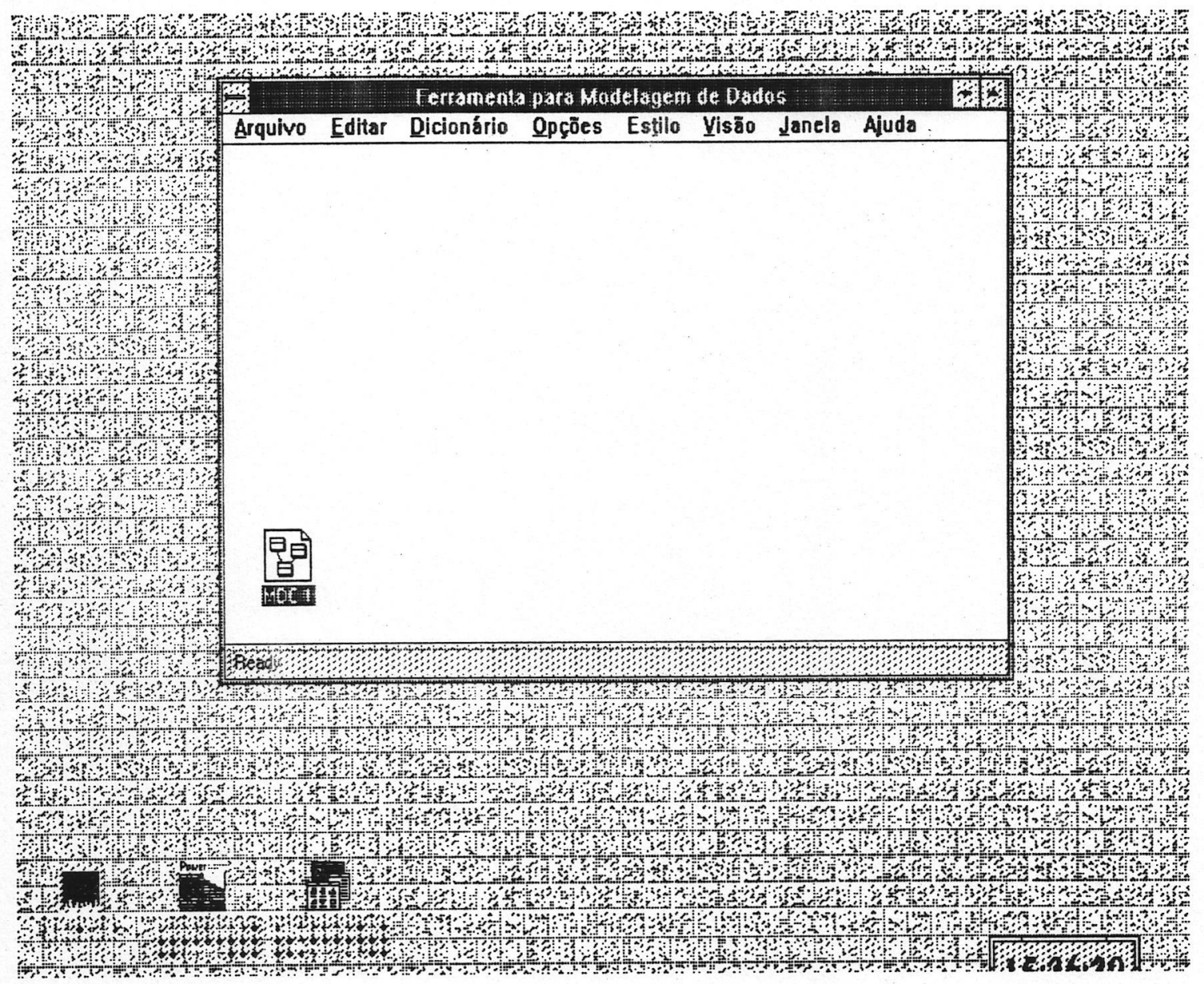

Figura 5.1: Menu Principal de uma Ferramenta para Modelagem de Dados 
As opções do menu principal apresentado na Figura são:

- Arquivo: aqui estão presentes todas as opções para a manipulação de arquivos tais como carregar, deletar, salvar, renomear, entre outros. Além dessas, existem outras funções para impressão de diagramas e relatórios;

- Edição: esta opção está ligada à manipulação dos objetos pertencentes a interface diagramática, ou seja, as entidades, relacionamentos, imagens ("bitmap" que auxiliam a visualização do diagrama), entre outros. As opções de manipulação são: deleção, cópia e mudança de localização;

- Dicionário: esta opção está relacionada à definição dos modelos de dados e seus respectivos atributos, entidades e relacionamentos de uma forma não diagramática. Além dessas definições, a checagem de consistências do modelo e geração do modelo lógico para o modelo relacional estão presentes nesta opção do menu principal;

- Opções: fornecem os recursos semelhantes ao de um software gráfico. Estes recursos seriam para agrupar, esconder e proteger os objetos da interface diagramática;

- Estilo: esta opção define os estilos dentro do diagrama tais como tamanho, tipo e cor de letras, definição de cores dos objetos, e opções para mostrar ou não os nomes dos objetos;

- Display: esta opção é para a manipulação da visualização do diagrama;

- Janela: esta opção é para a manipulação das janelas que contêm os diagramas, ou seja, a ferramenta pode ter mais de um diagrama na memória onde cada um estaria em janelas separadas. A manipulação refere-se à alteração dos atributos da janela e visualização de mais de uma janela ao mesmo tempo;

- Ajuda: esta opção contém informações sobre a utilização da ferramenta.

Como pode ser observado, grande parte das opções do menu principal está relacionada aos recursos para diagramação. Neste sentido, a decisão sobre a interface diagramática é estratégica na elaboração da metodologia de desenvolvimento da ferramenta.

Dentro do conceito de enciclopédia, uma outra grande funcionalidade é a integração com outros tipos de modelos tais como Diagrama de Fluxos de Dados, SADT ("Structured Analisys and Design Technique"), diagramas orientados a objetos, entre outros. No contexto de Integração das Empresas de Manufatura, onde o desenvolvimento integrado 
de sistemas de informação é de vital importância, este tipo de ferramenta que verifica a consistência entre diferentes tipos de modelos tornou-se um recurso poderoso para esta finalidade. Neste sentido, a ferramenta para modelagem de dados deve fornecer meios para a integração com diferentes modelos.

No entanto, o processo de desenvolvimento de uma ferramenta envolvendo outras metodologias requer um grupo de pessoas especializadas nas mesmas. Além do domínio das metodologias, existe a necessidade de programadores qualificados para a implementação dos elementos correspondentes aos diagramas.

Apresentada a concepção de uma ferramenta para modelagem de dados, a próxima seção refere-se a uma visão geral do desenvolvimento da ferramenta deste trabalho.

\subsection{Visão Geral do Desenvolvimento da Ferramenta}

Baseado no capítulo anterior, proponho uma ferramenta para modelagem de dados composta de três componentes bem definidos: base de dados, interface e SBC. O desenvolvimento de cada componente foi suportado pela elaboração de um meta modelo de dados (Figura 5.2). O meta modelo é essencial para o desenvolvimento da base de dados pois constitui-se no MER da ferramenta. Com relação aos outros componentes, será descrita a influência deste meta modelo nos respectivos processos de desenvolvimento. Dessa forma, o meta modelo tornou-se um documento fundamental pois constituiu-se o elo de ligação entre as pessoas do grupo de desenvolvimento do protótipo.

O desenvolvimento dos componentes ocorreu de forma paralela pois, como mencionado, houve a formação de um grupo de pessoas para esta atividade. Vale ressaltar que a base de dados comum só foi implementada depois da instalação do SGBD no servidor de rede do laboratório onde foi desenvolvido este trabalho (LAMAFE). Antes da instalação do SGBD, tanto a interface como o SBC acessaram base de dados próprias mas com a mesma configuração gerada a partir do meta modelo de dados. 


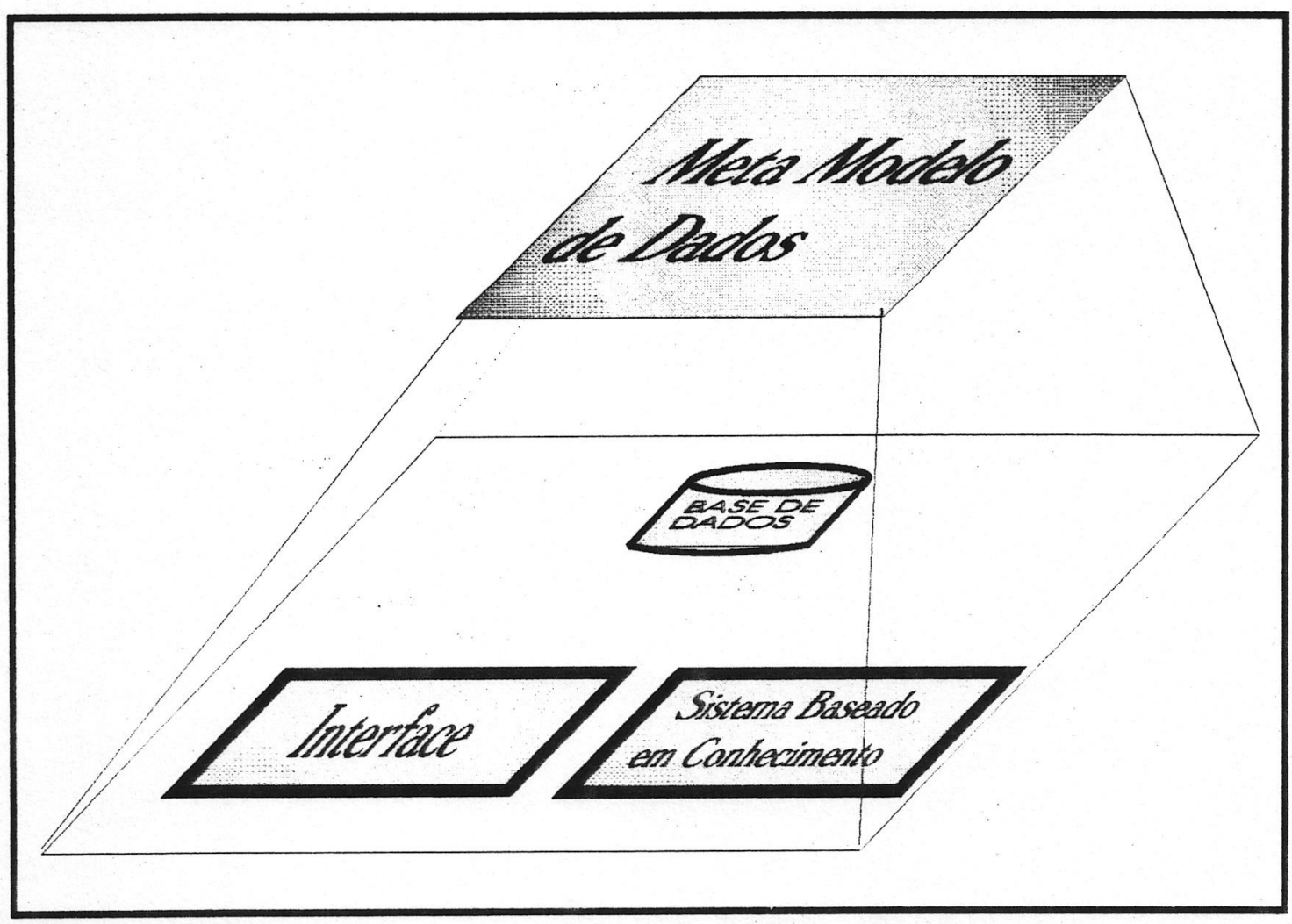

Figura 5.2: Processo Geral do Desenvolvimento da Ferramenta

O restante deste capítulo descreve o desenvolvimento de cada componente da ferramenta, os recursos computacionais utilizados e a arquitetura final implementada

\subsection{Desenvolvimento da Ferramenta}

No processo de desenvolvimento de cada componente foram utilizados softwares comerciais de grande porte como um SGBD corporativo, um Shell para construção de Sistemas Baseados em Conhecimento e uma ferramenta portável entre sistemas operacionais para a interface da ferramenta. Da seção 5.4.1 até a 5.4.3 são mostrados os processos de cada componente abordando as metodologias utilizadas e uma descrição da implementação, incluindo os softwares utilizados. A seção 5.4 .4 aborda os recursos levantados para viabilizar a integração entre os componentes. 


\subsubsection{Base de Dados}

Como já foi dito, o meta modelo de dados corresponde ao MER da ferramenta. Dessa forma, o componente que depende diretamente da sua elaboração é a base de dados, e por isso será o primeiro a ser apresentado. Esta seção aborda a metodologia utilizada para elaborar o meta modelo de dados e o processo de implementação da base de dados.

\subsubsection{Metodologia Utilizada para a Representação do Meta Modelo}

Para a construção do meta modelo foi necessário selecionar um modelo lógico baseado em objetos (uma classificação foi mostrada no capítulo 3) capaz de representá-lo. Este modelo teria que fornecer meios para viabilizar a representação de uma metodologia para desenvolvimento de modelos de dados. O resultado desta seleção foi a utilização do MER, que consiste na técnica mais utilizada para modelagem lógica de dados. O nível de semântica do MER é elevado pois permite representar um alto nível de abstração nos relacionamentos entre as entidades.

Atualmente são metodologias que utilizam o MER com algumas extensões para uma melhor representação do mundo real, em termos de dados. No campo de desenvolvimento de sistemas, essas extensões abstraem alguns conceitos utilizados em orientação a objetos tais como generalização, composição e agregação.

Para a representação do meta modelo foi utilizado o MER sem qualquer extensão, ou seja, foram utilizados apenas os conceitos iniciais estabelecidos por Peter Chen [CHEN90]. No entanto, a representação deste meta modelo permite a elaboração de modelos de dados que contenham abstrações de generalização, composição e agregação.

Após a elaboração do meta modelo de dados, iniciou-se o processo de implementação da base de dados, que é abordada na seção 5.4.1.3. Para viabilizar esta implementação foi necessário adquirir conhecimento sobre o SGBD, incluindo a sua instalação.

A próxima seção apresenta o meta modelo de dados elaborado na forma de um MER com a descrição de seus atributos e o elo de ligação para outras ferramentas que atuam em modelagem de processos. 


\subsubsection{O Meta Modelo de Dados Desenvolvido}

O meta modelo de dados elaborado contém uma representação das entidades relevantes a um MER. Este nível de abstração é complexo, uma vez que foi elaborado um MER para representar MER Extendido. Dessa forma, existe uma entidade para descrever entidades, outra para descrever relacionamentos e assim por diante. A Figura 5.4 ilustra o meta modelo de dados elaborado.

Como pode ser visto na Figura 5.3, todas as entidades são relacionadas à elaboração de um MER, com exceção de duas: informação e associa_dados. Estas entidades são relevantes para construção de modelos de processos nos quais há uma associação das informações com os processos que as utilizam. $\mathrm{O}$ elo de ligação entre o modelo de dados e o modelo de processos é a entidade atributos, que corresponde aos dados das informações. Como este trabalho não verifica consistências com outros tipos de modelos, essas entidades não foram detalhadas, e o interesse na sua descrição foi apenas o de ressaltar a ligação com o modelo de processos.

A fase de normalização do meta modelo de dados apresentou dificuldades para viabilizar a representação de relacionamentos envolvendo mais de duas entidades. A solução encontrada foi a descrição de duas entidades: relacionamento que descreve o tipo de relacionamento entre as entidades e ent_rel que determina as entidades envolvidas no relacionamento $\mathrm{O}$ restante das entidades do meta modelo não apresentou maiores dificuldades para a obtenção da terceira forma normal. O meta modelo de dados normalizado é o seguinte:

entidade (codigo entidade, nome, numero, normalizada, agregação, descrição) relacionamento (codigo_relação, nome, tipo, descrição)

atributo (codigo_atributo, nome, codigo_dominio, opcional)

sinonimo (codigo_atributo, codigo_sinonimo, nome_sinonimo, descrição)

dominio (codigo_dominio, nome, codigo_valor, tipo_elementar, descrição, maxval, minval, tamanho, precisão)

lista_valores (codigo_atributo, valor)

modelo (codigo modelo, nome, descrição) 
ent_rel (codigo_relação, codigo_entidade, auto, dependencia, cardinalidade, opcional)

De acordo com as regras de derivação para o modelo físico, a partir dos relacionamentos do tipo m:n são geradas algumas tabelas de relacionamento que não foram representadas no modelo. As tabelas de relacionamentos e seus atributos são:

mod_ent (codigo_modelo, codigo_entidade)

mod_rel (codigo_modelo, codigo_relacao)

atri_ent (codigo_atributo, codigo_entidade, chave_primária, chave_estrangeira)

atri_rel (codigo_atributo, codigo_relacao)

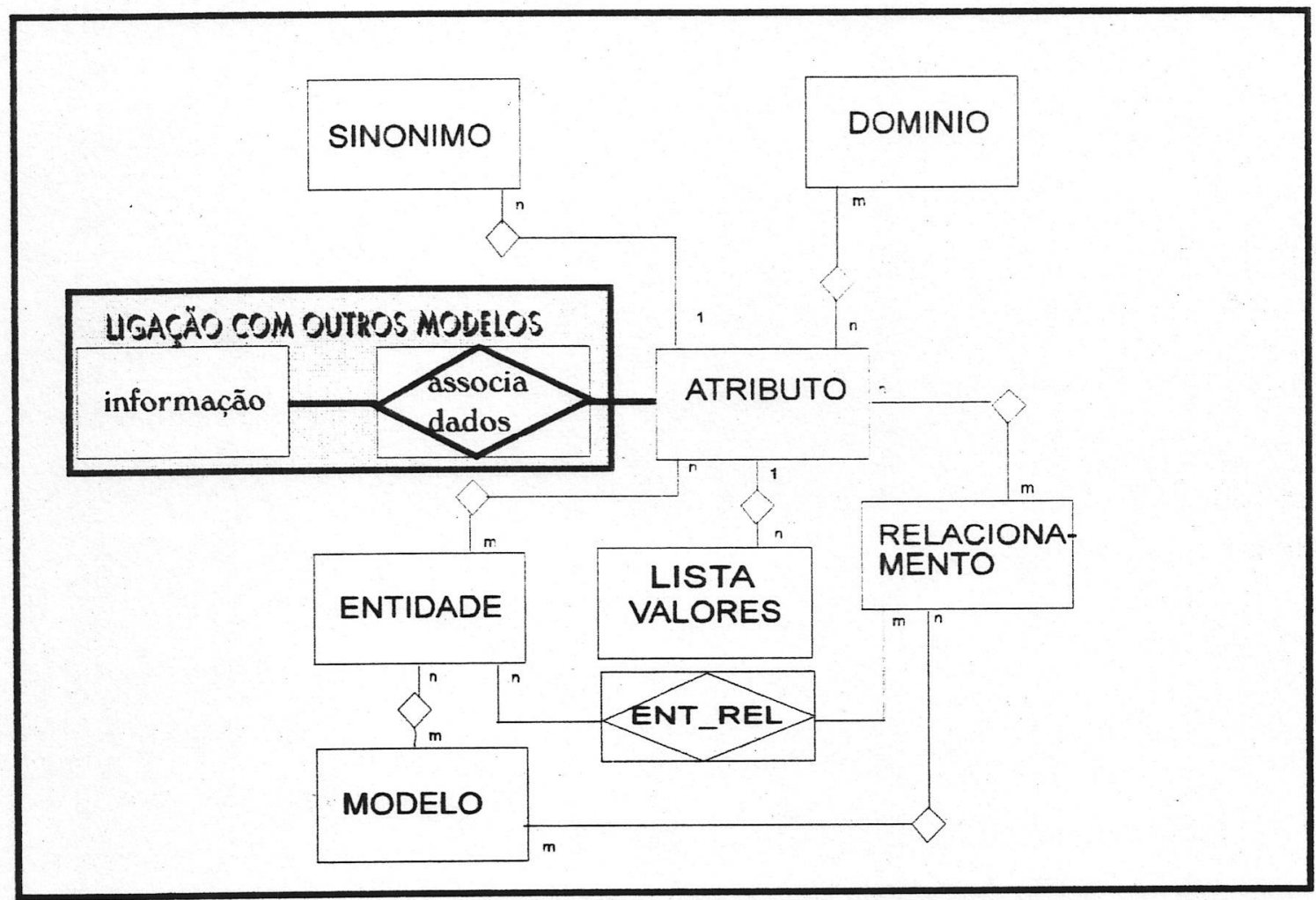

Figura 5.3: Meta Modelo de Dados

Como pode ser observado na Figura 5.3 e na descrição dos atributos do meta modelo, grande parte de suas entidades (tais como domínio, sinônimo, valores, entidade, entre outras) estão relacionadas com a entidade atributo. Isto se deve ao fato que os atributos 
suportam as informações que fluem na empresa, e dessa maneira têm que ser muito bem definidos. Isto reflete a importância que os dados (atributos) possuem para a empresa e justifica a afirmação apresentada no capítulo 3 de que o dado deve ser tratado como um recurso da empresa.

Como o MER possui um alto nível de semântica, os conceitos de generalização/especialização, composição e agregação estão associados com a abstração representada no relacionamento entre as entidades. Para representar esses conceitos, foi necessário incluir um atributo "tipo" na entidade relacionamento para determinar qual conceito está sendo utilizado. Como já foi dito, a entidade ent_rel indica quais entidades do modelo estão envolvidas nos relacionamentos.

\subsubsection{Implementação da Base de Dados}

A implementação da base de dados da ferramenta foi feita a partir da descrição do meta modelo apresentado. De acordo com as regras de derivação apresentadas no capítulo 2, foram geradas tabelas a partir das entidades pertencentes ao MER. Novamente vale ressaltar que para as entidades informação e associa_dados não foram geradas tabelas, pois para este trabalho não foi levada em consideração a implementação desta ligação.

Para a geração das tabelas, foi necessário a criação de um arquivo que contém os comandos de definição de dados (Definition Data Language -- DDL, Anexo A). O SGBD utilizado para a implementação da base de dados é o Oracle V7.0.12 e, com isso, a DDL utilizada contém comandos específicos desse SGBDR. Após a instalação do Oracle, um usuário com privilégios de DBA (Database Administrator) foi cadastrado para criação e manutenção da base de dados da ferramenta. Dessa forma, com a utilização da senha do usuário citado acima, foi carregado para o Oracle o arquivo que contém a definição das tabelas.

Atendendo aos requisitos da ferramenta, o Oracle foi instalado no servidor de rede. Para viabilizar a comunicação através da rede foi utilizado um produto (SQL*Net) também fornecido pela Oracle, o qual é instalado tanto no servidor como nas estações. Este produto será descrito na seção 5.4.4.3. Os privilégios dos usuários que acessam as tabelas da base de dados da ferramenta são de leitura e escrita ("connect"), não sendo permitido criar ou deletar as tabelas da base de dados da ferramenta. 
O Oracle, fornece soluções eficientes para o gerenciamento da informação, e as suas características atendem aos requisitos citados no capítulo 2. Algumas delas que podem ser ressaltadas são:

- suporte a bases de dados com potencial de centenas de gigabytes;

- suporte a um elevado número de usuários concorrentes executando uma variedade de aplicações sobre os mesmos dados;

- trata-se de um sistema aberto pelo fato de aderir aos padrões industriais em relação a linguagem de acesso a dados, sistemas operacionais, interfaces para o usuário e protocolos de rede para comunicação;

- garantia de integridade de dados através de "business rules" (regras de negócios), que ditam os padrões de dados aceitáveis;

- fornece a tecnologia de banco de dados distribuídos;

- portabilidade sobre os diferentes sistemas operacionais;

- compartilhadamento de informações entre diferentes tipos de computadores e sistemas operacionais através de redes.

O SGBDR Oracle ainda possui diferentes produtos tais como precompiladores, drivers de rede, CASE, automação de escritórios, entre outros. Com isso, o SGBDR Oracle constitui-se em uma solução que atende a grande parte dos requisitos de gerenciamento das informações de uma empresa.

\subsubsection{Interface}

Para a construção da interface da ferramenta foi utilizada a metodologia de projeto funcional associado a diagramas de eventos, abordado na seção 5.4.2.1. A seção 5.4.2.2 apresenta, além do sistema operacional e da linguagem utilizada, uma descrição da implementação dos elementos da interface e da definição das estruturas de dados. Para mostar a funcionalidade da ferramenta para modelagem de dados, na seção 5.4.2.3 é apresentado o menu principal da mesma. Na seção 5.4.2.4 é apresentada uma descrição da implementação dos recursos para a diagramação. 


\subsubsection{Metodologia Utilizada para o Desenvolvimento da Interface}

A primeira etapa no desenvolvimento da interface foi a construção do projeto funcional, onde é determinada a sequência de telas da ferramenta. Para realizar este projeto funcional, algumas ferramentas de modelagem de dados disponíveis no mercado foram analisadas com o objetivo de levantar a funcionalidade de uma interface diagramática. Entre as ferramentas observadas estão S-Designor, System Architect, Bachman e Easy*Case. De acordo com o resultado desta análise, foram levantados os requisitos para uma interface diagramática apresentados no capítulo anterior e a base para que se realizasse o projeto funcional da ferramenta.

No projeto funcional foram descritas as telas que a ferramenta suporta para a entrada dos elementos de um modelo de dados (Figura 5.4). Dentro desta fase, um grande tempo foi consumido para especificar a funcionalidade de uma interface diagramática. Para tanto, foi necessário desenvolver um diagrama de eventos que controla os dispositivos para entrada de dados (teclado + mouse), ou seja, para manipular os objetos contidos nos diagramas em tela são utilizados eventos que por sua vez são acionados pelos periféricos de entrada.

Existem dois tipos básicos de telas suportados pela ferramenta, acionadas a partir do menu principal. Um tipo é para entrada de dados na forma não diagramática (caixas de diálogo), tanto para elementos do modelo de dados como para descrição de outros recursos, tais como impressão de relatórios, renomeação de aquivos, entre outros. $\mathrm{O}$ outro tipo corresponde a uma tela que contém os recursos para a diagramação, à qual é associado um diagrama de eventos mais elaborado. A partir desta tela são acionadas outras telas, não diagramáticas, para a descrição dos elementos do modelo de dados.

Após a definição do projeto funcional, partiu-se para escolha da linguagem de desenvolvimento para a implementação da ferramenta. A próxima seção apresenta o processo de implementação da ferramenta, abordando as características do sistema operacional e da linguagem de desenvolvimento utilizados. 


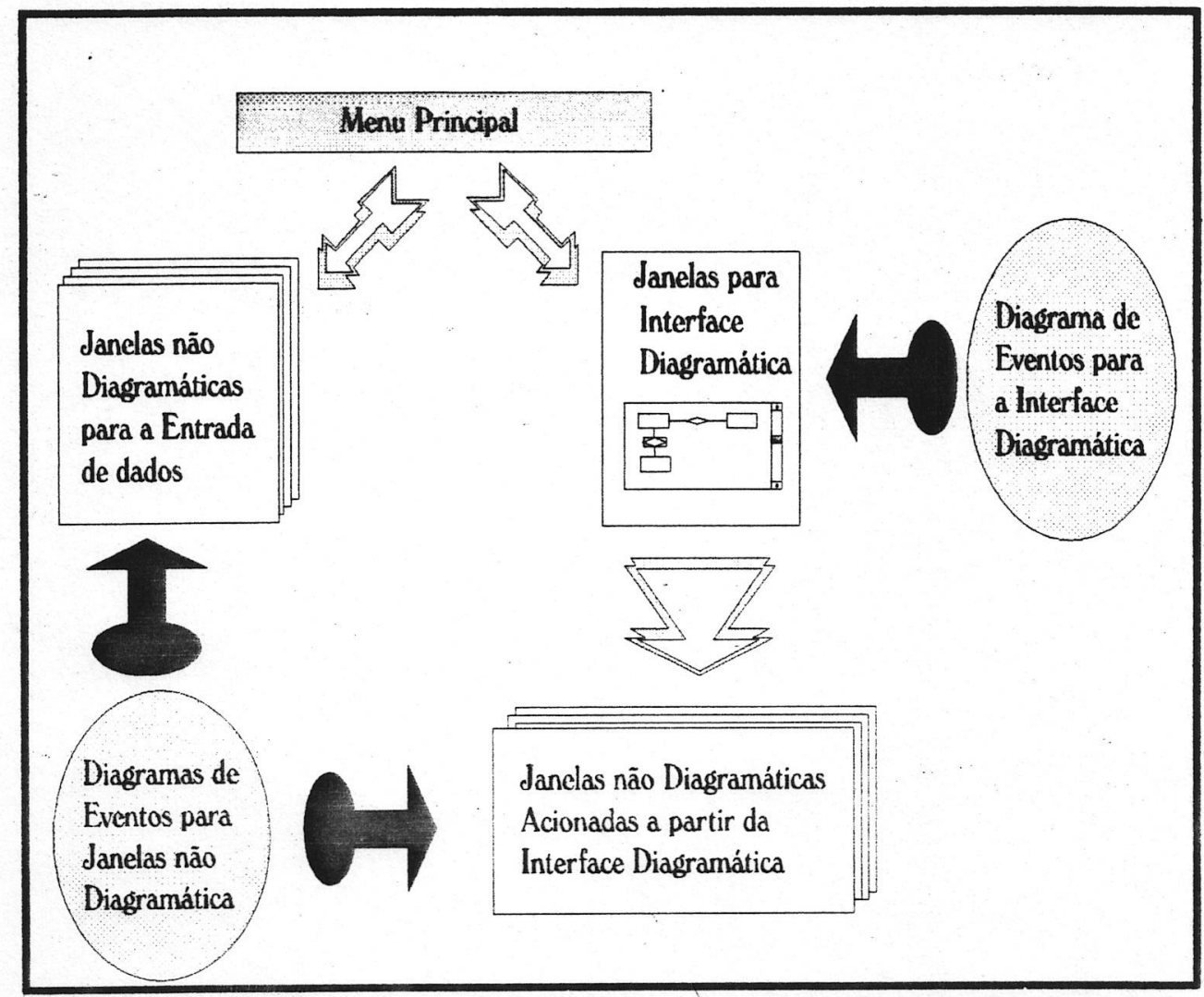

Figura 5.4: Projeto Funcional da Ferramenta

\subsubsection{Implementação da Interface}

O sistema operacional escolhido para a implementação da interface foi o DOS/Windows. Algumas justificativas para esta escolha são: a maioria das ferramentas analisadas apresentam uma versão neste ambiente, facilidade na aquisição de uma linguagem para o desenvolvimento de sistemas, recursos poderosos para a implementação de sistemas, entre outros. Algumas das caraterísticas largamente usadas pelas linguagens neste ambiente são a facilidade para geração de menus, manipulação de janelas e a utilização do padrão ODBC de acesso a diferentes SGBD's.

Os principais elementos da interface implementados utilizando-se destas características são: 
- menus: estes são responsáveis pelas operações principais requeridas pelo usuário. Existe apenas dois níveis de menu: o principal, que aparece horizontalmente na janela principal, e os submenus, que são acionados a partir de cada opção do menu principal;

- ambiente de trabalho: é a janela principal da aplicação onde é realizada a elaboração diagramática dos modelos de dados. Podem existir no máximo 2 ambientes de trabalho abertos ao mesmo tempo;

- caixa de ferramentas: é uma janela filha que "flutua" em cada janela de diagrama. Funciona como uma caixa de ferramentas ("toolbox") para que o usuário possa escolher sua opção para a modelagem. As opções contidas nesta janela são descritas na seção 5.4.3.4;

- caixas de diálogo: são janelas filhas utilizadas para entrada de dados de uma forma não diagramática. Este tipo de janela corresponde a um dos tipos básicos de telas abordados na seção 5.4.2.1;

Outro recurso importante fornecido por este sistema operacional são as barras de rolagem ("scrollbars"). Estas são utilizados nas janelas diagramáticas onde o usuário pode rolar seu ambiente de trabalho para visualizar o modelo de dados além dos limites da tela.

Antes da implementação destes elementos da interface, foi realizada a definição das estruturas de dados a serem manipuladas pelos mesmos. A dependência da interface em relação ao meta modelo de dados baseia-se justamente nesta definição, onde para cada entidade foi implementada uma estrutura de dados correspondente. Devido à característica de diagramação da interface, foram incluídos alguns campos nas estruturas que identificam a posição relativa dos objetos na janela. Estes campos são utilizados pelas rotinas disparadas pelos eventos, cujo objetivo é a manipulação visual dos elementos da janela diagramática.

Para a implementação desses recursos, foi utilizada a ferramenta de desenvolvimento PowerBuilder Enterprise Edition. Para alguns autores, é considerada a principal ferramenta para desenvolvimento de aplicativos cliente/servidor no ambiente Windows. No entanto, a principal característica considerada é que esta ferramenta permite uma rápida prototipação, atendendo os requisitos para a implementação deste trabalho.

Uma grande vantagem na utilização desta ferramenta está no fato de fornecer interfaces para a maioria dos servidores de base de dados, além de prover suporte para ODBC 
(descrito no capítulo 2). Além disso, o PowerBuilder fornece uma interface direta com SGBD Oracle, cuja performance é melhor. Neste sentido, optou-se pela utilização da interface para acessar a base de dados da ferramenta para modelagem de dados.

O PowerBuilder é orientado a eventos, ou seja, monitora constantemente os periféricos de entrada acionando as rotinas da ferramenta para modelagem de dados. De acordo com o projeto funcional, esta característica foi considerada fundamental na escolha da ferramenta para desenvolvimento.

Outra característica relevante do PowerBuilder é que os elementos da interface tais como menus, janelas, barras de rolagem, entre outros recursos, têm a concepção de composição. Em outras palavras, para cada ambiente de trabalho existe uma caixa de ferramentas e várias caixas de diálogo para a entrada dos elementos dos modelos de dados.

\subsubsection{Descrição do Menu Principal da Ferramenta para Modelagem de Dados}

Na seção 5.2 foi apresentada a concepção de uma ferramenta para modelagem de dados, e foi descrito um menu principal com várias opções representando sua funcionalidade. No desenvolvimento deste protótipo, foram implementadas algumas das opções apresentadas, ilustradas na Figura 5.5. A opção que aciona o sistema baseado em conhecimento é a checagem do modelo, dentro de dicionário.

Com a implementação destas opções; acredita-se que a ferramenta forneça grande parte da funcionalidade apresentada na concepção de uma ferramenta para modelagem de dados. 


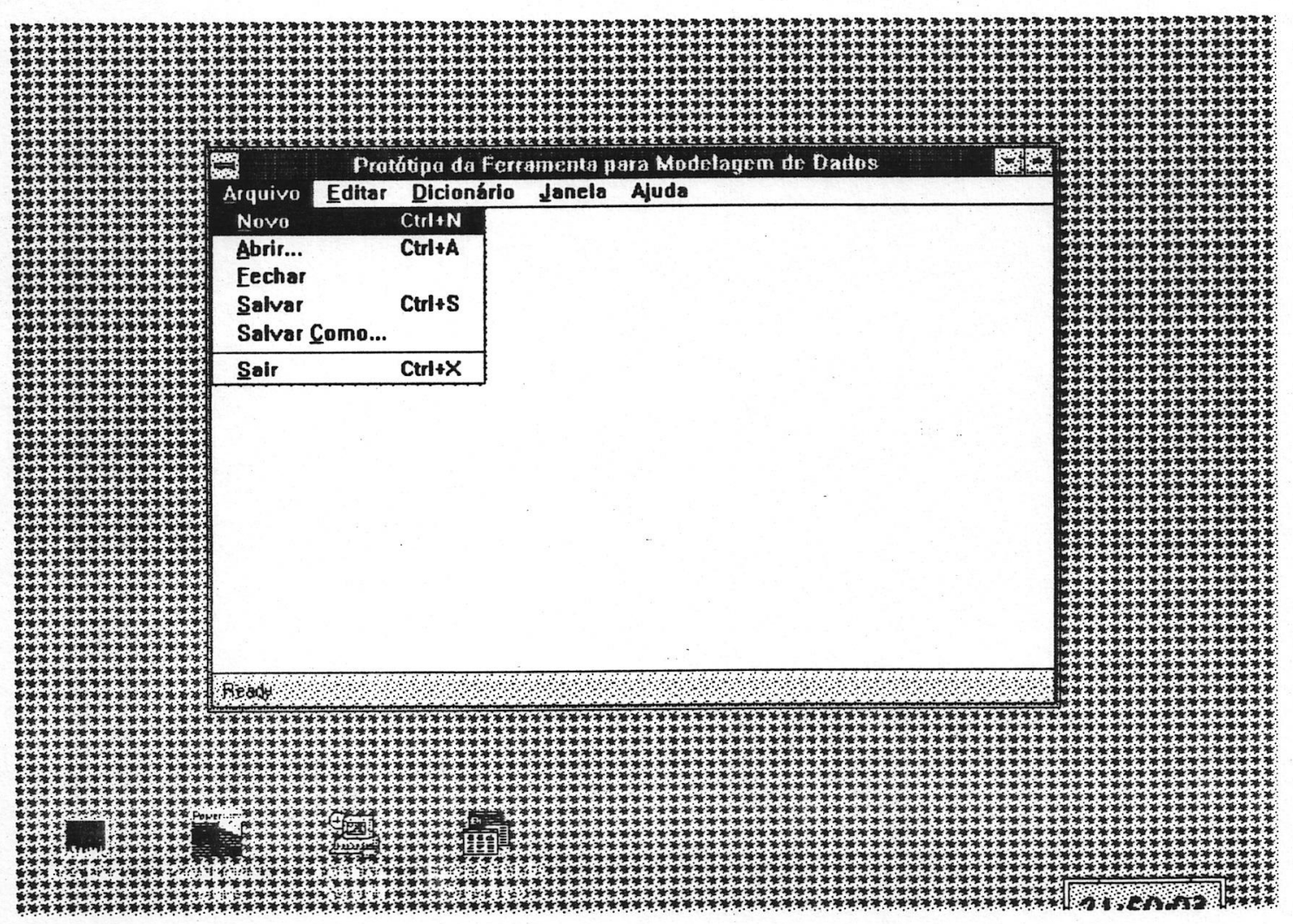

Figura 5.5: Menu Principal da Ferramenta.

\subsubsection{Interface Diagramática}

Entre os recursos implementados na interface, o ambiente de trabalho constituiu-se no mais importante, pois nele é feita a digramação dos modelos de dados, e a partir dele são acionados tanto a caixa de ferramentas quanto as caixas de diálogo.

No ambiente de trabalho foram definidos objetos de interface correspondentes a cada elemento de um modelo de dados, ou seja, um objeto para representar entidade, outro para representar relacionamento, e assim por diante. A notação utilizada para representar graficamente o modelo de dados foi a de Bachman, com algumas modificações para representar as extensões citadas anteriormente. A caixa de ferramentas, descrita a seguir, possui todos os objetos que podem ser representados em um modelo de dados baseado nesta ferramenta.

Como já foi dito, esta ferramenta manipula até dois modelos de dados simultaneamente. Outra restrição está relacionada ao número de entidades que cada ambiente de trabalho 
deve ter: no máximo trinta, devido a limites de tempo de execução apresentados pelo PowerBuilder.

Para cada ambiente de trabalho existe uma caixa de ferramentas que manipula o respectivo modelo. Para a criação de um MER, o usuário deve inicialmente abrir um ambiente de trabalho (janela vazia). Com o ambiente pronto para receber informações, deve-se, então, iniciar a criação do MER propriamente dito. Para isso é essencial o uso da caixa de ferramentas, que "flutua" na janela principal da aplicação. Um ítem da caixa de ferramentas deve ser selecionado e então a operação sobre o modelo em questão pode ser alcançada. A seguir estão os ítens da caixa de ferramentas e suas respectivas funções (Figura 5.6):

1. seta: a mais importante no sentido de organização diagramática do modelo. Com esta ferramenta é possível marcar qualquer elemento do modelo e modificá-lo (tamanho, posição, atributos, etc);

2. entidade: para a criação de uma entidade;

3. relacionamento comum: para a criação de um relacionamento entre duas entidades;

4. agregação: para a criação de um relacionamento agregado entre duas entidades;

5. generalização: para a criação de relacionamentos que indicam processos de generalização/especialização entre duas ou mais entidades;

6. composição: para a criação de relacionamentos que indicam processos de composição entre duas ou mais entidades;

Com a utilização sucessiva desta caixa de ferramentas, o usuário elabora um modelo de dados referente a alguma área da empresa. Para verificar se o modelo elaborado está consistente, aciona-se a opção checagem do modelo, abordada na seção anterior. Após a inferência, o resultado da verificação é apresentado em uma janela do ambiente de trabalho sendo utilizado. A próxima seção aborda a construção deste SBC. 


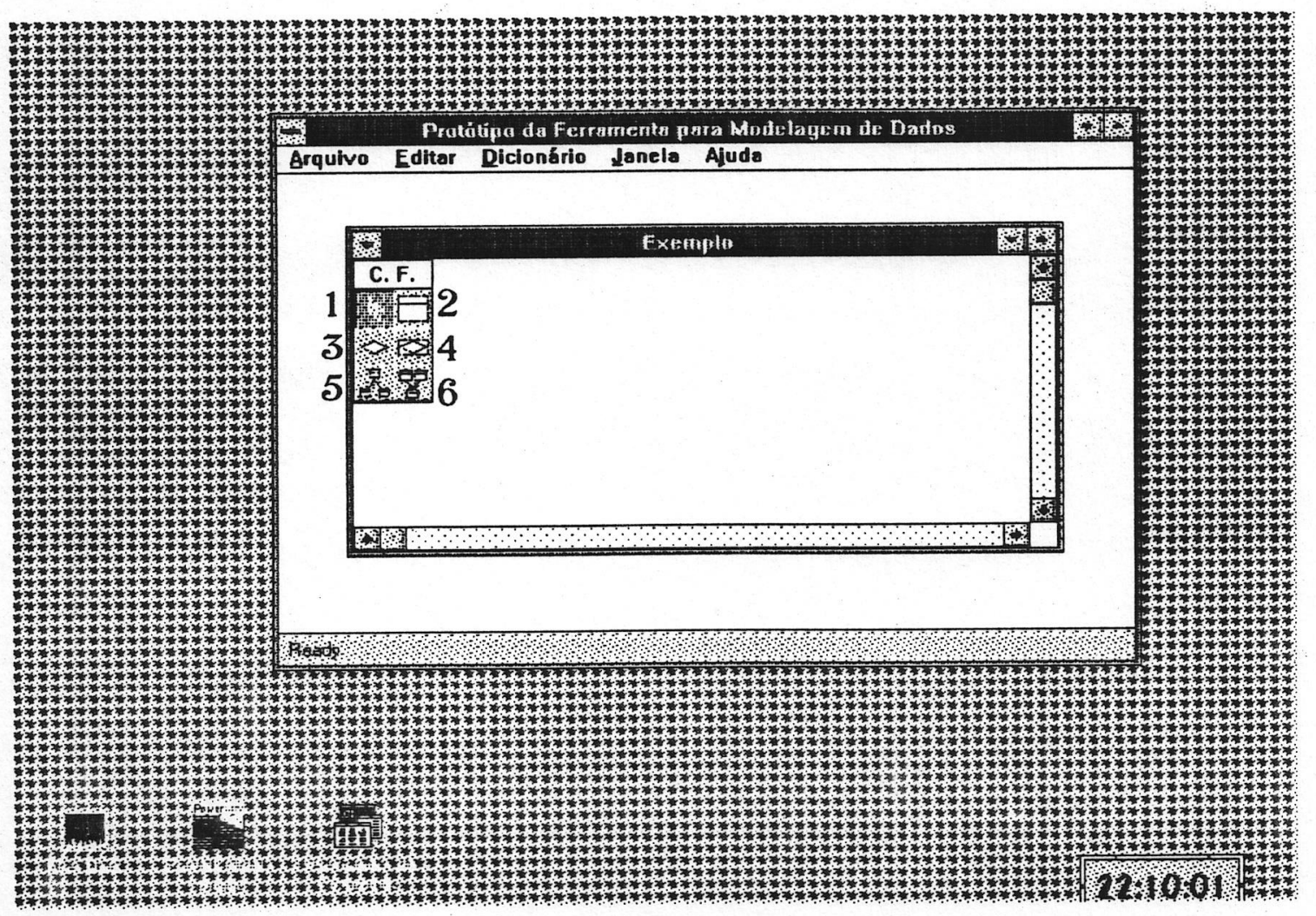

Figura 5.6: Caixa de Ferramenta Representando os Elementos de um Modelo de Dados

\subsubsection{Sistema Baseado em Conhecimento}

O componente responsável pela verificação de consistências dos modelos de dados cadastrados pela ferramenta é um SBC. Como já foi mencionado, estes sistemas diferem dos sistemas convencionais pelo fato de representar e manipular o conhecimento.

O passo inicial para o desenvolvimento deste componente foi a identificação das características envolvidas no domínio do conhecimento em questão, onde também foi verificada a validade da construção do mesmo (seção 5.4.3.1). A seção 5.4.3.2 apresenta a metodologia adotada para construção deste componente da ferramenta. As seções 5.3.4.3 e 5.3.4.4 apresentam o processo de implementação resultante da metodologia adotada. 


\subsubsection{Identificação das Características}

Um passo importante no processo de construção de um SBC é a identificação das caraterísticas do domínio do conhecimento. A partir deste levantamento, é realizada uma avaliação para verificar a real necessidade de se utilizar a tecnologia de SBC para o domínio em questão. No caso do desenvolvimento deste trabalho, as justificativas encontradas para a construção do SBC foram:

- o domínio foi bem limitado às fases de projeto conceitual e projeto lógico da metodologia para desenvolvimento de base de dados;

- existe a necessidade de retenção do conhecimento relacionado ao projeto de base de dados, devido a existência de uma certa rotatividade de pessoas responsáveis por esta área;

- a falta de um projetista com experiência pode afetar a eficiência do SGBD sendo utilizado, uma vez que modelos de dados mal elaborados afetam a performance desses recursos.

Como o objetivo deste SBC é indicar inconsistências em modelos de dados, o seu domínio de conhecimento pode ser classificado como diagnose e/ou aconselhamento, pois o sistema oferece soluções para as inconsistências encontradas. Para a representação do conhecimento foram utilizados regras de produção e conceitos de orientação a objetos pois o shell disponível para a implementação do SBC possui estes esquemas de representação, o que torna possível a atuação nos domínios de conhecimentos citados acima..

\subsubsection{Metodologia Utilizada para a Construção do SBC}

A metodologia utilizada para a construção do SBC é ilustrada na Figura 5.7, onde pode ser observado um ciclo de vida no qual o ponto de partida é a aquisição do conhecimento.

Como foi apresentado no capítulo 3 , quando a aquisição é realizado por uma equipe de engenheiros de conhecimento, o processo é denominado elicitação, e contém as fases de aquisição, validação, estruturação e pré-representação. Neste trabalho, estas fases estão representadas nos 3 retângulos iniciais da Figura 5.8. As fases que complementam o ciclo de desenvolvimento são implementação (representação) e validação do sistema. 
Uma característica importante que deve ser ressaltada é que no processo de desenvolvimento de SBC's sempre pode haver refinamentos. Isto implica em novos conhecimentos a serem adquiridos e incorporados à base de conhecimento, o que justifica o termo ciclo

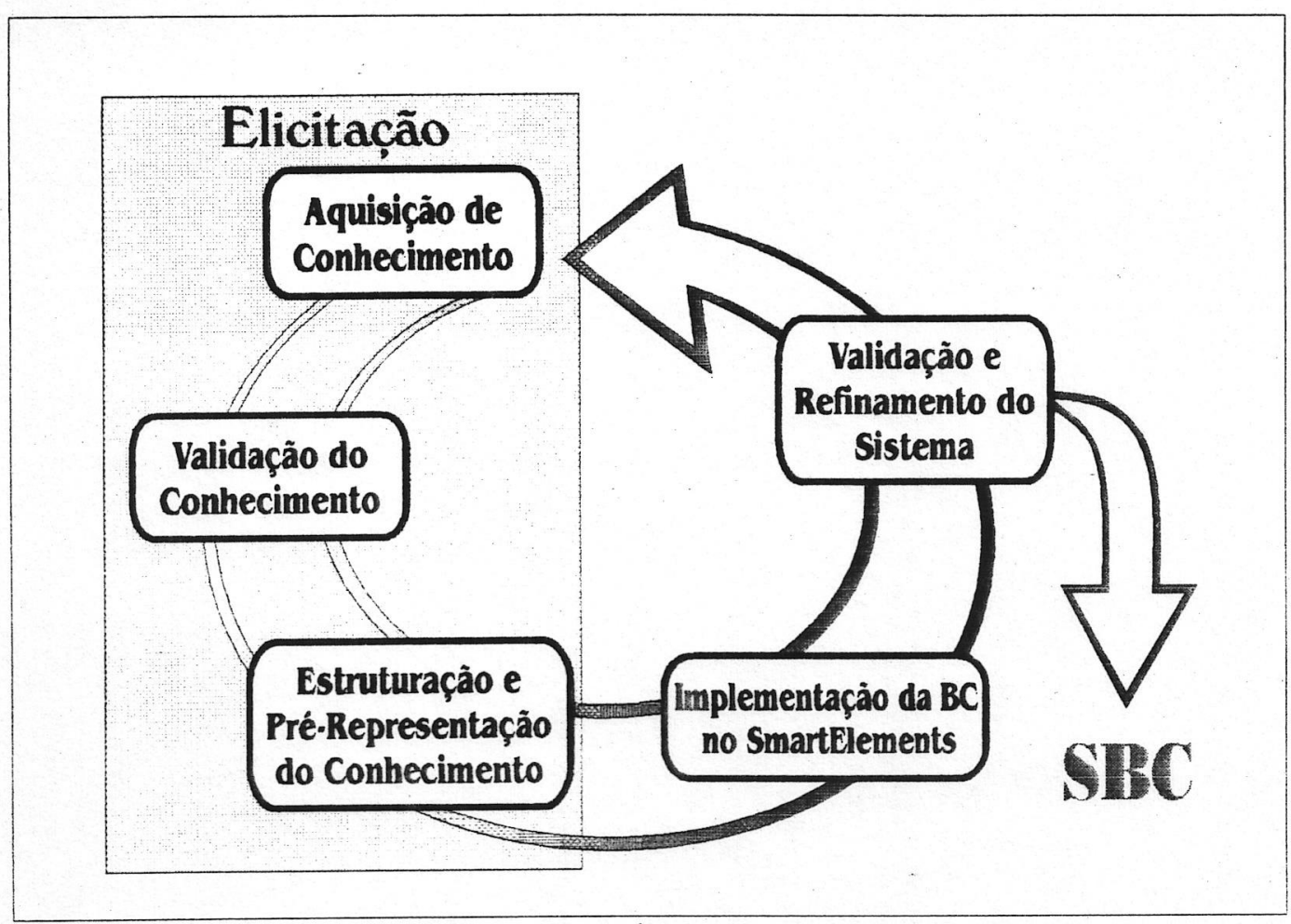

Figura 5.7: Ciclo de Vida de um SBC

A próxima seção aborda a estruturação do SBC e é seguida pela apresentação das atividades desenvolvidas dentro de cada fase citada acima.

\subsubsection{Estruturação do SBC}

A estrutura básica de um SBC foi discutida no capítulo 3. A partir desta concepção foi desenvolvida a estrutura do SBC para a implementação deste trabalho. Como pode ser visto na Figura 5.8, foram levantados cinco componentes para a implementação.

O SBC utiliza uma memória de trabalho -- MT -- que armazena todas as informações em tempo de execução. Estas informações podem ser geradas pela própria inferência do SBC ou recuperadas da base de dados. A base de dados do SBC é a mesma para a interface da 
ferramenta, ou seja, foi gerada a partir do meta modelo e está armazenada no SGBD Oracle em um servidor de rede. Os outros componentes são discutidos nas próximas seções.

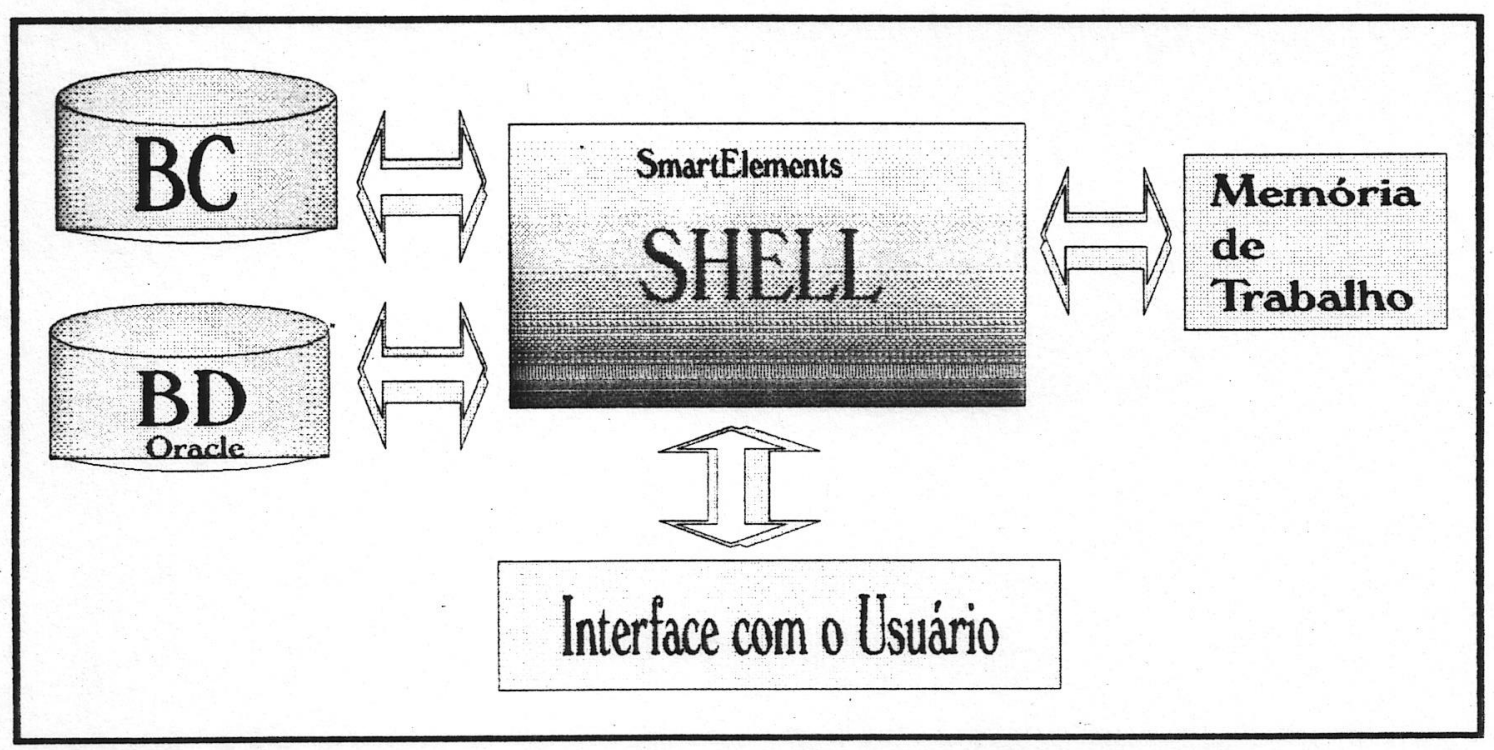

Figura 5.8: Estrutura do SBC Implementado

\subsubsection{Descrição do Shell Utilizado}

Como já foi no capítulo anterior, um shell auxilia a construção de SBC's, pois já contém o motor de inferência, com os métodos de raciocínio, e mecanismos de representação de conhecimento. Para a implementação do SBC foi utilizado o shell SmartElements que constitui em uma nova versão do shell Nexpert Object. Assim como o Nexpert Object, o SmartElements roda em ambiente Windows e em diferentes plataformas operacionais.

Os métodos de raciocínio fornecidos por este shell são algumas variações do foward chaining e backward chaining apresentados no capítulo 3 . Isto confere ao engenheiro do conhecimento um maior número de opções na obtenção da melhor performance para 0 SBC.

Os mecanismos de representação fornecidos por este shell são dois: alguns conceitos de orientação a objetos e regras de produção. Com a sua utilização, o engenheiro de conhecimento descreve o mundo em termos de símbolos físicos chamados objetos, generalizações destes objetos chamadas de classes, partes destes objetos chamados de 
subobjetos, propriedades que descrevem os objetos e classes, e slots que são propriedades específicas dos objetos e classes. Uma característica que pode ser ressaltada é que o mecanismo de herança pode ser definido tanto no sentido do objeto para a classe como da classe para o objeto. No entanto, o mecanismo "default" é o primeiro. Dessa forma, o conhecimento é codificado em forma de regras que operam em objetos, classes e slots como mostra a Figura 5.9.

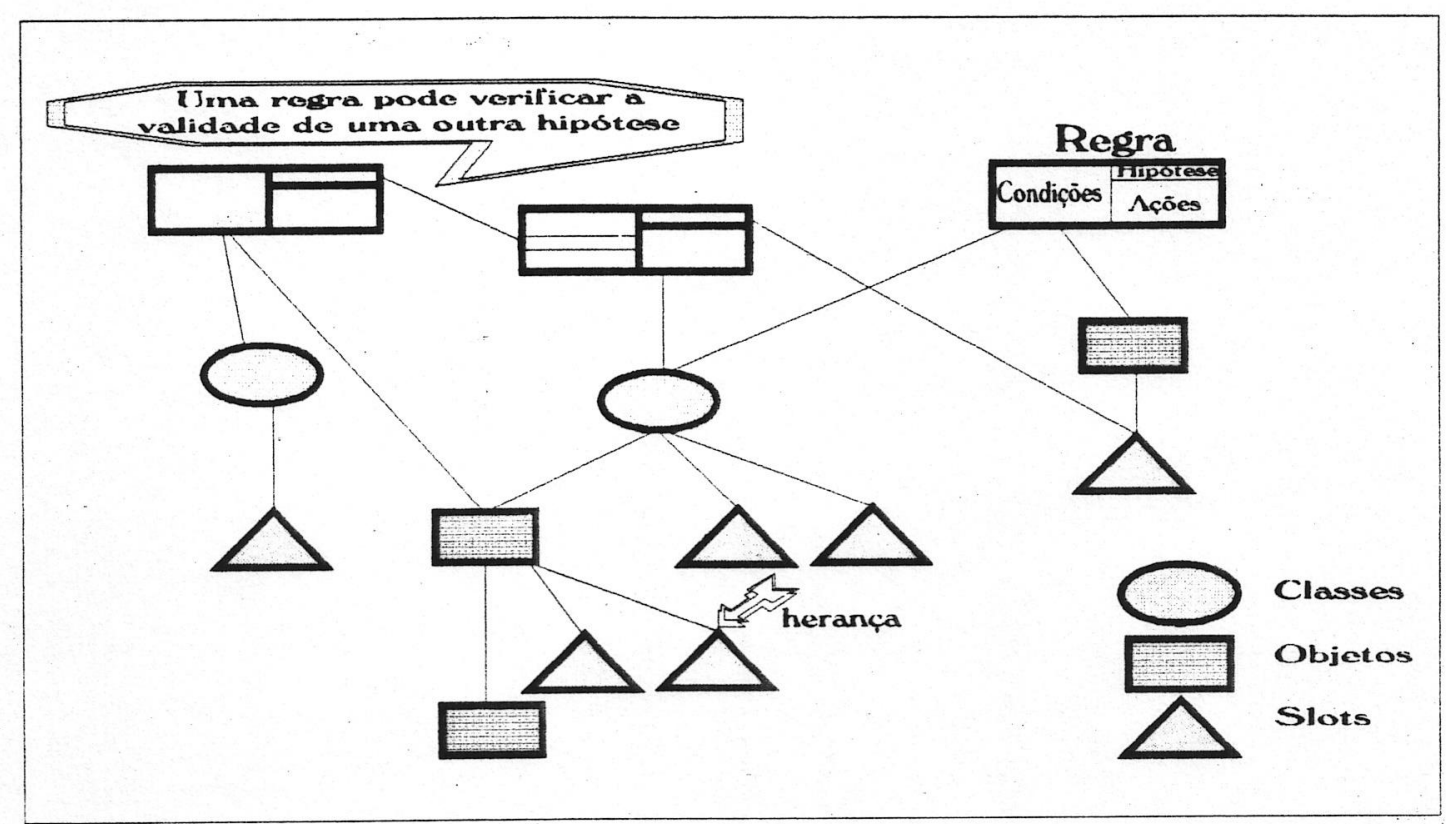

Figura 5.9: Relação Regras-Objetos no SmartElements

Como pode ser observado, uma regra no SmartElements é dividida em três campos básicos: o lado esquerdo ("Left Hand Side" - LHS) contém as condições e o lado direito ("Right Hand Side" - RHS) contém a hipótese e as ações a serem tomadas. Uma hipótese é verdadeira se todas as condições forem verdadeiras e com isso são disparadas as ações. Tanto as condições como as ações operam sobre as propriedades das classes e dos objetos.

Este shell oferece uma grande variedade de ferramentas tais como geradores de gráficos, linguagens para programação, produtos de redes, e "bridges" que viabilizam o acesso a banco de dados tais como Ingres, Sybase, Informis, Dbase, Oracle, entre outros. Para 
este trabalho, está sendo utilizada a "bridge" que permite a conexão com a base de dados da ferramenta implementada em Oracle.

\subsubsection{Interface do SBC}

Para viabilizar a troca de informações com o SBC foram implementados dois tipos de interfaces: uma é realizada através de uma rotina embutida na interface da ferramenta e a outra através de uma interface desenvolvida no shell.

No primeiro caso, a inferência para a verificação de consistência do modelo é acionada através de uma opção presente em dicionário no menu principal da ferramenta para modelagem de dados. Quando esta opção é escolhida, o modelo que está sendo cadastrado é gravado em uma área específica da base de dados e o shell SmartElements é acionado via uma rotina implementada na linguagem $\mathrm{C}++$ embutida na interface como uma biblioteca de ligação dinâmica (Dynamic Link Library -- DLL). Através desta rotina são passados alguns parâmetros ao $\mathrm{SBC}$, que neles se baseia para recuperar as informações necessárias na base dados. Após a inferência, o shell grava o resultado em uma tabela específica da base de dados, a qual é acessada pela interface da ferramenta a fim de mostrar este resultado em uma janela.

No caso do acesso direto ao SBC, foi necessário implementar uma interface desenvolvida no próprio shell onde o usuário deve fornecer o nome do modelo e alguns parâmetros para a realização da inferência. Uma característica desta interface direta com o SBC é a independência dos componentes da ferramenta, ou seja, não é necessária a utilização da interface da ferramenta para verificar a consistência dos modelos de dados.

\subsubsection{Engenharia do Conhecimento}

O último componente do SBC a ser descrito é a BC. Como já foi dito, o processo para a construção da $\mathrm{BC}$ é denonimado Engenharia do Conhecimento.

$\mathrm{O}$ primeiro passo foi delimitar o domínio de conhecimento com o objetivo de atender às justificativas para a construção deste SBC. O resultado desta tarefa foi a seleção das fases de projeto conceitual e projeto lógico da metodologia para o desenvolvimento da base de dados, abordada no capítulo anterior. A escolha destas fases baseou-se no fato que o objetivo principal da ferramenta é a modelagem lógica dos dados. 
Com isso foi realizado um levantamento bibliográfico relacionado a estas fases. Este levantamento teve o objetivo de aprofundar-se em tópicos importantes de como um projetista raciocina para verificar a consistência de um modelo de dados. A partir deste estudo inicial deu-se início ao desenvolvimento das fases citadas na seção 5.4.3.2. A Figura 5.10 ilustra as atividades realizadas nestas fases.

A aquisição de conhecimento consistiu em buscar informações referentes às fases de modelagem lógica dos dados, ou seja, projeto conceitual e projeto lógico. Como mencionado, a fase de análise das necessidades gerais de informação, que também constitui-se em uma fase lógica, é desenvolvida por outro tipo de ferramenta que visa a modelagem de processos que inclui o fluxo de informações da empresa.

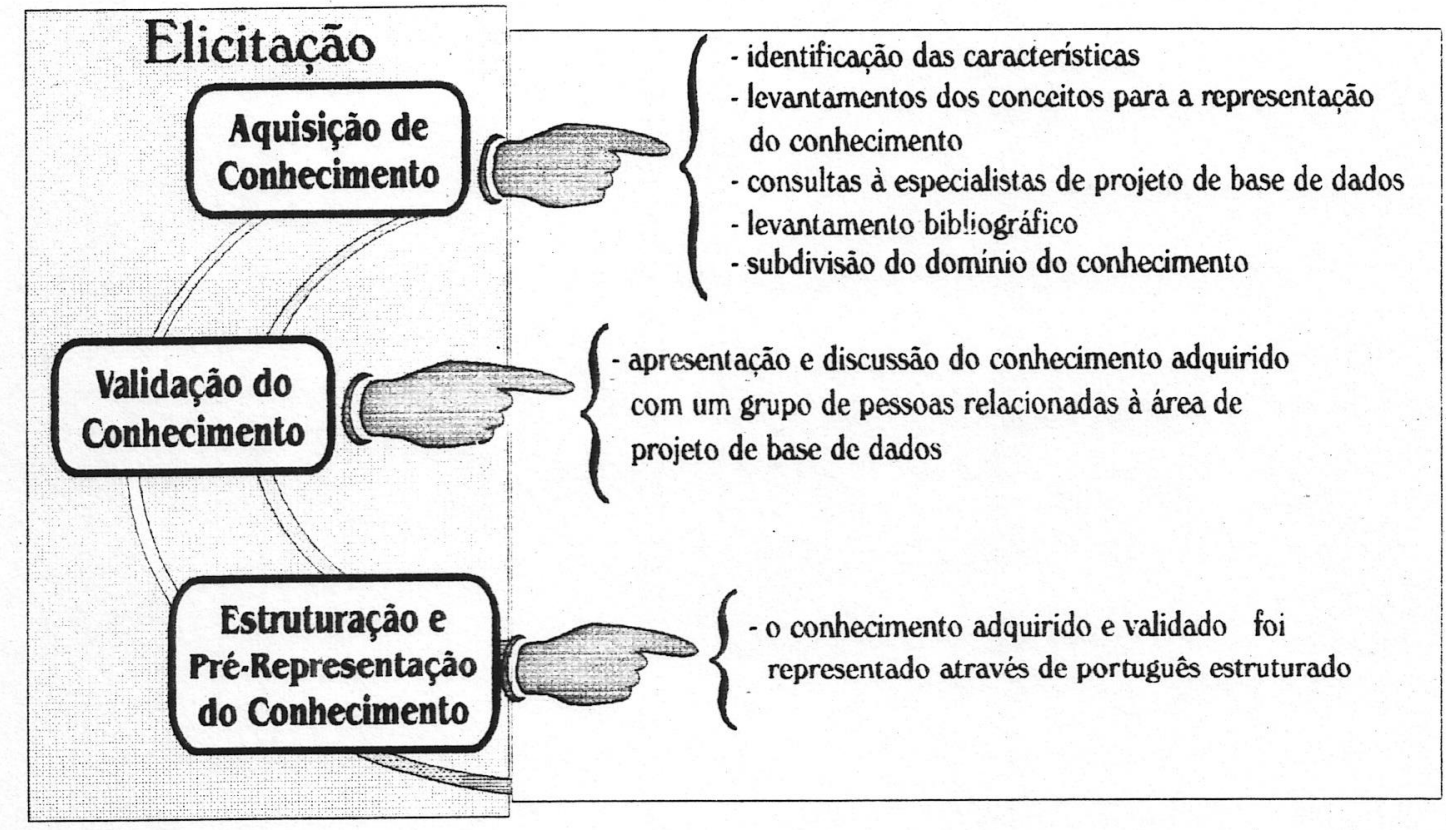

Figura 5.10: Atividades Realizadas no Processo de Elicitação

A partir daí, a aquisição foi direcionada pelo nível de abstração representado no meta modelo, ou seja, levantar todo o conhecimento envolvido na elaboração de um MER juntamente com as extensões desejadas. É importante ressaltar que nesta fase houve algumas consultas ao grupo de Base de Dados do ICMSC.

Ainda neste processo inicial de aquisição de conhecimento foram analisadas algumas ferramentas existentes no mercado relacionadas a modelagem de dados. Nesta análise, 
foi observada a parte de verificação de consistências de modelos de dados, ou seja, quais as regras utilizadas pelas ferramentas para consolidar um modelo. De acordo com o escopo deste trabalho, as regras observadas foram as que verificavam a consistência de modelo de dados e não a consistência entre diferentes tipos de modelos, como o de processos.

Um ponto importante a ser ressaltado é que a checagem da normalização, que corresponde a fase de projeto lógico, baseou-se no fato de verificar se a entidade está ou não assinalada como normalizada. Em outras palavras, na definição de uma entidade na interface da ferramenta, o usuário é totalmente responsável pela sua normalização. Isto é justificado pelo nível alto de semântica que deve ser representado para uma verificação automática da normalização

Após este estudo inicial, já com uma idéia mais concisa do conhecimento a ser estruturado, decidiu-se subdividir o domínio de conhecimento. Cada elemento componente do MER (Entidade, Relacionamento, Atributo, Sinônimo, Domínio, Chaves) passou a compor um subdomínio que foi analisado separadamente e, paralelamente, foi realizado um estudo sobre suas interdependências. Assim o conhecimento adquirido sobre cada subdomínio pôde ser analisado sobre a estrutura global estabelecida, e mantido em subdomínios diferentes para serem tratados de maneira independentes

Essa divisão se fez necessária principalmente para manter uma certa organização do conhecimento, mas foi importante também para se obter uma visão da extensão e real complexidade do domínio de conhecimento.

O próximo passo na elicitação foi a validação do conhecimento. Uma maneira de se realizar a validação do conhecimento adquirido foi reunir pessoas com um certo domínio em projeto de banco de dados e apresentar o conhecimento adquirido. Após as discussões realizadas sobre esta apresentação, partiu-se, então, para a fase de PréRepresentação.

$\mathrm{Na}$ última fase da elicitação, a Pré-Representação, o conhecimento adquirido e validado foi representado através de português estruturado. Acredita-se que com esta notação, o conhecimento pode ser representado de maneira clara e padronizada. $\mathbf{O}$ formato que se adotou para Pré-Representação também tinha a finalidade de servir como parte da documentação. No Anexo B há uma descrição dessa Pré-Representação. 
A fase de Representação do Conhecimento teve como ponto inicial o documento gerado pela fase de Pré-Representação. Como já foi dito, os mecanismos utilizados para a representação do conhecimento foram alguns conceitos de orientação a objetos e regras de produção onde o shell SmarElements foi usado na construção da base de conhecimento. A Figura 5.11 ilustra as fases de Representação e Validação do Conhecimento.

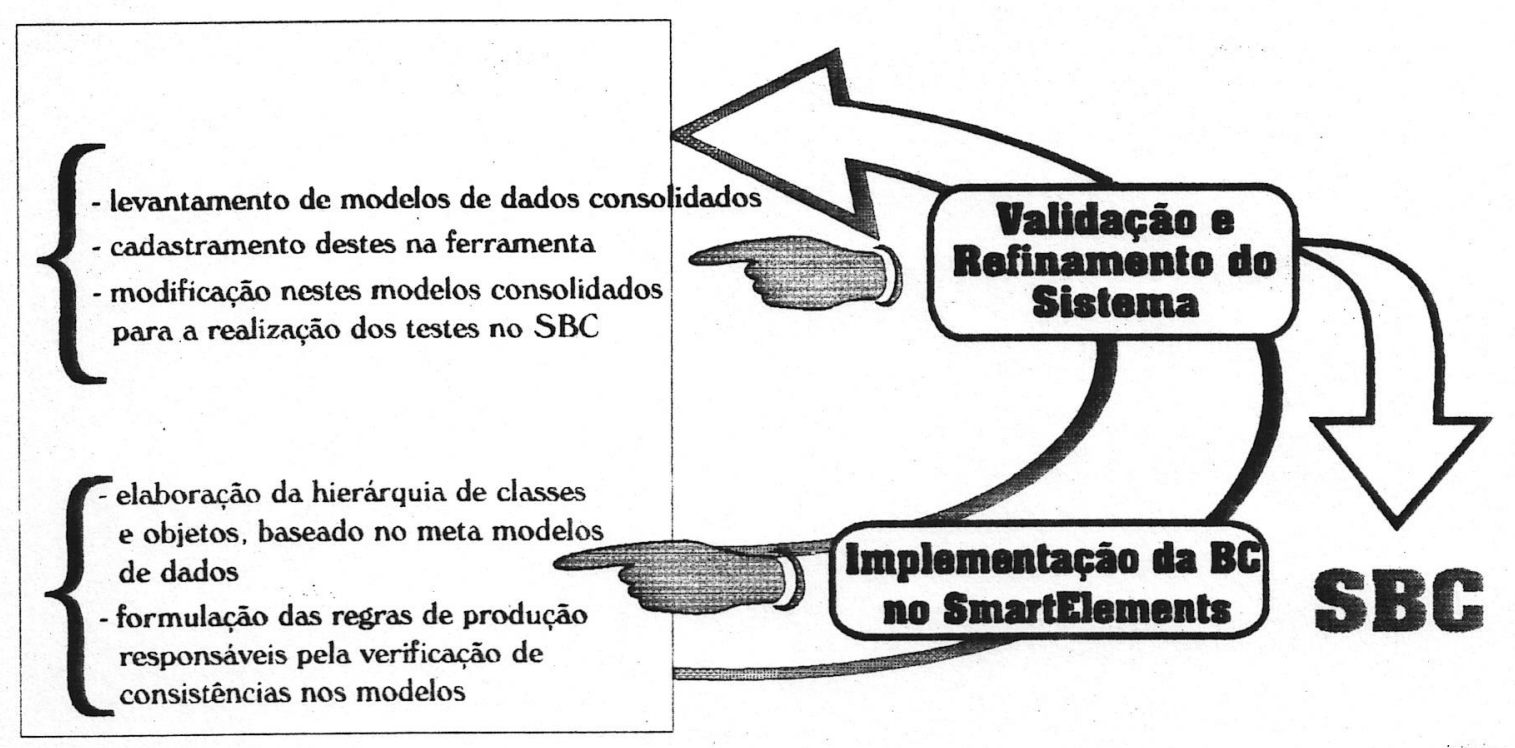

Figura 5.11: As Fases de Representação e Validação

Para representar os elementos de um MER extendido foi concebida uma hierárquia de classes e objetos que contém todas as informações sobre as entidades do meta modelo. Além dessa representação foi necessária a elaboração de outras classes que auxiliam o processo de inferência do Shell.

Uma grande influência para estabelecer essa representação foi a forma pela qual o meta modelo estava representado, ou seja, o diagrama que continha a hierarquia de classes tinha que fornecer meios para manipular as informações contidas em um modelo relacional (modelo gerado a partir do MER que representa o meta modelo).

Para o SBC acessar essas informações, foi elaborado um mapeamento entre um modelo relacional e um diagrama orientado a objetos, segundo os mecanismos fornecidos pelo Shell utilizado. Dessa forma, o Shell, que contém a representação na forma de diagrama 
orientado a objeto, pôde acessar as informações contidas no SGBD relacional Oracle. Este mapeamento é descrito na seção 5.4.4.1.

As regras levantadas para a verificação de consistência do modelo de dados foram representadas através de regras de produção. As regras de produção, juntamente com a troca de mensagens entre as mesmas, são as responsáveis pela ativação da inferência do Shell. Em outras palavras, a estratégia utilizada por um projetista para consolidar um modelo de dados foi representada como regras de produção.

No processo de validação foram utilizados alguns modelos de dados consolidados para verificar o conhecimento representado no Shell. Para a realização destes testes, foram feitas modificações nestes modelos a fim de "forçar" o aparecimento de inconsistências. Esta estratégia foi utilizada para validar todas as regras armazenadas na $\mathrm{BC}$.

Com isso, completou-se a primeira fase do ciclo de desenvolvimento do SBC na metodologia utilizada. Posteriormente serão realizados refinamentos conforme as necessidades da ferramenta para a modelagem de dados.

Dessa forma, foram descritos o processo de desenvolvimento dos três componentes da ferramenta, incluindo uma apresentação sucinta dos softwares utilizados. Além do mapeamento descrito acima, para a integração dos componentes (softwares utilizados para a implementação) foram utilizados alguns recursos que viabilizaram sua comunicação. Uma descrição desses recursos é apresentada a seguir.

\subsubsection{Recursos Utilizados para a Integração dos Componentes}

Um dos principais conceitos utilizados para a integração dos componentes é o de sistemas abertos (abordado no capítulo 2). Neste trabalho, foram utilizados softwares "abertos" que viabilizaram a integração dos componenentes. No entanto, como foram adotadas diferentes metodologias para a implementação dos componentes da ferramenta, foi necessário elaborar um mapeamento entre as mesmas. Além desses recursos, foram utilizados alguns produtos que viabilizaram a comunicação através da rede e com o SGBD Oracle. 


\subsubsection{Mapeamento do MER para Orientação a Objetos}

Como já foi dito, a base de dados da ferramenta está implementada na forma de tabelas que consistem em uma derivação do modelo relacional, que por sua vez é derivado do MER (meta modelo de dados). O SBC, outro componente da ferramenta, utiliza a forma de classes e objetos para representar a descrição do domínio. Dessa forma, foi necessário realizar um mapeamento entre estas diferentes formas de representação. A estratégia utilizada neste mapeamento foi a de encontrar elementos correspondentes àqueles do meta modelo de dados em um diagrama orientado a objetos. As principais regras para este mapeamento são:

- as entidades entidade, relacionamento, atributo, dominio, sinonimo e modelo do meta modelo são classes no diagrama orientado a objeto. Em termos de implementação, para cada registro das tabelas, geradas a partir destas entidades, existe um objeto correspondente na $\mathrm{BC}$;

- os relacionamentos do tipo m:n do meta modelo tais como ent_rel, atri_ent, atri_rel, mod_ent e mod_rel também são mapeados como classes. Em termos de implementação, para cada registro de uma tabela gerada a partir desses relacionamentos, existe um objeto correspondente na $\mathrm{BC}$.

A Figura 5.12 ilustra um exemplo deste mapeamento, onde a entidade relacionamento corresponde à classe de mesmo nome.

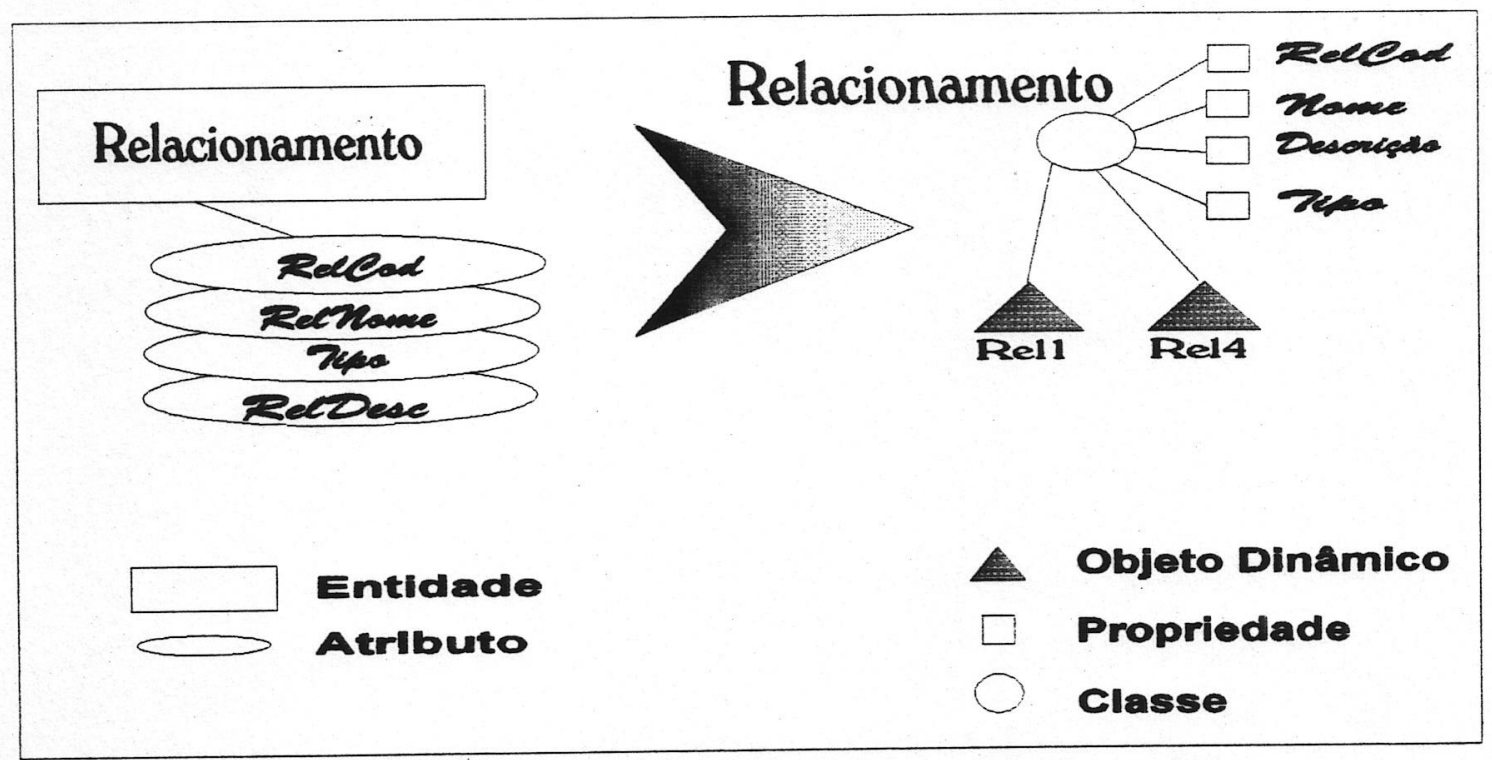

Figura 5.12: Exemplo de um Mapeamento Realizado pela Ferramenta 
No meta modelo, as entidades relacao e ent_rel abstraem os conceitos de generalização, composição e agregação. Em relacao, um atributo descreve o tipo de relacionamento entre as entidades e em ent_rel estão as entidades envolvidas. Quando é realizado o mapeamento, existem algumas que separam os diferentes tipos de relacionamentos em diferentes classes na representação do Shell. $\mathbf{O}$ objetivo desta estratégia foi modularizar a representação do conhecimento para facilitar o processo de inferência do Shell.

Com isto, as informações manipuladas pela interface da ferramenta são gravadas no SGBD Oracle, o qual também é acessado pelo Shell SmarElements, que por sua vez busca as informações para a verificação de consistências.

\subsubsection{Descrição dos Produtos Utilizados na Integração dos Componentes}

A integração da interface da ferramenta e do SBC (localizados em estações clientes) com o SGBD (localizado no servidor) foi viabilizada com a utilização de alguns programas para interfaces de aplicações (Application Programing Interface -- API's). A Figura 5.13 ilustra como é realizada a utilização destas API's.

Para a interface, implementada em PowerBuilder, acessar o SGBD Oracle foram utilizados dois produtos: a interface direta com o Oracle e o SQL*Net que viabiliza a comunicação de um cliente com o servidor através da rede. Novamente, vale ressaltar que o Oracle está no servidor de rede, cujo sistema operacional é o Netware Novell V3.11, e o SQL*Net está instalado tanto no servidor quanto no cliente.

Para o SBC, implementado no SmartElements, acessar o Oracle foi utilizada uma "bridge" fornecida pelo fabricante do Shell. Vale ressaltar que a "bridge" é específica para o Oracle. Aqui também foi utilizado o SQL*Net para viabilizar a comunicação na rede. 


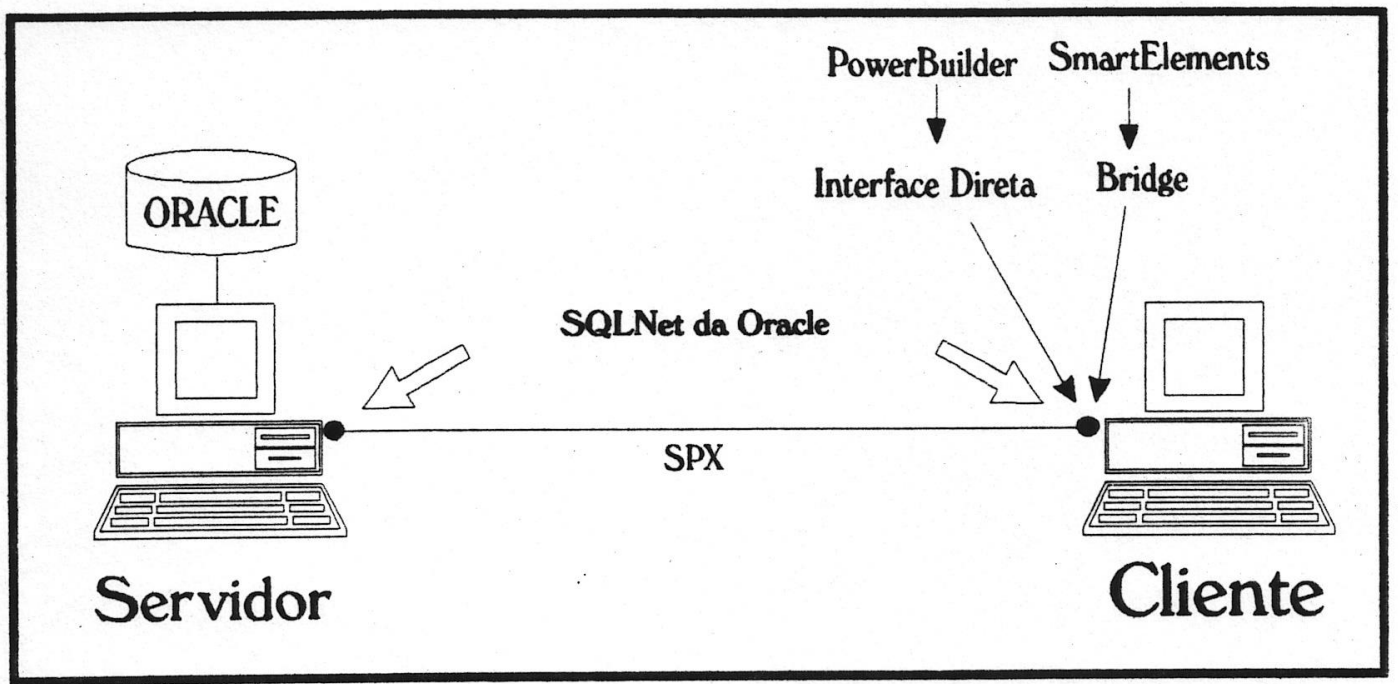

Figura 5.14: API's Utilizadas pela Ferramenta

\subsection{Arquitetura de Implementação da Ferramenta}

Vários usuários podem, ao mesmo tempo, utilizar a ferramenta para modelagem de dados, instalada nas estações clientes, e acessar a base de dados comum que está instalada em um servidor de rede Novell 3.11. O controle de acesso as tabelas é realizado pelo SGBDR Oracle.

O usuário, em uma estação cliente da rede, acessa a interface da ferramenta para modelagem de dados onde realiza o projeto conceitual (MER-extendido) e o projeto lógico (normalização) de uma área da empresa. O processo de desenvolvimento do modelo de dados é realizado pelos recursos de diagramação implementados no ambiente de trabalho da interface. Dessa maneira, o usuário graficamente descreve as entidades, relacionamentos e atributos. Essas informações a respeito do modelo são armazenadas em memória até que o usuário grave o modelo elaborado ou acione a opção para verificação de consistência.

Quando esta última opção é selecionada, a interface grava o modelo sendo desenvolvido em uma área específica da base de dados e então o SBC é acionado. Este, por sua vez, recupera as informações necessárias e checa o modelo gravando o resultado em uma tabela específica. A interface, após a inferência, acessa esta tabela e mostra o resultado na janela que contém o modelo. 
Outra opção consiste na opção do usuário carregar um modelo de dados já existente na empresa e realizar algumas modificações. Novamente, ele pode verificar a consistência do modelo, conforme foi citado acima.

Como foi mencionado, a verificação de consistência do modelo de dados pode ocorrer de duas maneiras. A outra maneira de se acessar o SBC é através de uma janela implementada no próprio Shell, onde o usuário escolhe o modelo de dados e aciona o motor de inferência. $O$ resultado é apresentado na mesma janela.

\subsection{Considerações Finais}

Neste capítulo foi apresentado todo o processo de implementação da ferramenta para modelagem de dados. Primeiro foi mostrada a concepção de uma ferramenta para modelagem de dados onde foi apresentado um menu principal com várias opções representando a funcionalidade. A seguir foi apresentada uma visão geral do desenvolvimento da ferramenta, onde cada componente da arquitetura foi abordado separadamente. Também foram apresentados os recursos utilizados para a integração destes componentes. Por último, foi mostrada a arquitetura de implementação da ferramenta.

Com esta implementação, foi possível atender aos requisitos levantados no capítulo anterior, e boa parte da concepção de uma ferramenta para modelagem de dados. No entanto, o resultado desta implementação deve ser considerado como um protótipo, uma vez que para a construção de uma ferramenta comercial seria necessário uma análise das reais necessidades do mercado brasileiro. Em outras palavras, seria necessário um contato maior com empresas a fim de levantar os seus requisitos com relação à area de modelagem de dados.

No próximo capítulo é mostrado um exemplo de aplicação do protótipo da ferramenta para modelagem de dados, onde são evidenciadas as caraterísticas de diagramação e de verificação de consistências. As áreas envolvidas neste exemplo estão inseridas no contexto de CIM e a empresa da qual estas fazem parte é a Fábrica Integrada Modelo, localizada no Projeto da USP de São Carlos. 


\section{EXEMPLO DE APLICAÇÃO DA FERRAMENTA}

\subsection{Considerações Iniciais}

Este capítulo apresenta uma aplicação da ferramenta para modelagem de dados na Fábrica Integrada Modelo -- FIM -- demonstrando a sua situação atual em termos de modelagem de processos. A ferramenta é aplicada em duas funções resultantes do processo de modelagem da FIM (considerada como uma empresa), onde são descritos os modelos de dados e suas representações na ferramenta.

Para demonstrar a opção de verificação de consistência nos modelos de dados, este capitulo mostra ainda a inferência realizada pelo SBC em um dos modelos citados acima e apresenta os resultados da mesma. Finalmente, são apresentados alguns exemplos que contém as extensões do MER discutido neste trabalho, uma vez que os modelos de dados levantados na FIM não apresentam estas característcas.

\subsection{A Fábrica Integrada Modelo}

Atualmente a modelagem da FIM encontra-se na sua segunda versão, conhecida como Cenário 2. Nesta versão, a fabricação de uma peça é coberta por todas as fases para sua produção, do projeto até a sua usinagem.

Como mencionado, o processo de modelagem de empresa facilita a integração dos sistemas de informação da empresa. Para a modelagem de processos da FIM foi utilizada a técnica de SADT (mencionado no capítulo 5), que determina tanto a hierárquia de processos como o fluxo de informações entre os mesmos. $\mathrm{O}$ resultado desta modelagem, versão 2, foi a configuração de oito funções, classificadas em dois processos macros: orçamento e fabricação. Como pode ser visto na Figura 6.1, cinco funções estão classificadas em orçamento (planejar orçamento, preparar projeto, preparar processo, definir prazos e apresentar orçamento) e quatro em fabricação (programação CN, planejar produção e fabricar).

A nível de hardware, os sistemas de informação que representam estas funções são executadas em microcomputadores no padrão IBM-PC (PS-ValuePoint), onde o servidor 
de rede é um PS/2. Estes microcomputadores estão interligados através de um cabo coaxial onde o software de rede é o Novell Netware V3.11.

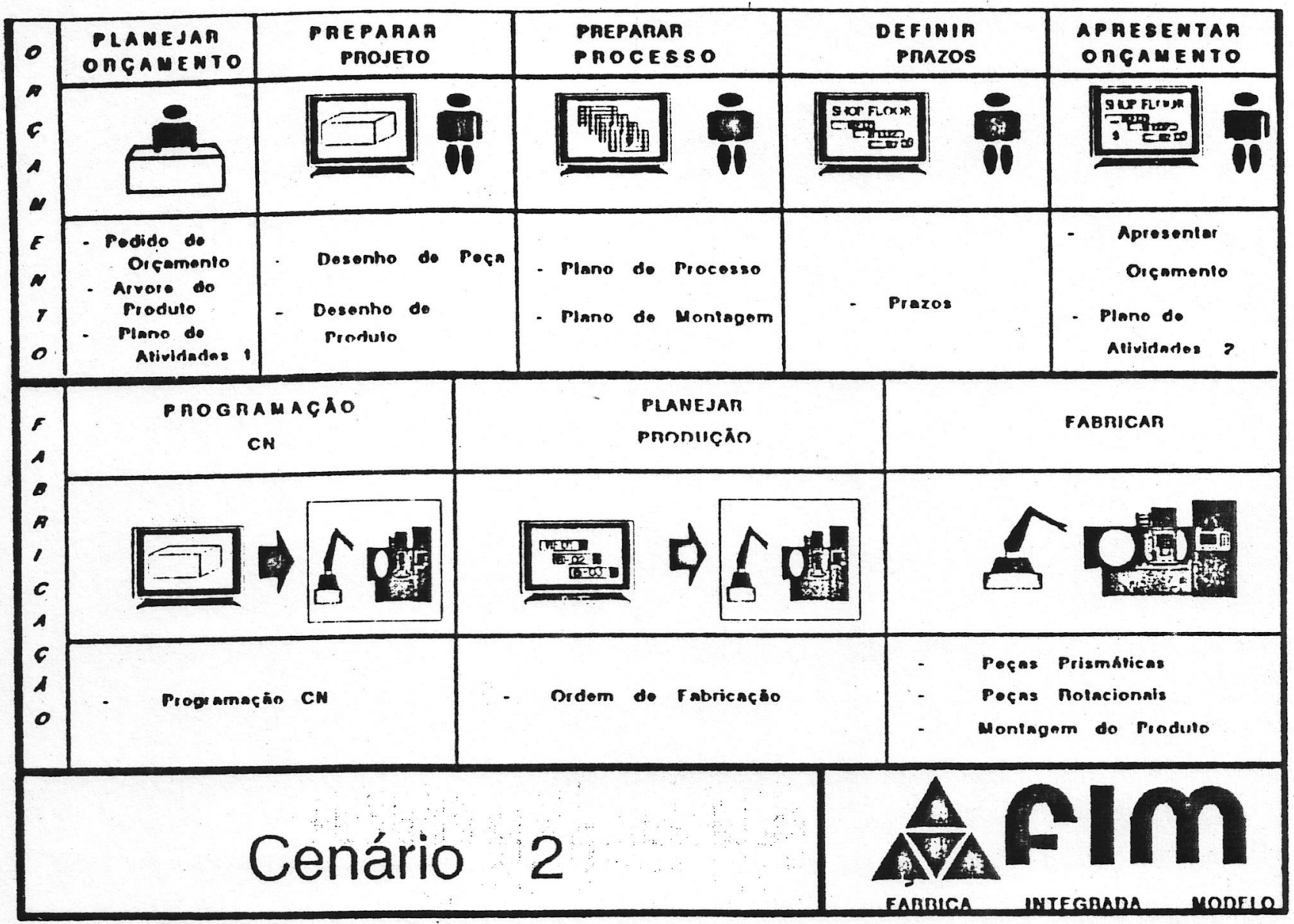

Figura 6.1: 0 Cenário 3 da FIM

A nivel de software, os sistemas resultantes de algumas destas funções foram implementados na linguagem CLIPPER, acessando arquivos DBF (sem a utilização de um SGBD de grande porte). Para outras funções são utilizados softwares comerciais, como o AutoCAD V10 para a fase de projeto do produto. O controle do fluxo de informações entre os sistemas neste cenário é realizado por um sistema, o CIM-Manager, que habilita as funções (sistemas) que devem ser executadas juntamente com os dados necessários. 
Atualmente existem alguns estudos sobre futuros cenários da FIM, entre os quais a utilização de uma base de dados centralizada usando o SGBDR Oracle é prevista. Como já foi mencionado, para a utilização de um SGBDR é necessária a elaboração de modelos de dados normalizados para garantir que a base de dados seja livre de anomalias de transações. Neste sentido, a utilização desta ferramenta serve como um mecanismo para garantir a elaboração destes modelos normalizados, além de fornecer uma documentação computadorizada que pode ser acessada de qualquer local da FIM.

Para mostrar como isto pode ser realizado, as próximas seções apresentam uma descrição das funções de projeto e processo e os respectivos modelos de dados. Vale ressaltar que estas funções foram escolhidas por conterem um número razoável de entidades e relacionamentos para a demonstração da ferramenta para modelagem de dados.

\subsubsection{Projeto do Produto}

O primeiro processo realizado na fabricação de um novo produto é o planejamento do orçamento. Nesta fase, é realizado um cadastramento do pedido do cliente onde o produto recebe um codigo no qual é referenciado por todas as fases do desenvolvimento. $\mathrm{Na}$ FIM, este codigo é descrito na entidade peca que é utilizada praticamente em todos os processos.

Em seguida inicia-se a fase de projeto do produto, onde o principal objetivo é o desenvolvimento de novos produtos. No caso da FIM, esta atividade é realizada com a utilização de elementos padronizados, ou seja, para cada produto são idenficados os seus componentes e a sua diferenciação baseia-se na descrição dos parâmetros desses componentes. Para esta atividade é utilizado o software AutoCAD V10, onde para cada elemento padronizado foi implementado uma rotina. Estas rotinas auxiliam a geração dos desenhos de pecas e do produto final. A geração de cada desenho tem a responsabilidade de um colaborador (pessoa habilitada para esta atividade).

O modelo de dados que atende as necessidades de informações descritas é apresentado na Figura 6.2. Uma descrição dos atributos das entidades envolvidas neste modelo já normalizado é mostrada a seguir. Vale ressaltar que a descrição detalhada de cada atributo não faz parte do escopo deste trabalho. 


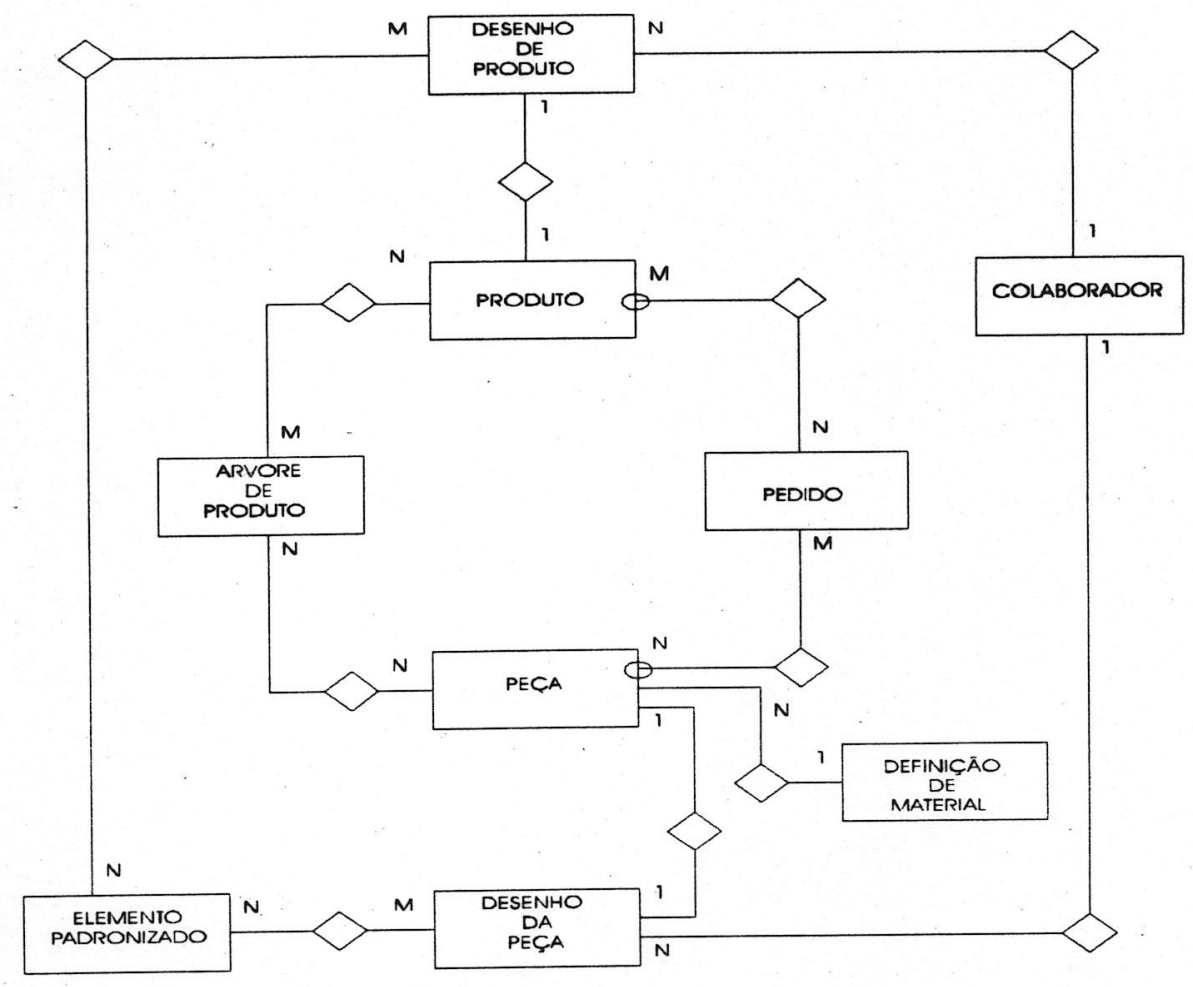

Figura 6.2: Modelo de Dados da Fase de Projeto do Produto

desenho_do_produto (codigo_dpr, nome_dpr, local_dpr, status_dpr, data_dpr, dwg_dpr) desenho_de_peca (codigo_dpe, nome_dpe, locali_dpe, status_dpe, data_dpe,dwg_dpe) arvore_do_produto (codigo_arv, data_arv, id_pai, nivel) pedido (codigo_ped, nome_ped, status_ped, data_ped, custo, preco, prazo) peca (codigo_peca, nome_peca, fabric_peca, local_peca, status_peca, custo, preco) produto (codigo_prod, nome_prod, fabric_prod, local_prod, status_prod, custo, preco) colaborador (codigo_col, nome_col, status_col, endereco, fone, cargo) material (codigo_mat, nome_mat, descrição_mat) elemento padronizado (codigo_elp, nome_elp, descricao_elp) Como pode ser observado, todas as entidades têm como chave primária um codigo que a determina. $\mathrm{O}$ atributo status aparece em várias entidades e indica a disponibilidade do 
recurso associado. A entidade arvore_do_produto indica a composição de um produto, ou seja, as pecas que juntas formam a estrutura do produto.

Utilizando a ferramenta desenvolvida para auxiliar a modelagem de dados, este modelo de dados é representado segundo a representação do meta modelo de dados apresentada no capitulo anterior. A Figura 6.3 ilustra uma das fases de desenvolvimento deste modelo.

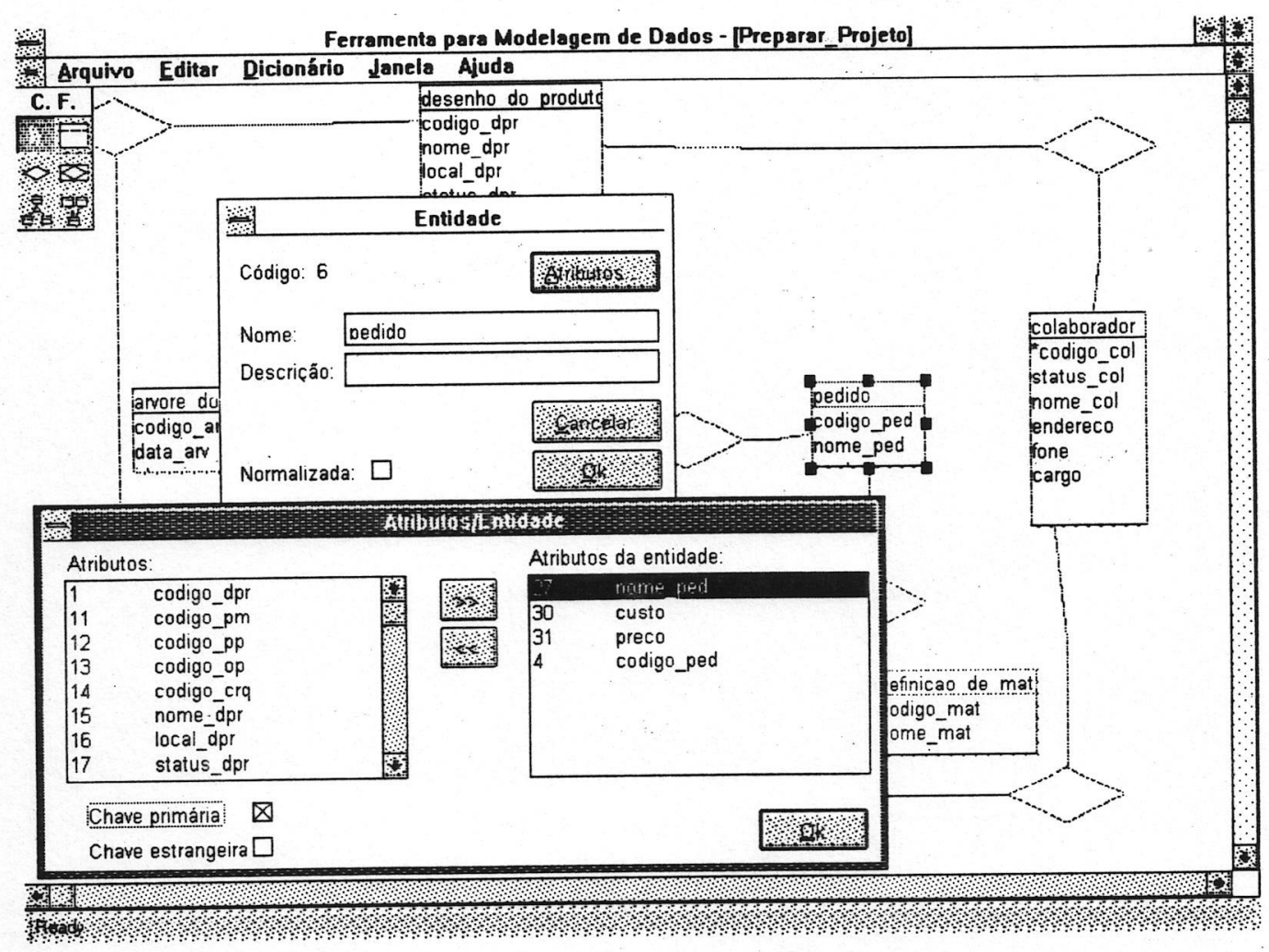

\section{Figura 6.3: Modelo de Dados da Fase de Projeto do Produto na Ferramenta}

Com a utilização da ferramenta é possível realizar as fases de projeto conceitual e de projeto lógico e com isso ter uma representação computadorizada do modelo. Dessa forma, qualquer modificação pode ser realizada a qualquer instante sem ter que redesenhar manualmente o modelo. Após a realização destas fases, pode ser acionada a opção de verificação de consistências, através do SBC, que é apresentada na seção 6.3 


\subsubsection{Planejamento do Processo}

A fase seguinte a de Projeto do Produto é o Planejamento do Processo. As principais informações que fluem de uma fase para outra estão relacionadas com a geração dos desenhos (peca e produto).

O objetivo desta fase é a confecção tanto do plano de montagem do produto como dos planos de processo de fabricação das pecas que compõem o produto. No caso da FIM, para a elaboração desses planos são utilizados planos "neutros" devido ao conceito de elemento padronizado utilizado na fase de projeto. Como os produtos contém pecas que variam apenas na definição dos parâmetros destes elementos, planos "neutros" podem ser gerados basicamente com as informações presentes em todos os planos. Neste sentido, na elaboração dos planos (processo e montagem) são utilizados estes planos "neutros" o que diminui o tempo global para a fabricação do produto. Uma descrição do modelo de dados desta área é ilustrado na Figura 6.4.

Segue uma descrição dos atributos das entidades envolvidas neste modelo já normalizado:

produto (codigo_prod, nome_prod, fabric_prod, local_prod, status_prod, custo, preco) peca (codigo_peca, nome_peca, fabricante_peca, local_peca, status_peca, custo, preco) colaborador (codigo_col, nome_col, status_col, endereço, fone, cargo) plano_de_montagem (codigo_pm, nome_pm, status_pm, data_pm) plano_de_processo (codigo_pp, nome_pm, status_pp, data_pp) operacao (codigo_op, nome_op, status_op, data_op, termpo_duracao, num_sequencia) croqui (codigo_crq, nome_crq, status_crq)

Novamente, todas as entidades têm como chave primária um codigo que a determina. Como pode ser observado nesta descrição, existem três entidades que são comuns às duas fases: colaborador, produto e peca. A entidade operacao contém todas as 
operações relacionadas aos planos de montagem e de processo e relaciona-se com a entidade croqui (ilustração gráfica do produto ou da peca) que auxilia a elaboração das operações contidas nos planos.

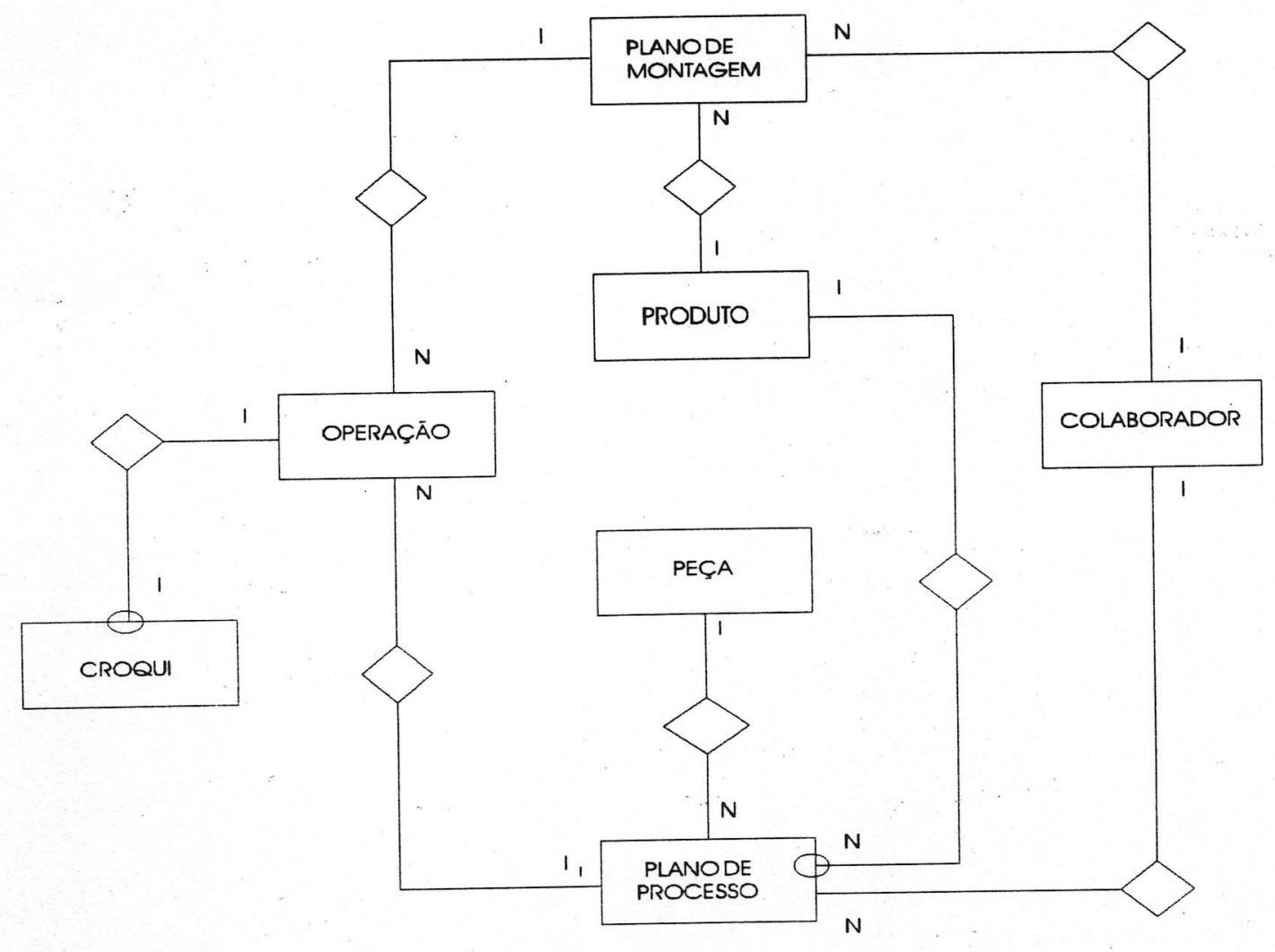

Figura 6.4: Modelo de Dados da Fase de Planejamento do Processo

Utilizando a ferramenta para modelagem de dados, este modelo de dados é representado segundo a estrutura apresentada no capítulo anterior. A Figura 6.5 ilustra uma das fases de desenvolvimento deste modelo de dados.

Analogamente é gerada a mesma estrutura computacional para representar o modelo de dados desta área. Com o modelo de dados normalizado, é possível verificar a consistência do modelo. 


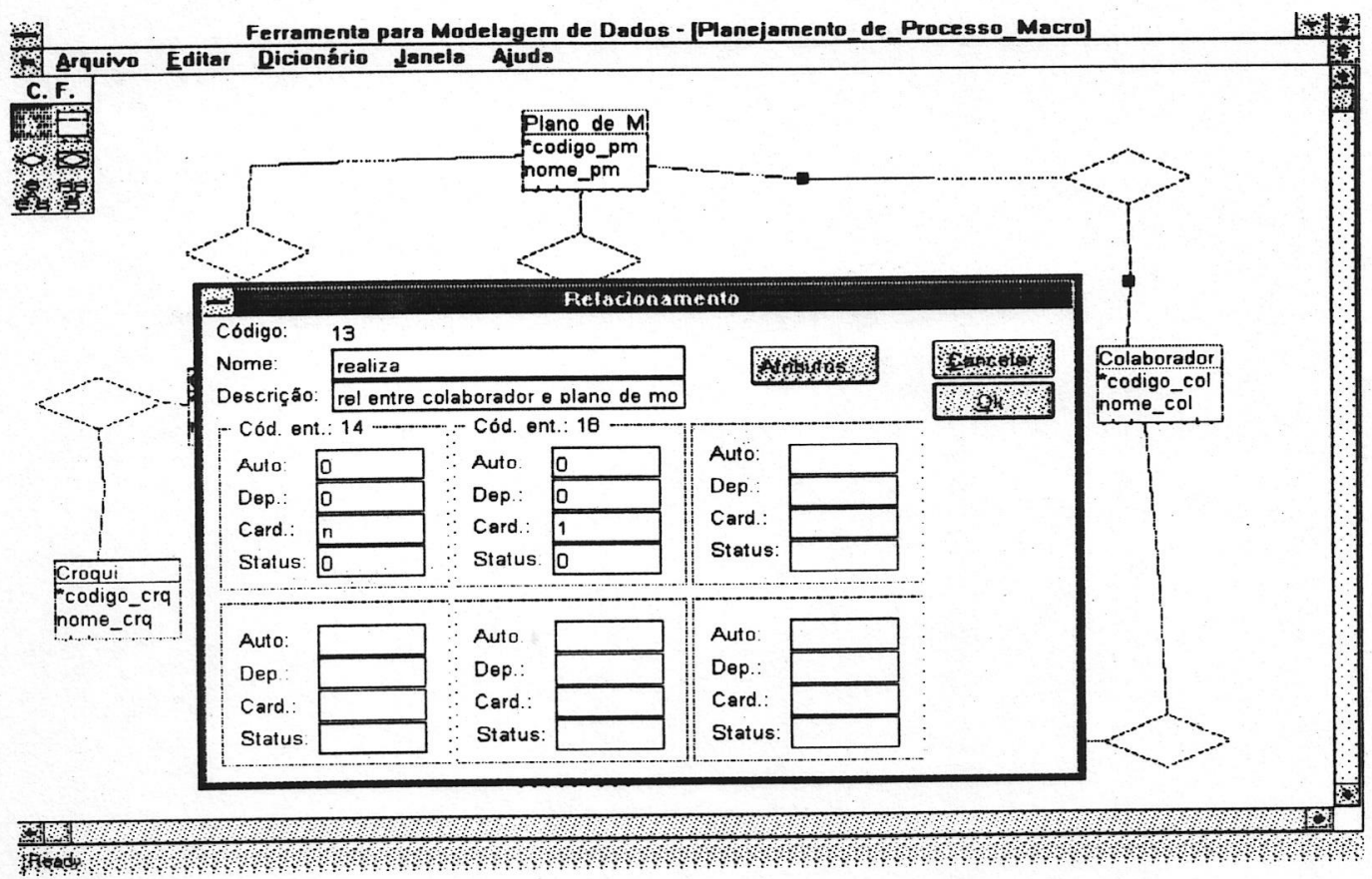

Figura 6.5: Modelo de Dados da Fase de Planejamento do Processo na Ferramenta

\subsubsection{Visualização Simultânea dos Modelos de Dados}

Para mostrar a funcionalidade da ferramenta, uma situação que pode ser evidenciada é que os projetistas destes modelos podem realizar consultas a diferentes modelos de dados, gerando uma situação com mais de um modelo na memória. Para ilustrar esta situação a Figura 6.6 mostra os modelos de dados de preparar projeto e planejar processo simultaneamente na memória da ferramenta para modelagem de dados.

Nesta situação, apenas um dos modelos fica ativo para a manipulação. Para ativar o outro modelo de dados, basta um "click" com o mouse na janela que contém o mesmo. Com este recurso, o projetista pode consultar os modelos de outras áreas para auxiliar a construção do seu modelo de dados. 


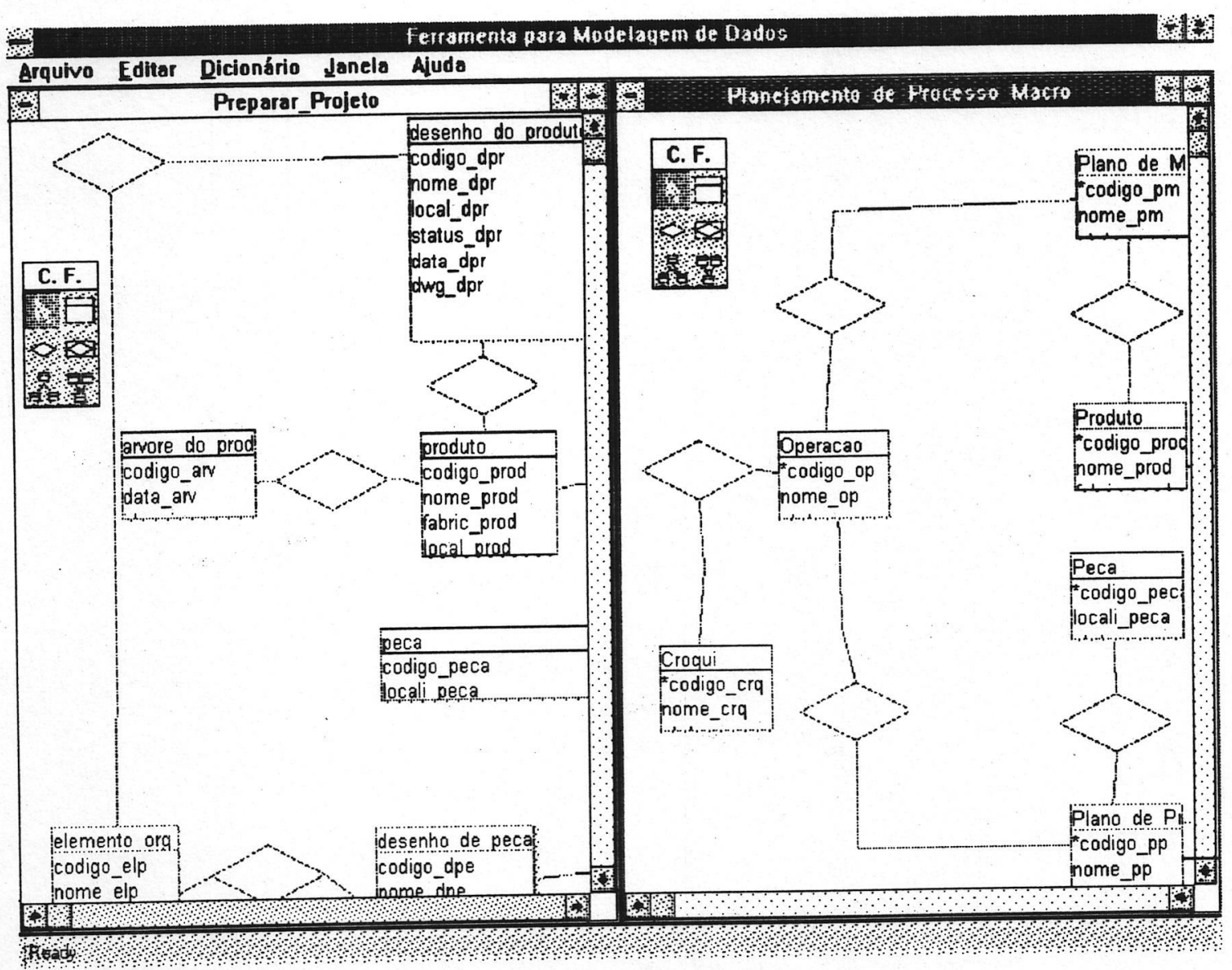

Figura 6.6: Visualização Instantânea dos Modelos de Dados.

\subsection{Verificação de Consistências nos Modelos de Dados}

Após a elaboração dos modelos de dados, é realizada a verificação da consistência dos mesmos. Para ilustrar esta situação, o modelo de dados da área de projeto do produto foi alterado para "forçar" o aparecimento de uma inconsistência (Figura 6.7). Isto foi feito para mostrar o resultado de uma inferência do SBC que é apresentado em uma janela da interface da ferramenta. Esta janela contém o erro e uma possível ação para a correção.

Como pode ser visto na Figura 6.7, a entidade colaborador "perdeu" seus dois relacionamentos. Escolhida a opção para a verificação, foi acionado o SBC que por sua vez realizou a inferência sobre o modelo e identificou a inconsistência. A janela localizada no meio da tela apresenta o erro que causou a insconsistência. A solução proposta está 
presente, mas é necessário rolar a janela para a direita. Neste caso a solução é relacionar a entidade colaborador à alguma outra entidade.

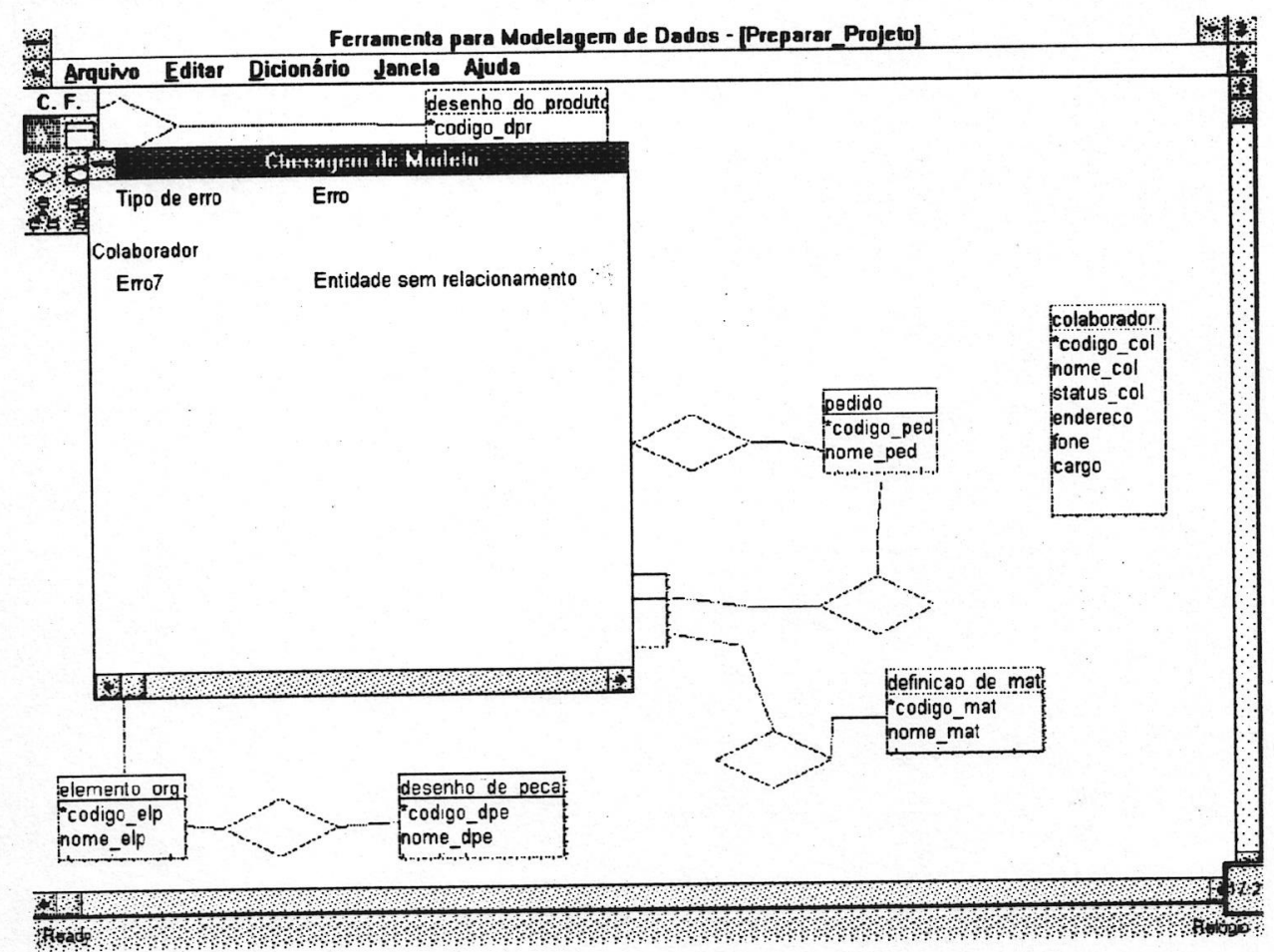

Figura 6.7: Modelo da Área de Projeto Alterado.

Voltando a situação anterior e acionando novamente o SBC, o resultado apresentado na janela mostra que o modelo está livre de inconsistências Figura 6.8. 


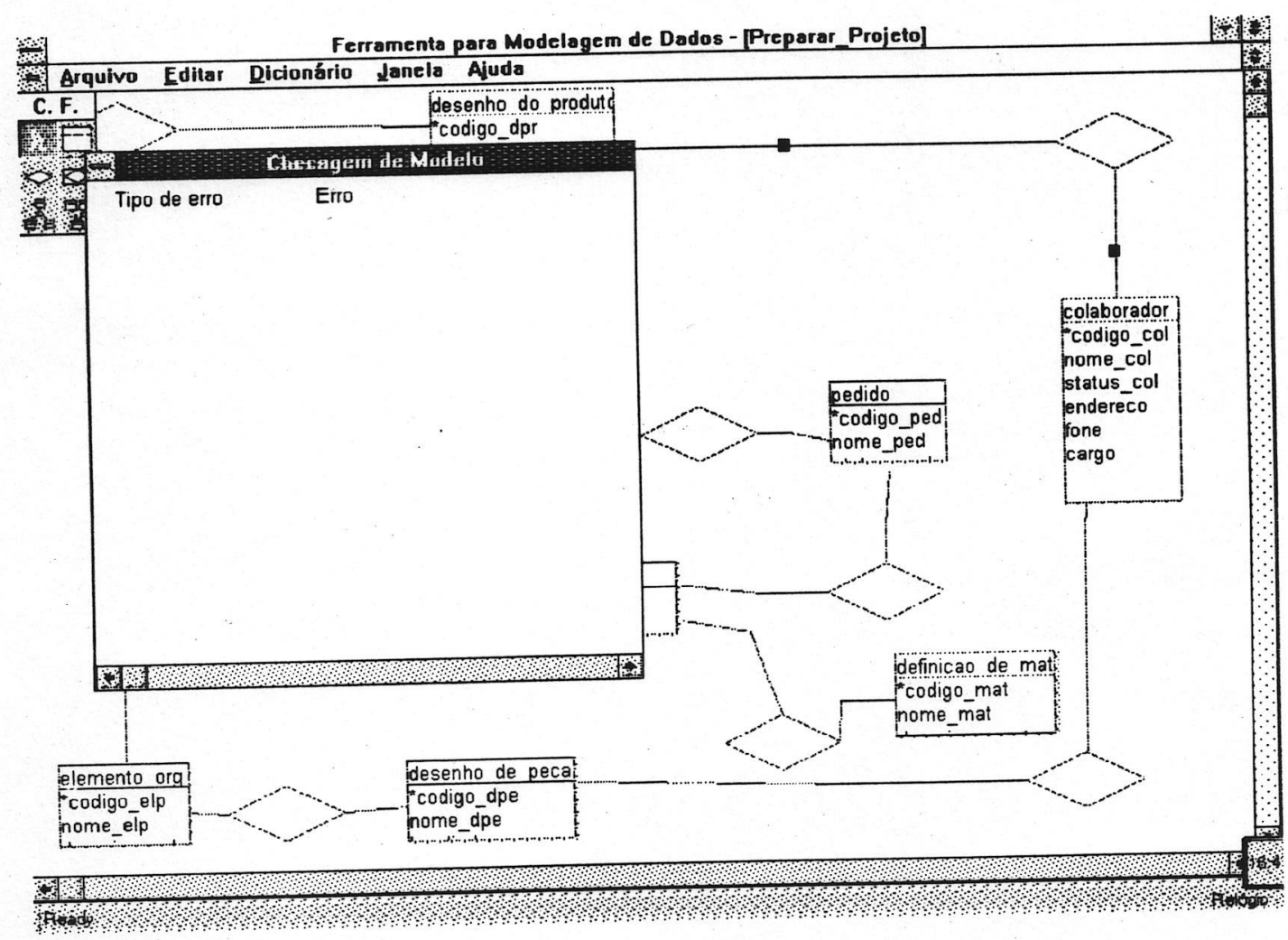

Figura 6.8: Modelo da Área de Projeto Consolidado

\subsection{Exemplos de Utilização das Extensões do MER}

Como foi mencionado no capítulo 3, para uma melhor descrição do mundo real em termos de MER é necessária a utilização de algumas extensões tais como generalização, composição e agregação. Vale ressaltar que estas representações são realizadas tanto visualmente quanto a nível de base de dados. Em outras palavras, a ferramenta para modelagem de dados armazena o significado dos modelos de dados.

Com a utilização desta ferramenta, a representação visual destas extensões podem ser observadas nas figuras $6.9,6.10$ e 6.11 . 

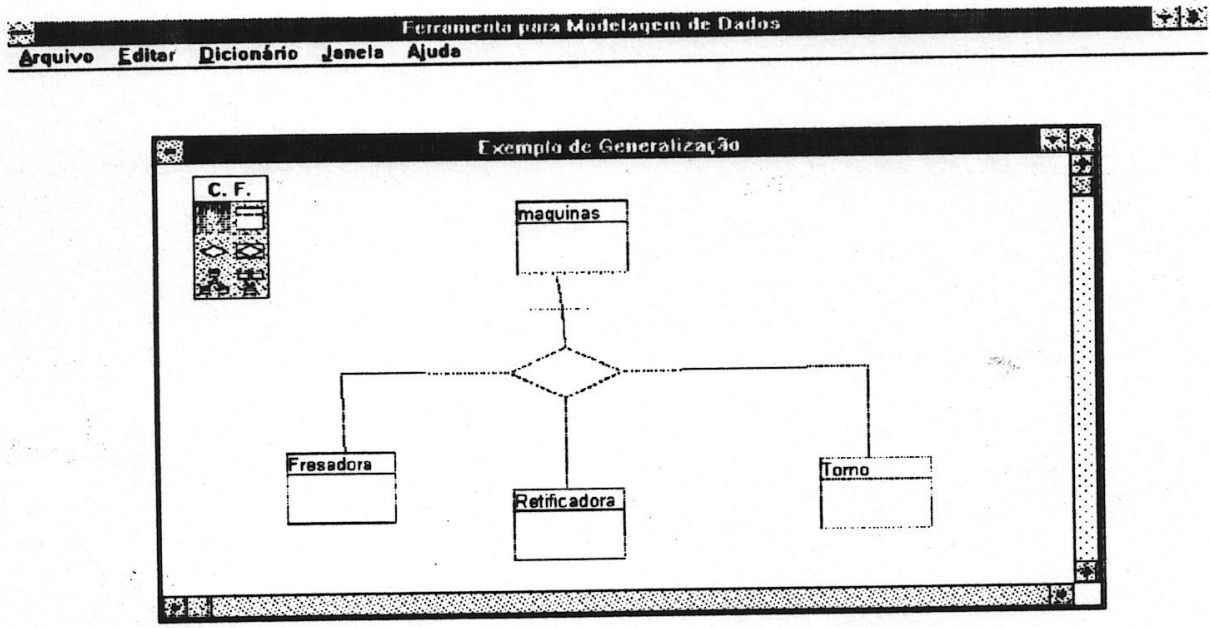

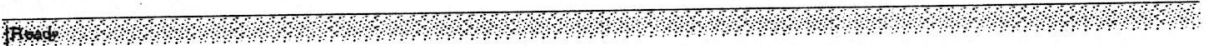

Figura 6.9: Exemplo de Generalização

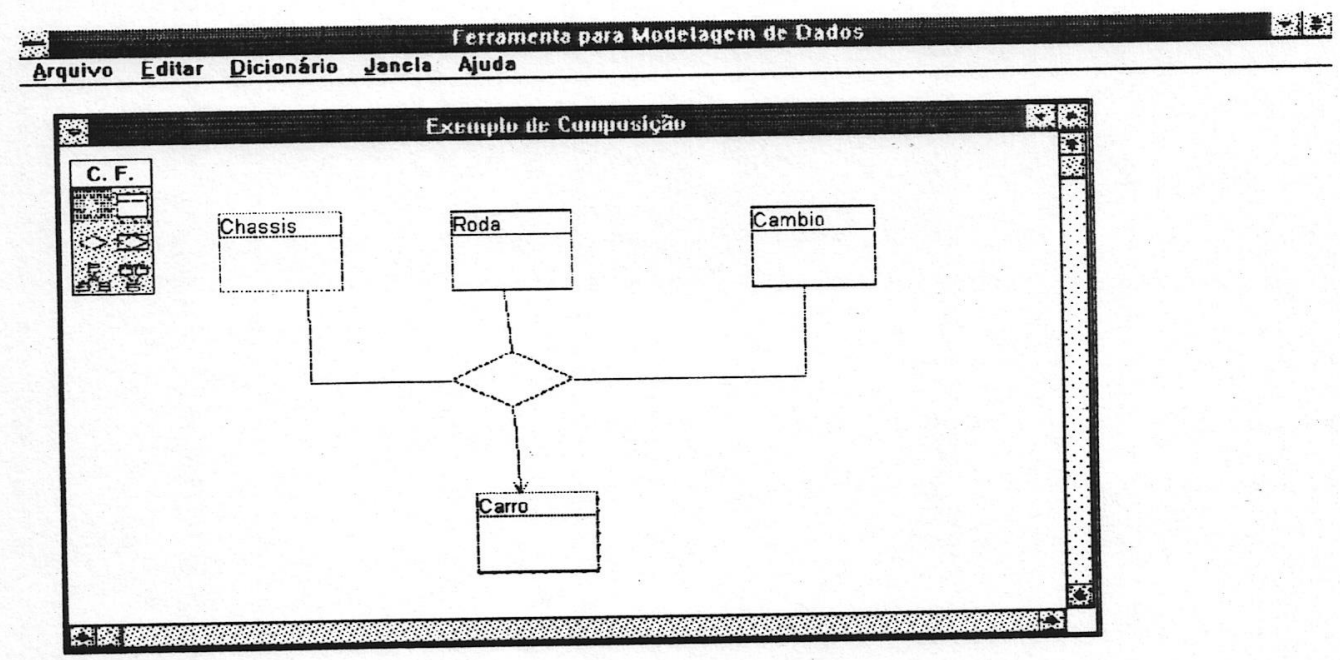

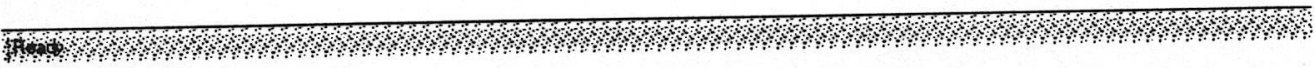

Figura 6.10: Exemplo de Composição 

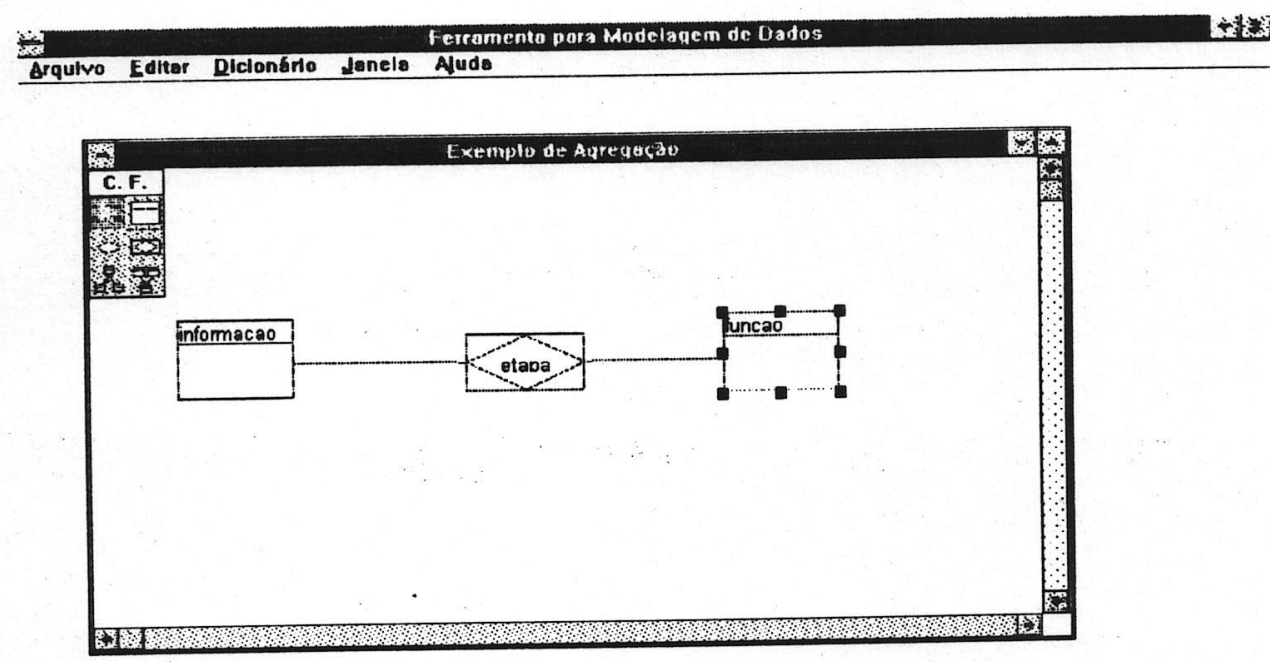

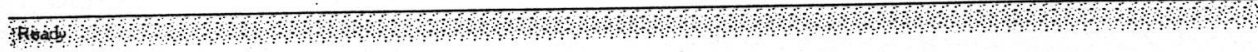

Figura 6.11: Exemplo de Agregação

\subsection{Considerações Finais}

Neste capítulo foi apresentada brevemente a Fábrica Integrada Modelo mostrando a sua situação atual, cenário 2 , e os processos resultantes da fase de modelagem. Para exemplificar uma aplicação da ferramenta para modelagem de dados, foram detalhadas as funções de preparar projeto e planejar processo. Para as duas funções, foram apresentados os modelos de dados utilizando a ferramenta. Para este exemplo da FIM, foi mostrada uma aplicação do SBC onde foi feita uma alteração no modelo de dados de projeto. Por último, foram apresentados alguns exemplos com as extensões do MER.

Novamente vale ressaltar que o objetivo da apresentação deste exemplo foi mostrar algumas telas e parte da funcionalidade da ferramenta. $\mathrm{O}$ próximo capítulo apresenta a conclusão do trabalho realizado e mostra algumas sugestões para trabalhos futuros. 


\section{CONCLUSÕES E SUGESTÕES PARA TRABALHOS FUTUROS}

O desenvolvimento deste trabalho envolveu a aplicação de vários conceitos relacionados as áreas de base de dados, inteligência artificial e manufatura. Além desses conceitos, também foram aplicadas teorias de desenvolvimento e integração de sistemas de informação através de uma rede de computadores. $O$ resultado desta aplicação foi a concepção de uma ferramenta para modelagem de dados e a implementação de um protótipo dessa ferramenta.

Dentro de cada uma dessas áreas foram abordados conceitos relevantes para a integração das empresas de manufatura. Foi mostrada a importância de uma estratégia de atuação e apresentada uma metodologia de integração da manufatura que suporta o processo de integração frente às estratégias de negócios da empresa e às tecnologias de informação disponíveis. A MIM é suportada pelo modelo de empresa que contém as informações necessárias para o desenvolvimento de planos diretores de integração. A ferramenta desenvolvida neste trabalho atua na fase de desenvolvimento de modelo de dados, no qual consiste em um componente do modelo de empresa

A elaboração da arquitetura da ferramenta evidenciou a utilização de conceitos provenientes de áreas distintas da computação tais como Sistemas Baseado em Conhecimento, Análise Lógica dos Dados e a Tecnologia da Informação.

A experiência de um projetista de banco de dados é de vital importância no processo de integração dos sistemas. Para representar e manipular esse conhecimento humano foi utilizado um Sistema Baseado em Conhecimento. O uso desta tecnologia viabiliza a tranferência do conhecimento e/ou experiência de especialistas da empresa para o computador.

Foi mostrado que a integração dos sistemas de informação inicia com uma análise estratégica dos dados, ou seja, das informações que fluem entre os processos da empresa. A abordagem sobre a análise lógica dos dados mostrou a importância que o dado representa como um recurso para a integração da empresa. Dessa forma, a elaboração de modelos de dados consistentes suporta fluxo de informações consistentes.

Com relação a tecnologia de informação, foram mostrados vários recursos ressaltando a importância de cada um. No entanto, para o desenvolvimento deste trabalho foram 
utilizados parte desses recursos, os quais relacionam-se principalmente com SGBD e rede de computadores.

Vale ressaltar que a MIM ainda está em desenvolvimento e, com isso, não foi aplicada na prática. No entanto, algumas de suas filosofias estão sendo implantadas na Fábrica Integrada Modelo e uma delas, como já foi dito, é a implantação de um SGBD de grande porte. A utilização da ferramenta para modelagem de dados já suporta um requisito dessa tarefa que é a elaboração de modelos de dados normalizados e integrados. Os modelos de dados elaborados por esta ferramenta estão armazenados computacionalmente no servidor Oracle da FIM.

Com o desenvolvimento deste trabalho foi possível adquirir grande maturidade nos requisitos necessários para integração dos sistemas de informação de uma empresa de manufatura. Dessa forma, os objetivos traçados para este desenvolvimento foram plenamente atingidos.

Alguns trabalhos podem ser realizados utilizando a documentação gerada pela implementação desta ferramenta e outros necessitam de uma nova implementação. Entre as funcionalidades que podem ser adicionadas à implementação realizada neste trabalho estão uma verificação mais rigorosa da normalização e a geração do modelo relacional dos modelos de dados. A primeira requer um nível de semântica adicional, pois existe a necessidade de se armazenar as dependências funcionais entre os atributos de uma entidade. A segunda requer a adição de regras ao Sistema Baseado em Conhecimento da ferramenta que viabiliza o mapeamento do MER ao modelo relacional. Ambas alteram o meta modelo de dados adicionando novas entidades para suportar essas funcionalidades

Outras características que podem ser implementadas estão relacionadas com a geração de "triggers" (recurso altamente utilizado pelos SGBDR's que ajudam a manter a integridade do banco de dados) e engenharia reversa (método para a obtenção de uma análise lógica a partir de uma estrutura implementada). Estas duas caracteristicas estão envolvidas com a modelagem física da base de dados.

Como foi dito, com relação a implementação, foi desenvolvido um protótipo de uma ferramenta para modelagem de dados. No entanto, para o desenvolvimento de uma ferramenta comercial é necessária a utilização de uma linguagem que forneça uma melhor performance. Uma análise da ferramenta desenvolvida indica que a linguagem utilizada (PowerBuilder) atendeu os requisitos deste trabalho pois além de fornecer uma rápida 
prototipagem, é de rápido apredinzado. Uma linguagem que atenderia os requisitos de performance é o $\mathrm{C}++$, porém seu aprendizado é demorado.

Dentro do objetivo de uma ferramenta comercial, uma funcionalidade importante a ser adicionada é o direcionamento da utilização dos recursos fornecidos pela Tecnologia da Informação. Por exemplo, na descrição de uma entidade haveria algumas definições a mais tais como a localização do banco de dados (em um ambiente distribuído), por quais abordagens (arquitetura de conectividade aberta, capítulo 2) seria acessada, entre outras. Com isso, haveria uma maior nível de documentação que auxiliaria o processo de integração dos sistemas de informação da empresa.

Uma última sugestão é a utilização desta ferramenta como um material educacional, uma vez que envolve vários conceitos tanto de computação como de integração do sistema de manufatura. 


\section{REFERÊNCIA BIBLIOGRÁFICA}

[AGOSTINHO-89] AGOSTINHO, O.L. Material de aula do curso de pós graduação (Apostila): Sistemas Flexiveis de Manufatura. São Carlos: EESC-USP, 1989.

[AGOSTINHO-91]AGOSTINHO, O.L. Material de aula do curso de pós graduação/ (Apostila): Sistemas Flexíveis de Mamufatura. São Carlos: EESC-USP, 1991.

[AGOSTINHO-92] AGOSTINHO, O.L. Os sistemas devem se adaptar ao desejo dos consumidores. Máquinas e Metais, Ano XXVII, n. 317, 1992.

[ARARIBOIA-89] ARARIBOIA, G. Inteligência Artificial:Um Curso Prático. Livros Técnicos e Científicos Editora Ltda, 1989.

[AVILA-91] ÁVILA, B.C. Representação de Conhecimento Utilizando Frames. Dissertação de Mestrado, São Carlos, ICMSC-USP, 1991.

[BAN-90] BAN, H. Programming Distributed Systems, Silicon Press, 1990.

[BELLI-92] BELLI, F; RADERMACHER, F.J. Industrial and Engineering Applications of Artificial Intelligence and Expert Systems. 5th International Conference IEA/AIE, Alemanha, 1992.

[BREMER-92] BREMER, C.F.; MELLO, M.C.F.; ROZENFELD, H.O. Conceito de Planejamento Fino e Controle da Produção. CICOMGRAF, São Paulo, 1992.

[CERICOLA-91] CERICOLA, O.V. Banco de Dados Relàcional e Distribuido. Livros Técnicos e Científicos Editora Ltda, Rio de Janeiro, 1991.

[CHEN-76] CHEN, P.P. The Relationships Model-Toward a Unified View of Data. ACM Transactions a Database Systems, março, 1976.

[CHEN-90] CHEN, P.P. Gerenciamento de Banco de Dados - A Abordagem Entidade Relacionamento para Projeto Lógico, McGraw Hill, 1990.

[CORRÊA-94a] CORRÊA, G.N.; RODRIGUES, S.R.; ROZENFELD, H. Uma Ferramenta para Modelagem de Dados em Empresas de Manufatura, Anais do II Congresso Internacional de Mendoza, Argentina, 1994.

[CORRÊA-94b] CORRÊA, G.N.; RODRIGUES, S.R.. Um Sistema Baseado em Conhecimento para Apoiar a Obtenção de Modelos de Dados em Empresas de Manufatura. I SUCESU Regional de Ribeirão Preto, 1994. 
[DATE-84] DATE, C.J. Introdução a Sistemas de Banco de Dados, Editora Campus, Rio Janeiro, 1984.

[ESPRIT-89] ESPRIT Consortium AMICE Open System Architecture for CIM. Brussels, 1989 .

[GUENGERICH-94] GUENGERICH, S. Downsizing em Sistemas de Informação. Makron Books do Brasil Editora Ltda. São Paulo, 1994.

[HACKATHORN-93] HACKATHORN, R.D. Conectividade de Banco de Dados Empresariais, Livraria e Editora Infobook, Rio de Janeiro, 1993.

[HAMMER-93] HAMMER, M.; CHAMPY, J.. Reengenharia. Editora campos, Rio de Janeiro, 1993.

[HAYES-ROTH-83] HAYES-ROTH, F.; WATERMAN, D.; LENAT, D. Building Expert Systems. Addison-Wesley Publishing Inc., 1983.

[HAYES-ROTH-87a] HAYES-ROTH, F. Expert Systems. Encyclopedia of Artificial Intelligence.S.C. Shapiro (Ed.), John Wiley \& Sons Inc., 1987.

[HAYES-ROTH-87b] HAYES-ROTH, F. Rule-Based Systems Encyclopedia of Artificial Intelligence.S.C. Shapiro (Ed.), John Wiley \& Sons Inc., 1987.

[KORTH-89] KORTH, H.F.; SILBERSCHATZ, A; Sistemas de Banco de Dados. Editora McGraw-Hill, 1989.

[KOSANKE-90] KOSANKE, K.; KLEVERS, T. CIM-OSA: arquiteture for enterprise integration - A report on currente developments, Computer Integrated Manufacturings Systems. vol. 3, n. 1, Fev., 1990.

[KUSIAK-90] KUSIAK, A. Intelligent Mamufacturing Systems.Prentice-Hall, New Jersey, 1990.

[LUGER-89] LUGER, G.F.; STUBBLEFIELD, W.A.; Artificial Intelligence and the Design of Expert Systems. The Benjamin/Cummings Publishing Company, Califórnia, 1989.

[MARTIN-91] MARTIN, J. Engenharia da Informação. Rio de Janeiro, Editora Campus, 1991.

[MOODY-90] MOODY, P. E. Strategic Manufacturing-Dynamic New Directions for the 1990 's. Dow-Jones Irwino. Illinois, 1990.

[PAYNE-90] PAYNE, E.C.; MCARTHUR, R.C. Developing Expert Systems: A Knowledge Engineer's Handbook for Rules \& Objects. Estados Unidos, 1990. 
[PEDERSEN-89] PEDERSEN, K. Well-Structured Knowledge Bases Part I. AI Expert, Abril 1989, pp 44-55.

[RICH-93] RICH, E. Inteligência Artificial. McGraw Hill, São Paulo, 1993.

[RINGLAND-88] RINGLAND, G.A.; Duce, D.A.(Eds.). Approaches to Knowledge Representation: An Introductiono. John Wiley \& Sons Inc., 1988.

[RODRIGUES-93] RODRIGUES, S.R.; MONARD, M.C. Sistemas Baseados em Conhecimento: Conceitos Fundamentais e Aplicações. Anais COMDEX'93, agosto, 1993.

[ROZENFELD-94] ROZENFELD, H; Aguiar, A.F.S.; Metodologia para Integração de Sistemas de Automação, Anais do Conai, 1994.

[ROZENFELD-93] ROZENFELD, H; RENTES, A.F.; CORREAA, G.N.. Proposta de uma Metodologia Integrada para Criação de Modelo de Dados em Empresas de Mamufatura. Anais COBEM, 1993.

[ROZENFELD-92a] ROZENFELD, H.; TAKAHASHI, S.; RENTES, A.F.; Modelamento de Empresas: Requisito para Mamufatura Integrada por Computador. Anais do CONAI, 1992.

[ROZENFELD-92b] ROZENFELD, H.; TAKAHASHI, S; RENTES, A.F.; ALLIPRANDINI, D. H. Plano Diretor de Automação --- Uma Necessidade para o Usuário Garantir a Integração da Mamufatura. Anais do ENUSAI, 1992.

[SAWAKI-91] SAWAKI, J. Um Sistema Baseado em Conhecimento para Apoio aos Usuários da Biblioteca NAG. Dissertação de Mestrado, São Carlos, ICMSC-USP, 1991

[SHEER-93] SHEER, A.W. Architecture of Integrated Information System. Berlim, 1993.

[SHEER-91] SHEER, A.W. CIM --- Towards the Factory of the Future. Berlim, 1991.

[TAKAHASHI-91] TAKAHASHI, S. Desenvolvimento de um Sistema de Gerenciamento para Manufatura Integrada por Computador. Dissertação de Mestrado, EESC-USP, São Carlos, 1991.

[TANEMBAUM-89] TANEMBAUM, A.S. Computer Networks, Ed. Prentice-Hall, 1989.

[TUTHILL-90] TUTHILL, G.S. Knowledge Engineering: Concepts and Pratices for Knowledge-based Systems, TAB BOOKS, 1991.

[YONG-92] YONG, C. S. Tecnologia de Informação. Revista de Administração de Empresas, São Paulo, 1992.

[ZUBOFF-88] ZUBOFF, S. In the New Age of the Smart Machine: The Future of Work and Power. New York, Basic Books, 1988. 


\section{ANEXO A - CRIAÇÃO DA BASE DE DADOS}

Após a realização dos projetos lógico e físico de uma base de dados torna-se possível a sua implementação, possívelmente através de algum gerenciador de banco de dados.

Como mencionado, para a implementação da ferramenta para modelagem de dados optou-se pelo Sistema de Gerenciamento de Base de Dados Relacionais (SGBDR) Oracle para a criação das tabelas necessárias à Base de Dados. Neste intuito, utilizou-se os comandos DDL (Linuagem de Definição de Dados) providos pela linguagem de consulta SQL acessando o SGBDR através de uma interface fornecida pela Oracle chamada SQL*DBA.

\section{Tablespaces e Data Files}

O armazenamento de tabelas dentro do SGBDR Oracle é feito sobre estruturas lógicas chamadas "Tablespaces" (Espaços da Tabela), as quais estão relacionadas aos "DataFiles" (Arquivos de Dados) que correspondem às estruturas fisicas. Uma tablespace pode ter vários arquivos de dados associados e a capacidade de armazenamento está diretamente relacionada aos mesmos.

A criação de "tablespaces" e "datafiles" é realizada através de comandos DDL da linguagem SQL do SGBDR Oracle. Para o desenvolvimento da ferramenta criou-se uma tablespace chamada base_de_dados com dois datafiles: bd_arq_1 e bd_arq 2. A sintaxe exata do comando é descrita abaixo:

create tablespace base_de_dados

/* cria uma "tablespace" chamada base_de_dados*/

datafile 'bd_arq_1' size 5M, 'bd_arq 2 ' size $5 \mathrm{M}$

/* arquivos de dados bd_arq_1 e bd_arq_2 são usados para definir a "tablespace" */ online;

* O comando create tablespace nome_tablespace, cria um espaço para tabelas com o nome nome_tablespace, cujo tamanho é definido por seus arquivos de dados 
A permissão de acesso às tablespaces para os usuários, visando a criação de objetos (por ex. tabelas), é dada pelo Administrador da Base de Dados (DBA)

\section{Criação de tabelas}

De forma análoga à criação de tablespaces e datafiles, as tabelas foram criadas por meio do comando DDL Create Table da linguagem SQL. Os comandos para criação de todas as tabelas relativas à Base de Dados foram colocados dentro de um único arquivo chamado NBD_DDL.SQL. Os comandos são executados pela ferramenta SQL*DBA do SGBDR Oracle. A sintaxe dos comandos é descrita a seguir:

* O comando create table nome_da_tabela (lista de atributos), cria uma tabela com o nome nome_da_tabela, com os atributos descritos em lista de atributos.

create table modelo ( ${ }^{*}$ cria a tabela de modelos

modcod number primary key, $I^{*}$ código do modelo; chave primária da tabela modnome varchar2(30) not null, /* nome do modelo (não pode ser nulo) moddesc varchar2(200)); $\quad / *$ descrição do modelo

$$
\begin{gathered}
\text { create table relacionamento }\left(\quad /^{*}\right. \text { cria a tabela de relacionamentos } \\
\text { relcod number primary key, } \quad /^{*} \text { código do relacionamento; chave primária da } \\
\text { tabela }
\end{gathered}
$$

relnome varchar2(30) not null, $/ *$ nome do relacionamento (não pode ser nulo) tipo_rel number not null, $\left.\quad\right|^{*}$ tipo do relacionamento reldesc varchar2(200), $\quad l^{*}$ descrição do relacionamento

nX number,

/* coordenada do eixo dos $\mathrm{X}$ onde o objeto que representa o relacionamento está situado

nY number, /* coordenada do eixo dos $\mathrm{Y}$ onde o objeto que representa o relacionamento está situado 
objnum number); $\quad / *$ número do objeto representado pelo relacionamento

create table tipodado (

I* cria a tabela de tipos de dados

tipocod number primary key, $/ *$ código do tipo de dado; chave primária da tabela

tipo_elem varchar(20) not null); /* tipo de elemento do tipo de dado

create table entidade ( $\quad / *$ cria a tabela de entidades

entcod number primary key, $\quad / *$ código da entidade; chave primária da tabela entnome varchar2(30) not null, $/ *$ nome da entidade ger_tab number(1) not null, $\quad / *$ indica se a entidade gera uma tabela entagreg number(1) not null, $/ *$ indica se a entidade é uma entidade agregada entdesc varchar2(200), /* descrição da entidade nX number,

I* coordenada do eixo dos $\mathrm{X}$ onde o objeto que representa a entidade está situado

nY number,

I* coordenada do eixo dos $\mathrm{Y}$ onde o objeto que representa a entidade está situado

nLargura number, $/ *$ largura do objeto que representa a entidade nAltura number, $1 *$ altura do objeto que representa a entidade objnum number); /* número do objeto representado pela entidade

create table ent_rel ( / $*$ cria a tabela ent_rel relcod number not null, $/ *$ código do relacionamento; não pode ser nulo entcod number not null, $/ *$ código da entidade; não pode ser nulo foreign key (relcod) references relacionamento on delete cascade, 
/* indica que relcod é chave estrangeira vinda da tabela relacionamento

foreign key (entcod) references entidade on delete cascade,

$/ *$ indica que entcod é chave estrangeira vinda da tabela entidade

auto number(1) not null, $/ *$ indica se a entidade relaciona-se consigo mesmo nesse relacionamento

constraint er_ch primary key (relcod, entcod, auto), $/ *$ a chave primaria dessa tabela será composta por relcod, entcod e auto

dep number(1), $/ *$ indica se a entidade é dependente nesse relacionamento card varchar2(3), /* a cardinalidade desse lado do relacionamento status number(1), /* status desse lado do relacionamento

nLadoLig number, /* nLadoLig, nInterX, nInterY, fporcX, fporcY:

"coordenadas" da entidade em relação ao relacionamento no diagrama do MER */

nInterX number,

nInterY number,

fporcX number,

fporcY number);

create table dominio ( $/ *$ cria a tabela de domínios

domcod number primary key, $/ *$ código do domínio; chave primária da tabela domnome varchar2(30) not null, $/ *$ nome do domínio tipocod number not null, /* código do tipo de dado do domínio foreign key(tipocod) references tipodado on delete cascade, $1 *$ indica que tipocod é chave estrangeira vinda da tabela tipodado domdesc varchar2(200), /* descrição do domínio maxval number, $/ *$ valor máximo que algo nesse domínio pode assumir minval number, /* valor mínimo que algo nesse domínio pode assumir defval number, /* valor "default" para algo nesse domínio tamanho number, $/ *$ tamanho de algo nesse domínio 
precisao number); /* precisão de algo nesse domínio

create table atributo ( $/ *$ cria a tabela de atributos

atricod number primary key, $/ *$ código do atributo; chave primária da tabela atrinome varchar2(30) not null, /* nome do atributo; não pode ser nulo domcod number not null, /* código do domínio do atributo; não-nulo foreign key(domcod) references dominio on delete cascade, $/ *$ indica que domcod é chave estrangeira vinda da tabela domínio atriop number(1), /* indica se o atributo é opcional atridesc varchar2(200)); /* descrição do atributo

create table lista_valores $/ *$ cria a tabela de entradas em listas de valores atricod number not null, $/ *$ código do atributo ao qual está relacionado a lista; não pode ser nulo

foreign key(atricod) references atributo on delete cascade, $1 *$ indica que atricod é chave estrangeira vinda da tabela atributo constraint lv_ch primary key(atricod), /* a chave primária dessa tabela será a correspondente ao atributo ao qual está ligado valor varchar2(30)); /* um valor contido na lista

create table sinonimo( $/ *$ cria a tabela de sinônimos de atributos sincod number not null, /* código do sinônimo; não pode ser nulo sinonome varchar2(30) not null, /* nome do sinônimo; não pode ser nulo atricod number not null, /* código do atributo ao qual o sinônimo pertence; não pode ser nulo foreign key(atricod) references atributo on delete cascade, $/ *$ indica que atricod é chave estrangeira vinda da tabela atributo 
constraint sin_ch primary key(sincod,atricod), /* a chave primária dessa tabela será composta por sincod e atricod sindesc varchar2(200)); /* descrição do sinônimo

create table mod_ent ( $/ *$ cria a tabela mod_ent modcod number not null, /* código do modelo; não pode ser nulo entcod number not null, $/ *$ código da entidade; não pode ser nulo foreign key(modcod) references modelo on delete cascade, $/ *$ indica que modcod é chave estrangeira vinda da tabela modelo foreign key (entcod) references entidade on delete cascade, /* indica que entcod é chave estrangeira vinda da tabela entidade constraint me_ch primary key(modcod,entcod)); /* a chave primária dessa tabela será composta por modcod e entcod

create table mod_rel ( $/ *$ cria a tabela mod_rel

modcod number not null, $/ *$ código do modelo; não pode ser nulo relcod number not null, /* código do relacionamento; não pode ser nulo foreign key(modcod) references modelo on delete cascade, /* indica que modcod é chave estrangeira vinda da tabela modelo foreign key (relcod) references relacionamento on delete cascade, $/ *$ indica que relcod é chave estrangeira vinda da tabela relacionamento constraint me_ch primary key(modcod,relcod)); /* a chave primária dessa tabela será composta por modcod e relcod

create table atri_ent ( $/ *$ cria a tabela atri_ent (ver ....) atricod number not null, $/ *$ código do atributo; não pode ser nulo entcod number not null, $/ *$ código da entidade; não pode ser nulo foreign key(atricod) references atributo on delete cascade, $/ *$ indica que atricod é chave estrangeira vinda da tabela atributo 
foreign key (entcod) references entidade on delete cascade, $/ *$ indica que entcod é chave estrangeira vinda da tabela entidade constraint ae_ch primary key(atricod,entcod), /* a chave primária dessa tabela será composta por atricod e entcod chprim number(1), /* indica se o atributo é chave primária da entidade chest number(1)); /* indica se 0 atributo é chave estrangeira da entidade

create table atri_rel ( $/ *$ cria a tabela atri_rel (ver ....)

atricod number not null, $/ *$ código do atributo; não pode ser nulo relcod number not null, $/ *$ código do relacionamento; não pode ser nulo foreign key(atricod) references atributo on delete cascade, /* indica que atricod é chave estrangeira vinda da tabela atributo foreign key (relcod) references relacionamento on delete cascade, $1 *$ indica que relcod é chave estrangeira vinda da tabela relacionamento constraint me_ch primary key(atricod,relcod)); /*a chave primária dessa tabela será composta por atricod e relcod 


\section{ANEXO B - ENGENHARIA DO CONHECIMENTO}

\section{BASE DE CONHECIMENTO}

Para a construção da base de conhecimento, foram utilizados conceitos de orientação $a$ objetos e regras de produção. Por isso, utilizou-se a ferramenta de auxílio à construção de sistemas baseados em conhecimento Smart Elements v. 2.0, composto pela Open Interface, ambiente de desenvolvimento de interface gráfica, e pela Nexpert Object, ambiente de desenvolvimento da base de conhecimento

Como mencionado anteriormente, os elementos de um MER e seus relacionamentos são descritos no Meta Modelo de Dados. Para cada elemento é possível criar uma classe de objetos, onde cada objeto ligado a essa classe é uma instância, num MER criado, daquele elemento. Por exemplo, uma classe Entidade pode ser criada, onde cada objeto dessa classe representa uma instância do elemento Entidade do Meta Modelo de Dados.

Dessa forma, as classes criadas foram: Entidade, Atributo, Sinônimo, Domínio, Relacionamento, Modelo e Tipo de Dado. Cada objeto das classes possui um nome e um código dentro de sua respectiva classe, além de uma descrição. Além dessas características foi incluída uma outra chamada código da classe para facilitar a identificação do objeto. Foram criadas ainda duas classes especializadas de Relacionamento: GE, para relacionamentos do tipo Generalização/Especialização, e CO, para relacionamentos do tipo Composição.

As regras (ou hipóteses) foram levantadas juntos a especialistas e outras fontes. Grande parte delas pode ser considerada "subjetivas". Estas necessitam de uma certa intuição por parte do projetista. Por isso foram deixadas de lado, principalmente por apresentarem certa dificuldade para serem representadas no computador. Dentre as subjetivas podem ser citadas aquelas que tratam da normalização da base de dados. As "objetivas" são aquelas que foram representadas com o auxílio da NEXPERT e são listadas a seguir (junto com o nome da hipótese, entre parênteses, usada na base de conhecimento): 


\section{Regras para atributos}

- Regra: Nenhum atributo pode ser livre (Verifica_Atributos_Livres)

Erro: $\quad$ Atributo não está sendo usado para caracterizar nenhuma entidade ou relacionamento

Sugestão: Atribuí-lo a alguma entidade ou algum relacionamento

- Regra: Todo atributo deve ter um domínio (Verifica_se_Atributo_Tem_Dominio) Erro: $\quad$ Atributo não tem um domínio definido

Sugestão: Defina um domínio para ele, ou use um dos já definidos

\section{$\underline{\text { Regras para entidades }}$}

- Regra: $\quad$ Toda entidade deve ter no minimo um Atributo e uma Chave Primária (Ent_Tem_Atr_e_Chave)

Esta regra implica em dois erros possíveis:

Erro 1: Entidade não tem nenhum atributo caracterizando-a

Sugestão: Defina um atributo para ela, ou use um dos já definidos

Erro2: $\quad$ Entidade não tem chave primária

Sugestão: Um dos seus atributos deve ser usado como chave primária dela

- Regra: $\quad$ Toda entidade deve participar de um relacionamento, mesmo que seja com ela mesma (Verifica_Part_Ent_em_Rel)

Erro: $\quad$ Entidade não se relaciona com outras entidades, nem consigo mesmo

Sugestão: Definir um relacionamento para ela, ou utilizar um dos já definidos 


\section{Regra para relacionamentos em geral}

- Regra: A cardinalidade deve ser sempre definida (Verifica_Card_Indef)

Erro: A cardinalidade de uma das entidades relacionadas pelo relacionamento não está definida

Sugestão: Definir sua cardinalidade

\section{$\underline{\text { Regras para relacionamentos especiais }}$}

- Regra: Toda composição deve ter pelo menos duas partes; se não tiver, pode não ser útil mantê-la (CO_com_Unica_Parte)

Erro: $\quad$ Este relacionamento de Composição foi definido para apenas duas entidades, provavelmente um "todo" e uma "parte"

Sugestão: Ver se é realmente necessário e, se for, colocar as outras partes

- Regra: Toda generalização deve ter pelo menos duas especializaçôes; se não tiver, pode não ser útil mantê-la (GE_com_Unica_Especializacao)

Erro: Este relacionamento de Gener./Espec. foi definido para apenas duas entidades, provavelmente um "pai" e um "filho"

Sugestão: Ver se é realmente necessário e, se for, colocar outros filhos

\section{Regra geral para os elementos num MER}

- Regra: Nome deve ser único na base de dados (Verifica_Nome_Unico)

Erro: Este nome já é usado em outros lugares na base de dados 
Sugestão: Procurar um nome que seja único

Além das regras já mencionadas, foram definidas algumas outras hipóteses com a finalidade de criar classes especiais, recuperar dados e testar condições auxiliares:

Atr_Ligado_em_Ent e Atr_Ligado_em_Rel : utilizados pelo método Encontrar_Atributos_Livres para verificar se todo atributo está ligado numa entidade ou num relacionamento;

Recupera_Atributo, Recupera_AtriEnt, Recupera_AtriRel, Recupera_Dominio, Recupera_Entidade, Recupera_EntRel, Recupera_Modelo, Recupera_Relacionamento, Recupera_Sinonimo e Recupera_TipoDado : recuperam os dados necessários para a verificação das regras, da base de dados armazenado no SGBDR ORACLE;

Relacion_CO e Relacion_GE : a partir dos relacionamentos recuperados, estas hipóteses, com o auxílio dos métodos Associa_CO e Associa_GE, agrupa os relacionamentos de Composição e de Generalização/Especialização nas classes CO e GE, respectivamente.

Embora sejam poucas regras, elas se tornam poderosas por se aproveitarem de um conceito importante da NEXPERT OBJECT: o "pattern-matching", ou casamento de padrão. Para fazer uso dele, basta escrever <|nome_da_classe $\mid>$.propriedade. Através desse conceito, é possivel percorrer todos os objetos de uma determinada classe à procura da existência ou ausência de determinadas características. Por exemplo, se deseja-se saber quais atributos não tem um domínio definido, basta fazer uma condição com um "pattern-matching" como, por exemplo, $<\mid$ Atributo $\mid>$.DomCod $=$ UNKNOWN, ao invés de ter que pegar o nome de cada objeto e daí processar o atributo DomCod de cada um.

Além desse, há outro conceito importante na NEXPERT OBJECT V. 3.0: o uso de métodos. Um método possui regras e procedimentos embutidos, sendo que podem inclusive trabalhar com variáveis locais. Os métodos comunicam-se com classes, objetos e propriedades através de mensagens, de forma a colocar determinados valores em seus slots ou processar algum conhecimento para que uma hipótese possa ser confirmada ou descartada. Quando a comunicação é realizada através de "pattern-matching", eles se tornam ainda mais úteis pois permitem que se selecione um objeto por vez numa classe, e então se processe alguma condição ou hipótese em cima dele.

Por exemplo, na regra que verifica atributos livres, após ter recuperado todas as informações referentes a atributos, pode-se enviar um método "Encontrar_Atributos Livres" para todos 
os atributos na classe Atributo, através de um "pattern-matching". Neste método, processam-se as informações necessárias (se está em algum objeto da classe AtriEnt, ou em algum objeto da classe AtriRel, ou seja, se existe uma entrada para o atributo na tabela AtriEnt ou AtriRel) para um objeto, e ao terminar passa-se ao próximo, até o processamento de todos

Segue-se uma descrição de como os métodos são usados, além de quais regras os usam:

\begin{tabular}{|l|l|l|}
\hline Método & $\begin{array}{l}\text { Regra ou Método } \\
\text { que o Aciona }\end{array}$ & Descrição do Método \\
\hline Associa_CO & Relacion_CO (Regra) & $\begin{array}{l}\text { Procura por objetos que } \\
\text { representam relacionamentos de } \\
\text { Composição na classe Relação. } \\
\text { Quando encontrados, são ligados } \\
\text { à classe CO }\end{array}$ \\
\hline Associa_GE & Relacion_GE (Regra) & $\begin{array}{l}\text { Procura por objetos que } \\
\text { representam relacionamentos de } \\
\text { Generalização/Especialização na } \\
\text { classe Relação. Quando } \\
\text { encontrados, são ligados à classe } \\
\text { GE }\end{array}$ \\
\hline Encontrar_Atributos_Livres & Verifica_Atributos_Li- \\
vres (Regra) & $\begin{array}{l}\text { Para cada objeto da classe } \\
\text { Atributo, verifica-se se este está } \\
\text { ligado numa entidade ou } \\
\text { relacionamento, através das } \\
\text { hipóteses Atr_Ligado_em_Ent e } \\
\text { Atr_Ligado_em_Rel, que } \\
\text { procuram uma entrada para o } \\
\text { atributo em questão nas classes } \\
\text { AtriEnt e AtriRel }\end{array}$ \\
\hline
\end{tabular}




\begin{tabular}{|c|c|c|}
\hline Método & $\begin{array}{l}\text { Regra ou Método } \\
\text { que o Aciona }\end{array}$ & Descrição do Método. \\
\hline $\begin{array}{l}\text { Encontra_Atributo_sem_Dom } \\
\text { inio }\end{array}$ & $\begin{array}{l}\text { Verifica_se_Atributo_ } \\
\text { Tem_Dominio (Regra) }\end{array}$ & $\begin{array}{l}\text { Para cada objeto da classe } \\
\text { Atributo, verifica-se se este tem } \\
\text { um domínio definido }\end{array}$ \\
\hline Encontra_Card_Indefinida & $\begin{array}{l}\text { Verifica_Card_Indef } \\
\text { (Regra) }\end{array}$ & $\begin{array}{l}\text { Para cada objeto da classe } \\
\text { EntRel, verifica-se se este tem a } \\
\text { cardinalidade definida, ou seja, se } \\
\text { a entidade relacionada pela } \\
\text { instância da tabela EntRel } \\
\text { (representada por um objeto nessa } \\
\text { classe) tem sua cardinalidade } \\
\text { definida }\end{array}$ \\
\hline Lista_das_Especializacoes & $\begin{array}{l}\text { RelCod_do_GE ou } \\
\text { RelCod_do_CO } \\
\text { (Método) }\end{array}$ & $\begin{array}{l}\text { Procura entre os objetos da classe } \\
\text { EntRel por entidades que são } \\
\text { especializadas através de } \\
\text { _RelCorrente e coloca-as numa } \\
\text { lista em_Lista }{ }^{1}\end{array}$ \\
\hline
\end{tabular}

1Utiliza duas variáveis locais: _RelCorrente (o relacionamento sendo processado) e _Lista (lista de entidades relacionadas pelo relacionamento) 


\begin{tabular}{|c|c|c|}
\hline Método & $\begin{array}{l}\text { Regra ou Método } \\
\text { que o Aciona }\end{array}$ & Descrição do Método \\
\hline Nao_Possui_ChPrim & $\begin{array}{l}\text { Ent_Tem_Atr_e_Chav } \\
\text { e (Regra) }\end{array}$ & $\begin{array}{l}\text { Verifica se cada objeto (que } \\
\text { representa uma entidade) de } \\
\text { Ent_com_Atr pertence tambem à } \\
\text { classe Ent_com_ChPrim; se nao } \\
\text { pertencer o objeto é associado a } \\
\text { classe Ent_sem_ChPrim, ou seja, } \\
\text { 'isola' as Entidades que não têm } \\
\text { chave primaria }\end{array}$ \\
\hline Nome_Unico & $\begin{array}{l}\text { Pega_Nome_ClasCod } \\
\text { e_Codigo (Método) }\end{array}$ & $\begin{array}{l}\text { Busca os nomes que são } \\
\text { repetidos, através da comparação } \\
\text { do Nome de cada objeto com os } \\
\text { Nomes dos outros objetos. Para } \\
\text { que nao seja comparado consigo } \\
\text { mesmo, basta verificar se o } \\
\text { Código da Classe e Codigo do } \\
\text { objeto sendo comparado com ele } \\
\text { são diferentes }\end{array}$ \\
\hline
\end{tabular}

${ }^{2}$ Utiliza três variáveis locais: _Nom,_Clas e_Cod (Nome, Código da Classe e Código, respectivamente do objeto em questão) cujos valores provém do método Pega_Nome_ClasCod_e_Codigo 


\begin{tabular}{|c|c|c|}
\hline Método & $\begin{array}{l}\text { Regra ou Método } \\
\text { que o Aciona }\end{array}$ & Descrição do Método \\
\hline $\begin{array}{l}\text { Pega_Nome_ClasCod_e_Codi } \\
\text { go }\end{array}$ & $\begin{array}{l}\text { Verifica_Nome_Unico } \\
\text { (Regra) }\end{array}$ & $\begin{array}{l}\text { Pega o Nome, ClasCod e Codigo } \\
\text { de cada objeto, e verifica se o } \\
\text { nome é único mandando essas } \\
\text { informações para o método } \\
\text { Nome_Unico }\end{array}$ \\
\hline Possui_Atr & $\begin{array}{l}\text { Ent_tem_Atr_e_Chav } \\
\text { e (Regra) }\end{array}$ & $\begin{array}{l}\text { Separa os objetos da classe } \\
\text { Entidade em aqueles que tem } \\
\text { atributos e aqueles que não têm, } \\
\text { ligando-os nas classes } \\
\text { Ent_com_Atr e Ent_sem_Atr, } \\
\text { respectivamente }\end{array}$ \\
\hline Possui_ChPrim & $\begin{array}{l}\text { Ent_Tem_Atr_e_Chav } \\
\text { e (Regra) }\end{array}$ & $\begin{array}{l}\text { Separa as Entidades que possuem } \\
\text { chave primária das que não têm }\end{array}$ \\
\hline Procura_CO_com_Erro & $\begin{array}{l}\text { CO_com_Unica_Parte } \\
\text { (Regra) }\end{array}$ & $\begin{array}{l}\text { Se o tamanho da lista de partes, } \\
\text { armazenado na propriedade Num } \\
\text { do relacionamento, for igual a } 2 \text {, } \\
\text { indica que o relacionamento CO } \\
\text { em questão tem uma única parte. } \\
\text { Assim liga-se esse relacionamento } \\
\text { à classe CO_com_Unico_Subtipo }\end{array}$ \\
\hline
\end{tabular}




\begin{tabular}{|c|c|c|}
\hline Método & $\begin{array}{l}\text { Regra ou Método } \\
\text { que o Aciona }\end{array}$ & Descrição do Método \\
\hline Procura_Ent_sem_Rel & $\begin{array}{l}\text { Verifica_Part_Ent_em } \\
\text {--Rel (Regra) }\end{array}$ & $\begin{array}{l}\text { Através dos objetos armazenados } \\
\text { na classe EntRel, procura-se } \\
\text { descobrir se a Entidade participa } \\
\text { de algum relacionamento, } \\
\text { procurando algum objeto dessa } \\
\text { classe que contenha seu código. } \\
\text { Se não houver, é ligada à classe } \\
\text { Ent_sem_Rel }\end{array}$ \\
\hline Procura_GE_com_Erro & $\begin{array}{l}\text { GE_com_Unica_Espe } \\
\text { cia-lizacao (Regra) }\end{array}$ & $\begin{array}{l}\text { Se o tamanho da lista de } \\
\text { especializações, armazenado na } \\
\text { propriedade Num do } \\
\text { relacionamento, for igual a } 2 \text {, } \\
\text { indica que o relacionamento GE } \\
\text { em questão tem uma única } \\
\text { especialização. Assim liga-se esse } \\
\text { relacionamento à classe } \\
\text { GE_com_Unico_Subtipo }\end{array}$ \\
\hline RelCod_do_CO & $\begin{array}{l}\text { CO_com_Unica_Parte } \\
\text { (Regra) }\end{array}$ & $\begin{array}{l}\text { Busca-se o código do } \\
\text { relacionamento CO na classe CO } \\
\text { e então aciona-se dois métodos: } \\
\text { Lista_das_Especializacoes (para a } \\
\text { classe EntRel) e } \\
\text { Retorna_Tamanho (para a classe } \\
\text { CO) }\end{array}$ \\
\hline
\end{tabular}




\begin{tabular}{|l|l|l|}
\hline Método & $\begin{array}{l}\text { Regra ou Método } \\
\text { que o Aciona }\end{array}$ & Descrição do Método \\
\hline RelCod_do_GE & $\begin{array}{l}\text { GE_com_Unica_Espe } \\
\text { cia-lizacao(Regra) }\end{array}$ & $\begin{array}{l}\text { Busca-se o código do } \\
\text { relacionamento GE na classe GE } \\
\text { e entao aciona-se dois metodos: } \\
\text { Lista_das_Especializacoes (para a } \\
\text { classe EntRel) e } \\
\text { Retorna_Tamanho (para a classe } \\
\text { GE) }\end{array}$ \\
\hline Retorna_Tamanho & $\begin{array}{l}\text { Rel_Cod_do_GE ou } \\
\text { Rel_Cod_do_CO } \\
\text { (Método) }\end{array}$ & $\begin{array}{l}\text { Retorna em_Num o tamanho de } \\
\text { uma lista }\end{array}$ \\
\hline
\end{tabular}

A partir destes métodos e regras, obtém-se os elementos que estão com erro. Estes são ligados a classes de erros, das quais "herdam" descrições dos erros ocorridos e sugestões sobre como podem ser consertados (ver lista das regras). Estas classes de tipos de erros são: Atr_Livre (atributos livres), Atr_sem_Dom (Atrributos sem domínio), CO_com_Unico_Subtipo (relacionamentos de Composição com um único subtipo), Ent_sem_Atr (entidades sem atributos), Ent_sem_ChPrim (entidades sem chave primária), Ent_sem_Rel (entidades sem relacionamento), GE_com_Unico_Subtipo (relacionamentos de Generalização/Especialização), Nome_Repetido (nomes repetidos) e Rel_sem_Card (relacionamentos sem cardinalidade de um ou ambos dos lados).

${ }^{3}$ Utiliza uma variável local:_Num (para armazenar o número de entidades relacionadas por um relacionamento), correspondente à propriedade Num da classe Relacionamento 